\title{
CHARACTERIZATION OF BOVINE UTERINE AND \\ CONCEPTUS PROTEINS
}

By

FRANK FITZHUGH BARTOL

\begin{abstract}
A DISSERTATION PRESENTED TO THE GRADUATE SCHOOL OF THE UNIVERSITY OF FLORIDA

IN PARTIAL FULFILLMENT OF THE REQUIREMENTS FOR THE DEGREE OF DOCTOR OF PHILOSOPHY
\end{abstract}

UNIVERSITY OF FLORIDA 


\section{ACKNOWLEDGEMENTS}

For a period of now more than seven years the author has been a graduate student in the Department of Dairy Science and a member of the interdisciplinary reproductive biology group at the University of Florida. It has indeed been a privilege, and a challenging and rewarding experience, to have had the opportunity to grow and learn in this unique academic environment. The author is eternally grateful to all members of this academic community whose combined interests, efforts, and energies have served to create and continue to foster an enthusiastic spirit of cooperation and comradery in science that can only inspire those fortunate enough to have experienced it.

The author expresses his sincerest appreciation and thanks to Dr. William W. Thatcher, chairman of the advisory committee, mentor, and friend throughout the author's graduate career. Dr. Thatcher's enthusiasm and intensity of interest in research are exceeded only by his extreme patience, which becomes increasingly evident the longer it is tried. For his constant faith and support the author is forever grateful.

Special thanks are expressed to Dr. Fuller W. Bazer for his friendship, insight, and guidance throughout the course of these studies. Dr. Bazer is also acknowledged for technical support, having allowed the author to take up residence in his laboratory for the past several years. Conversations and experiences in this setting, both formal 
and informal, have been invaluable, and the author is grateful for having had daily opportunities for such interaction.

Thanks are expressed to Dr. R. Michael Roberts for his technical insight, guidance, and support throughout the course of these studies and for helping the author feel at least a bit at home in the biochemistry laboratory.

Dr. Daniel C. Sharp, III, is acknowledged for contributing to the author's knowledge and appreciation of rhythm, and for shedding some light on the complex interactions of reproductive physiology.

Thanks are due to Dr. Maarten Drost for surgical training and assistance and for bringing his unique perspective to this research.

It is with deepest and most sincere appreciation that the author acknowledges Dr. Donald H. Barron. The refreshing insight which Dr. Barron brings to interpretation of physiological data has been a constant source of inspiration and rejuvenation even in the darkest hours. The author looks forward to the privilege of continued interaction with Dr. Barron, whose unique philosophy and approach to research will serve as a constant source of stimulation in the author's future endeavors.

Special thanks are due to fellow graduate students past and present including Dr. Rod Geisert, Dr. Ron Kensinger, Dr. Randy Renegar, Jeff Moffatt, and Jeff Knickerbocker; as well as post-doctoral fellows, Dr. J.D. Godkin, Dr. G.S. Lewis, and Dr. A. Fazleabas. Thanks are also extended to Louis Guilbault, Joan Curl, Linda Rico, Chuck Wallace, and Dr. David Wolfenson. The friendship, support, and assistance provided by these individuals are deeply appreciated. 
A special debt of gratitude is owed Warren Clark for his friendship and technical expertise. Future generations of students will be fortunate to "learn the ropes" from Mr. Clark. Thanks are also due to Dr. M.S.A. Kumar, Candy Stoner, and Carol Underwood for their artistic and technical assistance, and to June Wallace and Adele Koehler for typing of this manuscript.

The author expresses his sincerest gratitude to his mother, Dorothy F. Bartol, and Grace Z. Vogel for their support, faith, and patience. Finally, the author acknowledges, with heart-felt gratitude, his wife, Anne A. Wiley, for her invaluable assistance, patience, insight, and love. 
TABLE OF CONTENTS

$\underline{\text { Page }}$

ACKNOWLEDGEMENTS. . . . . . . . . . . . . . . . . . $i i$

LIST OF TABLES. . . . . . . . . . . . . . . . . . vil

LIST OF FIGURES . . . . . . . . . . . . . . . . . . . . . viii

ABSTRACT. . . . . . . . . . . . . . . . . . . . $x$

CHAPTER

I REVIEW OF LITERATURE . . . . . . . . . . . . . . . 1

The Problem in Perspective. . . . . . . . . . 1

Endocrine and Physiological Aspects of the Estrous

Cycle and Early Pregnancy . . . . . . . . . 8

The Uterus. . . . . . . . . . . . . . 26

The Conceptus................ . . 78

II UTERINE PROTEINS IN UNILATERALLY PREGNANT CATTLE . . . . . 103

Introduction. . . . . . . . . . . . . 103

Materials and Methods . . . . . . . . . . 104

Results . . . . . . . . . . . . . . . 114

Discussion. . . . . . . . . . . . . 135

III CHARACTERIZATION OF BOVINE ENDOMETRIAL PROTEINS. . . . . 149

Introduction. . . . . . . . . . . . . . 149

Materials and Methods .............. 150

Results . . . . . . . . . . . . . 159

Discussion. . . . . . . . . . . . . 180

IV CHARACTERIZATION OF PROTEINS PRODUCED IN VITRO BY PERI-

ATTACHMENT BOVINE CONCEPTUSES. . . . . . . . . . . 195

Introduction. . . . . . . . . . . . . 195

Materials and Methods ... . . . . . . . . 197

Results . . . . . . . . . . . . . 203

Discussion. . . . . . . . . . . . . . 223 
V GENERAL DISCUSSION. . . . . . . . . . . . . . . 238

LITERATURE CITED . . . . . . . . . . . . . . . . 256

BIOGRAPHICAL SKETCH. . . . . . . . . . . . . . . 292 


\section{LIST OF TABLES}

Table

Page

2.1 Arithmetic means ( \pm SEM) and ranges for uterine and

feta1-placental physical responses measured on day 270

of gestation for nine cows. . . . . . . . . . 116

2.2 Arithmetic means ( \pm SEM) of steroid concentrations ( $E_{1}$, $E_{2}, E_{2} \mathrm{SO}_{4}, \mathrm{P}_{4}$ ) in uterine milk supernatant (UMS) and peripheral plasma (P1)............. . 117

2.3 Gross and partial within-cow correlations of steroid in peripheral plasma and uterine milk supernatant. . . . . 120

2.4 Concentration and content ( $\bar{X} \pm$ SEM and range) of selected constituents of bovine uterine milk supernatant recovered on day 270 of gestation . . . . . . . . . . . . 122

3.1 Distribution of cattle. . . . . . . . . . . 153

3.2 Responses ( $\overline{\mathrm{X}} \pm \mathrm{SEM}$ ) of endometrial explants from early pregnant (P) and nonpregnant (NP) cattle......... 162 


\section{LIST OF FIGURES}

Figure

Page

2.1. Schematic diagram of surgical preparation used to establish unilateral pregnancy in cattle. . . . . . . . 106

2.2 Representative Sephacryl S-200 elution profile of proteins in unfractionated UMS (day 270) . . . . . . . 124

2.3 Two-dimensional polyacrylamide gel electrophoresis (12.5\% acrylamide) of acidic (Panel $A$; IEF) and basic (PaneI B; NEPHGE) polypeptide components of day 270 UMS . . 127

2.4 Two-dimensional polyacrylamide gel electrophoresis ( $10 \%$ acrylamide) of acidic (IEF) proteins characteristic of UMS (A) and peripheral plasma (B). . . . . . . . 129

2.5 Crossed-immunoelectrophoresis indicating serum-identical proteins in UMS (top) and peripheral plasma (bottom) from a day 270 unilaterally pregnant cow .......... 132

2.6 DEAE-ion-exchange chromatograms of ammonium sulfate precipitable proteins in UMS (A), bovine serum (B), and bovine colostral whey (C) . . . . . . . . 134

2.7 Crossed-immunoelectrophoresis (C-IEP) revealing serumand immunoglobulin-identical components of day 270 bovine UMS. . . . . . . . . . . . . . . 137

3.1 Release of nondialyzable ${ }^{3} \mathrm{H}$-labelled macromolecules by bovine endometrial tissue during $48 \mathrm{~h}$ incubation in vitro . 161

3.2 Comparison of representative Sephacryl S-200 gel filtration elution profiles of dialyzed MEM from day 19 pregnant (A) and day 270 unilaterally pregnant (ligated uterine horn) endometrial explants (B)......... 167

3.3 Representative Sepharose CL-6B gel filtration elution profile of bovine endometrial proteins from S-200 area I. . 169

3.4 Representative ion-exchange chromatograms of dialyzed bovine endometrial explant medium . . . . . . . . . 172

3.5 Two-dimensional polyacrylamide gel elctrophoresis ( $10 \%$ acrylamide) and fluorography of polypeptides in bovine endometrial explant MEM and tissues . . . . . . . . 175 
3.6 Fluorograph of a 2D-PAGE (IEF) gel ( $10 \%$ acrylamide) depicting major bovine endometrial-specific polypeptides present in MEM. . . . . . . . . . . . . . . 179

3.7 Fluorographs prepared from 2D-PAGE (IEF) gels (10\% acrylamide) of polypeptides in bovine endometrial explant MeM 0.0 a

4.1 Percent retention (least square mean \pm SEM) of ${ }^{3} \mathrm{H}-$ leucine as nondialyzable product in $24 \mathrm{~h}$ cultures of bovine conceptuses from days $16,19,22$, and 24 . . . . 205

4.2 Representative DEAE anion exchange chromatograms of radiolabelled proteins in dialyzed MEM from day 16 (A), 19 (B), 22 (C), and 24 (D) bovine conceptus cultures following $24 \mathrm{~h}$ incubation in vitro. . . . . . . . . . . 208

4.3 Fluorographs prepared from representative 2D-PAGE (IEF) gels ( $10 \%$ acrylamide) of polypeptides in dialyzed bovine conceptus culture MEM from days 16 (A), 19 (B), 22 (C),

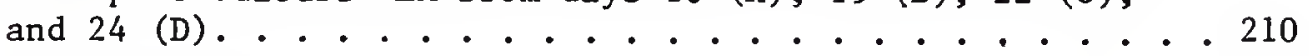

4.4 Fluorographs of 2D-PAGE (IEF) gels ( $10 \%$ acrylamide) showing conceptus tissue polypeptides into which ${ }^{3} \mathrm{H}$-Leu was incorporated in vitro. . . . . . . . . . . . 214

4.5 Fluorographs prepared from 2D-PAGE (IEF) gels ( $10 \%$ acrylamide) of polypeptides in dialyzed bovine conceptus MEM from days 19 (A) and 29 (B), and isolated chorionic culture MEM from day 69 (C) . . . . . . . . . . 216

4.6 Fractionation procedure for partial purification of major low molecular weight, acidic polypeptides produced in vitro by bovine conceptuses. . . . . . . . . 219

4.7 Characteristics of partially purified low molecular weight, acidic bovine conceptus proteins. . . . . . . . 222

4.8 Isolation of the high molecular weight bovine conceptus glycoprotein. . . . . . . . . . . . . . . 225 


\begin{abstract}
Dissertation Presented to the Graduate School of the University of Florida in Partial Fulfillment of the Requirements for the Degree of Doctor of Philosophy
\end{abstract}

CHARACTERIZATION OF BOVINE UTERINE AND CONCEPTUS PROTEINS

$$
\text { By }
$$

Frank Fitzhugh Bartol

$$
\text { April, } 1983
$$

Chairman: William W. Thatcher

Major Department: Animal Science

Studies were conducted to characterize proteins in bovine uterine milk (UM) obtained from ligated (L) uterine horns (UH) of unilaterally pregnant (UPx) cattle on days (D) 180, 210, 240 and 270; and produced de novo from radiolabelled amino acid substrate (AAS) by endometrium from nonpregnant (NPx; D4, 16, 19), pregnant (Px; D16, 19, 22, 24, 69), and UPx (D270; LUH, PUH) cattle; and by bovine conceptuses (D16, 19, $22,24,29$ ) and chorion (D69) in vitro.

Accumulation of UM in LUH of UPx cattle $(n=12)$ was detectable per rectum by D166-180. Mean ( \pm SEM) recovery of D270 UM from UPx cows $(\mathrm{n}=9)$ was $205.3 \pm 68.20 \mathrm{ml} / \mathrm{LUH}$. Estrone and estradiol concentrations in UM supernatant (UMS) and peripheral plasma were similar, while estrone-sulfate and progesterone were higher in plasma. Day 270 UMS was enriched in protein, prostagland in F (PGF), calcium and glucose. Calcium concentration was positively correlated with protein concentration $(r=.68, P<.01)$ and PGF content $(r=.92, P<.08)$. Bovine UMS 
was enriched in basic proteins of less than 40,000 molecular weight $\left(M_{r}\right)$. Serum and UM-specific proteins were identified.

Endometrial explants (EE) from Px, NPx and UPx cattle produced proteins de novo from AAS. In vitro responses of EE from P (D16, 19, $22,24)$ and NP (D16, 19) cattle suggested a stabilizing conceptus effect on endometrial protein synthesis. Medium (MEM) from all EE was enriched in polypeptides in four $\mathrm{M}_{\mathrm{r}}\left(\mathrm{x} 10^{-3}\right) / \mathrm{pH}$ classes $(\mathrm{I}, \simeq 14 />7.2$; II, 19-24/5.4-6.3; III, 28-31/6.9-7.3; IV, $\geq 150 / \leq 5.1)$. Class II and III polypeptides were identified in UMS.

Uptake of AAS and quality of polypeptides produced de novo by conceptuses were related to stage of development. Day 16, 19, 22 and 24 conceptus-MEM was enriched in low $M_{r}$, acidic polypeptides ( ${ }_{r}{ }_{r} A$; $22-26 / 6.5-5.6,20-26 / 5.5-5.4,16-20 / 5.0-4.5)$; not prominent products of D29 and D69 tissues. A high ${ }_{r}$ glycoprotein $\left(\bar{X} M_{r} \times 10^{-3} \pm S E M \simeq\right.$ $735 \pm 22)$, produced by all conceptus tissues, and $\operatorname{LM}_{\mathrm{r}} \mathrm{A}^{\mathrm{A}}$ were isolated from MEM via anion exchange and gel filtration chromatography.

Results are discussed relative to conceptus-maternal interactions necessary for establishment and maintenance of pregnancy. 
CHAPTER I

REVIEW OF LITERATURE

\section{The Problem in Perspective}

It was the purpose of research described in this dissertation to examine components of the bovine uterine environment. Emphasis was placed on proteins, particularly those contributed to this unique milieu by the endometrium (uterine mucosal epithelium) and conceptus (embryo and extraembryonic membranes) during the peri-attachment period of early pregnancy. This period, defined as the time from initial elongation of the trophoblast (extraembryonic membranes) until definitive microvillar attachment of the outer trophoblastic membrane (chorion) to maternal endometrium (approximately days 16 to 24 ; see Wathes and Wooding, 1980; King et al., 1981), has been repeatedly associated with a high incidence of embryonic mortality in cattle (Greenstein and Foley, 1958a,b; Hawk et al., 1955; Ayalon, 1978; Hawk, 1979). Mossman (1937) observed that establishment of pregnancy in eutherian mammals involved interactions between two interdependent systems defined as the conceptus and uterus. Clearly, the consequence of failure in either component is failure of pregnancy. Thus, the importance of factors which may contribute to successful intercommunication of these two systems is evident. However, even after centuries of investigation, the precise means by which the conceptus interacts with its maternal environment to establish and maintain pregnancy is imprecisely understood. 
Throughout history innumerable theories have been suggested to explain the relationship between conceptus and maternal units. One of the earliest recorded attempts to explain maternal support of the developing conceptus was that of Diogenes of Apollonia (ca. 480 B.C.), who suggested that the placenta (extraembryonic membranes) was the organ of fetal nutrition (DeWitt, 1959). The source of nutrients, however, remained a mystery. Students of Hippocrates believed the fetus to be nourished per os by suckling on maternal cotyledons or uterine paps (DeWitt, 1959). This theory of fetal nutrition suggested that menstrual blood (in humans) served as a nutrient source to the early conceptus with excess deposited as amniotic fluid. Later, as the uterus grew, it was thought that pressure of the pregnant reproductive tract against the breasts would cause them to pump milk into the uterine arteries, to supply the uterine paps directly (DeWitt, 1959; Needham, 1959).

Aristotle (384-322 B.C.) argued against Hippocratic theories. He observed that the fetus was encased in several layers of membranes and that such encasement would prevent fetal suckling in utero (DeWitt, 1959). The teachings of Aristotle relative to embryology and maternalfetal relationships were set down in Peri Zoon Geneseos ("On the Generation and Development of Animals"), and dominated the sciences of natural history and development for nearly 2000 years (Haeckel, 1897; Needham, 1959). The impact of these concepts, heavily influenced by Hippocratic philosophies, is emphasized in the description and drawings of female generative organs by both Leonardo da Vinci (1452-1518) and Andreas Vesalius (1514-1564), which still showed arteries connecting the breasts to the reproductive tract (Needham, 1959; DeWitt, 1959; Saunders and O'Malley, 1982). 
With the Renaissance came a legion of observations critical to development of modern concepts of embryology and conceptus-maternal relationships. Leonardo da Vinci (1452-1519) was familiar with the ungulate placenta and observed that it was connected, but not united with the uterus by little sponges or cotyledons (Steven, 1975a; DeWitt, 1959). It was also his contention that both fetal respiration and nutrition took place via the umbilical cord (DeWitt, 1959). Jean Fernel (1485-1558) was perhaps the first to suggest that improper uterine environment might adversely affect embryonic development. Challenging both Hippocratic and Aristotelian doctrine, he theorized that, in women, menstrual blood in utero might be deleterious to the embryo (DeWitt, 1959). Thus was born the idea that the process of conception followed a logical order and that condition of the uterine environment was important to this order.

The frontispiece of De Generatione Animalium (1650) by William Harvey (1578-1657 A.D.) was inscribed with the words, "ex ovo omnia" (p.133; Needham, 1959). This major concept, that all living things are born from eggs, predated Regnar De Graafs' investigations of the mammalian ovary (De Mulierum Organis; 1672) by nearly 25 years, and Karl Ernst Baers' description of the mammalian ovum (History of the Evolution of Animals; 1828, 1837) by nearly 200 years (Haeckel, 1897; Needham, 1959). In his treatise of 1650, Harvey observed "An egge is, as it were, an exposed womb; wherein there is a substance concluded, as the representative and substitute or vicar of the breasts" (p.151; Needham, 1959). Thus it was recognized that the conceptus was nourished by substances within the womb (uterus) much as the neonate was nourished by the products of the breasts. 
Walter Needham (1631-1691) was described as the father of the dynamic aspect of physico-chemical embryology (Needham, 1959). In his major treatise, De Formatu Foetu (1667), he refuted the Hippocratic theory of uterine paps and argued that the substance which could be squeezed from uterine cotyledons was distinct from 1 ymph and important in fetal nutrition (Amoroso, 1952; DeWitt, 1959; Needham, 1959). Needham is credited with naming this substance uterine milk (Amoroso, 1952; Needham, 1950, 1959). This view was supported by observations of John Mayow (1643-1679) who, in De Respiratione Foetus in Utero et Ovo (1674), also observed that the uterus was naturally adapted for separation of gaseous oxygen from arterial blood, and that the placenta was, therefore, the respiratory organ of the fetus in utero (see DeWitt, 1959; Needham, 1959).

Though many erroneous theories relative to the nature and means by which the mammalian conceptus was supported in utero persisted throughout the 17 th and 18 th centuries (see Needham, 1959), the observations of William Harvey, Walter Needham and John Mayow set the stage for development of more modern concepts of the relationship between the conceptus and its uterine environment. With publication of A Theory of the Structure of the Placenta, by Charles Sedgwick Minot (1852-1914) in 1891, many of the diverse opinions relative to nature of the interface between the conceptus and its environment were reconciled (DeWitt, 1959). According to DeWitt (1959), this paper correctly described the nature of early associations between the chorion and underlying endometrium during the peri-attachment period in both ungulates and man, and correctly identified the nature of chorionic vascularization. 
During this same period potential sources of nutrient materials provided to the conceptus in utero were more clearly defined as reviewed by Amoroso (1952). Bonnet (1882) coined the term "embryotrophe" and defined it as any substance which could be regarded as a product of degeneration of maternal tissues or as glandular secretions of the endometrium (Amoroso, 1952). Later, Bonnet (1899; see Amoroso, 1952) was the first to demonstrate active phagocytosis of embryotrophe by the ruminant trophoblast. Meyer (1925) used the term embryotrophe to describe all available material supplied to the conceptus in utero (Amoroso, 1952). Grosser (1927) observed that such material could be supplied either directly from maternal blood (hemotrophe), or as a result of endometrial synthetic activity (histotrophe; Amoroso, 1952). Whatever the source, the extent to which substances provided to the conceptus specifically by the maternal reproductive tract are important for embryonic growth, appears to be related to the nature of the maternal-fetal interface (placental type) and responsively demonstrated by stage of maturity of the neonate.

Grosser (1909; In: Steven, 1975b) classified placentae of mammals based upon number of maternal and fetal tissue layers separating the two bloodstreams. The epitheliochorial placenta, now known to be characteristic of cattle, sheep, pigs and horses (Wathes and Wooding, 1980; Steven, 1975b), was shown to consist of six tissue layers including (1) endothelium of fetal capillaries; (2) fetal connective tissue (mesenchyme); (3) fetal chorionic epithelium; (4) maternal uterine epithelium; (5) maternal connective tissue; and (6) maternal endothelium. Other general classifications of placentae included the endotheliochorial type (most carnivores), and the hemochorial type 
(Man, primates, and rodents). The former were characterized by absence of both maternal epithelium and connective tissue, and the latter by absence of all maternal tissue layers except blood (Steven, 1975b). An early but persistent view in comparative placentation suggested that the six layered epitheliochorial placenta of ungulates presented the most formidable barrier to diffusion and transfer of nutrients between mother and fetus (Steven, 1975b). Barcroft (1946) disagreed with this view observing that, in general, the greater the number of placental layers the more fully developed the animal at birth. Furthermore, animals with epitheliochorial placentae do not support ectopic (extra-uterine) pregnancy and undergo a characteristically prolonged, free-living period in utero prior to attachment (Cook and Hunter, 1978; Steven, 1975b). By comparison, animals with hemochorial placentae (in which fetal chorion is apposed directly to maternal blood) do not experience a prolonged free-living period in utero, do support pregnancy in ectopic sites, have characteristically shorter gestation lengths (except Man), and are born in an immature, helpless, of ten embryonic state (Barcroft, 1946; Mossman, 1937; Needham, 1950). Consequently, these species require intense, prolonged, postnatal care to reach maturity. For these reasons it is apparent that, in mammals with epitheliochorial placentae (including the cow), the relationship between the conceptus and its uterine environment is unique. Furthermore, substances provided the conceptus by the maternal reproductive tract are at least permissive, if not trophic, with respect to embryonic growth.

More recently, embryo transfer (Seidel, 1981; Betteridge et al., 1980) and in vitro culture studies (Wright and Bondioli, 1981) further 
emphasized importance of the uterine environment for maintenance of conceptus and establishment of pregnancy in domestic farm species. Yet, the suggestion of Harvey over 300 years ago that the mammalian uterus, by providing substances to the conceptus, acts as a "vicar of the breasts" (p.151; Needham, 1959) to the developing embryo, remains as nearly precise a statement as is currently possible relative to the nature and function of components of the uterine environment.

From an evolutionary standpóint, tendency toward increasingly longer periods of uterine gestation in eutherian mammals suggested a requirement for interdependence of conceptus and maternal units (Mossman, 1934). Conceptus adaptation to prolonged uterine gestation. was suggested to involve development of ability to produce biologically active agents necessary to effect maintenance of pregnancy (Amoroso and Perry, 1975). Interdependence between conceptus and maternal units might be considered most highly developed in species, such as cattle, which possess epitheliochorial placentae since (1) the uterus is the preferred site for establishment of pregnancy; (2) conceptuses experience a prolonged free-living period in utero early in gestation; (3) attachment is superficial; and (4) gestation is prolonged (Mossman, 1934; Needham, 1950; Cook and Hunter, 1978). The critical nature of the peri-attachment period in bovine gestation (Aya1on, 1978; Hawk, 1979) and the necessity for synchrony in bovine embryo transfer (Seide1, 1981; Betteridge et a1., 1980; Sreenan, 1978) emphasize importance of both the uterine environment and conceptus "signals" in pregnancy recognition (Short, 1976). Like the uterine environment, 1ittle is known of the nature or function of products of the periattachment bovine conceptus. 
Historically, study of structure has preceded that of function. It was in this spirit that research described herein was conducted.

\section{Endocrine and Physiological Aspects of the Estrous Cycle and Early Pregnancy}

As suggested by Short (1976), the sexual cycle displayed by mammalian females may have developed as a natural mechanism for maximizing reproductive efficiency by providing multiple opportunities for establishment of pregnancy. In large domestic farm species, including seasonally polyestrus sheep and horses and polyestrus pigs and cattle, it is the recurring estrus period (period of sexual receptivity) that provides this opportunity. The condition of recurring estrus in nonpregnant farm species is referred to as the estrous cycle, and occurs as a consequence of the integrative action of anterior pituitary polypeptide and ovarian steroid hormones which must either (1) stimulate conditions required to provide a non-hostile intrauterine environment for sustenance of the conceptus; or (2) in the absence of pregnancy, induce changes necessary to insure resumption of cyclicity so as to provide another opportunity for conception. In this light, it is the objective of the following section to review general endocrinological and physiological aspects of the estrous cycle and early pregnancy with particular emphasis on the cow. Endocrine profiles associated with recurrent estrus in major domestic farm species have been extensively characterized. The reader is referred to reviews by Schams et a1. (1977), Britt et al. (1981), Hansel et al. (1973), Bazer et al. (1981b) and Ginther (1979), for extended bibliographies and comparison of endocrine profiles characteristic of cattle, sheep, pigs and horses. Endocrine profiles characteristic of later stages of 
pregnancy and the periparturient period in cattle were presented by Smith et al. (1973), Robertson and King (1979) and Eley et al. $(1981 \mathrm{a}, \mathrm{b})$.

\section{Cyclicity}

The sexually mature bovine female (Bos taurus) has an estrous cycle length of 20 to 21 days with a normal range of 17 to 25 days (Salisbury et al., 1978; Robinson, 1977). Bovine estrous cycle length is not affected by season of year, although reproductive phenomena such as age at first estrus and interval to first postpartum estrus may be affected by interactions of season with plane of nutrition (Harrison et al., 1982; Grass et a1., 1982; Rzepkowski et al., 1982; Peters et al., 1980; Tucker and Ringer, 1982). Heifers (nulliparous females) tend to exhibit estrous cycles approximately 1 day shorter than cows (parous females; Robinson, 1977). Four general phases of the bovine estrous cycle are associated with characteristic alterations in peripheral plasma endocrine profiles which are responsible for changes in animal behavior (Arave and Albright, 1981) and morphology, histology and biochemistry of the reproductive organs necessary for establishment of pregnancy or reestablishment of cyclicity (Britt et al., 1981).

Estrus, generally designated day 0 , is the period of sexual receptivity. This phase is usually $16 \mathrm{~h}$ to $21 \mathrm{~h}$ in duration (Schams et a1., 1977), but may be as short as $9 \mathrm{~h}$ to $10 \mathrm{~h}$ during periods of high environmental temperature in summer months of the northern hemisphere, or in tropical climates (Chenault et al., 1975). Endocrinologically, estrus is characterized by high peripheral plasma estrogen (E) and low progesterone $\left(\mathrm{P}_{4}\right)$ (Robinson, 1977; Schams et al., 1977). Peripheral 
plasma estradiol $\left(\mathrm{E}_{2}\right)$ begins to increase about 3 days prior to onset of estrus and reaches maximal levels $(\simeq 10 \mathrm{pg} / \mathrm{ml})$ during estrus (Wetteman et al., 1972; Hansel et al., 1973; Chenault et al., 1975; Schams et al., 1977). This period of rising $E$ is associated with increasing uterine blood flow (UBF) to peak levels at estrus in cattle (Ford et al., 1979), sheep (Greiss and Anderson, 1969) and pigs (Ford and Christenson, 1979). Onset of estrus precedes ovulation, which is spontaneous, by $20 \mathrm{~h}$ to $30 \mathrm{~h}$. Estrus is associated with a surge of peripheral plasma luteinizing hormone (LH) of 10 to $25 \mathrm{ng} / \mathrm{ml}$ above basal concentrations of approximately $1 \mathrm{ng} / \mathrm{ml}$ (Schams et al., 1977; Rahe et al., 1980; Britt et al., 1981). Both estrus and the LH surge are precipitated by declining peripheral plasma $\mathrm{P}_{4}$ and increasing $\mathrm{E}_{2}$ (Britt et al., 1981; Schams et al., 1977).

Metestrus (approximately days 1 to 3 ) is associated with waning peripheral plasma E concentrations, cessation of estrous behavior, ovulation, and initiation of luteinization of ovarian follicular granulosa cells (Hansel et al., 1973; Britt et al., 1981; Robinson, 1977). Chenault et al. (1975) detected a 50\% decline in plasma $\mathrm{E}_{2}$ by $5 \mathrm{~h}$ after the $\mathrm{LH}$ peak and basal $\mathrm{E}_{2}$ concentrations ( 1 to $3 \mathrm{pg} / \mathrm{ml}$ ) obtained by $14 \mathrm{~h}$ (Chenault et al., 1975). Luteinization results in formation of the ovarian corpus luteum (CL) and initiation of $\mathrm{P}_{4}$ production. Histological and cytological descriptions of luteinization were presented by Priedkalns and Weber (1968), and Channing (1970). Enzymatic changes associated with this phenomenon were described for the cow by Lobel and Levy (1968).

Diestrus, the longest phase of the estrous cycle (approximately days 4 to 18 ), is characterized endocrinologically by increasing peripheral plasma $\mathrm{P}_{4}$ concentrations from around 1 to $2 \mathrm{ng} / \mathrm{ml}$ in late 
metestrus to 6 to $10 \mathrm{ng} / \mathrm{ml}$ by days 12 to 15 during mid-diestrus. The CL establishes full functionality during this period as reflected by peaks in luteal tissue weight (Bartol et al., 1981a; Hansel et al., 1973), ovarian blood flow, and $\mathrm{P}_{4}$ production (Wise et al., 1982; Ford and Chenault, 1981; Hansel et al., 1973).

Regular waves of ovarian follicular development during the estrous cycle are preceded by increases in peripheral plasma follicle stimulating hormone (FSH) and responsively demonstrated, especially during late diestrus, by rises in peripheral plasma E concentrations (Glencron et al., 1973; Hansel et al., 1973; Ireland et al., 1979; Schams et al., 1973; Wetteman et al., 1972) and increases in UBF (Ford et al., 1979). Consequently, the final phase of the estrous cycle, proestrus (approximately days 19 and 20 ), is a period of waning plasma $\mathrm{P}_{4}$ and rising E concentrations, associated with demise of the CL (1uteal regression) and development of the ovulatory Graafian follicle (Ireland et al., 1979; Dufour et al., 1972; Schams et al., 1977; Hansel et al., 1973).

Central to recurring estrus in cattle is the process of luteal regression. This process is thought to occur as a consequence of the action of products of the ovarian follicle(s) (presumably $E_{2}$ ) on uterine endometrium leading to uterine production of a luteolysin, prostaglandin-F $2 \alpha\left(\mathrm{PGF}_{2 \alpha}\right)$, which effects luteolysis via a local uteroovarian pathway.

Considerable data exist to support the concept that ovarian follicular growth is continuous throughout the estrous cycle (Marion et al., 1968; Choudry et al., 1968; Ireland et al., 1979). Rajakoski (1960) maintained that there were two waves of bovine follicular growth: one between days 9 and 12; and a second between days 
12 and 16 which gave rise to the ovulatory follicle. The dynamic nature of ovarian follicle growth in cyclic cattle was supported by the work of Dufour et al. (1972). When largest ovarian follicles present were marked in situ on different days throughout the estrous cycle, the ovulatory follicle could be predicted only if marked after day 18. Hence, follicular growth and atresia was occurring throughout the estrous cycle.

Follicular growth is stimulated by $\mathrm{FSH}$, while a combination of FSH and LH appeared to induce maximal $E_{2}$ biosynthesis (Thibault, 1977 ; Merz et al., 1981). Data of Lacroix et al. (1974) support a two-cell mechanism for $\mathrm{E}$ synthesis by bovine ovarian follicles involving the $\Delta^{5}$-pathway (conversion of pregnenalone to androstenedione through $\Delta^{5}$-3ß-hydroxysteroids; Ryan and Smith, 1965). It was suggested that ovarian thecal cells were responsible for testosterone production which would then be aromatized to estrogen.in granulosa cells (Lacroix et al., 1974). Recent data of Merz et al. (1981) indicated that $85 \%$ of bovine ovarian follicles ( $\geq 8 \mathrm{~mm}$ diameter) from cyclic cattle on days 6,12 or 18 bound FSH in granulosa and human chorionic gonadotropin (HCG; LH-1ike activity) in theca cells. Additionally, $38 \%$ of follicles bound HCG in granulosa cells, and this binding was correlated with increased $\mathrm{E}_{2}$ concentration in follicular fluid. In vitro production of $\mathrm{E}_{2}$ by the two largest follicles obtained from cyclic cattle on days $4,8,12,14,16$ and 19, was unaffected by cycle stage (Bartol et a1., 1981a). Data suggested that follicles were present on ovaries of cattle throughout the estrous cycle which were capable of producing significant amounts of $\mathrm{E}_{2}$ (Bartol et al., 1981a). Evidence for the necessity of follicles in luteal regression was presented by VillaGodoy et al. (1981). Data indicated that electrocautery of visible 
follicles combined with X-irradiation of ovaries in cyclic cattle on days 9,12 or 15 postestrus produced heavier CL at day 24 compared to those from non-treated controls (5.5g vs. 1.1g). Data also indicated a luteolytic effect of ovarian follicles after day 15 (Villa-Godoy et al., 1981).

Since the landmark observations of Loeb (1923), presence of the uterus or uterine tissue was found to be essential for luteal regression in many species including cattle (Wiltbank and Casida, 1956; Malven and Hansel, 1964), sheep (Anderson et al., 1969), pigs (Spies et al., 1958; Du Mesnil Du Buisson, 1966) and horses (Ginther and First, 1971). Initial investigations demonstrated that surgical removal of the uterus prior to day 16 resulted in prolonged luteal lifespan in cattle (Wiltbank and Casida, 1956), as well as sheep, pigs and mares (Anderson et al., 1969; Ginther, 1981). Subsequent reports showed that cattle (Bland, 1970) and ewes (McCracken and Caldwell, 1969) with congenitally absent uterine horns adjacent to CL bearing ovaries had prolonged luteal lifespans. These studies confirmed earlier observations from surgical preparations, and established the concept of local uteroovarian control of CL lifespan in these species. This concept suggests that the uterine luteolysin is transferred from the uterine venous drainage to the ovarian arterial supply via a countercurrent mechanism. Current evidence for such a mechanism in cattle is strong but still circumstantial. In this regard, the reader is referred to reviews by Ginther (1967, 1981) and the studies of Hixon and Hansel (1974) and Shemesh and Hansel (1975b).

Distension or irritation of uterine mucosa with intrauterine devices (IUD), chemical irritants, or bacterial infections shortened 
cycle length and luteal lifespan in cattle and sheep (Hawk, 1968; Ginther, 1967; Moore and Nalbandov, 1953; Hansel and Wagner, 1960; Anderson et al., 1969). Administration of $\mathrm{E}_{2}$ or oxytocin to cattle during early diestrus resulted in premature luteolysis only if the uterus was present (Brunner et a1., 1969; Wiltbank et al., 1961; Armstrong and Hansel, 1959). Ablation of endometrium with caustic chemicals or as a consequence of chronic bacterial infection resulted in lengthened estrous cycles in cattle, pigs, sheep and mares (Anderson et al., 1969; Hawk, 1968; Hughes et al., 1977). Substances such as estrogen and oxytocin, or devices such as IUD's and chemical irritants appeared to precipitate premature luteal regression through a common path. Whether physiological or mechanical, stimulation of endometrium during diestrus in the uterine horn ipsilateral to the CL was sufficient to cause production and release of the luteolysin as reflected by shortened estrous cycles in treated cattle. Hence, the endometrium was established as a major functional component of the bovine luteolytic system.

Current data support the notion that the endogenous bovine uterine luteolysin is $\mathrm{PGF}_{2 \alpha^{\circ}}$. Since the observations of Babcock (1966), and Phariss and Wyngarden (1969), exogenous $\mathrm{PGF}_{2 \alpha}$ was shown to be luteolytic in cattle (Hafs et al., 1974; Lauderdale, 1974; Thatcher and Chenault, 1976), as well as pigs (Diehl and Day, 1974; Moeljono et al., 1976a,b), ewes (Goding, 1974) and mares (Douglas and Ginther, 1972; Allen and Rowson, 1973; Noden et al., 1974). Arachidonic acid, the principle substrate in PG synthesis (Ramwell et al., 1977; Granstrom, 1981; Nelson et al., 1982), was suggested by Hansel et al. (1975) to be the bovine luteolysin. In other studies, however, the abrupt increase in bovine 
endometrial content of arachidonic acid, noted to occur between days 10 and 14 (Hansel et al., 1975), was found to precede striking increases in endometrial tissue (Shemesh and Hansel, 1975a,b) and uterine Iuminal flushing PGF content (Lamonthe et al., 1977; Bartol, 1981a), as well as uterine venous plasma concentrations of $\mathrm{PGF}_{2 \alpha}$ (Shemesh and Hansel, 1975b; Nancarrow, 1972) that occur after day 15. Furthermore, evaluation of peripheral plasma concentrations of 13,14-dihydro-15keto-PGF $2 \alpha$ (PPGFM), the inactive metabolite of $\mathrm{PGF}_{2 \alpha}$, revealed temporal associations between elevated PPGFM and declining $\mathrm{P}_{4}$ accompanying luteolysis in cyclic cattle (Kindahl et al., 1976; Thatcher et al., 1979) and sheep (Peterson et al., 1976). Bartol et al. (1981a) demonstrated that, in cyclic cattle, uterine flushing PGF content increased between days 16 and 19 at a time when a stable population of high affinity $\mathrm{PGF}_{2} \alpha^{\text {-specific binding sites were present in luteal }}$ tissues. Hixon and Hansel (1974) observed that uterine infusion with $\mathrm{PGF}_{2 \alpha}$ per cervix on days 12 or 13 postestrus caused increases in $\mathrm{PGF}_{2 \alpha}$ concentrations in ovarian and carotid arterial and jugular venous plasma. Collectively, these studies provided strong evidence favoring $\mathrm{PGF}_{2 \alpha}$ as the endogenous bovine uterine luteolysin.

Thatcher et al. (1979) reported that $E_{2}-17 B$ (3 mg I.V.) given to cyclic cattle on day 13 postestrus caused an increase in PPGFM which peaked at $6 \mathrm{~h}$ post-injection and returned to pre-injection levels by $9 \mathrm{~h}$ post-injection. Bartol et al. (1981b) demonstrated that the predictable $\mathrm{E}_{2}$ induced $6 \mathrm{~h}$ increase in PPGFM was accompanied by a concommitant increase in uterine luminal content of the parent compound, $\mathrm{PGF}_{2 \alpha}$, as well as total protein. Recently, Knickerbocker et al. (1982), using an identical protocol, measured UBF and uterine venous concentration 
of both PGF and PGFM, as well as PPGFM. The $6 \mathrm{~h}$ increase in PPGFM was reflected directly, at the level of the uterus, by increased uterine production of both $\mathrm{PGF}_{2 \alpha}$ and PGFM. These studies demonstrated that bovine uterine PG synthesis and metabolism in response to $\mathrm{E}_{2}$ could be accurately assessed by monitoring PPGFM.

The $\mathrm{E}_{2}$ induced increase in bovine UBF seen by Knickerbocker et al. (1982) agreed with previous studies (Roman-Ponce et al., 1978), and resembled similar UBF responses shown to occur in normal cyclic cattle during late diestrus as follicular E increased (Ford et a1., 1979). Bearing in mind that $\mathrm{E}_{2}$ induced increases in uterine production and metabolism of PG (Knickerbocker et a1., 1982) required prior induction of uterine enzymes including cyclooxygenase (Huslig et al., 1979), 15-hydroxyprostenoate dehydrogenase, and $\Delta^{13}$-reductase (Anggard, 1971), normal increases in UBF during late diestrus in cyclic cattle (Ford et al., 1979) might be considered to reflect increased uterine metabolic activity associated with enhanced production of the luteolysin, $\mathrm{PGF}_{2 \alpha}$. Data reviewed above are consistent with the concept that $\mathrm{E}_{2}$, of ovarian follicular origin, acts on diestrus endometrium to induce increases in metabolic activity. Increased endometrial metabolic activity may be met by increased UBF and reflected by enhanced production of $\mathrm{PGF}_{2 \alpha}$ from tissue stores of arachidonic acid. Luteolysis may then result from binding of endometrially produced $\mathrm{PGF}_{2 \alpha}$ at specific receptors in luteal tissues. It should be mentioned, however, that recent data, summarized by McCracken et al. (1981), suggest an important role for pituitary oxytocin in this luteolytic system.

\section{Early Pregnancy}

If conception occurs following mating, luteal maintenance and not luteal regression becomes the goal if pregnancy is to be maintained. 
Levels of peripheral plasma steroids $\left(\mathrm{P}_{4}\right.$ and $\left.\mathrm{E}\right)$ and $\mathrm{LH}$ in early pregnant cattle approximated those seen in cyclic (nonpregnant) cattle during the same period post-estrus (Wetteman and Hafs, 1973; Wetteman et a1., 1972; Folman et al., 1973; Hasler et al., 1980), but $\mathrm{P}_{4}$ did not decline after days 18 to 19 . In this respect the period of bovine pregnancy of primary concern in this review, between conception and early conceptus attachment around day 22 to 24 (Wathes and Wooding, 1980), corresponds in a temporal sense to periods of metestrus and diestrus in nonpregnant (cyclic) cattle. Early pregnancy might, therefore, be considered the beginning of a prolonged pregnancy-associated diestrus period during which $\mathrm{P}_{4}$ appears as the predominant maternal peripheral plasma steroid.

Maintenance of peripheral plasma $\mathrm{P}_{4}$ concentrations is, to date, the earliest measurable manifestation of pregnancy in large domestic farm species (Sauer, 1979). The CL is required for maintenance of pregnancy in all large domestic species (Aitken, 1979; Hansel et al., 1973). Luteal tissue is required throughout gestation in the cow and sow, but not in the ewe and mare in which ovariectomy during the second half of gestation does not result in abortion (Hafez and Jainudeen, 1974). Necessity of the CL for establishment and maintenance of pregnancy in mammals was recognized even before the discovery of $\mathrm{P}_{4}$. In a recapitulation of the Born-Fränkel theory, Hartman (1924) stated that product(s) of the CL effected those changes in the uterus which made implantation possible. Hartman (1924) observed that ovaries (CL) were necessary for continuance of pregnancy since ovariectomy during early pregnancy "invariably" caused early embryonic death. Furthermore, Hartman (1924) indicated that the direct cause of death in such cases was "malnutrition of the embryos" (p.449) as a consequence of collapse 
of the uterine mucosa. These observations clearly indicate that, in order for the conceptus to survive and mature, at least two important processes must occur (1) prevention of luteolysis and (2) induction of a supportive, non-hostile uterine environment (Cook and Hunter, 1978).

The obvious difference between a cyclic and pregnant animal is presence of a conceptus in utero. Consequently, luteal maintenance, characteristic of pregnancy, reflects response of the CL to physiological conditions initiated by the conceptus and/or its products within the uterine lumen. Short (1969) referred to the process by which the peri-attachment conceptus signaled its presence to the maternal unit, as reflected by luteal maintenance, as maternal recognition of pregnancy. In cattle, the precise mechanism(s) whereby "recognition" is accomplished is not well understood. Clearly, this event must occur very early in gestation, and may require both luteotrophic and antiluteolytic factors.

In cattle, sheep and pigs, presence of conceptus tissues in utero prior to days 17 (Northey and French, 1980; Betteridge et al., 1980), 12 (Rowson and Moor, 1967; Martal et al., 1979) and 13, respectively (Dhinsda and Dziuk, 1968; Bazer et al., 1982), resulted in prolongation of the estrous cycle as a consequence of luteal maintenance. Interestrus interval was extended in cattle from which conceptuses were removed on day 17 ( $25 \pm 1.2$ days) as compared to either non-mated controls (21 days) or cattle from which conceptuses were removed on day 15 (20.2 \pm 0.8 days; Northey and French, 1980). Additionally, intrauterine infusion of conceptus homogenates on days 15 through 17 extended inter-estrus interval (Northey and French, 1980). Surgical transfer of 
84 single and 51 twin bovine embryos to synchronous ( \pm 1 day) recipients resulted in pregnancies only when performed before day 17 (Betteridge et al., 1980). Thus, the bovine conceptus must be present in utero at least from days 15 through 17 if luteal maintenance is to be initiated.

Location of the conceptus as well as timing appeared important for successful recognition. Sreenan (1978) reported that a significantly greater percentage of single bovine embryos were either still present in utero at slaughter on day 40 or 60 , or represented as live calves at term, when transferred to the uterine horn ipsilateral (60\%) rather than contralateral (24\%) to the CL bearing ovary in synchronous recipients. In surgically prepared, unilaterally pregnant cattle, luteal maintenance resulted when the gravid uterine horn was ipsilateral but not contralateral to the CL (Ginther, 1981). Similar observations were made for sheep (Rowson and Moor, 1962; Ginther, 1981), but not pigs in which infusion of porcine embryonic extracts was effective in maintaining bilateral luteal function in unilaterally pregnant gilts (Ball and Day, 1982a). Studies suggest that, in early pregnant cattle and sheep, a local utero-ovarian venoarterial pathway is involved with luteal maintenance.

Several studies indicated that peripheral plasma concentrations of $\mathrm{P}_{4}$ were greater in pregnant than in nonpregnant or cyclic (non-bred) cattle after day 10 post-mating or estrus (Boyd et al., 1969; Henricks et al., 1970; Holness et a1., 1977; Ford et a1., 1979; Lukazewska and Hansel, 1980), although such differences were not detected by others (Batson et al., 1972; Folman et al., 1973; Hasler et al., 1980). Work reviewed recently by Ginther (1981) suggested that venous blood from 
the gravid uterine horn of cattle and sheep contained a "luteotrophic factor." In these studies, luteal maintenance was consistently achieved when venous effluent from the gravid uterine horn was provided access to contralateral uterine venous or ovarian arterial supply. Beal et al. (1981) reported that a heat-labile component of homogenates and extracts of day 18 bovine conceptuses stimulated production of $\mathrm{P}_{4}$ by dispersed bovine luteal cells in vitro. Similarly, Godkin et al. (1978) detected a factor in day 13 to 15 ovine conceptuses which stimulated in vitro production of $\mathrm{P}_{4}$ by ovine luteal slices. Protein extracts from pig conceptuses were shown to bind LH receptors in porcine luteal tissues (Saunders et al., 1980). However, Ball and Day $(1982 a, b)$ presented evidence for a non-thermolabile luteotropin in aqueous extracts of porcine conceptuses.

In contrast to these studies, several reports indicated that luteostatic and/or antiluteolytic mechanisms might be associated with conceptus induced CL maintenance. In cyclic cattle, uterine infusion of conceptus homogenates from days 15 through 17 delayed decline in peripheral plasma $\mathrm{P}_{4}$, but did not stimulate it as compared to uninfused controls (Northey and French, 1980). Smith et al. (1982) failed to detect any simple relationship between length of day 16 bovine conceptuses and ability of dispersed luteal cells to respond to LH in vitro. Poffenbarger et al. (1982), using a mouse Leydig cell bioassay, did not detect LH activity in homogenates of day 16 to 20 bovine conceptuses or in culture medium in which day 16 and 17 conceptuses were incubated for $12 \mathrm{~h}$. Similarly, no evidence of LH or prolactin activity was detected in ovine conceptus homogenates by radioreceptor assay, nor did homogenates stimulate $\mathrm{P}_{4}$ synthesis or CAMP in isolated ovine luteal cells (Ellinwood et a1., 1979a). 
In both cattle (Kindahl et al., 1976) and ewes (Peterson et al., 1976) PPGFM levels were depressed during early pregnancy as compared to the same period post-estrus during which plasma $\mathrm{P}_{4}$ levels were declining in cyclic controls. Kindahl et al. (1981) suggested that, in cattle, $\mathrm{P}_{4}$ might regulate duration of uterine release of $\mathrm{PGF}_{2 \alpha}$ as reflected by suppressed PPGFM. It was further suggested that chronic $\mathrm{P}_{4}$, characteristic of early pregnancy, might suppress gonadotropic support to accessory ovarian follicles which, otherwise, could provide estrogenic stimulation necessary for a luteolytic surge of uterine $\mathrm{PGF}_{2 \alpha}$ (Kindahl et al., 1981). Alternatively, maternal $\mathrm{P}_{4}$, products of the conceptus, or both were suggested to stimulate production or activity of an endogenous inhibitor of uterine PG synthesis (Kindahl et a1., 1981). Wlodawer et al. (1976) provided evidence for presence of such an inhibitor in bovine endometrium.

Rico et al. (1981) presented evidence supporting the idea that the bovine conceptus could modify uterine response to an endocrine stimulus. Plasma PGFM response of day 18 pregnant cattle given $E_{2}-17 B$ (3 mg, I.V.), as described above (see Thatcher et al., 1979; Bartol et al., 1981b; Knickerbocker et al., 1982), was suppressed as compared to that of $E_{2}-17 \beta$-treated, day 18 cyclic controls (Rico et al., 1981). Data from the University of Florida (D. Wolfenson, personal communication) indicated that increases in ovarian arterial concentrations of $\mathrm{PGF}_{2 \alpha}$, observed during the normal period of luteolysis in cyclic cattle (days 19-20), were absent in pregnant cattle at the same stage. A conceptus effect on uterine production and/or transport of the luteo1ysin $\left(P G F_{2 \alpha}\right)$ was suggested. Evidence that $P G$ may be subject to active, carrier-mediated transport in reproductive tissues of various species 
was presented by Bito and coworkers (Bito, 1972; Bito and Spellane, 1974; Bito et a1., 1976).

Present data clearly indicate that maternal recognition of pregnancy in the cow, as defined by maintenance of a functional CL, involves complex interactions between the peri-attachment conceptus and underlying uterine tissues. This process undoubtedly involves both luteotrophic and antiluteolytic phenomena. Products of the conceptus may act directly on the CL, either to stimulate luteal function or antagonize the luteolysin. Additionally, interaction of conceptus and maternal units as early as day 16 or 17 may initiate modifications in uterine tissue and/or utero-ovarian vascular dynamics which alter production, metabolism and transport of the luteolysin. Elucidation of the mechanism(s) responsible for pregnancy recognition in cattle will require further investigation of the nature and function of substances produced by both maternal and conceptus units during the peri-attachment period. For a comparison of mechanisms thought to be involved with maternal recognition of pregnancy in cattle, sheep, pigs and mares, the reader is referred to Bazer et al. (1981c).

\section{Importance of the Uterine Environment}

Early pregnancy (pre-attachment stage) in domestic farm animals corresponds in a temporal sense to the period of diestrus in nonpregnant (cyclic) animals. Hence, successful reproduction depends initially upon uterine response to the integrative action of circulating ovarian steroids, and other important endocrine agents present during this period, appropriate to establish an environment capable of sustaining the pre-attachment conceptus. The unique embryotrophic quality of the uterine environment was demonstrated by failure of embryos from sheep 
(Winterberger-Torres, 1956) and pigs (Murray et al., 1971; Pope and Day, 1972), as well as mice, rats and rabbits (Heap et al., 1979), to develop to, or past, the blastocyst stage when confined surgically to the oviduct. Similarly, an exhaustive review of culture media and conditions used for support of bovine, ovine and porcine conceptuses in vitro indicated that no system supported development beyond the hatched blastocyst stage (Wright and Bondioli, 1981). Such observations lead Heap et al. (1979) to suggest that mammalian ova could develop independently of their uterine environment prior to blastulation.

As reviewed above, the bovine conceptus must be present in utero prior to day 17 post-estrus if pregnancy is to be established (Betteridge et al., 1980). Furthermore, removal of conceptuses from pregnant cattle on day 17 , but not on day 15, resulted in prolongation of the estrous cycle (Northey and French, 1980). Therefore, the bovine conceptus does not appear to interact detectably with its uterine environment prior to day 15 post-estrus. However, a strict requirement for synchrony between donors and recipients in bovine embryo transfer ( \pm 2 days; Sreenan, 1978; Seidel, 1981), which must be accomplished prior to day 17 (Betteridge et al., 1980), emphasizes the importance of the uterine environment during this period. That such an environment can be established independently of the presence of a conceptus is demonstrated by the fact that embryos can be transferred and pregnancies established in cyclic recipient cattle which are reproductively synchronous ( \pm 2 days) with pregnant donors (Sreenan, 1978; Seidel, 1981). In these cattle, as in early pregnant cattle during the same period post-estrus uterine response to circulating endocrine agents 
of maternal origin results in establishment of a supportive, embryotrophic, uterine environment. Thus, "the stage is set before the play begins" (p.175; Barcroft, 1934).

The maternal endocrine agent essential to establishment of an embryotrophic uterine environment is $\mathrm{P}_{4}$. While Sauer (1979) indicated that preovulatory ovarian $\mathrm{E}$ was important in potentiating uterine response to this hormone (see below), $\mathrm{P}_{4}$ replacement therapy alone maintained pregnancy in ovariectomized cattle (Hawk et al., 1963), sheep (Foote et al., 1957; Cumming et al., 1974) and pigs (Gentry et a1., 1973). In cattle, several workers reported more successful conception following estrous cycles in which plasma $\mathrm{P}_{4}$ was higher than usual (Corah et al., 1974; Holness et al., 1977). Data support the notion that the $\mathrm{P}_{4}$-dominated, diestrus uterus is required to insure support to the developing conceptus.

Perhaps the earliest physical response of the maternal unit to presence of a conceptus in the uterine lumen is an increase in uterine blood flow and/or vascular permeability indicating initiation of interaction between the conceptus and its uterine environment (Sauer, 1979). Transient 2- to 3-fold increases in blood flow to the gravid uterine horn(s) were observed in cattle, between days 15 and 17 (Ford et al., 1979); sheep, between days 12 and 16 (Greiss and Anderson, 1970); and pigs, between days 12 and 13 (Ford and Christenson, 1979). Additionally, Boshier (1970) described a positive Pontamine Blue reaction in uteri of pregnant ewes between days 15 and 16 . Increased blood flow and uterine vascular permeability, induced locally by the conceptus, may enhance potential for exchange of substances between uterine and vascular compartments important for initiation of luteostatis and/or maintenance of a supportive intrauterine environment. 
Removal of the uterus before, or the conceptus after that period post-estrus associated with conceptus-induced transient increases in bovine UBF (days 15-17) resulted in prolongation of the estrous cycle (Wiltbank and Casida, 1956; Northey and French, 1980). Consequently, uterine responsiveness during this period, whether to maternal or conceptus signals, is crucial for successful reproduction. Psychoyos and Casimiri (1980) noted that, in species which display a decidual response, the period associated with increased uterine vascular permeability was also the only neriod during which trauma-induced deciduogenesis would occur. Endometrial sensitivity to both mechanical and physiological stimuli were suggested to be maximal during this time (Psychoyos and Casimiri, 1980). Present data suggest a similar period of uterine sensitivity in cattle between days 15 and 17 . Uterine responses to endogenous stimuli during this period dictate whether a luteolytic or embryotrophic (1uteostatic) path will be followed. Either is consistent with the presumed goal of the sexual (estrous) cycle, that of maximizing reproductive efficiency. If, during this period, signals integrated by uterine tissues are of maternal origin alone, the luteolytic path is taken and another opportunity for conception (estrus) provided. In contrast, if appropriately timed signals integrated by uterine tissues are of both maternal and conceptus origin, the embryotrophic path is taken and pregnancy established. A wider or less well defined period of uterine sensitivity might decrease reproductive efficiency by providing fewer opportunities for conception as a consequence of irregularities in estrous cycle length.

As established by Hartman (1924), conceptus-induced prevention of luteolysis is a necessary prerequisite to maintenance of pregnancy. 
It is difficult, if not impossible, to separate those conceptus-induced maternal responses associated with luteostasis from those required for induction of an embryotrophic uterine environment. Indeed these two phenomena are far from independent, and mechanisms associated with one may well insure the other. In cattle, these mechanisms are especially

unclear. However, the bovine uterus clearly serves as a major integrator of goal-directed activity as defined by phenomena necessary for maximal reproductive success.

\section{The Uterus}

\section{Bovine Uterine Anatomy}

According to Mossman (1980), "the sole purpose of the uterus of a placental mammal is to furnish a conduit through which spermatozoa reach the eggs, and to contain and sustain the developing conceptus from the morula or early blastocyst period until parturition" (p.3).

The uterus of the cow is bipartite, consisting of two distinct uterine horns (cornua), approximately $25 \mathrm{~cm}$ in length, joined posteriorly in a short, common uterine body and suspended from the pelvis by the broad ligament (corpus uteri; Skjerven, 1956a; Priedkalns, 1976). The uterine wall consists of three basic, histologically distinguishable layers including (1) the serosa, or perimetrium; (2) the muscularis, or myometrium; and (3) the mucosa, or endometrium. The perimetrium consists primarily of semidense collagenous tissue and is covered by peritoneal mesothelium except in posterior portions adjacent to the cervico-vaginal area. Underlying the perimetrium, the myometrium consists of both an outer longitudinal and inner circular layer of smooth muscle fibers (Priedkalns, 1976). The inner-most mucosal layer, or endometrium, is of particular importance to this discussion since it 
is this layer which relates mother to conceptus both structurally and functionally (Mossman, 1980).

In ruminants two morphologically distinct areas are apparent on the luminal surface of the endometrium. These are the caruncular and intercaruncular areas (Priedkalns, 1976). Histologically, both areas are comprised of three tissue layers. Surface epithelium (propria mucosa) may be cuboidal, columnar and pseudostratified columnar (Priedkalns, 1976; King et al., 1981; Wathes and Wooding, 1980; Mossman, 1980). This layer is continuous with the submucosa (stratum compactum). There is no uterine mucosal muscularis (Priedkalns, 1976). Below the stratum compactum, the stratum spongiosum is seen as a layer of loosely arranged collagenous and few reticular connective tissue fibers. This layer extends from the stratum compactum to the myometrium and is sometimes referred to as the deep submucosa (Priedkalns, 1976).

In cattle, caruncular areas appear as isolated thickenings of the propria submucosa (Priedkalns, 1976). Atkinson et al. (1982) described these structures as pedunculated nodules, present on the bovine fetal endometrium as early as day 200 of gestation. From 70 to 140 of these morphologically distinct, aglandular areas may be present in a single bovine uterus (Amoroso, 1952). These discrete structures, rich in fibroblasts and extensively vascularized, serve as maternal components of placentomes, the principle sites of attachment and maternal-fetal gas exchange during gestation (see Kingman, 1948; Bjorkman, 1973; King et al., 1980; Wooding and Wathes, 1980; King et al., 1981). Intercaruncular areas of the bovine endometrium represent the glandular component of the uterus. These areas are penetrated by many simple, coiled, tubular glands lined with ciliated and nonciliated epithelium. Such glands are present throughout the endometrium, 
extending into the stratum spongiosum and even the myometrium depending upon reproductive status. Mouths of endometrial glands open only on the intercaruncular surface (Priedkalns, 1976).

Uterine vascular anatomy of the cow, as well as other major domestic farm and laboratory species, was reviewed by Ginther (1976). Further descriptions of bovine uterine vasculature were presented by Ginther and Del Campo (1974), Yamauchi and Fumihiko (1968) and Yamauchi and Sasaki (1969a,b). The following description is based largely upon these publications.

Each side of the bovine uterus receives blood from three major vessels. These include (1) the ovarian artery (OA); (2) the uterine artery (UA); and (3) the vaginal artery (VA). Branches of each of these arteries course through the broad ligament to provide vascular support to different regions of the reproductive tract. The OA originates from the dorsal aorta and divides in the broad ligament to form the uterine, tubal and ovarian branches of the OA (UBOA, TBOA and $O B O A)$. The UBOA provides blood to central and anterior ends of each horn. A branch of the internal iliac artery, the UA also divides into primary branches (UBUA) within the broad ligament. These vessels supply major arterial support to the uterine body and horns. Toward the uterus UBUA divide forming arcuate arteries (AA) which penetrate the myometrium, run between longitudinal and circular muscle layers and encircle each uterine horn. Longitudinal myometrial smooth muscle is supplied by AA while basal arteries (BA), branches of the AA, supply the inner circular smooth muscle layer. Further branching and coiling of the BA give rise to the tortuous radial arteries (RA) which supply inner-most endometrial tissue layers. Since the RA are most intimately 
associated with endometrial tissues it was suggested that these vessels might be responsible for the phenomenon of metestrus bleeding (Hansel and Asdell, 1951). These vessels were also suggested to serve as important components of the maternal vascular supply to the placenta (Yamauchi and Fumihiko, 1968; Carter et al., 1971; Ginther, 1976). Anastomoses of branches of the VA (UBVA) with UBUA may also supply blood to the uterine body. Venous drainage of the uterus is essentially parallel and opposite that of the arterial supply. However, primary drainage of the uterus occurs through the ovarian vein (OV). It is the unique anatomical relationship between the UBOV, OV, and OA that is thought to permit countercurrent exchange of the uterine luteolysin (see Ginther, 1976).

Uterine lymphatics may be found running essentially parallel to blood vasculature (Reynolds, 1949). Although these vessels are undoubtedly important physiologically, few if any studies of bovine uterine lymphatic supply have been conducted. However, the reader is directed to recent work of Staples et al. (1982) in which uterine lymphatic drainage of both the sheep and goat was described.

While it is established that reproductive organs are well supplied with lumbar and sacral nerves (Getty, 1975), the integrative role of neural input to the bovine uterus remains unclear. Primary innervation of the uterus arises from the hypogastric plexus which provides sympathetic adrenergic input. Structural similarities between certain catechol-estrogens (Fishman, 1977) and the sympathetic neurotransmitters (catecholamines; e.g., norepinephrine), however, suggest that uterine response to nervous input may be more important than previously realized (see Ball et al., 1975; Davies et al., 1975; Kelly and Abel, 1980). 


\section{Steroids and Endometrial Response}

Predictable cyclic fluctuations in endometrial histology, cytology and metabolic activity occur largely as a result of the integrative action of steroid hormones. Consequently, prior to a review of uterine histology and components of the uterine environment, a brief description of mechanism of action of steroid hormones is warranted. Information presented below was obtained largely from reviews by O'Malley and Means (1974), O'Malley and Schrader (1976), Clark et al. (1977), Schrader and O'Malley (1978), Stormshak (1979) and Walters and Clark (1980).

Entry of steroids from extracellular space into uterine cells is believed to occur by passive diffusion (Clark et al., 1977; Schrader and O'Ma11ey, 1978; Stormshak, 1979). Evidence was presented, however, to suggest that E entry might be protein mediated (Milgrom et al., 1973) and that E-specific binding sites might be present on the endometrial cell surface (Pietras and Szego, 1977). Upon entry, steroids may bind specifically to high-affinity, low capacity cytosol receptors, or nonspecifically to low-affinity, high capacity components of the intracellular milieu (Stormshak, 1979; Clark et al., 1977). The latter components may be important in maintaining availability of steroids within target tissues.

High affinity cytosol receptors for both $\mathrm{P}_{4}$ and $\mathrm{E}$ are thought to be dimeric proteins consisting of an A and B subunit, each of which can bind one molecule of steroid (Schrader and O'Malley, 1978). Binding of hormone $(H)$ to the cytosol receptor $\left(R_{C}\right)$ forms an $H \cdot R_{c}$ complex which is then translocated from the cytosol to the nucleus $\left(H \cdot R_{n}\right)$. Once within the nuclear envelope the $B$ subunit of the $H \cdot R_{n}$ binds specifically to an acceptor site on nonhistone protein of nuclear chromatin (Schrader and O'Malley, 1978; Stormshak, 1979). Binding of the B subunit at an 
acceptor site is thought to effect exposure of a specific sequence of nucleotide base pairs on DNA. This event is accompanied by dissociation of the A subunit which subsequently binds to exposed DNA in a nucleotide sequence-specific manner and initiates transcription of specific RNA molecules necessary for synthesis of steroid-induced proteins (C1ark et al., 1977; Schrader and O'Malley, 1978; Stormshak, 1979). Fate of the $H \cdot R_{n}$ complex following these events remains unclear, but may involve recycling of receptors from nucleus to cytosol (Walters and Clark, 1980; Schrader and O'Malley, 1978).

Nuclear translocation of $E \cdot R_{c}$ requires 2 to $3 \mathrm{~min}$. (Clark et al., 1977; Katzenellenbogen et a1., 1980). Following translocation, uterine responses to $\mathrm{E}$ include both early and late uterotrophic events (Clark et a1., 1977; Katzenellenbogen et a1., 1980). Early uterotrophic events generally occur within $4-6 \mathrm{~h}$ of tissue exposure to $\mathrm{E}$ and include hyperemia, 1ysosome labilization, and increases in water imbibition, precursor uptake and synthesis of phospholipids, RNA and E-specific proteins (Clark et a1., 1977; Kirkland et al., 1978, 1981; Katzene1lenbogen et al., 1980). These events are thought to be prerequisite to tissue growth. Late uterotrophic events including increases in net cellular content of RNA, DNA and protein, as well as cell division, reflect E-induced growth phenomena (Katzenellenbogen et a1., 1980; Kirkland et a1., 1978, 1981). These events may be detected within $5 \mathrm{~h}$ to $10 \mathrm{~h}$ of $\mathrm{E}$ exposure and continue for $24 \mathrm{~h}$ to $30 \mathrm{~h}$ (cell division; Katzenellenbogen et al., 1980).

Increases in nuclear content of RNA polymerase II, within 15 min. of $\mathrm{E}$ exposure, characteristically precede early E-induced uterotrophic responses (Katzenellenbogen et al., 1980; Stormshak, 1979). This 
enzyme catalyzes transcription of mRNA prerequisite to synthesis of E-specific proteins (Clark et a1., 1977). Increases in nuclear content of RNA polymerase I, responsible for transcription of rRNA, are detectable within $2 \mathrm{~h}$ to $6 \mathrm{~h}$ post $\mathrm{E}$ exposure and precede late uterotrophic events (Clark et a1., 1977; Katzenellenbogen et a1., 1980). Ovine endometrial RNA polymerase I activity increased within $6 \mathrm{~h}$ postadministration of $\mathrm{E}_{2}-17 \beta\left(500 \mu \mathrm{g}, \mathrm{I} . \mathrm{M}_{\text {. }}\right.$ ) to diestrus ewes (Luebke et al., 1980). Less immediately dramatic changes in protein and RNA synthesis are seen following $\mathrm{P}_{4}$ exposure and nuclear translocation of $\mathrm{P}_{4} \cdot \mathrm{R}_{\mathrm{C}}$ stimulation of specific mRNA occurs within $4 \mathrm{~h}$ to $6 \mathrm{~h}$ of $\mathrm{P}_{4}$ exposure, with maximal stimulation not seen before $18 \mathrm{~h}$ to $20 \mathrm{~h}$ (Schrader and O'Malley, 1978; Clark et al., 1977). Endometrial response to $\mathrm{P}_{4}$ requires $\mathrm{E}$ priming (Walters and $\mathrm{Clark}$, 1980). Since $\mathrm{P}_{4}$ may also regulate tissue E receptor levels (Walters and Clark, 1980), temporal patterns of appearance and relative amounts of each hormone ( $E$ and $P_{4}$ ) may dictate extent and nature of endometrial response.

Estrogen stimulates endometrial synthesis of both its own and $\mathrm{P}_{4}$-specific cytoșol receptors (Janne et al., 1978; Clark et al., 1977). Consequently E potentiates uterine responsiveness both to itself and $\mathrm{P}_{4}$. Uterine sensitivity to ovarian steroids ( $E$ and $\mathrm{P}_{4}$ ) is modified through the integrative action of $\mathrm{E}$ and $\mathrm{P}_{4}$. Estrogen-induced increases in endometrial $\mathrm{P}_{4}$ cytosol receptors augment uterine response to $\mathrm{P}_{4}$ (Clark et al., 1979). Progesterone, in turn, modifies uterine responsiveness to $\mathrm{E}$ both by inhibiting synthesis of $\mathrm{E}$ receptors and decreasing nuclear retention time of $E \cdot R_{n}$ (Clark et al., 1977; Katzenellenbogen et al., 1980). Consequently, $\mathrm{P}_{4}$ decreases ability of the uterus to respond in a totally $\mathrm{E}$ directed fashion (Clark et al., 1977). 
Uterine sensitivity to $\mathrm{E}$ may also be modified by other hormones. Walters and Clark (1980) indicated that certain androgens, such as dihydroxytestosterone, if present in very high levels, may compete successfu11y for cytosolic E receptors. Alternatively, local conversion of androgens to estrogens could also provide additional estrogenic support (Walters and Clark, 1980). To date, however, no such conversion has been reported for bovine, ovine or porcine endometria (see below). Recent studies (Gardner et al., 1978; Kirkland et al., 1981) indicated that, in ovariectomized rats, hypothyroidism diminished late uterotrophic responses to $E_{2}-17 B$. Diminished responsiveness was restored by administration of thyroid hormone $\left(\mathrm{T}_{4}\right)$. Thyroid hormone alone did not elicit a uterine response. However, $\mathrm{T}_{4}$ restored $\mathrm{E}_{2}-17 \mathrm{~B}$-induced uterine responsiveness in a dose dependent manner. Thus, uterine responsiveness to $\mathrm{E}$ may be modified by metabolic hormones.

In addition to its effect on uterine $\mathrm{E}$ receptor synthesis, $\mathrm{P}_{4}$ suppresses endometrial synthesis of its own cytosol receptor (Walters and Clark, 1980; Schrader and O'Malley, 1978). A short term effect of $\mathrm{P}_{4}$ on $\mathrm{E}$-primed endometrial tissue included a rapid increase in translocation of $\mathrm{P}_{4} \cdot \mathrm{R}_{\mathrm{c}}$ to $\mathrm{P}_{4} \cdot \mathrm{R}_{\mathrm{n}}$ (Walters and Clark, 1980). Levels of $\mathrm{P}_{4} \cdot \mathrm{R}_{\mathrm{n}}$ were maximal at $1 \mathrm{~h}$ and returned to basal levels by $9 \mathrm{~h}$ post-P $4^{\cdot}$ Rapid increase in $\mathrm{P}_{4} \cdot \mathrm{R}_{\mathrm{n}}$ was accompanied by a depression in $\mathrm{P}_{4} \cdot \mathrm{R}_{\mathrm{c}}$, followed by replenishment within $12 \mathrm{~h}$ post- $4_{4}$. This rebound phenomenon was suggested to indicate recycling of nuclear receptor to the cytosol (Walters and Clark, 1980). However, following the $12 \mathrm{~h}$ post-P 4 replenishment of $\mathrm{P}_{4}$ cytosol receptors, levels decreased to those characteristic of unprimed (E) tissue (Walters and Clark, 1980). Progestational reduction in $\mathrm{P}_{4}$ receptors was not irreversible and was overcome by administration of E (Walters and Clark, 1980; Schrader and O'Malley, 1978). Tissue $\mathrm{P}_{4}$ 
receptor levels may also be affected by products of the adrenals induced during conditions of environmental stress (Walters and Clark, 1980).

Clearly, uterine responsiveness to $\mathrm{E}$ and $\mathrm{P}_{4}$ depends upon temporal pattern of appearance and amount of each hormone present ( $E / \mathrm{P}_{4}$ ratio). Following E-induction of high levels of endometrial $\mathrm{P}_{4}$ receptors, $\mathrm{P}_{4}$ may eliminate or modify E-induced uterotrophic responses. However, as $\mathrm{P}_{4}$ suppresses endometrial production of its own receptors, E-induced events become less suppressed. Hence, $\mathrm{P}_{4}$ receptor levels dictate $\mathrm{P}_{4}$ response as reflected by E-induced uterotrophic events (Walters and Clark, 1980). In this respect, the $\mathrm{P}_{4}$ dominated uterus of pregnancy presents an intriguing problem in steroid receptor regulation which is not well understood. Walters and Clark (1980) suggested that nonestrogenic uterotrophic stimuli may act alone or synergistically with low levels of endogenous $\mathrm{E}$ to maintain an adequate $\mathrm{P}_{4}$ receptor population throughout gestation. In cattle and other species, such stimuli may be provided by the conceptus. Recently, Findlay et al. (1982) presented evidence that the ovine conceptus could affect caruncular and intercaruncular tissue levels of E receptors as early as day 9 of gestation.

Studies of endometrial content of cytosol receptors for $\mathrm{E}$ and $\mathrm{P}_{4}$ in normally cyclic domestic farm species revealed predictable patterns with respect to the review of receptor dynamics presented above. Endometrial content of cytoplasmic $E_{2}$ receptors was highest during proestrus and metestrus, when $\mathrm{E}$ was the dominant ovarian steroid, in cattle (Senior, 1975; Henricks and Harris, 1978), ewes (Koligian and Stormshak, 1977a; Miller et al., 1977) and gilts (Deaver and Guthrie, 1980). Endometrial $\mathrm{E}_{2}$ receptor levels were depressed throughout diestrus in cattle 
(Henricks and Harris, 1978) and ewes (Koligian and Stormshak, 1977a,b; Miller et a1., 1977), but not in gilts (Deaver and Guthrie, 1980) in which receptor levels increased transiently during mid-diestrus. The latter observation was consistent with current concepts of maternal recognition of pregnancy in the pig in which uterine recognition of conceptus produced E is critical (see. Bazer et al., 1982).

Bovine endometrial content of cytoplasmic $\mathrm{P}_{4}$ receptors was higher during proestrus (day 0) than diestrus (day 12; Zelinski et al., 1982). Data were generally consistent with those of Koligian and Stormshak (1977a) for cyclic ewes. Estrogen induction and $\mathrm{P}_{4}$ antagonism of endometrial cytosol receptor synthesis was demonstrated in the ewe (Koligian and Stormshak, 1977b). Studies related directly to endometrial steroid receptor regulation in cattle are unavailable. However, Atkins et al. (1980) reported that concentrations of $\mathrm{P}_{4} \cdot R_{n}$ (receptor sites/cell) were higher in the uterine horn ipsilateral as compared to that contralateral to the CL-bearing ovary on day 10 but not on days 4 or 18 postestrus in cyclic heifers. Data suggested a local uteroovarian field-effect associated with propagation of a maximally responsive embryotrophic uterine environment.

\section{Endometrial Histology During the Estrous Cycle and Early Pregnancy}

Histological and cytological alterations in bovine endometrial epithelial cells reflect tissue metabolic activity in response to fluctuating endocrine and other stimuli. In cyclic cattle, mitotic activity in both surface and glandular epithelium was noted to begin at or around estrus and continue for approximately 6 days into metestrus (Marinov and Lovell, 1968). Epithelial cell heights were lowest at estrus but continued to develop into diestrus (Marinov and Lovel, 1968; 
Skjerven, 1956a). Slight hemorrhage was observed in propria mucosa of caruncles just before ovulation (Marinov and Lovell, 1968). This microscopic hemorrhage is seen externally, $24 \mathrm{~h}-48 \mathrm{~h}$ later, as metorrhagia or metestrus bleeding (Hansel and Asde11, 1951).

Irregularities in bovine uterine epithelial cell heights were noted throughout the estrous cycle, but reached a maximum developmentally (30-35 $\mu \mathrm{m})$ during mid-diestrus (Skjerven, 1956a; Marinov and Love11, 1968; Wathes and Wooding, 1980). Characteristic of active diestrus endometrial tissue are columnar and pseudostratified columnar epithelial cells which contain numerous mitochondria, well developed golgi apparati and rough endoplasmic reticulum (RER; Skjerven, 1956a; Marinov and Love11, 1968; Wathes and Wooding, 1980). Nuclei were basally located, and cells contained many lipid vacuole inclusions just beneath apical microvilli (Marinov and Love11, 1968, Wathes and Wooding, 1980). Histochemical and histological evidence of apocrine-type secretion was noted (Skjerven, 1956a; Marinov and Lovel1, 1968). During late diestrus, in absence of a conceptus, degenerative or regressive changes occur in bovine endometrium. Epithelial cells were observed to become shorter and glands regressed from submucosa becoming gradually less active (Skjerven, 1956a; Marinov and Lovel1, 1968; Mossman, 1980). Agenesis of both apical microvilli and intracellular organelles was noted (Skjerven, 1956a; Marinov and Love11, 1968). Also characteristic of this period was appearance of large aggregates of smooth endoplasmic reticulum (SER) associated with very large mitochondria, the function of which remains unclear (4 to 5 times normal; Wathes and Wooding, 1980). Elevated levels of E characteristic of late diestrus and proestrus were reflected histologically by continued 
regression of epithelial cells (Marinov and Lovell, 1968). Estrogenassociated hypermia appeared as excess fluid in intercellular space of the stratum compactum (Marinov and Lovell, 1968). Leucocytes were identified between epithelial cells and at the basal lamina throughout the estrous cycle (Wathes and Wooding, 1980; King et a1., 1981).

Histological and cytological descriptions of bovine caruncular and intercaruncular epithelium during the peri-attachment period of early pregnancy between days 17 and 30 were incomplete prior to recent publications of King et al. (1980, 1981) and Wathes and Wooding (1980). These studies indicated that before days 17 to 18 of pregnancy endometrial tissues developed in a manner indistinguishable, histologically, from that of cyclic cattle. However, after this stage alterations in endometrial histology were unique to pregnancy and directly related to interactions of maternal tissues with the chorionic surface of the trophoblast. King et al. (1981) divided the period of early pregnancy between days 17 and 30 into three phases based upon relationship of trophoblast to endometrial surface. Included were: the apposition phase ( $\simeq$ days 17 to 18 ); the adhesion phase ( $\simeq$ days 18 to 20 ); and the attachment phase $(\simeq$ days $21-30)$.

Day 17 endometrial surface epithelium consisted of relatively uniform columnar and pseudostratified columnar cells, indistinguishable, ultrastructurally, from those of nonpregnant cattle (King et al., 1981). Epithelium was more regular in appearance in pregnant than nonpregnant cattle on day 18 (Wathes and Wooding, 1980). Cells were columnar, 20 to $25 \mu \mathrm{m}$ in height and at least $3 \%$ contained two nuclei. Binucleate cells were evenly distributed between gravid and nongravid uterine horns (Wathes and Wooding, 1980). Between days 19 and 20 definite 
areas of adhesion were described between trophoblastic and endometrial epithelium (Wathes and Wooding; King et al., 1981). However, microvil1i were observed only on the maternal epithelial surface and no interdigitation of conceptus and endometrial tissues was yet apparent (Wathes and Wooding, 1980). Also between days 19 and 20, two areas of maternal epithelium were identified. Endometrium beneath uninucleate trophoblastic cells consisted of tall (35-45 $\mu \mathrm{m})$ columnar epithelial cells which contained SER and large mitochondria. Other areas were scattered among columnar cells and consisted of large, pale, multinucleated, giant cells (mGC). These mGC contained numerous, basally located, membranebound granules indistinguishable morphologically from granules seen in conceptus trophoblastic binucleate cells (Wathes and Wooding, 1980; King et al., 1981).

Consistent with observations of Leiser (1975), attachment, evidenced by interdigitation of apical microvilli between maternal and conceptus surface epithelia, was observed throughout the gravid uterine horn between days 21 and 22 (Wathes and Wooding, 1980; King et al., 1981). Maternal giant cells continued to increase in size and number such that by day 24 mGC comprised $25 \%$ of total cell number and $50 \%$ of cell area in the gravid uterine horn (Wathes and Wooding, 1980; King et al., 1981). At this stage $m G C$ were as much as $100 \mu \mathrm{m}$ in width and contained up to eight nuclei (Wathes and Wooding, 1980). Maternal giant cells replaced strips of regular columnar epithelium and columnar cells adjacent to mGC appeared degenerated, with no SER and small mitochondria (Wathes and Wooding, 1980). Dying or degenerated columnar cells appeared to be phagocytosed by uninucleate cells of the trophoblast (Wathes and Wooding, 1980). Such maternal cell debris may serve as a source of histotrophe. 
By days 26 to 27 , areas of attachment were apparent in the nongravid uterine horn (Wathes and Wooding, 1980; King et a1., 1980, 1981). In the gravid horn mGC accounted for $70 \%$ of uterine luminal epithelium (Wathes and Wooding, 1980). Tall, narrow, columnar cells, adjacent to mGC, appeared to divide marginally forming a low cuboidal epithelium (Wathes and Wooding, 1980). Thus, although areas of unchanged endometrial epithelium persisted, two cell types predominated by day 28: (1) long narrow strips of $\mathrm{mGC}$ and (2) large areas of uninucleated cuboidal cells. Beyond day 28 , mGC degenerated and appeared to be phagocytosed by trophoblastic (chorionic) epithelial cells (Wathes and Wooding, 1980). In contrast, cuboidal cells persisted as the predominant endometrial intercaruncular cell type throughout the remainder of gestation (Wathes and Wooding, 1980; Wooding and Wathes, 1980).

Both origin and function of multinucleated bovine endometrial giant cells remain unclear. Previous descriptions of these cells by several investigators (Leiser, 1975; Bjorkman and Bloom, 1957; Bjorkman, 1968a; King et al., 1979, 1980, 1981) indicated that mGC were strictly of maternal origin. However, Wathes and Wooding (1980) presented convincing morphological and ultrastructural evidence that mGC form as a consequence of fusion of maternal columnar epithelial cells and conceptus trophoblastic binucleate cells. These workers suggested that transient formation of mGC between days 19 and 28 occurred primarily to allow delivery of conceptus binucleate cell products to maternal circulation. Such a process could provide a route for delivery of conceptus products necessary for luteostasis. However, absence of $\mathrm{mGC}$ before day 19 suggests that events associated with formation of these cells may be more important for establishment of an 
embryotrophic uterine environment. Additionally, fusion of maternal and fetal cells may be important in immunological aspects of pregnancy recognition (Beer and Billingham, 1976).

\section{Components of the Uterine Environment}

Response of uterine tissues to agents of maternal and conceptus origin leads to establishment and maintenance of a unique, embryotrophic uterine environment. The dynamic, complex nature of this environment is attested to by inability of investigators to maintain conceptuses, from both large domestic and laboratory species, to or beyond the hatched blastocyst stage in vitro (Brackett, 1981; Wright and Bondioli, 1981). As reviewed above and by Amoroso (1952), the importance of components of the mammalian uterine environment long has been recognized. The following section will review aspects of the nature of the uterine environment in domestic farm species during the peri-attachment period, with emphasis on the cow. Comments will be confined largely to observations of the diestrus cyclic and early pregnant uterine environment during the first 30 days of gestation.

Collection techniques. According to Amoroso (1952), "uterine milk" was first analyzed by Prevast and Morin (1842) and later by Schlossberger (1855) and Gamgee (1864). Since that time a multitude of studies in as many species have been conducted to examine components of the uterine environment. Methods employed for collection of uterine fluids are equally numerous and were reviewed by Bazer et al. (1978). Two basic approaches have been used, (1) chronic collection, involving placement of catheters or cannulae in the reproductive tract and collection of fluids in vessels maintained either intra- or extraabdominally; and (2) acute collection, involving recovery from the 
reproductive tract following either hysterectomy or slaughter and lavage of the uterine lumen with a defined medium to obtain flushings. Both methods were proven effective in large domestic species. However, Bazer et al. (1978) noted that the method of choice could influence results and should be chosen with experimental objectives in mind. Specifically, chronic collection techniques of ten produced genital tract fluids heavily contaminated with serum components (Bazer et al., 1978; Heap and Lamming, 1960, 1962; Bartol et a1., 1981b). Consequently, recent studies suggest that more reliable profiles may be obtained following acute collection procedures (Bazer et a1., 1978; Bartol et a1., 1981a,b; Roberts and Parker, 1976).

Regardless of technique employed, amount of material, particularly protein, recoverable from uteri of sheep and cattle during the estrous cycle and early pregnancy is small (3 to $20 \mathrm{mg}$ total protein/uterine flush; Roberts et a1., 1976; Bartol et a1., 1981a). Such difficulties led several investigators to exploit early observations of Bond (1898) which indicated that ligation of the oviduct or uterine horn in rabbits, guinea pigs and sheep permitted accumulation of copious amounts of luminal fluid. Harrison et al. (1976) demonstrated that large amounts of protein-rich uterine fluid could be obtained from late pregnant and postpartum ewes in which a blind pouch was created surgically in one uterine horn. Later, Bazer et al. (1979a) recovered similar fluid from late pregnant ewes ( $\geq 100$ days) rendered unilaterally pregnant by 1igation of one uterine horn. In both cases, uterine fluid accumulated in the nonpregnantuterine horn in response to endogenous physiological cues characteristic of late ovine gestation. It was suggested (Bazer et al., 1979a) that, although recovered during late gestation, components of such "uterine milk" might include substances normally required 
to provide an embryotrophic environment during early pregnancy. To date, this approach has not been attempted in cattle.

Electrolytes, free amino acids and reducing sugars. Analyses of electrolyte components of chronically collected uterine fluids from several species indicated regular cyclic fluctuations. Sodium (Na) and phosphorous ( $P$ ) in bovine and potassium $(K)$ and $P$ in ovine uterine fluids were elevated during diestrus (Heap, 1962; Heap and Lamming, 1960). Heap (1962) and Heap and Lamming (1960, 1962) detected only traces of calcium ( $\mathrm{Ca}$ ) in bovine uterine flushings regardless of estrous cycle stage. However, others (Lamonthe and Gray, 1970; Schultz et al., 1971) reported cyclic fluctuations in bovine uterine fluid Ca, $\mathrm{K}$, chloride $(\mathrm{Cl})$, and inorganic phosphate $\left(\mathrm{PO}_{4}\right)$. Both $\mathrm{K}$ and $\mathrm{PO}_{4}$ were elevated during diestrus, while $\mathrm{Ca}$ and $\mathrm{Cl}$ were elevated during proestrus and estrus. Mean uterine fluid concentrations of $\mathrm{K}$ and $\mathrm{PO}_{4}$ were higher, $\mathrm{Ca}$ lower and $\mathrm{Na}$ not significantly different from those determined for serum from the same cattle (Schultz et al., 1971; 0lds and Van Demark, 1957b). Such differences between uterine fluid and serum in readily diffusable electrolytes suggested that these two fluid pools were not in simple equilibrium. Furthermore, cyclic fluctuations in uterine fluid electrolytes suggested that endometrial cell membrane potential was influenced by hormonal state.

Rasmussen (1981) reviewed data indicating that most secretory cells respond to chemical (endocrine) stimuli with changes in membrane potential. Such changes are effected by alterations in ion currents (flux) across cell membranes (Rasmussen, 1981). Rasmussen (1981) indicated that, in general, hormones with opposite effects have opposite influences on membrane ion currents. Hence, opposing effects of $E$ and 
$\mathrm{P}_{4}$ (E/P 4 ratio) may dictate electrophysiological state of endometrial mucosa. Although not demonstrated in bovine endometrial tissue, such relationships were demonstrated in porcine chorioallantoic membranes (Bazer et al., 1981a).

Electrolyte components of uterine fluid from early pregnant cattle have not been characterized. However, it seems likely that prior to day 17, when embryo transfer is still possible (Betteridge et al., 1980), diestrus cyclic and early pregnant bovine uterine environments are quite similar. Although little is known about inorganic salt requirements of pre-attachment conceptuses of large domestic animals (Wright and Bondioli, 1981), in vitro studies indicated absolute requirements for both $\mathrm{Ca}$ and $\mathrm{K}$ in maintenance of preimplantation mouse and rat embryos (Biggers and Borland, 1976; Brackett, 1981; Wright and Bondioli, 1981). Sodium chloride (NaCL) was also identified as essential for maintenance of osmotic equilibrium (Wright and Bondioli, 1981). Identification of $\mathrm{Ca}, \mathrm{K}$ and $\mathrm{Na}$ in diestrus bovine uterine fluid (olds and Van Demark, 1957b; Schultz et al., 1971) suggests essential roles for these ions in support of the pre-attachment conceptus.

Fluctuation in uterine luminal electrolyte content, especially Ca, may reflect endometrial secretory activity and capacity to respond to conceptus signals. As compared to diestruus cyclic gilts at the same stage postestrus, Geisert et al. (1982b) observed a dramatic but transient increase in uterine flushing $\mathrm{Ca}$ content between days 11 and 12 in gilts containing tubular and early filamentous conceptuses. Similar observations were made in the roe deer during the period of rapid blastocyst elongation following termination of embryonic diapause (Aitken, 1977). In both species, rapid transient increases in 
uterine $\mathrm{Ca}$ content heralded immediate but more persistent increases in uterine protein content, as well as PGF and $\mathrm{PGE}_{2}$ content in pregnant pigs (Aitken, 1977; Geisert et al., 1982b). Douglas (1968) indicated that $\mathrm{Ca}$ played an essential role in coupling of cellular excitation to response in secretory cells (stimulus-secretion coupling). It was observed that the source of $\mathrm{Ca}$ for such events could be either intracellular or extracellular (Douglas, 1978). Geisert et al. (1982b) suggested that porcine blastocyst-induced endometrial release of free Ca was necessary to provide synchronized release of endometrial secretory proteins. It was further suggested that porcine blastocystinduced endometrial Ca flux potentiated events necessary for maintenance of an embryotrophic uterine environment.

In this respect, Milutinovic et al. (1977), studying pancreatic acinar cells in vitro, showed that if $\mathrm{Ca}$ concentration in medium was raised to between $10^{-6}$ and $2 \times 10^{-5} \mathrm{M}$, pancreatic zymogen granules aggregated with the plasma membrane. This interaction was shown to be specific for the luminal plasma membrane (Milutinovic et al., 1977). It was noted that, since Ca concentrations employed in vitro were similar to extracellular levels predicted in vivo after gland stimulation, a similar extracellular Ca-mediated, luminal-specific stimulation of secretion might function in vivo (Rasmussen, 1981). Rasmussen (1981) indicated that, in secretory cells, changes in either intra- or extracellular $\mathrm{Ca}$ concentrations were met by immediate adjustments in plasma membrane potential necessary to maintain $\mathrm{Ca}$ ion concentrations at or near maximal responsive levels. Thus, alterations in diestrus bovine uterine fluid electrolyte profiles may reflect changes in endometrial epithelial electrophysiology required to establish a maximally responsive environment for conceptus interaction. 
Free amino acids and sugars may serve as important energy substrates to both uterine and conceptus tissues. Fahning et al. (1967) identified 25 free amino acids and/or amino compounds in chronically collected bovine uterine fluids versus only 23 in blood serum from the same cyclic cattle. Quantitative changes in uterine fluid amino acid content were correlated with stage of estrous cycle and occurred independently of blood serum profiles (Fahning et al., 1967). Lowest uterine fluid amino acid concentrations were found at estrus, while highest concentrations occurred between days 8 and 10 of diestrus. These changes occurred independently of uterine fluid volume and, therefore, appeared to be hormonally mediated. Similar data are not available for early pregnant cattle.

Glucose was described as the major free sugar in bovine (Suga and Masaki, 1973), ovine, porcine and equine uterine flushings (Haynes and Lamming, 1967; Zavy et a1., 1982a). Concentrations of reducing sugars in uterine fluids collected chronically (Schultz et al., 1971) and acutely (Olds and Van Demark, 1957a,b) from cyclic cattle were highest during late diestrus (day 14; Schultz et al., 1971). Unfortunately, characterizational studies of changes in bovine uterine luminal content of specific sugars are unavailable. Recently, however, Zavy et al. (1982a) described changes in glucose and fructose content of uterine flushings from cyclic and early pregnant pigs and mares. Total recoverable glucose increased after day 12 in both pregnant and nonpregnant pigs with high levels detected in uterine flushings from pregnant pigs. In contrast, glucose content of uterine flushings was not affected by day postestrus or pregnancy status in mares (Zavy et al., 1982a). Both amino acids and glucose were suggested to be important energy substrates of uterine and fetal-placental tissues during later stages 
of pregnancy in cattle, sheep and pigs (Ferrel1 and Ford, 1980; Ferrell et al., 1976; Battaglia and Meschia, 1978; Silver and Comline, 1975, 1976). Additionally, in vitro culture studies indicated that preattachment stage bovine, ovine and porcine conceptuses required either an amino acid or glucose source for energy maintenance (Wright and Bondioli, 1981). Present data suggest that, in domestic species including cattle, uterine luminal content of both free amino acids and sugars increases during diestrus to meet metabolic demands of both uterine and, if present, conceptus tissues. Conversion of maternal glucose to fructose and metabolism of this sugar via the oxidative arm of the phosphogluconate pathway may be important for generation of reducing equivalents (NADPH) and ribose sugars necessary for biosynthesis of other conceptus products (Zavy et al., 1982a). This pathway of fructose metabolism would require that the conceptus depend heavily on amino acids for energy (Zavy et al., 1982a; Reitzer et al., 1979).

Proteins. Protein components of the uterine environment are undoubtedly important for support of the conceptus. However, definitive data are lacking relative to specific embryotrophic functions of these macromolecules, particularly in cattle, sheep and mares. Whether of serum or uterine origin, proteins present in the uterine lumen of domestic farm species may serve as enzymes and carrier molecules for steroids, prostaglandins, vitamins and minerals (Bazer, 1975; Ellinwood, 1979b). Additionally, certain uterine proteins may be important in limiting trophoblast invasiveness and regulating local immunological processes associated with maternal recognition of pregnancy (Bazer et al., 1981b; Fazleabas et a1., 1982a; Segerson, 1981; Segerson et al., 1982 ; Wietsma et al., 1982). 
Quantitative and qualitative analyses of uterine luminal proteins from cyclic cattle (Bartol et a1., 1981a; Mills, 1975; Roberts and Parker, 1974a, 1976), sheep (Roberts et al., 1976), pigs (Murray et al., 1972; Squire et al., 1972; Chen et al., 1975) and mares (Zavy et a1., $1979 a, b, 1982 b)$ revealed dynamic changes in protein profiles during the estrous cycle with maximal stimulation observed during diestrus. In these studies gel filtration and electrophoretic analyses of uterine luminal proteins indicated that the majority of these proteins were of serum origin or serum-like. However, increases in uterine protein content during diestrus were accompanied by increases in complexity, including appearance of proteins not characteristic of serum in cattle (Bartol et al., 1981a; Roberts and Parker, 1976), ewes (Roberts et al., 1976a), pigs (Murray et al., 1972; Squire et al., 1972) and mares (Zavy et al., 1979b, 1982b). Proteins characteristic of a maximally stimulated diestrus uterine environment waned, both in amount and number, during late diestrus in cyclic cattle (Bartol et al., 1981a; Roberts and Parker, 1974a,b), sheep (Roberts et al., 1976a), pigs (Squire et al., 1972; Geisert et a1., 1982b) and mares (Zavy et al., 1979b, 1982b), but persisted or even increased in complexity if pregnancy was established. Hence, while specific functions remain to be defined for many of these macromolecules, data suggest that a complex array of uterine luminal proteins is required for support of the conceptus and maintenance of pregnancy.

Considering the economic importance of cattle, surprisingly few studies have been conducted to investigate the qualitative array and temporal pattern of change in bovine uterine luminal proteins. Prior to the work of Roberts and Parker (1974a,b; 1976) virtually no information of this type was available in the literature. Comparison of 
electrophoretic, gel filtration and isoelectric focusing (IEF) profiles of proteins in uterine flushings collected acutely from nonpregnant and pregnant cattle from estrus through days 31 to 35 of gestation, with those of serum proteins, indicated that not more than 2 to $3 \%$ of total uterine luminal proteins were distinct from serum (uterinespecific; Roberts and Parker, 1974a, 1976). However, electrophoresis of proteins in bovine uterine washings toward the cathode at $\mathrm{pH} 4.5$, revealed three uterine-specific protein bands (Roberts and Parker, 1974a; Libby et al., 1982). When bovine serum albumin (BSA) was assigned the relative mohility value of $1.0(\mathrm{Ma} / \mathrm{b}=1.0)$, the three cathode migrating uterine-specific proteins (CMP) included one slow CMP at $\mathrm{Ma} / \mathrm{b}=1.2$ and two faster CMP at $\mathrm{Ma} / \mathrm{b}=1.3$ and 1.42 (Roberts and Parker, 1974a). All three CMP were detected electrophoretically in uterine flushings from both nonpregnant and pregnant cattle. The slow $\operatorname{CMP}(\mathrm{Ma} / \mathrm{b}=1.2)$ was observed in uterine flushings from both estrus and day 7 pregnant cattle (Roberts and Parker, 1974a). The two faster $\operatorname{CMP}(\mathrm{Ma} / \mathrm{b}=1.3$ and $1 / 42)$ were detected as early as day 12 in pregnant cattle but were also present, although less intensely, in nonpregnant cattle on days 14 and 18 postestrus (Roberts and Parker, 1974a). Interestingly, a slower $\operatorname{CMP}(\mathrm{Ma} / \mathrm{b}=1.20)$, suggested to be different from the protein band detected in uterine flushings from estrus and day 7 pregnant cattle, increased in intensity in flushings from day 16 pregnant cattle and persisted thereafter until day 35 when the study was terminated (Roberts and Parker, 1974a). Further characterization of these CMP proteins by gel filtration and IEF revealed two proteins in a $\mathrm{pH}$ range of 8.4 to 8.6 and one in a $\mathrm{pH}$ range of 5.0 to 5.5 . All three fell in the 15,000 to 35,000 molecular weight $\left(M_{r}\right)$ range (Roberts 
and Parker, 1974a). Additionally, three CMP were detected in uterine flushings from a single ovariectomized cow treated with $\mathrm{P}_{4}$ (100 mg/day) for two months (Roberts and Parker, 1974a). Similarly, Libby et a1. (1982) recently described three CMP proteins in uterine flushings from both pregnant-and nonpregnant beef cows on day 17 postestrus. Amount of each protein detected was correlated positively with CL wet weight (Libby et al., 1982).

Fractionation of uterine flushing proteins from pregnant cattle (days 7 through 31 ) on Sephadex G-100 produced six fractions (F1-F6) of which F3 and F5 were found to be enriched in uterine-specific proteins (Roberts and Parker, 1976). Three uterine-specific F3 protein bands were identified as distinct from serum by sodium-dodecyl sulfate polyacrylamide gel electrophoresis (SDS-PAGE). Molecular weight $\left(x 10^{-3}\right.$ ) estimates of these proteins were 38,40 and 48 . A quantitative shift in uterine content of F3 proteins was noted, with more of these products present after day 17 of gestation (Roberts and Parker, 1976). Based on SDS-PAGE all proteins in F5 were distinct from serum. Included were four main bands at $\left(M_{\mathrm{r}} \times 10^{-3}\right) 22,16,11.5$ and $<8$; and two faint bands at 32 and 26 (Roberts and Parker, 1976). Isoelectric focusing of F5 proteins revealed two major intense bands at $\mathrm{pH} 7.9$ and 8.1 , two medium stained bands at $\mathrm{pH} 5.5$ and 5.7, and four faint bands between $\mathrm{pH} 4.9$ and 5.5 (Roberts and Parker, 1976). Uterine proteins in F5 were seen with greatest intensity and in highest numbers between days 14 and 15 of pregnancy (Roberts and Parker, 1976).

Studies of Roberts and Parker (1974a, 1976) indicated that at least three and as many as 11 proteins were present in bovine uterine flushings which were distinct from serum. These uterine-specific proteins 
were generally less than 50,000 $\mathrm{M}_{\mathrm{r}}$ and included two basic and as many as six acidic products. The amount and number of these proteins increased in late diestrus (after day 12) and many persisted with pregnancy indicating a requirement for $\mathrm{P}_{4}$. It was suggested that some of the F3 proteins, which persisted until day 31 of gestation when the study was terminated, might be conceptus products or conceptus-induced endometrial products (Roberts and Parker, 1976). In this respect, an increasing quantitative shift in uterine flushing content of F3 proteins was noted in pregnant cattle after day 17 (Roberts and Parker, 1976). Additionally, identification of proteins in allantoic fluid with similar electrophoretic character to F3 and F5 proteins suggested conceptus uptake of uterine products (Roberts and Parker, 1976). Analysis of protein in uterine flushings from cyclic cattle (days $4,8,12,14,16$ and 19) by SDS-PAGE revealed protein bands in 32 ${ }_{\mathrm{r}}\left(\times 10^{-3}\right)$ categories between 18.7 and 292 (Bartol et a1., 1981a). Consistent with observations of Roberts and Parker (1974a, 1976), both amount and number as well as frequency of appearance of proteins were greatest during the late luteal phase (days 14 and 16; Bartol et al., 1981a). Additionally, quantitative and qualitative changes observed in SDS-PAGE uterine flushing protein profiles of cyclic cattle involved primarily proteins of less than 150,000 $\mathrm{M}_{\mathrm{r}}$ (Bartol et al., 1981a). Uterine flushing protein SDS-PAGE profiles from day 19 pregnant cattle were qualitatively and quantitatively similar to day 14 cyclic profiles. Additionally, four protein bands were identified in uterine flushings from day 19 pregnant cattle which were absent from flushings at al1 stages of the estrous cycle examined (Bartol et al., 1981a). Data complemented those of Roberts and Parker (1974a, 1976), indicating 
that the array of uterine luminal proteins, established during diestrus in cyclic cattle, persisted or even increased in complexity if pregnancy was established. Data also provided further support for the notion that conceptus-produced or induced products contributed to the bovine uterine environment during early pregnancy (Bartol et a1., 1981a). Laster (1977), using immunochemical techniques, detected a protein in uterine endometrium and flushings from pregnant but not nonpregnant cattle on day 15 postestrus. Based on gel filtration chromatography (G-200) this protein had an estimated $M_{r}\left(\times 10^{-3}\right)$ of 50 to 60 . This antigen was suggested to comprise less than $1 \%$ of total unfractionated endometrial protein. A second antigen, detected in uterine flushings and endometrium from both pregnant and nonpregnant cows, was designated uterine-associated since it could not be identified immunochemically in plasma, liver, kidney, spleen or muscle from pregnant cows (Laster, 1977). Both proteins, detected by 15 days postmating, were still present in cows at day 48 of gestation (Laster, 1972). It was suggested that the protein(s) identified in this study was different from those described by Roberts and Parker (1974a) although no definitive evidence was presented (Laster, 1977).

Dixon and Gibbons (1979) recovered large amounts of proteins in uterine secretions from three intact cattle that received $300 \mathrm{mg} \mathrm{P}_{4}$ daily to extend "diestrus" for 2 to 3 months $(660 \mathrm{mg}, 494 \mathrm{mg}$ and 592 $\mathrm{mg})$. This represented a considerable increase in recoverable protein compared to other studies in which only 3 to $20 \mathrm{mg}$ of total protein were recovered from untreated cyclic and early pregnant cattle (Roberts and Parker, 1974a, 1976; Bartol et a1., 1981a,b). Fractionation of proteins in bovine $\mathrm{P}_{4}$-induced uterine secretions by carboxymethyl 
cellulose (CMC) cation exchange chromatography, gel filtration and disc electrophoresis revealed at least nine nonserum proteins (Dixon and Gibbons, 1979). Of these, seven appeared in small amounts and were not characterized individually. Of the remaining two nonserum proteins one was determined to be lactoferrin and the other an acid phosphatase.

Data are not available to indicate specific proteins which are produced and secreted by bovine uterine endometrial epithelium. None of the uterine-specific products described above (Roberts and Parker, 1974a, 1976; Laster, 1977; Dixon and Gibbons, 1979) have been shown to result from de novo synthesis by endometrial tissue, although a requirement for $\mathrm{P}_{4}$ is apparent. Wathes (1980) demonstrated that caruncular and intercaruncular endometrial tissue from cattle on days $25,34,36$ and 44 of gestation incorporated significant amounts of $\mathrm{L}-{ }^{14} \mathrm{C}$ leucine $\left({ }^{14} \mathrm{C}-\mathrm{Leu}\right)$ and $\mathrm{L}-4,5-{ }^{3} \mathrm{H}$ leucine $\left({ }^{3} \mathrm{H}-\mathrm{Leu}\right)$ during a $48 \mathrm{~h}$ in vitro culture. Endometrial ${ }^{3} \mathrm{H}-$ and ${ }^{14} \mathrm{C}$-Leu incorporation was not affected by stage of gestation. Addition of steroids (E, $\mathrm{P}_{4}$ or both) or placental tissues to culture medium had no systematic effect on overall leucine incorporation or array of proteins into which ${ }^{3} \mathrm{H}-$ or ${ }^{14} \mathrm{C}$-Leu was incorporated (Wathes, 1980). Data indicated that bovine endometrial tissue from early pregnancy could incorporate radiolabelled amino acids into proteins in vitro. However, these labelled products, synthesized de novo, in vitro, were not systematically characterized (Wathes, 1980). Data of Wathes (1980) were consistent with earlier reports by Basha et al. (1979) and Rice et al. (1981) in which no significant effect of steroid treatment ( $E, \mathrm{P}_{4}$ or both) was detected on capacity of porcine endometrial tissues to synthesize protein de novo from radiolabelled amino acids in vitro. Together, data indicated that ability of bovine 
and porcine endometrial tissues to synthesize proteins in vitro depended upon in vivo hormonal state at the time they were removed. A number of enzymes are present in bovine endometrium and uterine fluids. Histochemical techniques revealed alkaline phosphatase activity associated with the apical border of bovine uterine luminal and glandular epithelium, as well as glandular secretions (Moss et al., 1954; Skjerven, 1956a,b; Kenney et al., 1965; Marinov and Lovell, 1968; Leiser and Wille, 1975). Studies repeatedly demonstrated alkaline phosphatase activity to be maximal during diestrus and depressed during proestrus and estrus. An inverse relationship between uterine glycogen content and alkaline phosphatase activity was recognized (Moss et al., 1954; Mannov and Lovell, 1968). Larson et al. (1970) suggested that alkaline phosphatase was important for bovine endometrial carbohydrate metabolism and stimulation of secretory activity. In this regard, Leiser and Wille (1975), using a histochemical approach, described intense increases in endometrial surface alkaline phosphatase activity associated with the apposition phase of bovine conceptus development. Both alkaline and acid phosphatase activities in bovine uterine fluid were maximal during diestrus (Schultz et al., 1971; Linford and Iosson, 1975) and increased following $\mathrm{P}_{4}$ treatment (Wordinger et al., 1971). A nonserum acid phosphatase $(\mathrm{p} I=9.7)$ was described by Dixon and Gibbons (1979) as a major uterine specific component of $\mathrm{P}_{4}$-induced bovine uterine fluid. Linford and Iosson (1975) showed that, in pregnant cattle between days 25 to 30 , endometrial acid phosphatase level in the gravid uterine horn was twice that of the nongravid horn. Similar relationships were not detected for either alkaline phosphatase or acid cathepsin (Linford and Iosson, 1975). Both acid and alkaline phosphatases were more active in bovine uterine fluid than blood (Schultz 
and Fahning, 1971). However, alkaline, but not acid phosphatase activity in blood fluctuated with stage of the estrous cycle (Schultz and Fahning, 1971). Hence, the conceptus-associated increase in bovine endometrial acid phosphatase activity described by Linford and Iosson (1975) may reflect a local conceptus-induced increase in endometrial enzyme activity associated with remodeling of the endometrium to accomodate placentation.

Roberts and Parker (1974b) reported several glycosidases but no proteinase or neuraminidase activity in bovine uterine flushings collected from days 0 to 21 of pregnancy. Activities of $\alpha$-L-fucosidase, $\alpha$-D-galactosidase, $\beta$-D-galactosidase, $\alpha$-D-glucosidase, $\alpha-N$-acetylgalactosaminidase and $\mathrm{B}-\mathrm{N}$-acetylglucosaminidase were elevated in uterine flushings as compared to serum. Of these, $\alpha$-L-fucosidase activity was greatest between days 13 to 15 . Other enzymes reached peak activity between days 19 to 21 of pregnancy (Roberts and Parker, 1974b). Glycosidase activities in uterine flushings from five cyclic cattle slaughtered between days 12 and 18 postestrus were similar to those found for pregnant cattle between days 13 to 15 (Roberts and Parker, 1974b). However, glycosidase activities in uterine flushings from one day 19 and two day 20 cyclic cows were much reduced when compared to those from pregnant cattle of the same stage and more nearly resembled the day 0 to 3 pregnant group (Roberts and Parker, 1974b). Data suggested a pregnancy associated persistency in uterine luminal glycosidase activity. In addition to glycosidases, antitrypsin activity equal to approximately $50 \%$ of that found in serum was identified in uterine flushings from pregnant cattle (Roberts and Parker, 1974b). Glycosidase and antitrypsin activities may be involved in control of 
blastocyst-endometrial adhesion and regulation of trophoblastic invasiveness (Roberts and Parker, 1974b; Mullins et al., 1980a; Fazleabas, 1982a).

The amount of protein recovered in uterine flushings from pregnant sheep increased after day 13 (Roberts et al., 1976a) suggesting a pregnancy associated quantitative shift similar to that described for cattle (Roberts and Parker, 1974a). Roberts et al. (1976a) identified a number of nonserum proteins in ovine uterine flushings. Eight such proteins were revealed by PAGE at $\mathrm{pH} 8.9$. Of these, five appeared as faint bands in gels of proteins from days 7, 11 and 13, but two appeared only in flushings from days 15 and 18 and one increased in intensity from day 15 to 18 (Roberts et al., 1976a). Electrophoresis at $\mathrm{pH} 4.5$ revealed three nonserum bands. All were found in ovine uterine flushings from day 7, 11, 13, 15 and 18 of pregnancy (Roberts et al., 1976a). Isoelectric focusing ( $\mathrm{pH} 3-10)$ of ovine uterine flushing proteins from days 11,13 and 15 of pregnancy revealed up to 32 protein bands (Roberts et al., 1976a). This agreed with earlier reports of as many as 35 protein bands in IEF gels of bovine uterine flushings (Roberts and Parker, 1974a). Using IEF, 10 nonserum protein bands were identified in uterine flushings from a day 15 pregnant sheep. Five were also identified in uterine flushings from ewes at earlier stages of pregnancy and the estrous cycle ( $\mathrm{PI}, 5.7$ to 7.0 ) and five were seen only in day 15 pregnant ewes (pI, 4.3 to 5.6; Roberts et al., 1976a). Data resembled those for cattle (Roberts and Parker, 1974a, 1976; Bartol et al., 1981a) and suggested that ovine conceptus-produced or induced proteins were present in utero by day 15 .

Uterine milk recovered from the ligated uterine horns of unilaterally pregnant sheep on day 140 of gestation (Bazer et al., 1979a) 
contained an average $(\bar{X} \pm S E M)$ of $13.4 \pm 3.4 \mathrm{~g}$ of total protein. This fluid was recovered from unilaterally pregnant sheep as early as day 30 but did not appear in copious quantities until after day 100 (Moffatt et al., 1980; Bazer et a1., 1979a). Two basic polypeptides with $M_{r}\left(\times 10^{-3}\right)$ of 57 and 59 were detected by SDS-PAGE as the major protein species present in ovine uterine milk (Bazer et al., 1979a). These two polypeptides were also present in uterine secretions from ovariectomized ewes treated 120 days with $\mathrm{P}_{4}$ alone (50 mg/day) or $\mathrm{P}_{4}$ plus estrone $\left(E_{1}, 5 \mu \mathrm{g} /\right.$ day $)$, with maximal stimulation in the latter group (Moffatt et al., 1980, 1981). Endometrial explants from pregnant ewes and ovariectomized ewes treated with $\mathrm{P}_{4}$ or $\mathrm{P}_{4}+\mathrm{E}$ secreted radiolabelled uterine milk proteins into culture medium during incubation with ${ }^{3}$ H-Leu (Moffatt, et al., 1980, 1981). Data indicated that the two uterine milk proteins are the major secretory products of ovien endometrium during pregnancy or chorionic $\mathrm{P}_{4}$ treatment. The ovine uterine milk proteins were not detected in uterine flushings from cyclic ewes on days $0,6,10,12$ and 16 postestrus suggesting a requirement of protracted $\mathrm{P}_{4} / \mathrm{E}_{1}$ stimulation for induction of synthesis of these proteins (Moffatt et al., 1981).

Progesterone stimulated and E suppressed acid and alkaline phosphatase activity in intercotyledonary ovine endometrium (Murdoch, 1972). Histochemistry revealed increasingly strong acid phosphatase activity associated with the apical uterine epithelial cell surface from day 14 to 16 in pregnant ewes, which gradually spread to subepithelial structures (Boshier, 1969). However, neither apical nor subepithelial activity was seen in nonpregnant ewes 14 or 16 days postmating (Boshier, 1969). Acid phosphatase activity persisted into the fourth week of 
gestation in intercaruncular, but not caruncular ovine uterine epithelium. Alkaline phosphatase activity was intensely apparent at the maternal-conceptus interface of sheep through the fourth week of gestation (Boshier, 1969). Glycosidase activity was highest between days 11 and 15 in uterine flushings from pregnant ewes (Roberts et al., 1976a). These levels were substantially higher than similar values obtained from cyclic ewes on days 13 and 15 postestrus (Roberts et al., 1976a). As in cattle, ovine uterine phosphatase and glycosidase activities appeared to be enhanced by chronic $\mathrm{P}_{4}$ and associated with presence of the conceptus.

Among domestic farm species, porcine uterine proteins have been characterized most extensively. As in other species, studies involving comparison of porcine uterine flushing protein profiles with those of serum indicated that uterine luminal proteins were, at least partially, products of active endometrial synthesis and secretion (Roberts and Bazer, 1980). Both quantity and heterogeneity of proteins identified in porcine uterine flushings were greatest during diestrus, reaching maximal levels on day 15 (Murray et al., 1972; Squire et al., 1972; Bazer, 1975) and persisting or even increasing throughout early to midpregnancy (Roberts and Bazer, 1980; Bazer, 1975; Geisert et al., 1982b). Quantitative and qualitative changes in porcine uterine flushing protein profiles characteristic of diestrus were induced and maintained in ovariectomized gilts treated with $\mathrm{P}_{4}$ (Knight et al., 1974a). Knight et a1. (1974a) reported a positive dose-response relationship between amount of $\mathrm{P}_{4}$ administered and total uterine protein recovered. Estrogen alone had no effect on porcine uterine protein content (Knight et al., 1974b). However, although ineffective alone, 
$\mathrm{E}_{2}$ acted synergistically when administered in lower doses (up to $25 \mu \mathrm{g} / \mathrm{kg}$ body weight/day), but antagonistically when administered in higher doses (50 $\mathrm{\mu g} / \mathrm{kg}$ body weight/day) with $\mathrm{P}_{4}$ (Knight et al., 1974b; Basha et al., 1980a; Roberts and Bazer, 1980). Basha et al. (1979) found that porcine endometrial explants incorporated radiolabelled amino acids into radiolabelled proteins, primarily lysozyme and a purple-colored phosphatase (uteroferrin; Roberts and Bazer, 1980), de novo. Using this approach, proteins synthesized by endometrium from pregnant and pseudopregnant pigs were found to be qualitatively identical (Basha et a1., 1980a,b). However, explants of endometrium from pregnant gilts synthesized nearly 30 times as much uteroferrin as explants from diestrus gilts (Basha et al., 1979). Thus, the qualitative array of porcine endometrial proteins produced in vitro appeared to be regulated by maternal endocrine status and stimulated quantitatively by presence of a conceptus (Basha et al., 1979; Geisert et al., 1982b).

The first porcine $\mathrm{P}_{4}$-induced endometrial protein to be purified and characterized was a purple-colored acid phosphatase found in maximal quantities in uterine flushings from cyclic gilts between days 12 and 16 postestrus (Squire et al., 1972; Chen et al., 1973; Schlosnagle et al., 1974). This glycoprotein, now called uteroferrin (Utf; Roberts and Bazer, 1980), was shown to have a $M_{r}\left(\times 10^{-3}\right)$ of 32 to 35 , and $\mathrm{pI}$ of 9.7. Each molecule of Utf is thought to bind one atom of ferric iron $\left(\mathrm{Fe}^{++}\right.$), which gives the molecule its purple color (Roberts and Bazer, 1980). Using immunofluorescent microscopy, Chen et al. (1975) and Renegar et al. (1982) found the site of synthesis and secretion of Utf in both diestrus cyclic and pregnant pigs to be endometrial epithelial cells. This protein was found to comprise 10 to $15 \%$ of total 
proteins in $\mathrm{P}_{4}$-induced porcine uterine fluid, and was synthesized and secreted as radiolabelled Utf by ${ }^{3} \mathrm{H}$-Leu-supplemented explants of endometrium from diestrus cyclic, pregnant, pseudopregnant and $\mathrm{P}_{4}$ treated pigs (Basha et a1., 1979, 1980a,b; Roberts and Bazer, 1980). During gestation, maximum Utf synthesis occurred between days 35 and 75 when $\mathrm{P}_{4} / \mathrm{E}$ ratio was greatest (Bazer et al., 1981b). Iron binding properties of Utf (see Roberts and Bazer, 1980) suggested that this protein might be important in supplying $\mathrm{Fe}^{+H}$ to the porcine fetus (Bazer, 1975). Recent studies of Renegar et al. (1982) indicated that Utf, once synthesized and secreted by maternal uterine epithelium, was taken up via chorionic areolae into placental chorioallantoic capillaries and delivered to the fetus via the umbilical vein. There, Utf was suggested either to bind specifically to Kupfer and/or endothelial cells in the fetal liver to provide iron necessary for hematopoesis, or to be cleared by the fetal kidney and transported, in urine, to the allantoic sac to serve as a temporary iron storage reservoir (Renegar et al., 1982). Indeed, Utf was identified in porcine allantoic fluid, during that time associated with maximal Utf synthesis (Bazer et al., 1975, 1981b). Here it was suggested to give up its $\mathrm{Fe}^{++}$to transferrin (Buhi et al., 1982). Thus, Utf is the first uterine-specific protein to be definitively associated with an embryotrophic role in any of the domestic farm species.

An inhibitor(s) of plasminogen activator was detected in uterine flushings of diestrus cyclic gilts during that period associated with maximal Utf synthesis (Mullins et a1., 1980a). Subsequently, $\mathrm{P}_{4}-$ induced porcine uterine secretions were shown to contain a group of basic, low $\mathrm{M}_{\mathrm{r}}$ serine-protease inhibitors (Fazleabas et al., 1982a). 
One of these proteins, purified via a series of gel filtration and cation exchange steps $\left(M_{r} \simeq 14,500\right)$, inhibited trypsin, plasmin and chymotrypsin, but not elastase, subtilisin or thermolysin (Fazleabas et al., 1982a). Immunohistochemical data showed this serine-protease inhibitor to be associated only with surface and glandular porcine uterine epithelium. Endometrial explants from pseudopregnant gilts, cultured with ${ }^{3}$ H-Leu, produced radiolabelled inhibitor, indicating that this protein was synthesized de novo and was, therefore, a uterine-specific product (Fazleabas et al., 1982a). Antiserum to the purified inhibitor cross-reacted with at least three other basic, low $M_{r}$ plasmin/trypsin inhibitors in porcine uterine secretions suggesting a family of isoinhibitors constituting up to $15 \%$ of total recovered uterine protein (Fazleabas et al., 1982a). In early pregnant pigs, inhibitor activity in uterine flushings increased systematically, in a manner related to stage of blastocyst elongation, with an abrupt increase associated with conceptus-induced uterine $\mathrm{Ca}$ release (Fazleabas et al., 1982b; Geisert et al., 1982b). Similar abrupt increases in uterine luminal plasminogen activator inhibitor activity were absent in cyclic gilts, but could be induced by a single injection of $E_{2}-17 \beta$ ( $5 \mathrm{mg}$ IM) on day 11 postestrus (Fazleabas et al., 1982b). Thus, E, acting on a $\mathrm{P}_{4}$ dominated uterus, was stimulatory to inhibitor synthesis. Fazleabas et al. (1982a) observed that the inhibitor(s) appeared to coat the elongating blastocyst. It was suggested that these proteins might protect the uterus from proteases known to be released by the porcine trophoblast (Mullins et al., 1980a). Additionally, $\mathrm{P}_{4}$-induced uterine serine-protease inhibitors were suggested to be important in prevention of degradation of other components of the uterine environment 
such as Utf. Although Roberts and Parker (1974b) detected antitrypsin activity in uterine flushings from early pregnant cattle, the origin of this activity (uterine vs. serum) was not determined.

Adams et al. (1981) described a retinol binding protein (RBP) found in uterine flushings from diestrus (day 15) cyclic gilts. This protein was also found in uterine flushings from ovariectomized gilts treated with $\mathrm{P}_{4}$ alone or $\mathrm{P}_{4}+\mathrm{E}$, but not $\mathrm{E}$ alone or corn oil vehicle (Adams et al., 1981). Evidence for a $\mathrm{P}_{4}$-induced retinoic acid binding protein was also presented (Adams et al., 1981). The $\mathrm{P}_{4}$-induced RBP had an estimated $\mathrm{M}_{\mathrm{r}}\left(\times 10^{-3}\right)$ of 17 to 20 and a $\mathrm{K}_{\mathrm{d}}$ for retinoic acid of $1.93 \times 10^{-6} \mathrm{M}$ (Adams et a1., 1981). As indicated by Bazer et al. (1981b), data are not available to explain whether RBP moves selectively into the $\mathrm{P}_{4}$-dominated uterus from serum or is synthesized and secreted by uterine tissues. However, detection of similar proteins in porcine allantoic fluid suggested that such molecules might be important in transport of Vitamin A from maternal to fetal units.

Activities of several enzymes in porcine uterine flushings increased during diestrus or other periods associated with chronically elevated $\mathrm{P}_{4}$ levels or presence of a conceptus. Notably, acid phosphatase activity, associated primarily with Utf, was elevated during diestrus, early to midpregnancy and in $\mathrm{P}_{4}$-induced uterine fluid as reviewed above. Interestingly, the $\mathrm{pI}$ of this porcine acid phosphatase (Utf, 9.7) is identical to that described for $\mathrm{P}_{4}$-induced bovine uterine fluid-associated acid phosphatase by Dixon and Gibbons (1979). Glucose phosphate isomerase (GPI) allows for interconversion of glucose-6-PO 4 and fructose-6- $\mathrm{PO}_{4}$. Over all days examined $(6,8,10,12,14,15,16$ and 18), GPI activity in uterine flushings was higher in pregnant than 
nonpregnant gilts (Zavy et al., 1982a). Both total and specific activities of GPI in uterine flushings were greatest during early diestrus (days 6 and 8 ) and proestrus (day 18) in nonpregnant gilts, and between days 12 and 18 in pregnant gilts (Zavy et al., 1982a). Periods of elevated GPI activity in pregnant gilts were temporally associated with similar periods of elevated uterine $E$ content of either conceptus or maternal origin (Zavy et al., 1982a). Administration of estradiol valerate (EV; $5 \mathrm{mg} /$ day) to cyclic gilts on days 11 through 15 stimulated uterine luminal GPI activity on days 15, 17 and 19 (Zavy et al., 1982a). Similar responses, noted in early pregnant or EV treated gilts, for uterine luminal, Ca, total protein, PGF, PGE and serine-protease inhibitor activities (Geisert et al., 1982a,c; Fazleabas, 1982a,b) provided strong support for the notion that conceptus produced estrogens stimulated an acute luminally directed surge of embryotrophe in the porcine uterus (Geisert et al., 1982b).

Although their functional roles are unclear, Roberts et al. (1976b) detected lysozyme, leucine aminopeptidase and cathepsin A, B, C, D and E activities in uterine flushings from ovariectomized $\mathrm{P}_{4}$-treated gilts. Activities of cathepsin $B, D$ and $E$ did not reach detectable levels before day 60 of chronic daily $\mathrm{P}_{4}$ treatment, suggesting a requirement of prolonged $\mathrm{P}_{4}$ support for induction of these enzymes (Roberts et al., 1976b). Similarly, Linford and Iosson (1975) failed to detect any increases in bovine endometrial acid cathepsin activity prior to days 50 to 70 of gestation.

In addition to those proteins and enzymes described above, Basha et al. $(1980 \mathrm{a}, \mathrm{b})$ identified four low $_{\mathrm{r}}$ acidic and two basic polypeptides in uterine flushings from pseudopregnant and unilaterally pregnant gilts for which no definitive roles were suggested. Riboflavin 
content was elevated in uterine flushings from gilts between days 6 and 8 of the estrous cycle and early pregnancy (Moffatt et al., 1980). Accumulation of riboflavin in the uteri of ovariectomized gilts was stimulated by administration of $\mathrm{P}_{4}$ and $\mathrm{E}_{2}$ (Moffatt et al., 1980).

In cyclic mares, total uterine luminal protein content increased after day 4 to maximal levels between days 12 and 16 and declined to minimal levels by day 20 (Zavy et al., 1978a, 1979a, 1982b). In contrast, uterine protein content in pregnant mares was depressed between days 8 to 14 , but increased thereafter to at least day 20 (Zavy et al., 1982b). Among the nonserum proteins identified in equine uterine flushings Zavy et al. (1979a) observed a lavender-colored component of uterine flushings from a pseudopregnant mare. This basic protein was shown to possess acid phosphatase activity and cross-react with antiserum directed against porcine Utf (Zavy et al., 1979a). This protein was detected immunochemically in uterine flushings from day 16 cyclic mares (Zavy et a1., 1979a). Additionally, 2D-PAGE of basic polypeptides in uterine flushings from diestrus cyclic (days 12 to 16), early pregnant and $\mathrm{P}_{4}$-treated ovariectomized mares revealed a component with virtually identical electrophoretic character to porcine Utf (Zavy et al., 1982b). Similarity in placental type between horses and pigs (diffuse epitheliochorial; Stevens, 1975) suggested that a Utf-like molecule might also be important in delivery of iron to the equine fetus (Zavy et al., $1979 \mathrm{a} ; 1982 \mathrm{~b})$. However, this has not been demonstrated to date. In addition to the Utf-like molecule, several other nonserum polypeptides were identified in equine uterine flushings by 2D-PAGE. At least eight low $M_{r}$, acidic polypeptides $\left(M_{r} \times 10^{-3}\right) / p I$ range $\approx$ $<21 / 5.9-7.0)$ were identified in uterine flushings from cyclic mares 
(Zavy et a1., 1982b). These polypeptides appeared with greatest intensity on day 12 , but persisted through day 18 postestrus. The same array of polypeptides was maintained beyond day 20 in uterine flushings from pregnant mares and was detectable in flushings from day 45 as well as in uterine fluids from pseudopregnant mares (Zavy et al., 1982b). Examination of the more basic array of polypeptides revealed six (19-24/7.0-7.5) which appeared in uterine flushings from cyclic mares between days 12 and 16, but persisted with pregnancy, pseudopregnancy or $\mathrm{P}_{4}$ therapy (Zavy et al., 1982b). It was suggested that some of these polypeptides might be the same as those identified on more acidic 2D-PAGE gels (Zavy et al., 1982b). Another basic polypeptide $(17 / 8.0)$, designated $U_{1}$, was detected in uterine flushings from cyclic mares between days 3 and 14 and was maintained until day 20 in pregnant mares (Zavy et al., 1982b). However, this protein was not induced by either $\mathrm{P}_{4}$ or $\mathrm{E}_{2}$ and was not found in uterine flushings from a day 45 pseudopregnant mare (Zavy et al., 1982b).

In addition to the $\mathrm{P}_{4}$-induced polypeptides identified in equine uterine flushings, an E-induced component was also identified. In ovariectomized mares, treated with $\mathrm{E}_{2}-17 \beta$ alone (10 mg/day for 2 days), two major proteins were identified in uterine flushings (Zavy et al., 1982b). One was serum albumin and the other, designated $D_{1}$, was a

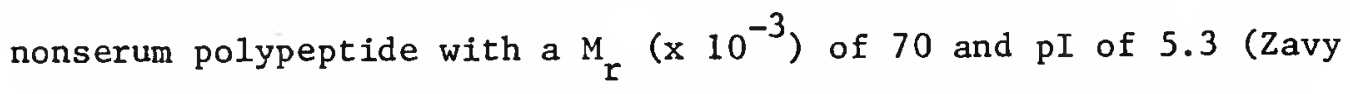
et al., 1982b). This product was sometimes detected faintly in uterine flushings from diestrus and early pregnant mares (Zavy et al., 1982b). Estrogen induced uterine proteins have not been described in pigs, cattle or sheep. Identification of this polypeptide $\left(D_{1}\right)$, as well as the other nonserum $\mathrm{P}_{4}$-induced polypeptides, in uterine 
flushings from nonpregnant, ovariectomized, hormone treated mares, indicated maternal origin for these products. To date, however, data relative to de novo synthesis of equine uterine proteins are unavailable.

Total acid phosphatase activity was higher in uterine flushings from early pregnant (days $14,16,18$ and 20) than cyclic pony mares (Zavy et al., 1979b). Results were generally consistent with those described above for bovine, ovine and porcine uterine phosphatase activities. Uterine luminal leucine aminopeptidase (LAP) activity, shown to be under $\mathrm{P}_{4}$ control in pigs (Roberts et al., 1976b), was highest during diestrus in cyclic mares (Zavy et al., 1978a). Patterns of GPA activity in uterine flushings were similar between cyclic and pregnant gilts and mares (Zavy et al., 1982b). Both total and specific GPI activities were elevated during late diestrus and persisted with pregnancy (Zavy et al., 1982b).

In this section proteins and enzymes characteristic of the uterine environment of domestic farm animals were reviewed. Emphasis was placed on those macromolecules shown to be distinct from serum proteins and considered, or known, to be products of uterine endometrial tissues. It is important to remember, however, that serum or serumidentical proteins were consistently identified as the major protein compounds in uterine fluids from all domestic species. Such serum proteins should not be ignored. Transudation of serum proteins into the uterine lumen occurs irrespective of molecular size (Beier, 1980). For example, disc gel electrophoresis revealed prealbumins, albumins, postalbumins, pretransferrins, transferrins and $\alpha$-globulins in uterine flushings from cyclic and early pregnant cattle (Roberts and Parker, 
1974a). Additionally, there is a general qualitative disparity between those serum-identical proteins identified in uterine flushings and in serum (Beier, 1980; Roberts and Parker, 1976; Roberts et a1., 1976a; Basha et a1., 1979; Zavy et al., 1979a,b, 1982a). Such observations suggest selective uptake of serum proteins into the uterine lumen. As is the case for most uterine-specific proteins and enzymes described above, functional roles of serum proteins in the uterine lumen of domestic species are not known. However, it is undoubtedly the entire array, rather than any single macromolecular component, that is essential to establish a complete embryotrophic uterine environment.

Prostaglandins. Like other components of the uterine environment, prostaglandins(PG) appear in the uterine lumen and tissues in a manner related to endocrine and pregnancy status. Interest in $\mathrm{PGF}_{2 \alpha}$ as the presumptive endogenous uterine luteolysin led to intense investigation of PG in uterine flushings and tissues in cyclic and early pregnant domestic animals. Content of $\mathrm{PGF}_{2 \alpha}$ in uterine flushings from cyclic cattle (Bartol et a1., 1981a; Lamonthe et al., 1977), sheep (Inskeep et al., 1980), pigs (Zavy et al., 1980) and mares (Zavy et al., 1978b) was elevated during mid- to late diestrus and associated with onset of 1uteolysis as described above. Prostaglandin $E_{2}$ was also detected in uterine flushings from diestrus cyclic cattle (days 16 and 19; Lewis et a1., 1982), as well as sheep (E1linwood et al., 1979b) and pigs (Geisert et al., 1982b). In sheep uterine flushing $\mathrm{PGE}_{2}$ content did not vary between days 13, 15 and 17 (E11inwood et al., 1979b). In contrast, $P G E_{2}$ content of porcine uterine flushings increased between days 11.5 and 14 (Geisert et al., 1982b). Paradoxically, as compared to cyclic controls, $\mathrm{PGF}_{2 \alpha}$ content was higher in uterine flushings from 
early pregnant cattle (Bartol et al., 1981a), sheep (Ellinwood et al., 1979b; Inskeep et al., 1980) and pigs (Zavy et al., 1980). The same relationship was noted for $\mathrm{PGE}_{2}$ (Lewis et al., 1982; Ellinwood et al., 1979b; Geisert et al., 1982b). Pattern of change in uterine luminal PG content in pregnant animals generally paralelled that of cyclic animals with major quantitative increases detected during the period associated with blastocyst elongation and apposition to the endometrium.

A major source of uterine luminal $P G$ and the primary source in cyclic animals is the endometrium. In vitro production of PG by endometrial tissue was demonstrated for pregnant cattle (Lewis et al., 1982), and cyclic and pregnant sheep (E1linwood et al., 1979; Findlay et al., 1981; Inskeep et a1., 1980), pigs (Guthrie et a1., 1978; Guthrie and Revroad, 1981; Patck and Watson, 1976; Watson and Patek, 1979) and mares (Vernon et al., 1981). Though production data are unavailable for cyclic cattle, studies indicated that, in general, endometrial content and in vitro production of $\mathrm{PGF}_{2 \alpha}$ increased from mid- to late diestrus (Shemesh and Hanse1, 1975a,b; Inskeep et a1., 1980; Patek and Watson, 1976; Vernon et a1., 1981). The condition of pregnancy does not appear to suppress potential for endometrial PG synthesis. Lewis et al. (1982) showed that endometrial slices from day 16 and 19 pregnant cattle produced radiolabelled $P_{2} F_{2}, P_{2}, P G F M$, and at least four other unidentified metabolites, when incubated with ${ }^{3} \mathrm{H}$-arachidonic acid. Quantities of PG produced were unaffected by day postmating or location of uterine horn relative to CL-bearing ovary (Lewis et al., 1982). Neither concentration nor content of PGF $2 \alpha$ or PGFM in endometrial tissue differed between cyclic and pregnant cattle 
on day 17 postestrus; although tissues from cyclic cattle synthesized greater quantities of PG (J. Curl and W.W. Thatcher, personal communication).

Overa11, data from sheep suggested that endometrial tissue PG content and production capacity was similar for pregnant and nonpregnant ewes and might even be enhanced by the condition of pregnancy and presence of a conceptus (Findley, 1981; Findley et al., 1981; Hyland et al., 1982; Inskeep et al., 1980). Endometrial tissue concentration and content, and in vitro production of $\mathrm{PGF}_{2 \alpha}$ was higher in pregnant than nonpregnant ewes on day 15 postestrus (E11inwood et al., 1979b; Findlay et a1., 1981). Although Lewis et al. (1978) found no difference in endometrial content of $\mathrm{PGE}_{2}$ between pregnant and nonpregnant ewes on days 15 and 16, Ellinwood et a1. (1979b) detected higher levels in pregnant than nonpregnant ewes on days 15 and 17 postestrus (Ellinwood et al., 1979b). Data indicated that endometrial and uterine luminal content of both $\mathrm{PGF}_{2 \alpha}$ and $\mathrm{PGE}_{2}$ were consistently higher in pregnant than nonpregnant ewes on days 13, 15 and 17 postestrus, with an increase in the $\mathrm{PGE}_{2}: \mathrm{PGF}_{2 \alpha}$ ratio seen in pregnant animals (E1linwood et al., 1979b; Findlay, 1981). The observation of Henderson et al. (1977) that, in ewes, $\mathrm{PGE}_{2}$ was antagonistic to the 1uteolytic effect of $\mathrm{PGF}_{2} \alpha$ in vivo, led several investigators to propose that $\mathrm{PGE}_{2}$ might be the antiluteolytic signal in pregnant sheep (Ellinwood et al., 1979b; Huie et al., 1981; Reynolds et al., 1981). In this regard, both PGI 2

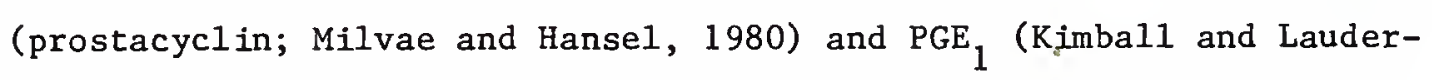
dale, 1975) stimulated plasma $\mathrm{P}_{4}$ when administered to cattle in vivo. However, the possibility that $\mathrm{PGE}_{2}$ might be involved in bovine luteostasis has not been examined carefully. 
The role(s) of uterine $P G$, particularly $\mathrm{PGF}_{2 \alpha}$, in control of luteal lifespan in domestic species, made discovery of elevated levels of these substances in uteri of early pregnant animals especially untenable. Requirement of luteostasis for maintenance of pregnancy led, necessarily, to intense investigation of phenomena which might help to explain how pregnancy is "recognized" in the face of this apparent threat to luteal function (see Bazer et a1., 1981c). However, if the goal of the reproductive process is production of viable offspring and not luteolysis, then enhanced uterine PG responses characteristic of early pregnancy must be consistent with this goal. Though this may seem a true paradox, it is interesting to note that in cattle, sheep and pigs, marked pregnancy-related increases in uterine PG responses occur at a time when removal of the conceptus(es) will result in prolongation of the estrous cycle (Bartol et al., 1981; Northey and French, 1980; Rowson and Moor, 1967; Inskeep et al., 1980; Dhindsa and Dziuk, 1968; Zavy et al., 1980; Bazer et al., 1982). Thus, at a time when uterine PG dynamics are most dramatically affected by pregnancy the embryotrophic path has already been taken.

The period associated with increased uterine luminal content of both PGF and $\mathrm{PGE}_{2}$ in early pregnant cattle (days 16-19; Bartol et al., 1981 ; ; Lewis et al., 1982) was also associated with persistency in number and amount of uterine luminal proteins and conceptus related stimulation of endometrial enzymes (Roberts and Parker, 1974a,b, 1976; Leiser and Wille, 1975; Linford and Iosson, 1975; Bartol et al., 1981a). Bartol et al. (1981a) reported positive correlations between uterine lumenal content of PGF and total protein in both cyclic $(r=0.37$, $\mathrm{P}<.02$; days $4,8,12,14,16$ and 19$)$ and pregnant $(r=0.42, P<.05$; 
days $8,12,14,16$ and 19) cattle. Findlay et al. (1981) presented evidence for a discrete effect of the day 15 ovine conceptus on caruncular and, to a lesser extent, intercaruncular tissue. As assessed in vitro, rate of protein synthesis was higher in endometrial tissue from pregnant than cyclic ewes on day 15 (Findlay et al., 1981). Increased uterine flushing content of both $\mathrm{PGF}_{2 \alpha}$ and $\mathrm{PGE}_{2}$ in pregnant as compared to nonpregnant ewes between days 13 and 17 was associated with increased protein content and complexity (E1linwood et al., 1979b; Roberts et al., 1976a). Porcine conceptus-induced increases in uterine luminal content of $P G F$ and $\mathrm{PGE}_{2}$ were associated with persistent increases in amount and complexity of uterine flushing proteins (Geisert et al., 1982b). Similar responses were elicited in cyclic gilts by administration of EV (5 mg on day 11 or 11-13; Geisert et al., 1982b). In both cases (conceptus-induced and EV-induced) $\mathrm{PGE}_{2}$ response preceded $\mathrm{PGF}_{2 \alpha}$ response and was accompanied by a rapid transient increase in uterine flushing Ca content (Geisert et al., 1982b,c). These events were suggested to be important for synchronized release of uterine histotrophe (Geisert et a1., 1982b). Collectively, these data suggest that pregnancy-associated alterations in uterine PG dynamics reflect endometrial response to secretagogues, likely of conceptus origin, necessary for maintenance of an embryotrophic environment.

It was observed that, in secretory cells (cells of the adrenal cortex or exocrine pancreas), Ca-dependent turnover (metabolism) of arachidonic acid within the endogenous phosphatidylinositol (PI) pool of cell membranes was an obligatory response to secretagogic stimulation (Rasmussen, 1981, Rubin, 1982). Rubin (1982) observed that turnover of membrane PI was a necessary event in the secretory process 
and that one of the products of this reaction including arachidonic acid (AAc), PG or lysophospholipids, might participate in cellular processes accompanying discharge of secretory product. When pancreatic acinar cell membranes were labelled with ${ }^{14} \mathrm{C}-\mathrm{AAC}$ and exposed to a secretagogue, amylase secretion increased and PI breakdown was seen (Marshall et al., 1980). Labelled AAc, incorporated into membrane PI, disappeared rapidly. Approximately half of the ${ }^{14} \mathrm{C}$-AAc appeared as phosphatidic acid and the other half as PGE $_{2}$ (Marshall et al., 1980). Furthermore, $\mathrm{PGE}_{2}$ stimulated amylase secretion which was blocked by inhibition of PG synthesis (Marshall et a1., 1980). Explanations of these data included possibilities that: (1) $\mathrm{PGE}_{2}$ might serve as a coordinate messenger with $\mathrm{Ca}$, or (2) secretagogue-induced PI turnover leads to release of $A A c$ and increased synthesis of $\mathrm{PGE}_{2}$ which acts to open Ca channels and may possibly increase Ca conductance of the plasma membrane (Rasmussen, .1981). Thus, response of certain secretory cells to secretogogic stimuli results in production of agents and/or conditions which may potentiate continued secretory response. In light of these data, continued production and elevated uterine content of PG during early pregnancy is far from untenable with respect to establishment of an embryotrophic environment and maintenance of pregnancy. Indeed, elevated levels of PG in uterine tissues and flushings from pregnant as compared to cyclic animals (after time associated with onset of maternal "recognition") may not only reflect endometrial secretory activity, but be necessary for its maintenance. In this respect, it is interesting that in both sheep and $\mathrm{pigs}, \mathrm{PGE}_{2}$ : $\mathrm{PGF}_{2 \alpha}$ ratios were higher during early pregnancy (Ellinwood et al., 1979b; Geisert et al., 1982b). Alterations in amount and ratio of PG 
in uterine flushings and tissues undoubtedly occur as a consequence of altered endometrial membrane dynamics associated with maintenance of an actively secretor epithelium and conceptus secretion of these products.

Data from laboratory species indicated that, as components of an embryotrophic uterine environment, PG may affect several other processes important for establishment and maintenance of pregnancy including (1) local uterine blood flow (Janson et al., 1975); (2) endometrial vascular permeability (Kennedy, 1980); (3) angiogenesis (Ezra, 1979); (4) fluid and electrolyte transport across epithelia (Biggers et al., 1978); (5) cellular proliferation (MacManus and Whitfield, 1974) and (6) steroid biosynthesis (Batta, 1975) (see Bazer et al., 1982). Data are lacking relative to such PG-mediated processes associated with reproduction in large domestic species.

Steroid metabolism. Progesterone and estrogens, in addition to integrating uterine metabolic activities including protein and PG synthesis, may be metabolized by endometrial tissue. Eley et al. (1983) incubated endometrial slices from pregnant (days 16, 19, 23 and 27) and nonpregnant (days 16 and 19 ) cattle with either ${ }^{3} \mathrm{H}-\mathrm{P}_{4}$ or ${ }^{3} \mathrm{H}$-androstenedione $\left({ }^{3} \mathrm{H}-\mathrm{A}_{4}\right)$ in vitro. Both labelled substrates were extensively metabolized during the $1 \mathrm{~h}$ to $3 \mathrm{~h}$ incubation. When data were adjusted for tissue wet weight, amount of ${ }^{3} \mathrm{H}-\mathrm{P}_{4}$ metabolized was similar in explants from days 16 and 19 irrespective of reproductive status (pregnant vs nonpregnant) or location of uterine horn. Endometrium from day 27 of pregnancy metabolized more ${ }^{3} \mathrm{H}-\mathrm{P}_{4}$ than that from days 16 or 19 $(59.1 \pm 2.6 \%$ vs $44.0 \pm 2.3 \% ; \mathrm{P}<.01)$, but a uterine horn effect was still undetected (Eley et al., 1983). Collectively, data indicated 
that bovine endometrial metabolism of $\mathrm{P}_{4}$ and $\mathrm{A}_{4}$ was affected by stage of gestation but was independent of local conceptus effects. Chromatographic analyses of radiolabelled metabolites indicated that ${ }^{3} \mathrm{H}-\mathrm{P}_{4}$ was metabolized more extensively than ${ }^{3} \mathrm{H}-\mathrm{A}_{4}$, but that the type of - metabolism was similar. Major metabolites were $5 \alpha$-reduced base steroids including, primarily, 3,20 dihydroxy-5 $\alpha$-pregnane from ${ }^{3} \mathrm{H}-\mathrm{P}_{4}$ and 3,17 dihydroxy-5 $\alpha$-androstane from $3_{\mathrm{H}-\mathrm{A}_{4}}$ (Eley et a1., 1983). No $\mathrm{C} 19$ metabolites were generated from ${ }^{3} \mathrm{H}-\mathrm{P}_{4}$, nor $\mathrm{C} 21$ from ${ }^{3} \mathrm{H}-\mathrm{A}_{4}$. Additionally, neither testosterone (T), $E_{1}$ nor $E_{2}$ were found (Eley et al., 1983). Similar results were reported for bovine endometrium by Knickerbocker et al. (1980).

Estrogen sulfoconjugates, particularly $E_{1} \mathrm{SO}_{4}$, are primary estrogens in maternal peripheral plasma during later stages of gestation in cattle (after day 70; Robertson and King, 1979; Hoffman et al., 1976; Thatcher et al., 1982; Eley et al., 1979a). However, detection of $\mathrm{E}_{1} \mathrm{SO}_{4}$ in both maternal plasma and fetal allantoic fluid as early as day 27 and 33 respectively suggested a requirement for sulfotransferase enzyme activity in either or both maternal and fetal tissues very early in bovine gestation. Data from late bovine gestation (days 247 and 273) suggested that E conjugation was compartmentalized, with maternal components of the placentome (caruncular tissue) responsible for production of $\mathrm{E}_{1} \mathrm{SO}_{4}$ and $\mathrm{E}_{2} \mathrm{SO}_{4}$ detected in peripheral plasma (Hoffman et al., 1976). To date, however, data relative to presence of sulfotransferase activity in uterine tissues from either cyclic or pregnant cattle are unavailable. Similarly, data are unavailable relative to bovine uterine sulfatase activity. However, Eley et al. (1979b) demonstrated that $\mathrm{E}_{1} \mathrm{SO}_{4}$ was luteolytic when administered chronically 
(28 or $56 \mathrm{mg} \mathrm{E} \mathrm{SO}_{4} /$ day S.C. from day 10 until onset of estrus) to cyclic cattle. Thus the possibility of sulfatase activity in diestrus bovine reproductive tissues exists.

Unlike bovine tissues, endometrium from pregnant sheep (days 14, $16,18,20,60$ and 140 ) converted ${ }^{3} \mathrm{H}-\mathrm{P}_{4}$ to ${ }^{3} \mathrm{H}-\mathrm{A}_{4}$, and both of these substrates to $\mathrm{T}, \mathrm{E}_{1}$ and $\mathrm{E}_{2}$ in vitro (Willis et al., 1979a,b, 1981). Conjugated estrogens (primarily $\mathrm{E}_{1} \mathrm{SO}_{4}$ ) were also detected (Willis et al., 1981). Findlay et al. (1981) detected trace amounts of radiolabelled phenolic steroids in medium following incubation of endometrium from pregnant and nonpregnant ewes (day 15 postestrus) with ${ }^{3} \mathrm{H}-\mathrm{A}_{4}$. Additionally ${ }^{3} \mathrm{H}-\mathrm{E}_{1}$ and ${ }^{3} \mathrm{H}-\mathrm{E}_{1} \mathrm{SO}_{4}$ were metabolized to aqueous and ether soluble forms respectively, indicating both sulfotransferase and sulfatase activities (Findlay et al., 1981). Data relative to the possibility of a local conceptus effect on ovine endometrial steroid metabolism are equivocal. Willis et al. (1981) reported that endometrial metabolism of both ${ }^{3} \mathrm{H}-\mathrm{P}_{4}$ and ${ }^{3} \mathrm{H}-\mathrm{A}_{4}$ was reduced in tissue from day 14 cyclic ewes as compared to that from pregnant ewes. However, comparison of tissues from pregnant and nonpregnant ewes on day 15 revealed no pregnancy related effect on in vitro metabolism of ${ }^{3} \mathrm{H}-\mathrm{A}_{4}$, ${ }^{3} \mathrm{H}-\mathrm{E}_{1}$ or ${ }^{3} \mathrm{H}_{-} \mathrm{E}_{1} \mathrm{SO}_{4}$, although effects were detected on tissue PGF content and rate of in vitro protein synthesis (Findlay et al., 1981). Additionally, metabolism of ${ }^{3} \mathrm{H}-\mathrm{P}_{4}$ by ovine endometrium from days 20,60 and 140 of gestation was not affected by stage of gestation or presence of conceptus membranes in culture (Willis et al., 1979b). Though far from definitive, data suggest that, like the cow, ovine endometrial steroid metabolism is a maternally regulated process that may be affected by duration of pregnancy. 
Both porcine and equine endometrial tissues converted ${ }^{3} \mathrm{H}-\mathrm{P}_{4}$ to $\mathrm{E}$ in vitro (Dueben et al., 1977, 1979; Fischer et a1., 1981; Seamans et al., 1979). Porcine endometrium converted both ${ }^{3} \mathrm{H}-\mathrm{P}_{4}$ and ${ }^{3} \mathrm{H}-\mathrm{A}_{4}$ to $\mathrm{T}, \mathrm{E}_{1}, \mathrm{E}_{2}$ and conjugated $\mathrm{E}_{1}$ and $\mathrm{E}_{2}\left(\mathrm{SO}_{4}\right)$ in vitro (Bazer et a1., 1982). Steroid sulfates and glucuronides were shown to be major porcine endometrial metabolites of $\mathrm{P}_{4}$ (Bazer et al., 1982; Tindall and Henricks, 1971). Porcine endometrium from days 16 and 25 of pregnancy produced ${ }^{3} \mathrm{H}-\mathrm{E}_{2} 17 \beta$ (not $17 \alpha$ ) from ${ }^{3} \mathrm{H}-\mathrm{P}_{4}$ and metabolism increased with stage of gestation (Fischer et a1., 1981). Endometrium from pseudopregnant gilts (day 25) also produced ${ }^{3}$ H-estrogens, but products did not cochromatograph with $\mathrm{E}$ standards suggesting a modulating role for conceptus tissues or products (Fischer et a1., 1981). Like the cow, porcine endometrium was shown to have $5 \alpha$-reductase activity (Henricks and Tinda11, 1971). Histochemical evidence indicated that equine endometrium directly apposed to the conceptus (as well as the conceptus itself) was a potential source of E (Flood and Marrable, 1975; Flood et a1., 1979). In vitro conversion of ${ }^{3} \mathrm{H}-\mathrm{P}_{4}$ to ${ }^{3} \mathrm{H}-\mathrm{E}_{1}$ by endometrium from pregnant (day 18) and cyclic (days 12 and 18) pony mares was enhanced by co-incubation with conceptus tissues (Seamans et al., 1979). Present data indicate that, in contrast to porcine, equine and, debatably (see Findlay, 1981) ovine endometrial tissues, bovine endometrium produced neither $\mathrm{E}\left(\mathrm{E}_{1}\right.$ or $\left.\mathrm{E}_{2}\right)$ nor $\mathrm{T}$ from ${ }^{3} \mathrm{H}-\mathrm{P}_{4}$ or ${ }^{3} \mathrm{H}-\mathrm{A}_{4}$ in vitro (Eley et al., 1983; Knickerbocker, 1980). Therefore, bovine endometrium is possibly lacking aromatase, as well as $17 \beta$-dehydrogenase (17B-HSD) and 17ß-oxidoreductase activities (Heap et al., 1979). Furthermore, primary products of bovine endometrial ${ }^{3} \mathrm{H}-\mathrm{P}_{4}$ and ${ }^{3} \mathrm{H}-\mathrm{A}_{4}$ metabolism were $5 \alpha$-reduced base steroids (E1ey et al., 1983; Knickerbocker et a1., 1980) which cannot be aromatized to estrogens (Wilson, 
1972). Data are consistent with the fact that estrogens $\left(E_{2}-17 B\right.$ and $\mathrm{E}_{1} \mathrm{SO}_{4}$ ) are luteolytic when administered to cattle during diestrus (Brunner et al., 1969; Wiltbank et al., 1961; Eley et al., 1979a), presumably via stimulation of endometrial PG synthesis (see above and: Bartol et al., 1981a,b). Thus, direct conversion of circulating $\mathrm{P}_{4}$ to E, or aromatizable steroids, would be counter to the goal of pregnancy maintenance. In sheep, in which $\mathrm{E}_{2}-17 \beta$ is also luteolytic (Stormshak et al., 1969; Goding, 1974), evidence for aromatase and $17 \beta-H S D$ activity in endometrial tissue from pregnant ewes (Willis et al., 1979a,b, 1981) is contrary to this notion. However, Findlay (1981) and Findlay et al. (1981) suggested that ovine endometrial conversion of ${ }^{3} \mathrm{H}_{-} \mathrm{A}_{4}$ to either $\mathrm{E}_{2}$ or $\mathrm{E}_{1}$ was neglibible.

Since $5 \alpha$-reduced steroids are, essentially, biologically inactive (Holzbauer, 1976; Kubli-Garfiar et al., 1979, 1980), bovine endometrial $5 \alpha$-reduction of $\mathrm{P}_{4}$ may potentiate effectiveness of conceptus products

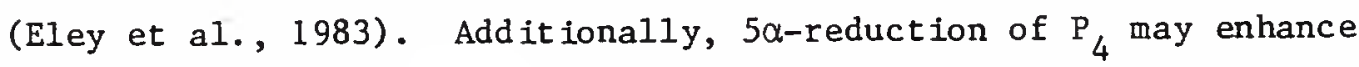
endometrial responsiveness to $\mathrm{E}$ by reducing $\mathrm{P}_{4}$ suppression of $\mathrm{E}$ receptor synthesis and $E \cdot R_{n}$ retention time (Clark et al., 1977; Katzenellenbogen et al., 1980). In vitro metabolism of ${ }^{3} \mathrm{H}-\mathrm{A}_{4}$ by endometrium from diestrus cyclic (days 16 and 19) and early pregnant (days 16, 19, 23 and 27) cattle was unaffected by presence of a conceptus (days 16 and 19), but increased with stage of gestation (Eley et al., 1983). Considering the importance of bovine endometrial responsiveness to the integrative action of steroid hormones in establishment and maintenance of an embryotrophic uterine environment, data suggest that at least partial endometrial autonomy with respect to steroid metabolic activity may represent an important uterine autoregulatory mechanism. 
Endometrial sulphotransferase and sulphatase activities during early pregnancy appear to be related to steroidogenic activity of the conceptus. Conceptus produced $E$ is considered essential for recognition of pregnancy in pigs (Bazer et al., 1982). Both free and conjugated $\mathrm{E}\left(\mathrm{E}_{1}, \mathrm{E}_{2}, \mathrm{E}_{3}, \mathrm{E}_{1} \mathrm{SO}_{4}, \mathrm{E}_{2} \mathrm{SO}_{4}\right.$ and $\left.\mathrm{E}_{3} \mathrm{SO}_{4}\right)$ content was increased in uterine flushings from pregnant as compared to nonpregnant gilts between days 10.5 to 14 (Geisert et 21 , 1982b). Uterine flushing E content in pregnant gilts, particularly $E_{2}, E_{2} \mathrm{SO}_{4}$ and $\mathrm{E}_{1} \mathrm{SO}_{4}$ increased in a manner related to stage of conceptus development, and were markedly elevated between days 11 and 14 (Geisert et al., 1982b). High levels of endometrial sulphotransferase relative to sulphatase activity in pregnant gilts prior to day 30 (Dwyer and Robertson, 1979) were suggested to provide readily metabolizable substrate to the conceptus for production of $\mathrm{E}$, while preventing large amounts of unconjugated $\mathrm{E}$ from entering maternal circulation (Bazer et al., 1982; Heap and Perry, 1974). In sheep, conceptus production of $\mathrm{E}$ is negligible (Gadsby et al., 1980; Willis et al., 1981). However, in contrast to pigs, ovine endometrial sulphotransferase activity was suppressed and sulphatase activity enhanced prior to day 20 of gestation (Dwyer and Robertson, 1979). Assuming a requirement for $\mathrm{E}$ at the conceptus-maternal interface for initiation of pregnancy, Dickman and coworkers (see Dickman et al., 1976; Dickman, 1979) suggested that species differences in endometrial steroid metabolism, such as those described above, were necessary to insure optimal levels of biologically active steroid locally, at the level of the endometrium.

Like sheep, E production by peri-attachment bovine conceptuses is minimal (Eley et al., 1983; Gadsby et al., 1980; Shemesh et al., 
1979). Estrone and $\mathrm{E}_{1} \mathrm{SO}_{4}$ concentrations in maternal peripheral plasma, reflective of conceptus E production (Thatcher et al., 1982; Eley et al., 1979a), were not elevated prior to day 60 of gestation (Eley et al., 1979b; Robertson and King, 1979). Since neither E nor aromatizable steroids are produced by diestrus bovine endometrial metabolism of $\mathrm{P}_{4}$ or $\mathrm{A}_{4}$ (Eley et al., 1983), significant amounts of biologically active $E$, if necessary for establishment of pregnancy, must be provided by a maternal (ovarian) source (Hansel et al., 1973). Absence of significant sulphotransferase activity and/or enhanced sulphatase activity in bovine endometrium during diestrus would facilitate action of unconjugated $E$ at the maternal-conceptus interface. In other species, notably the pig, biologically active E, in concert with other hormones present in utero during the peri-attachment period, was suggested to exert local effects on (1) uterine blood flow;

(2) water, electrolyte, carbohydrate and amino acid transport; and (3) induction of histotrophe (Bazer et al., 1979b; Findlay, 1981; Cook and Hunter, 1978). Details of bovine endometrial metabolism of $\mathrm{E}$ remain to be elucidated.

\section{The Conceptus}

Development

If the uterus is a major integrator of stimuli directed toward achievement of reproductive success, the conceptus and its products clearly represent primary effectors of uterine-mediated, embryotrophic events. In cattle, as reviewed above, an embryotrophic uterine environment is established independently of presence of a conceptus prior to day 16 postestrus. Once "the stage is set", however, events pursuant to the embryotrophic path require uterine integration of both maternal 
and conceptus signals. Though data are unclear as to the nature of such signals, their genesis appears to be related to developmental stage of the conceptus. For this reason, a brief description of bovine conceptus development is presented below. Emphasis is placed on evolution of extraembryonic membranes during the peri-attachment period as it is these tissues that relate the conceptus to its uterine environment both physically and biochemically. Information for the following section was obtained primarily from the works of Brackett et al. (1980), Chang (1952), Fléchon et al. (1978), Foley and Reece (1953), Greenstein and Foley (1955, 1958a,b), Greenstein et al. (1958), Hamilton and Laing (1946), Marion and Gier (1958), Melton et al. (1951), Wathes and Wooding (1980), Winters et al. (1942), and Wooding and Wathes (1980). Additionally, information was obtained from reviews of Eckstein and Kelly (1977), Perry (1981), and Steven and Morris (1975). For descriptions of bovine embryogenesis, as well as growth and development of all components of the embryo and extraembryonic membranes the reader is referred to the works of Greenstein and Foley (1958a,b), Eley et al. (1978), Hubbert et al. (1972), Swett et al. (1948), Winters et al. (1942), and the classic treatise of Hammond (1926). Developmental, morphological, histological and cytological descriptions of the bovine placentome were presented by Bjorkman (1968a,b, 1973), King et al. (1980), Kingman (1948), and Wooding and Wathes (1980).

In cattle, conception and initial cleavage stages occur in the oviduct. Once formed, the zygote, enveloped in its mucopolysaccharide coat, the zona pelucida (ZP), requires approximately $96 \mathrm{~h}$ to traverse the oviduct. Consequently, on day 3-4 the 16 cell, ZP-encased morula 
enters the uterine lumen. Cell divisions continue and, with rearrangement of blastomeres, a unilaminar blastocyst and blastocoelic cavity are formed by days 7-8. An area of one pole of the outermost layer of the blastocyst (ectoderm) becomes thickened forming the inner cell mass (ICM), or embryonic disc, which will give rise to the embryo proper. The remainder of the ectoderm is the trophoblast (feeding or nourishing layer; Perry, 1981), which will ultimately become the outer layer (chorion) of the epitheliochorial placenta. Between days 9 and 10 a slit appears in the $Z P$ and the blastocyst is extruded. This process, referred to as hatching, signals the beginning of a more rapid period of blastocyst development.

Following hatching ( $\simeq$ days 10 to 12 ) blastocoelic ectoderm becomes lined with a layer of endodermal cells derived by tangential division of a few cells of the embryonic disc (Perry, 1981). Thus a rudimentary yolk sac is formed and the trophoblast is bilaminar. Between days 12 and 15 a layer of mesoderm spreads outward from the ICM between the trophoblastic ectoderm (trophectoderm) and endodermal layers forming a trilaminar trophoblast. This somatic mesoderm splits, forming avascular and vascular mesoderm. Avascular mesoderm fuses with trophectoderm to yield trophoderm or somatopleure. Vascular mesoderm fuses with the inner, endodermal layer forming the splanchnopleuric yolk sac. Space between these two membranes is referred to as the exocoele or exocoelom. The yolk sac and its contents serve as a primary source of nutritional support to the developing embryo prior to establishment of a functional chorioallantois. In addition to formation of a yolk sac, establishment of the endoderm is prerequisite to elongation of the trophoblast, which begins around days 13 to 15 . 
The period of bovine conceptus development between day 16 and attachment is characterized by rapid growth and development of both embryo proper and extraembryonic membranes. Between days 16 and 17 , the trophoblast takes on a ribbon-like appearance (Chang, 1952). Length of the trophoblastic vessicle is highly variable at this time, with reports from 2 to over $500 \mathrm{~mm}$ (Hawk et al., 1955; Betteridge et al., 1980). Greenstein et al. (1958) observed that three cell types were distinguishable in day 16 and 17 trophoblast membrane following staining with Periodic-Acid-Schiff (PAS; for glycoproteins), and Sudan Black or 0 il Red 0 (for lipids). Cell types included (1) polygonal or cuboidal undifferentiated trophoblast or "stem" cells; (2) early stage trophoblastic giant cells (tGC), occasionally binucleated and PAS (+); and (3) moderate columnar trophoblast cells with basally located lipid vacuole inclusions (Greenstein et al., 1958). Also at this stage, the primitive streak is formed and embryonic organogenesis is underway.

By day 18 the bovine conceptus occupies nearly two-thirds of the gravid uterine horn. Vitteline (yolk sac) circulation is well established by this stage and thought to provide a major proportion of embryonic nutrients. Histologically and cytologically the trophoblastic surface at day 18 was shown to consist of cuboidal and columnar cells interspersed between $t G C$, which accounted for approximately $6 \%$ of the total cell population (Wathes and Wooding, 1980). Both cell types contained large areas of lipid inclusions. However tGC were often binucleated and always PAS (+) suggesting high glycoprotein content (Greenstein et al., 1958; Wathes and Wooding, 1980).

Between days 19 and 20, conceptus membranes extend throughout the gravid and into the contralateral uterine horn. The amnion is 
formed during this period by inversion of the trophoblast (chorion) on the dorsal embryonic surface, and fusion of the mesodermal layers (chorioamnion). With establishment of embryonic heart primordia, the yolk sac and choriovitelline circulation reach peak development and begin to regress. The trophoblastic (chorionic) surface at days 19 to 20 consisted of both uninucleate, columnar/cuboidal cells and binucleate $\mathrm{EGC}$, which constituted as much as $20 \%$ of total cell population (Greenstein et al., 1958; Wathes and Wooding, 1980). By day 20 tGC were described to contain numerous membrane bound granules; large active Golgi, confluent with developing granules; well developed RER and numerous lipid inclusions (Wathes and Wooding, 1980).

Following establishment of the amnion and initiation of embryonic heart-beat between days 20 to 22 , the allantois emerges from embryonic hindgut as a outgrowth of extraembryonic splanchnopleure. Growth of the allantois proceeds rapidly. Its expansion into the exocoele on a scaffolding of fluid and apposition with the trophoderm (chorion) is coordinated with regression of the yolk sac and choriovitelline circulation. Thus begins a coordinated transfer of function as the embryo shifts its dependence from self contained nutrients, provided by the choriovitelline circulation, to nutrients supplied via the chorioallantoic circulation of the true placenta. Vascularization of the chorion occurs via vessels of the mesoderm of allantoic, splanchnopleure, which are continuous with those of the embryo. Binucleate tGC remain prominent components of the trophoblastic membrane at this stage and, as reviewed above, interdigitation of apical microvilli occurs between maternal and conceptus (chorionic) surface epithelia.

Rapid expansion of extraembryonic membranes continues such that, by days 24 to 25 , membranes extend to the tip of the nongravid uterine 
born. Regression of yolk sac and choriovitelline circulation is complete by days 23 to 24 . Consequently, the burden of embryonic support depends entirely upon establishment of a functional placenta. Expansion of the allantois and its associated vascular bed is continuous during this period. Fusion of allantoic splanchnopleure and chorionic somatopleure occurs via villus projections on respective mesodermal surfaces. Vascularization of the allantois is completed between days 26 and 30 . Thus, a functional chorioallantoic membrane is completely established. Attachment of discrete areas of the chorion and maternal caruncles, reported to occur as early as day 27 (King et al., 1980), initiates formation of the characteristic bovine cotyledonary epitheliochorial placenta.

Conceptus-induced events associated with maternal recognition of pregnancy and reflected by dynamic alteration in the bovine uterus and uterine environment, as described above, are temporally related to several key events in conceptus development including (1) establishment of extraembryonic endoderm, prerequisite to; (2) trophoblastic elongation, and (3) differentiation of trophoblastic cell types (Greenstein et al., 1958). Although endoderm is established and initial elongation is underway by days 12 to 14 (Greenstein et a1., 1958; Chang, 1952), uninucleate columnar and binucleate tGC were not described prior to day 16 (Greenstein et al., 1958). Bearing in mind that embryo removal after this stage (day 16) results in prolonged diestrus (Northey and French, 1980), data suggest that this compliment of cells and tissues is required to generate appropriate stimuli for pregnancy maintenance. Relationship between these three developmental events and genesis of biologically active conceptus products is unclear. 
However, Boime et al. (1982) suggested that stage of trophoblast differentiation may affect transcription and/or translation of message (mRNA) necessary for synthesis of such products. Bovine trophoblast elongation, which is rapid after day 16, is essential (1) to insure increased surface area for nutrient uptake during transition from yolk sac to chorioallantoic nutrition; and (2) to increase uterine area affected by conceptus products. Substances produced by the conceptus in utero may act in a paracrine fashion to exert effects locally on endometrial or other uterine tissues and/or in an endocrine fashion where products enter the maternal bloodstream to affect distant target tissues (Krieger, 1982). Differentiation of trophoblastic cell types may facilitate such diverse modes of action. Wathes and Wooding (1980) suggested that the normal function of bovine tGC at all stages of gestation was to migrate into maternal uterine epithelium and release their granular contents. A similar role was suggested for ovine tGC (Steven et al., 1978). Wooding and Wathes (1980) suggested that this process might be important for transfer of large, nondiffusable molecules across the conceptus-endometrial microvillar junction.

\section{Conceptus Products}

Evidence that components and/or products of peri-attachment conceptuses are required to initiate luteostatic events in cattle, sheep and pigs was reviewed previously. In addition, such substances may be important for induction of histotrophe and establishment of immunological privilege for the conceptus (Cook and Hunter, 1978; Beer and Billingham, 1976, 1979; Beer and Sio, 1982). Surprisingly little is known of the specific nature of products of peri-attachment-stage conceptuses. 
Proteins. With the exception of Iuteotrophic activity (suggested to be proteinacious) reported for aqueous extracts of day 18 bovine conceptuses (Beal et al., 1981), studies of protein components of bovine extraembryonic membranes have been performed on tissues obtained after definitive attachment. Avivi et al. (1982) isolated and characterized a 94,000 dalton protein with thyrotropic (TSH) activity from bovine placental tissues obtained from days 40 to 120 of gestation. Krieger (1982) suggested that placental production of such pituitary-like polypeptides might be necessary to compensate for hormonal effects of pregnancy on maternal physiology. This TSH-like molecule has not been identified in conceptus tissues from earlier periods in gestation. Butler et al. (1982) described two very acidic proteins in extracts of bovine placental membranes from days 28 through 270 of gestation. One of these proteins $\left(M_{r} \times 10^{-3} \simeq 47\right.$ to 53 ; pI 4.0 to 4.4$)$ was unidentified. The second $\left(M_{r} \times 10^{-3} \simeq 65\right.$ to $70 ;$ pI 4.6 to 4.8) was suggested to be alpha ${ }_{1}$-fetoprotein $\left(\alpha_{1}-\right.$ FP).

Alpha ${ }_{1}$-fetoprotein is a fetus (conceptus)-specific serum protein found in virtually all mammalian embryos (Gitlin and Boseman, 1967; Lai et al., 1978a; Tomasi, 1978), and produced primarily by yolk sac and fetal liver. Lai et al. (1978b) showed $\alpha_{1}-$ FP to be the most predominant of three bovine fetus-specific serum proteins including $\alpha_{2}-\mathrm{FP}$ and $\beta$-FP. None of these proteins were detected in maternal serum at 11 weeks of gestation (Lai et al., 1978b). Smith et al. (1979) reported maximal $\alpha_{1}$-FP concentrations in bovine fetal fluids and tissues during the third to fourth month of gestation. Allantoic fluid levels of $\alpha-F P$ exceeded those in amniotic fluid but remained very low in maternal serum (Smith et al., 1979). During peak periods of elevated $\alpha-F P$ in 
allantoic fluid levels in maternal serum were not different from nonpregnant cattle (Smith et al., 1979). Such results suggest an intrauterine site of action for this protein. Recently, Janzen et al. (1982) detected $\alpha_{1}-$ FP in tissues of day 14 bovine trophoblasts $(n=2)$ and in al.lantoic fluid of one day 16 conceptus. Incubation of bovine conceptus tissues (day $17, \mathrm{n}=2$; day $27, \mathrm{n}=1$ ) with ${ }^{35}$ S-methionine indicated primary sites of synthesis to be yolk sac and fetal liver (Janzen et al., 1982). Analysis of tissues and fluids from day 14 to 46 bovine conceptuses indicated increasing concentrations of $\alpha_{1}-\mathrm{FP}$ with stage of gestation. Concentrations of $\alpha_{1}-F P$ in maternal serum were consistently and markedly lower (550 to $1.5 \times 10^{6}$ times) than those in conceptus tissues and fluids (Janzen et al., 1982). Additionally $\alpha_{1}-$ FP concentrations in uterine fluid consistently exceeded those of maternal serum by a factor of at least 1 to $2 \times 10^{6}$ between days 14 and 46 (Janzen et al., 1982). Collectively, data indicated that synthesis of bovine $\alpha_{1}$-FP begins well in advance of attachment (day 14), and the protein appears to be sequestered in significant amounts within the uterine lumen. - Failure of isolated day 27 allantois to synthesize ${ }^{35} \mathrm{~S}-\alpha_{1}-\mathrm{FP}$ from ${ }^{35} \mathrm{~S}$-methionine suggested that appearance of $\alpha_{1}-\mathrm{FP}$ in utero occurred via transudation across trophoblast membranes early in gestation (Janzen et al., 1982).

The role of $\alpha_{1}$ FP remains unclear. Presently, controversy exists as to whether $\alpha_{1}-\mathrm{FP}$ is an immunosuppressive or immunostimulating protein (Tomasi, 1978; Suzuki and Tomasi, 1980). Clearly, the former role (immunosuppressant) would be consistent with necessity for establishment of immunological privelege for the conceptus (Beer and Sio, 1982). Additionally, $\alpha_{1}$-FP may regulate availability of uterin luminal 
steroids. Rat $\alpha-F P$ was reported to bind both $T$ and $E_{2}$ with equal affinity $\left(\mathrm{Kd} \simeq 1 \times 10^{-10} \mathrm{M}\right.$; C1ark et al., 1977).

Placental lactogens were identified and/or isolated from placentae of cows (bPL; Buttle and Forsyth, 1976; Bolander and Fellows, 1976; Murthey et al., 1982) and ewes (oPL; Chan et al., 1976; Fellows et al., 1976), but not pigs (Forsyth, 1974). Recent reports suggest bPL to have $a M_{r}\left(x 10^{-3}\right)$ of $32-35$ and $\mathrm{pI}$ in the range of 5.5-5.7 (Murthey et a1., 1982; Kensinger et al., 1982). Kensinger et a1. (1982) demonstrated synthesis of bPL by near term fetal cotyledonary tissue in vitro. However, the principle site of action of this polypeptide in pregnant cattle is unclear. Bolander et al. (1976) reported peripheral plasma bPL concentrations in excess of $1100 \mathrm{ng} / \mathrm{ml}$ during late gestation in dairy cattle. In contrast, both Buttle and Forsyth (1976) and Schellenberg and Friesen (1982) reported low to undetectable levels of plasma bPL in late pregnant cattle. Concentrations of bPL were highest in fetal serum (Schellenberg and Friesen, 1982) suggesting a local (intrauterine or fetal) site of action for this polypeptide. Such effects might be particularly important during early pregnancy. Using a radioreceptor assay, Flint et a1. (1979) detected bovine placental lactogen (bPL) in homogenates of bovine conceptuses from days 17,24 and 25. It was suggested that presence of bPL in day 17 bovine conceptus homogenates was related to appearance of binucleate tGC, shown to differentiate in bovine trophectoderm by day 16 (Flint et al., 1979; Greenstein et al., 1958; Staples et a1., 1961). This concept was based on immunocytochemical, immunofluorescent and radioreceptor assay studies in sheep which indicated that oPL was localized in and, therefore, produced by ovine trophectodermal binucleate cells 
(Martal et a1., 1977; Reddy and Watkins, 1978). Watkins and Reddy (1980) proposed the existance of two types of ovine trophoblastic binucleate cells: (1) those responsible for production of oPL; and (2) those responsible for elaboration of other products. Recently, however, oPL was detected by immunofluorescent techniques in areas surrounding lipid droplets in day 14 uninucleate trophoblastic cells, prior to differentiation of binucleate cells (Carnegie et al., 1982). Ovine chorionic binucleate cells, present at laterstages of conceptus development (days 28 and 55), failed to bind antisera to oPL. Fluorescence was confined to areas surrounding lipid droplets of specific uninucleate cells (Carnegie et al., 1982). Considering these conflicting data in sheep and absence of any similar data in cattle, assumption of a tGC source for bPL is unwarrented at present.

Whatever the source, detection of PL in peri-attachment-stage bovine and ovine conceptuses raises questions as to the functional role of this polypeptide. Appearance of bPL in day 17 bovine conceptuses suggested a role for this protein in pregnancy recognition (FIint et al., 1979), although evidence to this effect remains circumstantial. The antiluteolytic action of ovine conceptuses is exerted by day 12 (Moor and Rowson, $1966 \mathrm{a}, \mathrm{b}, \mathrm{c}$ ), at least two days before oPL was detected in trophoblastic binucleate cells (Carnegie et al., 1982). Thus oPL does not appear to be the primary ovine luteostatic agent. Radioimmunoassay of oPL in endometrial tissues from pregnant ewes (days 16 , 18,20 and 22) revealed a striking increase in both caruncular and intercaruncular tissues after day 16 (Carnegie et al., 1982). While data may reflect migration of oPL-rich trophoblastic cells into maternal tissues (Martal et al., 1977; Watkins and Reddy, 1980), potential for 
a local (paracrine) effect exists. Porter (1980) reviewed data indicating that human PL (hPL) has a glucose-sparing, free fatty acid mobilizing effect on maternal tissues. This effect was suggested to be important for enhancing fetal (conceptus) glucose availability (Porter, 1980).

In addition to effects on the maternal system, PL may have important functions within the conceptus itself. Carnegie et al. (1982) observed that appearance of oPL only after day 12 , at the time of blastocyst transformation from spherical to filamentous form, might be related to blastocyst elongation and water movement across extraembryonic membranes. Indeed, hPL elicited changes in both short-circuit current and potential difference of porcine chorioallantoic membranes in vitro, which were consistent with prevention of water movement from fetal to maternal compartments (Bazer et al., 1981a). Recent observations that oPL, but not growth hormone or prolactin, stimulated amino acid transport in fetal rat diaphragm (Freemark and Handwerger, 1983) and ornithine decarboxylase activity in fetal and neonatal rat hepatocytes (Hurley et al., 1980) suggests that these polypeptides might play important roles as fetal (conceptus) "growth hormones" (Freemark and Handwerger, 1983).

Incubation of conceptus tissues in vitro, in the presence of radiolabelled amino acids, and analysis of labelled products in tissues and medium postincubation has proven to be an excellent method for assessing the variety of proteins and polypeptides synthesized by peri-attachment and later stage conceptuses. Wathes (1980) examined effects of steroids $\left(E_{2}\right.$ and $\left.\mathrm{P}_{4}\right)$ and endometrial co-culture on ability of bovine conceptus tissues from days 24 to 44 to incorporate 
radiolabelled $\left({ }^{3} \mathrm{H}\right.$ and $\left.{ }^{14} \mathrm{C}\right)$ leucine in vitro. Leucine was incorporated by conceptus tissues from all stages examined. Isolated allantois from days 25, 26 and 37, incorporated more leucine than chorion from the same stages, and incorporation was maximized in combined cultures (allantochorion). It was suggested that enhanced uptake of labelled leucine by allantoic tissues was related to the rapid expansion and fusion occurring during this period (Wathes, 1980). Incorporation of leucine by bovine conceptus tissues was not affected significantly by co-culture with uterine tissues (Wathes, 1980). Addition of steroids $\left(\mathrm{P}_{4}, \mathrm{E}_{2}\right.$ or $\left.\mathrm{P}_{4}+\mathrm{E}_{2}\right)$ tended to depress leucine incorporation, but no consistent change in protein profiles was seen following electrophoresis. Electrophoresis of chorionic tissue proteins in presence of SDS revealed a broad band of nondialyzable radioactivity in the 85,000 $M_{r}$ range. Labelled proteins in tissue and medium were not thoroughly characterized.

Lewis et a1. (1979) demonstrated continuous increase in uptake of several radiolabelled amino acids including ${ }^{3} \mathrm{H}$-glucosamine $\left({ }^{3} \mathrm{H}-\mathrm{glc}\right)$, ${ }^{14} \mathrm{C}$-leucine $\left({ }^{14} \mathrm{C}-1 \mathrm{eu}\right)$, and ${ }^{35} \mathrm{~S}$-methionine $\left({ }^{35} \mathrm{~S}\right.$-met $)$; by day 19 bovine and day 16 and 19 porcine conceptuses over a $24 \mathrm{~h}$ period in vitro. Postincubation analyses of nondialyzable radiolabelled components of medium by 2D-PAGE and fluorography indicated presence of labelled proteins synthesized de novo during culture (Lewis et al., 1979). Additionally, several products, found to be enriched in medium were present in only trace amounts in tissues. Data suggested that major peri-attachment stage conceptus secretory products might not be found in significant amounts in tissue extracts.

Masters et al. (1983) described a high molecular weight ${ }_{\mathrm{r}} \times 10^{-3}$ > 660) glycoprotein as the major ${ }^{3} \mathrm{H}$-glc-labelled product of bovine 
(day 19), ovine (days 14-16) and porcine (day 16) conceptuses following $24 \mathrm{~h}$ incubation in vitro. In each specie the glycoprotein appeared as an early eluting DEAE (+) peak of ${ }^{3} \mathrm{H}-\mathrm{glc}$. Each high $\mathrm{M}_{\mathrm{r}}$ product consisted of at least $50 \%$ carbohydrate and did not possess biochemical characteristics typical of mucins. Careful analysis of the ovine glycoprotein showed it to be composed of $\mathrm{N}$ - rather than 0-linked oligosaccharide chains containing D-galactose, N-acetylglucosamine, D-mannose and L-fucose. No sialic acid was detected (Masters et al., 1983). These high $M_{r}$ conceptus products were shown to be produced in vitro by ovine conceptuses from days 13 to 23 (Godkin et a1., 1982b) and porcine conceptuses from days 13 to 30 (Godkin et al., 1982a). Production of these high $M_{r}$ products was not apparent until elongation. was underway (Godkin et al., 1982a,b). Guillomot et al. (1982) demonstrated a glycoprotein coat on the outer surface of ovine endometrial and trophoblastic cells between days 13 and 15 . Ruthenium red and cationized ferritin reaction sites and concanavalin-A receptors became more homogeneously distributed over the trophoblastic surface from day 13 to day 15 (Guillomot et al., 1982). Similar changes were not observed on endometrial cell surfaces suggesting a biochemical change in the composition or distribution of ovine trophoblastic cell glycoprotein coat associated with elongation and attachment (Guillomot et al., 1982). Alterations in ovine trophoblastic surface glycoprotein coating observed by Guillomot et al. (1982) were consistent with observations of Godkin et a1. (1982b) relative to onset of production of high ${ }_{r}$ ovine glycoprotein. Masters et al. (1983) suggested that such products might normally be deposited between trophoblastic cells or on the chorionic surface to provide a protease resistant or immunologically 
tolerant coating for the conceptus. Alternatively, these high $\mathrm{M}_{\mathrm{r}}$ products may be associated with control of cell movement and rearrangement during elongation (Geisert et al., 1982a). Additionally, surface glycoproteins may be important for adhesion of conceptus and endometrial surfaces (Guillomot et a1., 1982; Oppenheimer, 1978).

Godkin et a1. (1982b) incubated individual ovine conceptuses from days 13 to 23 with ${ }^{3} \mathrm{H}-1$ eu in vitro. Analysis of nondialyzable, radiolabelled products in medium postincubation by 2D-PAGE and fluorography indicated that day 13 ovine conceptuses produced only one major polypeptide de novo. This product, called Protein-X, consisted of three similar isoelectric species $(\mathrm{pI} \simeq 5.4-5.7)$ and had a ${ }_{r}$ $\left(x 10^{-3}\right.$ ) of 17 to 21 as determined by SDS-PAGE and gel filtration (Godkin et al., 1982b). Pattern of proteins produced de novo increased in complexity with developmental stage of conceptuses. As observed by Lewis et a1. (1979), labelled products enriched in medium were absent or present in only trace amounts in conceptus tissues. Protein-X remained the primary product of ovine conceptuses from days 13 through 21. However, this polypeptide was no longer produced in detectable amounts by conceptus tissues from days 23 or chorion from day 30 (Godkin et a1., 1982b). Continued production of other polypeptides including the high $\mathrm{M}_{\mathrm{r}}$ glycoprotein (Masters et al., 1983) suggested that Protein-X was transiently produced by conceptus membranes during early pregnancy (Godkin et al., 1982b). Pattern of production of Protein-X (days 13 to 21) was similar to that of Trophoblastin (Martal et al., 1979) detected in day 14-16 but not day 21-23 ovine conceptuses. Trophoblastin, suggested to be a protein, was antiluteolytic when infused into uteri of cyclic ewes (Martal et al., 1979). Thus a 
potential role for Protein-X was established, but not verified (Godkin et a1., 1982b). Godkin et al. (1981) presented immunocytochemical evidence for uptake of Protein-X by endometrial tissues from intact, pregnant sheep. Recent in vitro studies (J.D. Godkin, personal communication) suggest that this association may stimulate synthesis and/or release of specific endometrial proteins. Findlay et al. (1981) showed that rate of protein synthesis in both caruncular and intercaruncular tissues was greater in pregnant than nonpregnant ewes on day 15 postestrus. Observations are consistent with ovine conceptus production of a histotrophic molecule (Godkin et al., 1982b; Findlay, 1981).

In addition to the high ${ }_{\mathrm{r}}$ glycoprotein (Masters et al., 1983), porcine conceptuses were shown to produce a variety of polypeptides de novo from radiolabelled amino acid substrate. Rice et al. (1981) identified four major bands of radioactivity in SDS-PAGE gels of protein in medium following explant culture of day 16 porcine conceptuses with ${ }^{3} \mathrm{H}-$ leu $\left(\mathrm{M}_{\mathrm{r}} \times 10^{-3} \simeq 75,40,32\right.$ and 28$)$. Godkin et al. (1982a) demonstrated that, like ovine conceptuses, array of polypeptides produced de novo by porcine conceptuses was related to developmental stage. Spherical $(4.9 \mathrm{~mm})$, tubular $(10-50 \mathrm{~mm})$ and early filamentous porcine blastocysts (>100 mm), recovered between days 10.5 and 12 of pregnancy, all released a group of low $M_{r}$, acidic polypeptides $M_{r} \times 10^{-3} \simeq 20-25$; $\mathrm{pI} \simeq$ 5.6-6.2) into medium as their principle products (Godkin et al., 1982a). The array of polypeptides synthesized by day 13 and 16 porcine conceptuses was more complex. Production of the low $\mathrm{M}_{\mathrm{r}}$ acidic proteins continued, but predominant polypeptides produced were larger and more basic $\left(M_{r} \times 10^{-3} \simeq 35-50 ; \mathrm{pI}>7.5\right)$ (Godkin et al., 1982a). In day 18 porcine conceptus cultures, proteins described for earlier stages 
persisted; however, their synthesis appeared depressed. Additionally, several higher $M_{r}$ embryonic products were detected (Godkin et al., 1982a). These polypeptides were shown to have identical electrophoretic properties to six major porcine fetal serum proteins including transferrin, fibrinogen ( $\beta$-chain), $\alpha$-FP, $\alpha_{1}$-antitrypsin, $\alpha_{1}$-antichymotrypsin and fetuin (Godkin et al., 1982a; Buhi et a1., 1982). Porcine conceptuses from days 25 and 30 no longer produced detectable amounts of either the low $M_{r}$ acidic polypeptides or slightly higher $M_{r}$, basic polypeptides identified at earlier stages (Godkin et al., 1982a). Instead, two acidic polypeptides $\left(M_{r} \times 10^{-3} \simeq 30\right)$ and a major band of material $\left(M_{r} \times 10^{-3} \simeq 50-60 ; p I 6.0-7.3\right)$ were identified as major products at this stage (Godkin et al., 1982a).

Definitive roles for ovine and porcine conceptus proteins remain unclear. Observations that conceptuses of both species produce certain polypeptides transiently, during elongation and attachment periods (Godkin et al., 1982a,b) suggests important roles for these products early in gestation. Alterations in array of polypeptides produced by ovine and porcine conceptuses during the peri-attachment period are clearly related to dynamic developmental phenomena occurring at this time (see Geisert et al., 1982a; Bindon, 1971). However, dramatic alterations in both quantity and quality of polypeptides produced by post-attachment conceptus tissues suggests a physical and/or biochemical effect of the maternal unit on conceptus protein production. Such changes may also be related to transition of conceptus membranes from a primarily secretory role, necessary to insure continued histotrophic stimulation, to a primarily absorptive role, consistent with placental function. 
Prostaglandins. Elevated levels of PG in uterine flushings from pregnant cattle (Bartol et al., 1981a; Lewis et al., 1982), sheep (E1linwood et al., 1979b) and pigs (Zavy et al., 1980), primarily after that period associated with maternal "recognition" of pregnancy and blastocyst elongation, suggested a conceptus, as well as an endometrial source for these ubiquitous molecules. Menezo et al. (1982) examined fatty acid composition of conceptuses obtained from superovulated cattle on days 7 through 14 . Total fatty acid content increased slightly from day $7(1.5 \mathrm{\mu g} /$ conceptus $)$ to $10(4.2 \mathrm{\mu g} /$ conceptus $)$ and more sharply thereafter reaching $13 \mu \mathrm{g} /$ conceptus in day 13 tissues (Menezo et al., 1982). Qualitative analyses of bovine conceptus fatty acids indicated an increase in elongation and desaturation of these molecules between days 11 and 13. Significant amounts of arachidonic acid (precursor for PG synthesis) were not detected in bovine conceptuses obtained prior to day 14 (Menezo et al., 1982). Quantitative and qualitative alterations in bovine conceptus tissue fatty acids were clearly related to stage of development and were most dramatic following "hatching" (loss of ZP) and initiation of trophoblastic elongation (Menezo et al., 1982).

Shemesh et al. (1979) collected bovine conceptuses from superovulated cattle on days 13,15 and 17 postestrus. Conceptuses were placed immediately in $1 \mathrm{ml}$ of defined culture medium and either (1) frozen or (2) allowed to incubate $48 \mathrm{~h}$ at $37 \mathrm{C}$. All samples (tissue + medium) were then homogenized and analyzed for PGF and PGE 2 by radioimmunoassay (Shemesh et al., 1979). Measurable amounts of both PGF and $\mathrm{PGE}_{2}$ were detected in both incubated and unincubated homogenates from all three stages. Prostaglandin content increased with conceptus 
age in both groups, but was 4 to 17 times higher in homogenates of incubated conceptuses suggesting active synthesis and release of PG by conceptus tissues (Shemesh et a1., 1979). Data were consistent with observations of Menezo et al. (1982) relative to availability of arachidonic acid precursor by at least day 14 .

Lewis et al. (1982) examined ability of bovine conceptuses from days 16 and 19 to metabolize arachidonic acid and $P_{2} \alpha$ in vitro. Conceptuses from both stages produced $\mathrm{PGF}_{2 \alpha}, \mathrm{PGFM}_{2} \mathrm{PGE}_{2}$ and, at least, four unidentified compounds as determined by Sephadex LH-20 chromatography. Consistent with observationsof Shemesh et al. (1979), conceptuses produced more $\mathrm{PGF}_{2 \alpha}$ than $\mathrm{PGE}_{2}$ and total PG production increased from day 16 to 19 (Lewis et a1., 1982). Conversion of ${ }^{3} \mathrm{H}-$ $\mathrm{PGF}_{2 \alpha}$ to ${ }^{3} \mathrm{H}-\mathrm{PGFM}$ by bovine blastocysts suggested that, in addition to other enzymes essential for PG synthesis (see Ramwell et al., 1977), conceptuses also contained 15-hydroxy-prostaglandin dehydrogenase and $\Delta^{13}$-prostagland in reductase (Anggard, 1971). However, as compared to endometrial tissues from the same cattle, bovine conceptuses produced considerably less PGFM (\% of ${ }^{3}{ }^{H}-\mathrm{PGF}_{2 \alpha}$ converted to ${ }^{3} \mathrm{H}-\mathrm{PGFM}$ : $34.3 \pm 1.5 \%$ vs $7.5 \pm 1.6 \%$ ); perhaps the uterus, not the conceptus, is the major site of PGF metabolism.

Data relative to conceptus production and/or metabolism of PG in other domestic species are limited. Recently, Hyland et a1. (1982) presented data indicating production of both PGF and PGE by ovine conceptuses from days 14 and presence of both prostaglandins in conceptus tissues from days 13 and 15. Ovine conceptuses contained and/or released more PGF than PGE, in agreement with earlier reports for bovine conceptuses (Shemesh et al., 1978; Lewis et a1., 1982). No 
data were presented relative to metabolism of PG. Maule-Walker et al. (1977) demonstrated metabolism of $\mathrm{PGE}_{2}$ to 13,14 -dihydro-15-keto-PGE 2 by porcine conceptus tissues, and suggested that amniotic membranes might be particularly important in conceptus conversion of both PGF $2 \alpha$ and $\mathrm{PGE}_{2}$ to their respective metabolites. These observations were generally consistent with those of Lewis et al. (1982) for bovine conceptuses. However, no further data relative to PG synthesis or metabolism by porcine conceptuses were presented.

Potential roles for PG in utero were reviewed above. Present data clearly indicate that the bovine conceptus may contribute significantly to the array of uterine luminal PG during early pregnancy. Preliminary data in sheep and pigs suggest a similar possibility. Data are entirely lacking relative to such information in the mare.

Steroids. Importance of steroid hormones in regulation of uterine metabolic events suggests that their production and/or metabolism by peri-attachment conceptus tissues may have dynamic consequences relative to maintenance of an embryotrophic uterine environment. Evidence for steroid production by bovine conceptuses was first presented by Shemesh et al. (1979). Measurable amounts of $\mathrm{P}_{4}$ were found in homogenates of both incubated and unincubated bovine conceptuses from days 13,15 and 16. Testosterone was also detected, but only in day 15 and 16 conceptuses (Shemesh et al., 1979). Levels of both steroids $\left(\mathrm{P}_{4}\right.$ and $\mathrm{T}$ ) were higher in incubated than unincubated conceptus homogenates (tissue + medium), indicating production of these steroids by conceptus tissues in vitro (Shemesh et al., 1979). Data suggested a requirement for both

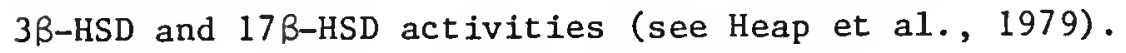


Bovine conceptus tissues were shown to metabolize neutral steroids extensively to 5B-reduced products (Chenault, 1980; Eley et al., 1983; Knickerbocker et al., 1980). Chenault (1980) reported that bovine conceptuses from days 13,14, 16 and 20, and trophoblast from day 24 converted ${ }^{3} \mathrm{H}-\mathrm{A}_{4}, \mathrm{~T}$ and etiocholanolone (Et; $3 \alpha$-hydroxy-5B-androstan17-one) to $5 \beta$-androstane products with 60 to $100 \%$ efficiency. Primary products from ${ }^{3} \mathrm{H}-\mathrm{A}_{4}$ were $\mathrm{Et}$ and $3 \alpha, 17 \alpha$-dihydroxy-5 $\beta$-androstane. In addition to these products, metabolism of ${ }^{3} \mathrm{H}-\mathrm{T}$ yielded $3 \alpha, 17 \beta$-dihydroxy$5 \beta$-androstane. Conceptus metabolism of ${ }^{3} \mathrm{H}$-Et produced $3 \alpha, 17 \alpha$-dihydroxy58-androstane (Chenault, 1980). Bovine conceptus steroid metabolic activity was not related to stage of development (Chenault, 1980). However, when day 24 conceptuses were separated into trophoblast, yolk sac, embryo and allantois, and components incubated with radiolabelled neutral steroid substrate, $98 \%$ of $5 \beta$-reductase activity was associated with the trophoblast (Chenault, 1980). Data suggested activity of several steroid metabolizing enzymes in bovine conceptuses including

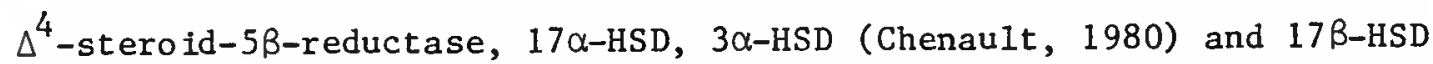
(Shemesh et al., 1979). Results of Chenault (1980) were confirmed and extended by work of Eley et al. (1983) and Knickerbocker et al. (1980). Metabolism of $\mathrm{P}_{4}$ is to primarily $5 \beta$-reduced pregnanes by bovine conceptuses from days 16 to 27 .

Bovine conceptus metabolism of neutral steroids to $5 \beta$-reduced products is in direct contrast to endometrial production of $5 \alpha$-reduced metabolites (Eley et al., 1983, Knickerbocker et al., 1980). Since bioactivity of both $5 \alpha$ - and $5 \beta$-reduced steroids is controversial (Holzbauer, 1976; Kubli-Garfias et al., 1979, 1980), the possibility exists that reduction of steroids by both tissues simply decreases 
amount of biologically active steroids present in utero. However, as observed by Eley et al. (1983), partitioning of isomeric forms of the reductase enzyme in two such interdependent tissues suggests a more important, functional role for one or both of these products. Chenault (1980) cited studies implicating 5B-reduced steroids in erythropoesis and hemoglobin synthesis. It was suggested that such effects might be important during genesis of the bovine circulatory system which begins around days 17 to 18 (Chenault, 1980; Greenstein and Foley, 1958a,b). The possibility that $5 \beta$-reduced steroids are involved in regulation of transcriptional events (see Chenault, 1980) suggests multiple sites of action both in conceptus and maternal tissues. Kubli-Garfias et al. $(1979,1980)$ demonstrated inhibition of uterine motility in vitro by $5 \beta-$, but not $5 \alpha$-reduced steroids, suggesting an important maternal site of action for $5 \beta$-reduced conceptus products. At present data are clearly inconclusive relative to the biological importance of $5 \beta$-reduced bovine conceptus steroid metabolites.

Although 58-reduced metabolites predominated, Eley et al. (1983) reported production of small amounts $(<200 \mathrm{pg})$ of both $E_{2}-17 B$ and $E_{1}$ from ${ }^{3} \mathrm{H}-\mathrm{A}_{4}$ by bovine conceptuses from days 16 to 27 . Neither $\mathrm{E}_{2}-17 \alpha$ or $E_{3}$ were detected, nor was there any evidence for production of sulphoconjugated estrogens (Eley et al., 1983; Chenault, 1980). Although produced in small amounts, $E_{2}-17 B$ was the predominant metabolite of $\mathrm{A}_{4}$ by peri-attachment bovine conceptus tissues (Chenault, 1980; Eley et al., 1983). In contrast, $E_{1}, E_{2}-17 \alpha$ and their sulphoconjugates were predominant estrogenic products of bovine placental tissues later in gestation (Hoffman et al., 1979; Robertson and King, 1979; Eley et al., 1979). Data suggest a specific requirement for conceptus produced free 
estrogens, especially $E_{2}-17 \beta$, during the peri-attachment period, although evidence remains purely correlative. Gadsby et al. (1980) indicated that aromatose activity in bovine conceptuses was highest between days 16 and 22. Production of even small amounts of $E$ by bovine conceptuses during this period may be important in initiation of events associated with establishment of pregnancy; particularly if endometrial tissues are hypersensitive to $E$ stimulation during this time as suggested above.

Ovine trophoblast tissue from days 14 to 18 converted both ${ }^{3} \mathrm{H}-\mathrm{A}_{4}$ and dehydroepiandrosterone (DHT) to other unidentified neutral steroid metabolites with 90 to $95 \%$ efficiency (Gadsby et a1., 1980). Although $5 \beta$-reduced products have not been described for peri-attachment stage ovine conceptus tissues, Ainsworth and Ryan (1967) demonstrated 5Breductase activity in near term ovine placental tissues. Like cattle, conversion of neutral steroid precursors to phenolic compounds by ovine conceptuses was low (Gadsby et a1., 1980). Ovine trophoblasts obtained between days 16 and 18 did not produce significant amounts of either $E_{1}$ or $E_{2}-17 B$ from ${ }^{3} \mathrm{H}-\mathrm{A}_{4}$ precursor (Gadsby et a1., 1980). However, Willis et al. (1981) reported metabolism of both ${ }^{3} \mathrm{H}-\mathrm{A}_{4}$ and ${ }^{3} \mathrm{H}-\mathrm{P}_{4}$ to $\mathrm{E}_{1}$ by ovine conceptuses from days 14,16 and 18. Production of $\mathrm{E}$ by ovine conceptus tissues remains controversial.

Production and metabolism of steroids by porcine peri-attachment conceptuses have been reviewed extensively. The reader is referred to Heap et al. (1979, 1981a,b) for details. While porcine conceptuses (day 16) converted ${ }^{3} \mathrm{H}-\mathrm{A}_{4}$ and ${ }^{3} \mathrm{H}-\mathrm{DHT}$ to other neutral steroid metabolites with $40 \%$ efficiency, phenolic steroids were, consistently, the predominant products of steroid metabolism (Gadsby et al., 1980). 
Initiation of porcine conceptus E production is associated with the period of rapid blastocyst elongation (Heap et al., 1981b) and is reflected by dramatic increase in both free and conjugated estrogens in uterine flushings obtained from pregnant gilts between days 10 and 14 (Geisert et al., 1982b; Zavy et al., 1980). Heap et al. (1979) summarized data suggesting that porcine blastocysts may be able to produce estrogesn from acetate precursor. Additionally, sulfatase activity was demonstrated in pig conceptus tissues (Heap and Perry, 1974). Thus, significant amounts of free estrogens may be produced by porcine conceptuses via deconjugation of sulphated E provided by endometrial tissues (see above and Bazer et al., 1982). Production of large amounts of estrogens by peri-attachment porcine conceptuses is consistent with current theories of pregnancy recognition and maintenance in this species (see Bazer and Thatcher, 1977; Bazer et al., 1982). Furthermore, porcine conceptus estrogen production was suggested to be critical for synchronization of endometrial release of histotrophe during the peri-attachment period (Geisert et al., 1982b,c; Bazer et al., 1982).

Increases in uterine luminal content of both $E_{1}$ and $E_{2}$ in pregnant mares between days 14 and 16 suggested a conceptus source for these steroids (Zavy et a1., 1979). Incubation of equine conceptus membranes obtained from days 8 to 20 of pregnancy and radioimmunoassay of medium indicated conceptus production of both $E_{2}$ and $E_{1}$. Estrogen production increased from day 12 to day 20 at a level comparable to that seen in porcine conceptuses. This increase in $\mathrm{E}$ production was clearly associated with increasing tissue mass since production per mg of conceptus tissue was constant during this period (Zavy et a1., 1979). Whether 
equine conceptus produced estrogens are required for pregnancy recognition in a manner similar to that suggested for pigs is debatable (see Bazer et al., 1982; Sharp, 1980). However, production of these steroids does occur at significant levels during that period associated with recognition in this specie (see Allen, 1979).

\section{Conclusion}

As is apparent from the preceeding review, the interdependent relationship between the conceptus and its uterine environment is complex. Considerable data have been amassed pertaining to the nature of components of this system, a system designed by nature to maximize chances of reproductive success. Temporal patterns of appearance of these components, whether contributed by maternal or conceptus units, have Ied to considerable speculation relative to their functional roles in establishment and maintenance of an embryotrophic uterine environment. However, definitive information in this regard is clearly lacking. Theories of function derived from factual correlative evidence are valuable in attempting to understand the dynamics of such a complex system. As facts continue to accumulate, however, perhaps the most propitious attitude to take relative to their organization is that suggested by Claude Bernard (1865; p.168): "We must have robust faith and not believe." 


\section{CHAPTER II \\ UTERINE PROTEINS IN UNILATERALLY PREGNANT CATTLE}

\section{Introduction}

Over 300 years ago Walter Needham coined the term "uterine milk" to describe fluid present in the uterine lumen which might serve as a source of nutrition to the developing fetus (Amoroso, 1952). The concept that the uterus must provide a complete medium for support of the developing conceptus (embryo and extraembryonic membranes) has, therefore, been long recognized. This concept is párticularly important in domestic species including the horse, pig, sheep and cow in which time from conception to placental attachment is prolonged (Cook and Hunter, 1978; Steven and Morris, 1975; Wathes and Wooding, 1980). Studies designed to examine components of uterine fluid from domestic species have been hampered by small amounts of material recovered in uterine flushings, particularly from sheep and cattle (Heap and Lamming, 1960; Iritani et al., 1969; Roberts and Parker, 1974a, 1976; Barto1 et al., 1981a). Observations of Bond (1898), that 1igation of the oviduct or uterine horn in rabbits, guinea pigs and sheep resulted in accumulation of luminal fluid, set the stage for more recent studies of a similar nature. Large volumes of protein-rich uterine fluid were obtained from pregnant sheep in which a pouch was surgically created in one uterine horn (Harrison et al., 1976). Later, Bazer and coworkers (1979a) recovered large amounts of protein-rich fluid from the ligated uterine horn of unilaterally pregnant sheep. 
Procedures similar to those reported for sheep (Harrison et al., 1976; Bazer et al., 1979a) have not been attempted in cattle. However, Dixon and Gibbons (1979) showed that protein-rich uterine fluid could be obtained from nonpregnant cattle following chronic progesterone therapy. While obviously a useful technique, components of such fluid may not be quantitatively or qualitatively representative of the array of macromolecules or other substances induced by normal endocrine and metabolic conditions of pregnancy. Objectives of the present study were to (1) establish a technique for creation of unilateral pregnancy in cattle in order to recover uterine milk (UM) from the ligated nongravid uterine horn, and (2) to characterize the composition of this fluid pool.

\section{Materials and Methods}

\section{Preparation of Unilaterally Pregnant Cattle}

Fifteen (15) cross-bred beef heifers were subjected to mid-ventral laparotomy after induction of deep analgesia with xylazine (Rompun; Haver-Lockhart, Shawnee, Kansas; Clark and Ha11, 1969; Pippi and Lumb, 1979). For each animal, the reproductive tract was exposed and the ovary containing the corpus luteum removed. An umbilical tape ligature was tied securely around the base of the ipsilateral uterine horn as near the external bifurcation as possible (Figure 2.1A). After placement of the ligature, the uterus was returned to the abdominal cavity and subcutaneous tissues and skin closed with suture materials. Cattle were maintained on pasture and bred by natural service during the first estrous period (day of onset of estrus = day 0 ) postsurgery with the goal of obtaining unilaterally pregnant cattle (Figure 2.1B). 


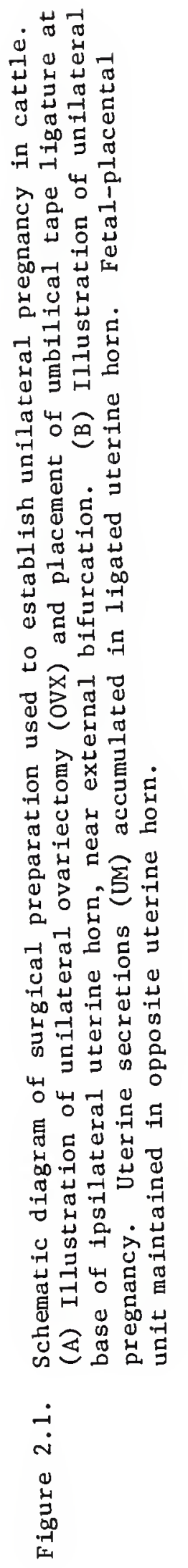



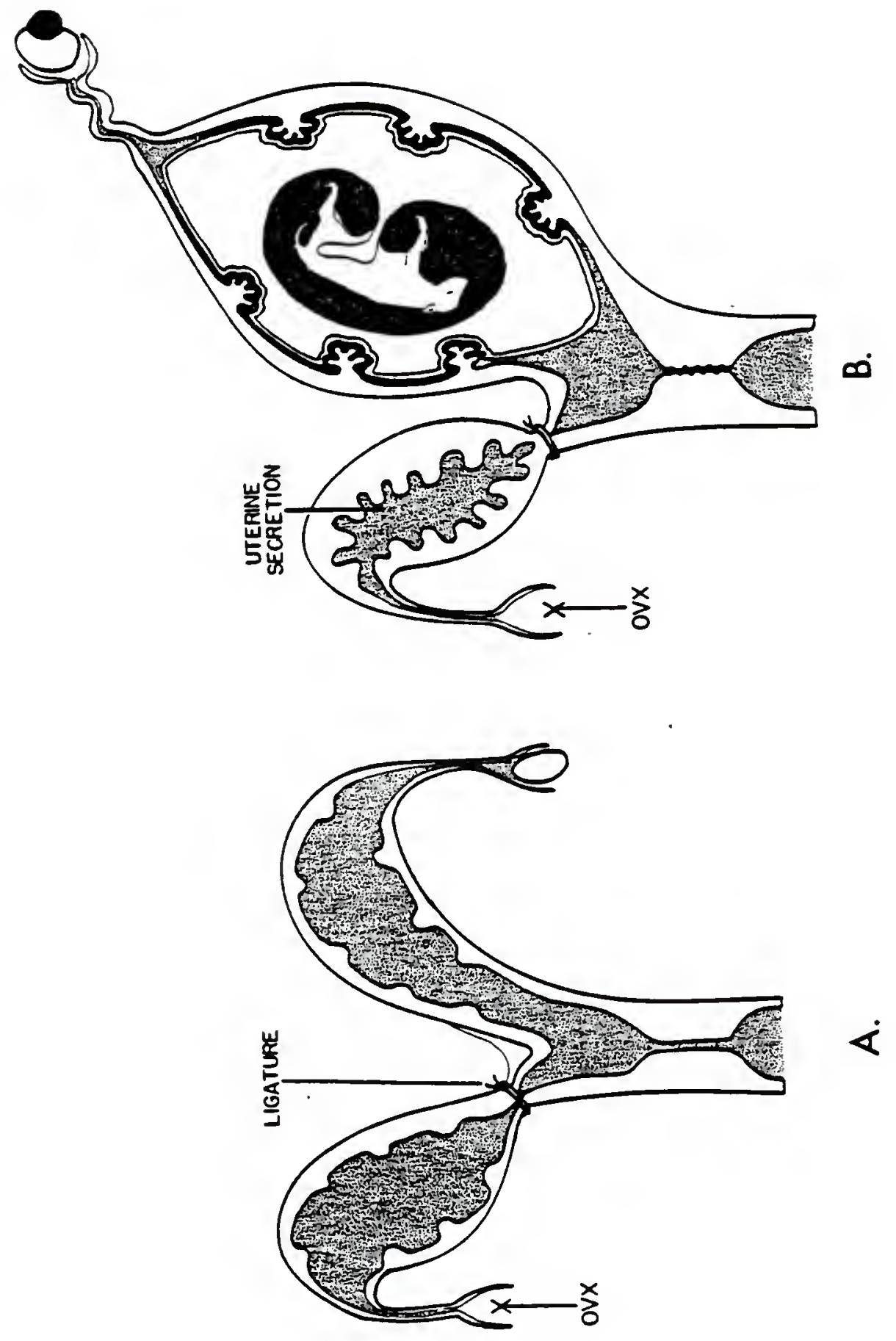
Detection and Recovery of Uterine Milk

After insemination cattle were palpated per rectum once each month for 4 months and once each week thereafter until day 270. Pregnancy status and presence or absence of UM in the ligated uterine horn were noted. On days $180(n=5), 210(n=6)$ and $240(n=4)$ cattle were subjected to standing flank laparotomy under local anesthesia (lidocaine -HCL, 2\%; Generix Drug Corp., Hollywood, FL). At surgery the ligated uterine horn was exteriorized and, if possible, a sample of UM withdrawn into a sterile syringe through a 16 gauge hypodermic needle. On day 270, pregnant cattle were killed at the University of Florida Meats Laboratory and reproductive tracts recovered. Uterine milk, present in ligated horns of all cattle on day 270 , was collected into sterile hypodermic syringes and the total volume recovered was recorded.

\section{Other Fluids and Tissues}

Jugular venous blood was collected into heparinized syringes from all cattle on days 180,210 and 240 . Mixed peripheral blood was collected in heparinized containers from each animal at slaughter on day 270. Additionally on day 270 , placental and fetal wet weights, amniotic and allantoic fluid volumes and fetal sex were recorded. Samples of day 270 endometrium from the intercaruncular areas in both ligated and pregnant uterine horns were obtained, fixed in Bouins fixative, embedded in paraffin and prepared for examination by light microscopy for general histological integrity.

\section{Processing of Uterine Milk and Plasma}

At the time of collection, an aliquot of each UM sample was applied to sterile bovine blood-agar bacteriological plates and incubated 24 to 
$48 \mathrm{~h}$ at $37 \mathrm{C}$ to evaluate the possibility of bacterial contamination. Whole UM samples were stored in aliquots of $50 \mathrm{ml}$ or less at $-20 \mathrm{C}$ until needed for analyses. In each case UM samples were thawed, centrifuged at $4 \mathrm{C}$ for $20 \mathrm{~min}$. at $6,000 \mathrm{~g}$, and supernatant (UMS) subjected to analyses described below. Peripheral blood samples were centrifuged as described above for UM, and individual plasma samples stored at $-20 \mathrm{C}$ prior to analyses.

\section{$\underline{\text { Radioimmunoassays }}$}

Progestin concentrations in all plasma and UMS samples were determined by radioimmunoassay (RIA) according to general procedures described by Abraham et al. (1971). Description and precision of this assay were reported by Chenault et al. (1975). Validation of the progestin isolation and assay procedures was reported by Knight et al. (1977). Antiserum, a gift of Dr. J.L. Fleeger, Texas A and M University, was prepared in a rabbit against $11-\alpha$-hydroxy-progesterone hemisuccinate conjugated to bovine serum albumin. Specificity of the RIA was such that the assay essentially measured progesterone (pregn-4ene-3,20 dione; $\mathrm{P}_{4}$ ). Sensitivity of this assay with respect to the standard curve was $25 \mathrm{pg}$. Inter- and intraassay coefficients of variation were $16.0 \%$ and $19.2 \%$.

Estrone $\left(E_{1}\right)$ and estradiol $\left(E_{2}\right)$ concentrations were measured by RIA in all UMS samples and in all plasma samples collected simultaneously with UM (days 180, 210, 240 and 270). Estrogens $\left(E_{1}\right.$ and $E_{2}$ ) were separated by LH-20 column chromatography following extraction with diethyl ether. The antibody, provided by Dr. V.L. Estergreen, Washington State University, was developed in sheep against estra-1,3,5 (10)-triene-3,17ß-diol,17-succinyl bovine serum albumin. Description 
and validation of the assay procedure was reported previously (Chenault et al., 1975, 1976). Inter- and intraassay coefficients of variation for $E_{1}$ were $11.7 \%$ and $13.8 \%$ and for $E_{2}, 17.4 \%$ and $16.6 \%$.

Estrone sulfate $\left(\mathrm{E}_{1} \mathrm{SO}_{4}\right)$ concentrations in UMS and plasma were determined by RIA after extraction of free estrogens $\left(E_{1}\right.$ and $\left.E_{2}\right)$ and hydrolysis with a sulfatase enzyme (sulfatase type H-II, Sigma Chemical Co., St. Louis, MO). Estrone liberated during hydrolysis was extracted with diethyl ether and quantified as described above. Validation of this procedure in our laboratory was published previously (Eley et al., 1981a). Inter- and intraassay coefficients of variation were $8.43 \%$ and $8.66 \%$

Concentrations of unextracted prostaglandin F (PGF) were determined directly in all UMS samples with a double-antibody RIA system described by Cornette et al. (1972). First antibody, donated by Dr. K.T. Kirton of the UpJohn Company (Kalamazoo, MI), was generated in rabbits against $\mathrm{PGF}_{2} \alpha$ conjugated to bovine serum albumin at the $C_{1}$ carbon. Second antibody was generated in goats against both heavy and light chains of rabbit IgG (Cappel Laboratories, Inc., Downington, PA). This assay was validated in our laboratory for measurement of immunoreactive PGF in bovine uterine flushings (Bartol et al., 1981b). Inter- and intraassay coefficients of variation were $7.58 \%$ and $13.68 \%$. Ligated uterine horn content of PGF ( $\mu \mathrm{g} / \mathrm{horn}$ ) was calculated as the product of PGF concentration ( $\mathrm{ng} / \mathrm{ml}$ ) and UM recovery volume (ml).

\section{Assay for Total Protein and Sugars}

All protein concentrations were estimated according to procedures of Lowry et al. (1951) using purified bovine serum albumin (BSA; fraction V, Sigma Chemical Co., St. Louis, MO) as a standard. Each 
sample of UMS was assayed in duplicate. Total protein content ( $\mathrm{g} /$ ligated uterine horn) was calculated as the product of UMS protein concentration (mg/m1) and recovery volume (m1).

Concentrations of glucose in UMS were determined according to methods previously described by Keilin and Hartee (1952). Fructose concentrations in UMS were determined by the method of Roe (1934). Glucose content (mg/ligated uterine horn) was calculated as described above for both PGF and total protein contents.

\section{Analysis of Calcium}

Calcium ( $\mathrm{Ca}$ ) concentrations in UMS were determined with a Calcette (Precision Systems Inc., Sudbury, MA). This apparatus employed EGTA for fluorometric titration of $\mathrm{Ca}$ in aqueous solutions as described by Alexander (1971). Calcium was measured in all undialyzed UMS samples obtained on day 270. Aliquots of each sample were then dialyzed extensively against several thousand volumes of $10 \mathrm{mM}$ tris (tris hydroxymethylaminomethane)-HCL buffer, $\mathrm{pH} 8.2$ at $4 \mathrm{C}$ for $24 \mathrm{~h}$ in $3500 \mathrm{M}_{\mathrm{r}}$ cut-off dialysis tubing (Spectrapor 3; Spectrum Medical Ind., Los Angeles, CA). Following dialysis, nondialyzable Ca was measured in each dialyzed UMS sample. Percentage of $\mathrm{Ca}$ retained was calculated as the ratio of postand predialysis $\mathrm{Ca}$ concentrations for each sample.

\section{Gel Filtration Chromatography}

An aliquot of each day 270 UMS sample was subjected to gel filtration chromatography on Sephacryl S-200 (Pharmacia Fine Chemicals, Uppsala, Sweden) in a $90 \times 1.5 \mathrm{~cm}$ column at $4 \mathrm{C}$ in $10 \mathrm{mM}$ tris-HCL buffer, $\mathrm{pH} 8.2$, containing $0.33 \mathrm{M} \mathrm{NaCl}$. The $\mathrm{K}_{\text {av }}$ for each protein peak was calculated as described by Reiland (1971) and compared with $\mathrm{K}_{\text {av }}$ 
values of the protein standards aldolase $\left(M_{r} \simeq 158,000\right)$, ovalbumin $\left(M_{r} \simeq 45,000\right)$, and ribonuclease $A\left(M_{r} \simeq 13,700\right)$ used to calibrate the column. Column void volume was determined using Blue Dextran $\left(M_{Y} \simeq\right.$ $2 \times 10^{6}$, Pharmacia Fine Chemicals, Uppsala, Sweden). Elution profiles were generated by determining absorbance of a $500 \mu 1$ aliquot of each fraction at $750 \mathrm{~nm}$ following Lowry protein assay reaction (Lowry et al., 1951).

\section{Anion Exchange Chromatography}

Aliquots of UMS, rennet precipitated bovine colostral whey, and bovine serum were titrated with ammonium sulfate $\left(\mathrm{NH}_{4}\right)_{2} \mathrm{SO}_{4}$ to a final concentration of $41 \%$, centrifuged at $1500 \mathrm{~g}$ for $15 \mathrm{~min}$, the resultant pellet resuspended in distilled water and the ammonium sulfate precipitation procedure repeated. The final pellet was dialyzed against several thousand volumes of $10 \mathrm{mM}$ sodium phosphate buffer, $\mathrm{pH} 7.4$, at $4 \mathrm{C}$ for $4 \mathrm{~h}$, centrifuged as described above and the supernatant subjected to anion exchange chromatography. Anion exchange chromatngraphy was performed on DEAF-cellulose (DE-52; Whatman, Inc., Clifton, NJ) according to methods described by Williams et al. (1975) for gross fractionation of bovine immunoglobulin classes. Proteins not binding

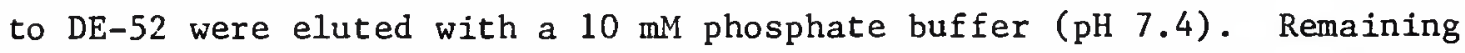
DE-52 positive proteins were eluted with a stepwise increase in $\mathrm{NaCl}$ concentration through $0.04 \mathrm{M}, 0.08 \mathrm{M}, 0.10 \mathrm{M}$ and $0.15 \mathrm{M}$. Absorbance at $280 \mathrm{~nm}$ (Model 35 spectrophotometer; Beckman, Palo Alto, CA) was determined for each eluted fraction for evaluation of elution profiles. Aliquots of UMS from each major DE-52 fraction area were subjected to double immunodiffusion (Ouchterlony, 1958) against rabbit anti-bovine IgA, IgG and IgM (Miles Research Products Div., Elkhart, IN). 
Two Dimensional Polyacrylamide Gel Electrophoresis (2D-PAGE)

Uterine milk supernatant and plasma samples were dialyzed extensively in Spectrapor 1 tubing $\left(M_{r}\right.$ cut-off $\simeq 6-8000$; Spectrum Medical Ind., Los Angeles, $\mathrm{CA}$ ) at 4C against $10 \mathrm{mM}$ tris-HCL buffer, $\mathrm{pH} \mathrm{8.2.}$ Individual samples were then lyophilized and this product dissolved in a volume of $5 \mathrm{mM} \mathrm{K} \mathrm{CO}_{3}$ containing $9.4 \mathrm{M}$ urea, $2 \%(\mathrm{v} / \mathrm{v}$ ) Nonidet $\mathrm{P} 40$ (BDH Chemicals Ltd., Poole, England), and $0.5 \%(\mathrm{w} / \mathrm{v})$ dithiothreitol (Clelands reagent; Sigma Chemical Co., St. Louis, MO) appropriate to allow 50 to $100 \mu \mathrm{g}$ of total protein to be loaded on each gel in a volume less than or equal to $100 \mu l$ (Horst and Roberts, 1979). Separation of both acidic and basic proteins by 2D-PAGE was accomplished according to methods described by Horst and Roberts (1979) and Basha et al. (1980a).

\section{Crossed Immunoelectrophoresis (C-IEP)}

Samples of UMS and plasma from the same cattle were subjected to C-IEP following procedures of Weeke (1973) and Eckersall and Beeley (1980). Electrophoretic procedures were performed using an LKB 2117 Multiphor horizontal bed apparatus (LKB, Stockholm, Sweden) attached to a Forma Scientific Model 2095 Bath and Circulator (Mallinckrodt Inc., Marietta, OH) adjusted to 14C. Current for electrophoresis was provided by an EC-400 completely regulated power source (E-C Apparatus Corp., St. Petersburg, FL). A homogeneous barbital buffer system consisting of $0.06 \mathrm{M}$ Sodium barbital, $0.01 \mathrm{M}$ barbituric acid, $0.37 \mathrm{M}$ tris and $0.75 \mathrm{M}$ glycine $(\mathrm{pH} 8.68)$ was used. All separations were performed in $1 \%\left({ }^{w} / v\right)$ agarose (Sigma type II, EEO; Sigma Chemical Co., St. Louis, MO) in buffer.

For initial separation, $3.5 \mathrm{ml}$ of molten agarose was poured onto warmed $5.0 \mathrm{~cm}^{2}$ glass plates ( $1 \mathrm{~mm}$ thick) and allowed to solidify at room 
temperature. A $0.25 \mathrm{~cm}$ well was punched in one corner of each gel $1 \mathrm{~cm}$ from an edge and $0.5 \mathrm{~cm}$ from the base. Gel plates were then placed onto the LKB 2117 Multiphor with wells oriented near the cathode. Buffer chambers were filled with $700 \mathrm{mls}$ each of barbital buffer and gels bridged to each chamber with wicks consisting of three thicknesses of paper soaked in buffer ( $5 \times 15 \mathrm{~cm}$ Whatman 1; Whatman Inc., Clifton, NJ). Samples ( 3 to $7 \mu 1$ ) were loaded into wells and electrophoretic separation of sample proteins accomplished by application of $2 \mathrm{v} / \mathrm{cm}$ of gel $(10 \mathrm{v})$ for $2 \mathrm{~h}$ at $14 \mathrm{C}$. Voltage applied was measured directly through the gel by insertion of voltmeter probes.

Following initial separation, the upper $4 \mathrm{~cm}$ of each gel, not containing sample proteins, was removed and replaced with $2.8 \mathrm{ml}$ of $1 \%$ agarose homogeneously mixed with $200 \mu 1$ of specific antiserum diluted to working concentration in barbital buffer (total secondary gel volume = $3.0 \mathrm{ml}$ ). Secondary electrophoresis was performed at $1 \mathrm{v} / \mathrm{cm}$ of $\mathrm{gel}(5 \mathrm{v})$ for 15 to $18 \mathrm{~h}$, at right angles to initial separation, toward the annode, under identical buffer and temperature conditions. Comparison of UMS and plasma protein components by C-IEP involved use of several antisera including goat anti-bovine whole serum (Lot No. 28475) and rabbit antibovine albumin (Lot No. 28476; U.S. Biochemical Corp., Cleveland, OH) as well as rabbit anti-bovine IgA (Lot No. 23, Control No. R054), IgG (Lot No. 31, Control No. R074) and IgM (Lot No. 31, Control No. R034; Miles Research Products Div., Elkhart, IN).

After secondary electrophoresis, background protein was removed by pressing each gel under several layers of filter paper (Whatman 1; Whatman Inc., Clifton, $\mathrm{NJ}$ ) and a $5 \mathrm{~cm}^{2}$ glass plate for $15 \mathrm{~min}$. at $90 \mathrm{~g} / \mathrm{cm}^{2}$. Gels were then rinsed $30 \mathrm{~min}$. in $0.9 \%(\mathrm{w} / \mathrm{v}) \mathrm{NaCl}$ followed by 
distilled $\mathrm{H}_{2} \mathrm{O}$ and pressed a second time. Deproteinized gels were dried onto $5 \times 7.5 \mathrm{~cm}$ glass slides at $60 \mathrm{C}$ for $20 \mathrm{~min}$. and stained $3 \mathrm{~h}$ with 0.5\% Coomassie brilliant blue R-250 (Sigma Chemical Co., St. Louis, M0) $\mathrm{w} / \mathrm{v}$ in an ethanol:acetic acid: water solution $(\mathrm{v} / \mathrm{v}, 9: 2: 2)$. Gels were destained in ethanol:acetic acid: water solution $(\mathrm{v} / \mathrm{v}, 9: 2: 2)$ for 5 to $15 \mathrm{~min}$.

Crossed immunoelectrophoresis allowed both quantitative and qualitative assessment of immunochemically similar proteins in UMS and plasma. The system employed allowed as many as four gels to be run simultaneously and, where possible, comparisons were made among gels within a run.

\section{Statistical Analysis}

Where appropriate, data were subjected to analysis of variance using procedures available in the General Linear Models program of the Statistical Analysis System (SAS; Barr et al., 1979). Statistical models considered variability associated with day, fluid pool (UMS vs. plasma) and cow. Day comparisons were made using orthogonal contrasts.

\section{Results}

\section{General}

Twelve of 15 cattle subjected to the unilateral ligation procedure were pregnant within two estrous cycles postsurgery. Of the three remaining cows, one never cycled and two failed to conceive and were culled. Earliest detection of UM by rectal palpation occurred in one cow on day 166 . Uterine milk was detectable by rectal palpation in 11 of 12 cows by day 180. Bovine UM was recovered successfully at flank laparatomy from cattle on days $180(5 / 6), 210(6 / 6)$ and $240(4 / 6)$. 
Recovery volumes at laparotomies ranged from 3.5 to $50 \mathrm{ml}$ (maximal volume attempted). In three instances adhesions prevented exteriorization of the ligated uterine horn required for UM recovery. Three of 12 unilaterally pregnant cattle gave birth to live calves between days 245 and 260 . Uterine milk was recovered from all nine cows remaining pregnant at day 270 (time of slaughter).

At all stages recovered, UM was golden-brown and odorless. Absence of growth on bovine blood agar bacteriological plates after 24 to $48 \mathrm{~h}$ at $37 \mathrm{C}$ suggested that UM was bacteria free, and its presence was not bacterially induced. Arithmetic means $(\bar{X} \pm S E M)$ and ranges of observations for day 270 UM recovery volumes as well as fetal weights, placental fluid volumes, and membrane weights are presented in Table 2.1 .

Gross morphology of day 270 placentae and fetal-maternal attachments appeared normal in every respect. In two cases in which uterine ligation was incomplete and the ligated uterine horn was patent with the pregnant horn, placental membranes did not pass through the opening into the 1 igated horn. However, UM was found in both compartments. Maternal caruncles in the day 270 1igated uterine horns were small and unstimulated. General appraisal of intercaruncular endometrial histology did not reveal any striking abnormalities or dissimilarities between pregnant and ligated uterine horns.

\section{Components of Uterine Milk}

Presented in Table 2.2 are arithmetic means ( \pm SEM) of concentrations of $E_{1}, E_{2}, E_{1} \mathrm{SO}_{4}$ and $\mathrm{P}_{4}$ in UMS and plasma obtained on days 180 , 210, 240 and 270. Comparison of steroid concentrations between fluid pools (UM vs. plasma) only involved data where paired samples of UM and 
Table 2.1. Arithmetic Means ( \pm SEM) and ranges for uterine and fetalplacental physical responses measured on day 270 of gestation for nine cows.

UM volume, ml

Fetal wt., Kg

Allantoic fluid, L

Amniotic fluid, L

Placentome number

Placentome wt., g

Intercotyledonary memb. wt., $g$

Total placental wt., g
$205.3 \pm 68.2$

$32.5 \pm 1.51$

$11.73 \pm 2.14$

$3.27 \pm 0.45$

$82 \pm 5$

$4335.6 \pm 593.2$

$1548.4 \pm 215.7$

$6053.9 \pm 371.5$
$20.0-635.0$

$25.8-38.1$

$6.94-27.14$

$1.30-6.23$

$62-112$

$2555.0-6203.0$

$806.0-2883.0$

$3615.0-7816.0$ 


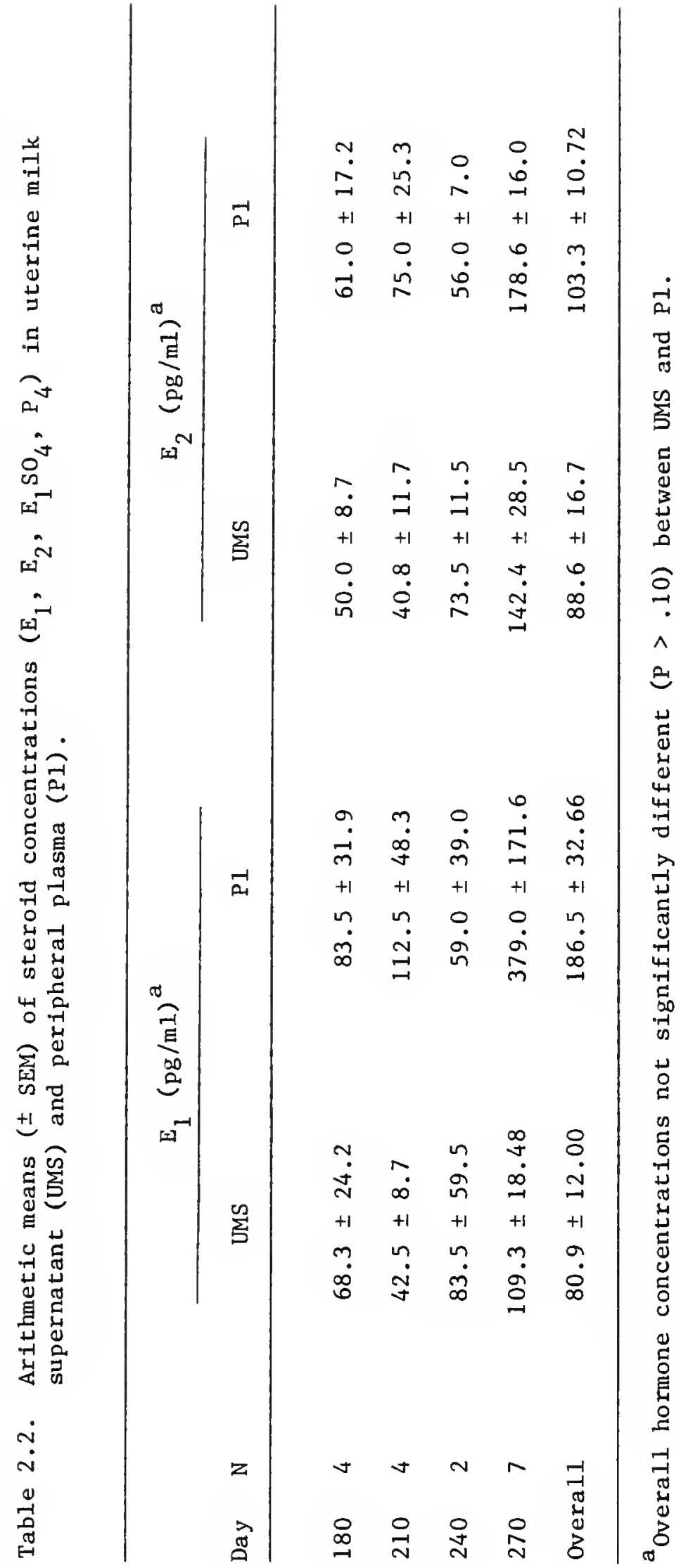




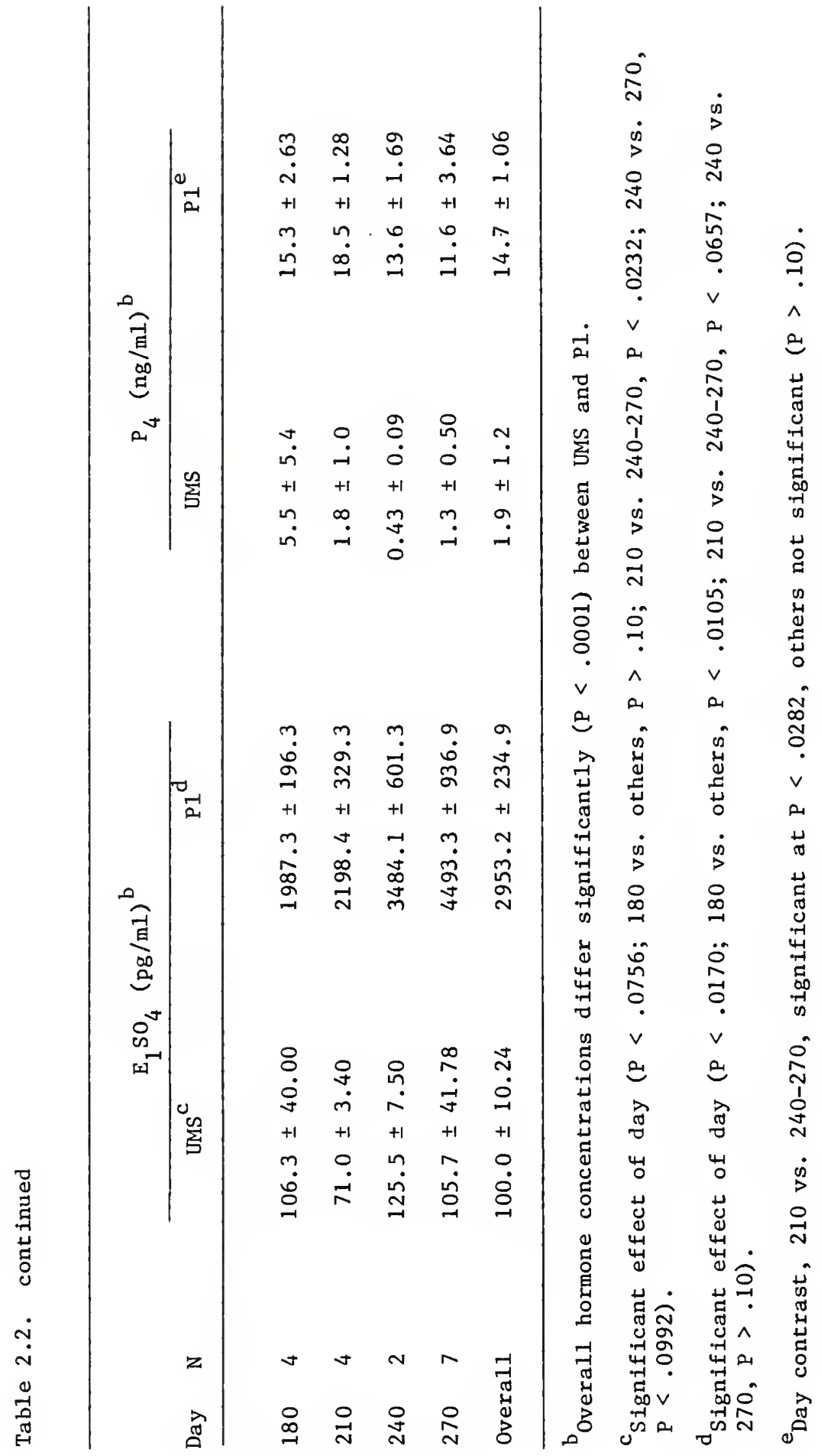


plasma were obtained. Overall, mean concentrations of $E_{1}$ and $E_{2}$ were not different $(P>.10)$ between UMS $\left(E_{1}, 80.9 \pm 12.0 \mathrm{pg} / \mathrm{ml} ; E_{2}, 88.7 \pm\right.$ $15.7 \mathrm{pg} / \mathrm{ml})$ and plasma $\left(E_{1}, 186.5 \pm 32.66 \mathrm{pg} / \mathrm{ml} ; E_{2}, 103.3 \pm 10.72\right.$ $\mathrm{pg} / \mathrm{ml})$. Additionally, neither $E_{1}$ nor $E_{2}$ concentrations were affected significantly by day $(\mathrm{P}>.10)$. In contrast, overall $\mathrm{E}_{1} \mathrm{SO}_{4}$ concentrations $(\bar{X} \pm S E M)$ were higher in plasma than in UMS $(2953.2 \pm 234.9 \mathrm{pg} / \mathrm{ml}$ vs. $100.00 \pm 10.24 \mathrm{pg} / \mathrm{ml} ; \mathrm{P}<.0001)$. Concentrations of $\mathrm{E}_{1} \mathrm{SO}_{4}$ in UMS varied among days $(P<.076$; Table 2.2), increasing after day 210 $(P<.02)$ to highest concentrations on day $240(P<.09)$. A more systematic effect of day was detected for plasma $\mathrm{E}_{1} \mathrm{SO}_{4}(\mathrm{P}<.02$; Table 2.2) which increased after day $180(P<.01)$ to highest concentrations on days 240 and $270(P<.07)$. Progesterone concentrations $(\bar{X} \pm$ SEM $)$ were nearly ten times higher in plasma than UMS $(P<.0001 ; 14.7 \pm 1.06$ $\mathrm{ng} / \mathrm{ml}$ vs. $1.9 \pm 1.2 \mathrm{ng} / \mathrm{mI})$. Concentrations of $\mathrm{P}_{4}$ in UMS were not affected by day $(\mathrm{P}>.10)$, but plasma $\mathrm{P}_{4}$ concentrations were higher on day 210 than later $(\mathrm{P}<.03$; Table 2.2). Significant day $\mathrm{X}$ fluid interactions were not detected for any steroids measured.

Presented in Table 2.3 are significant $(P<.10)$ gross and withinanimal partial correlations detected between steroids measured in peripheral plasma and UMS. Positive correlations were detected between plasma $E_{1}, E_{2}$ and $E_{1} S_{4}$ concentrations. A negative correlation was detected between plasma $\mathrm{E}_{1} \mathrm{SO}_{4}$ and $\mathrm{P}_{4}$. When data were adjusted for the effect of cow, significant within-animal partial correlations were detected only between plasma $E_{1}$ and $E_{2}(r=.97, P<.05)$ and $P_{4}$ and the two unconjugated estrogens, $E_{1}$ and $E_{2}(r=.99, P<.01 ; r=.98$, $\mathrm{P}<.01)$. Of steroids measured in UMS, significant gross and partial correlations were only detected between $E_{1}$ and $E_{2}$ (gross: $r=.69$, 
Table 2.3. Gross (upper) and partial within-cow (lower) correlations of steroids in peripheral plasma and uterine milk supernatant.

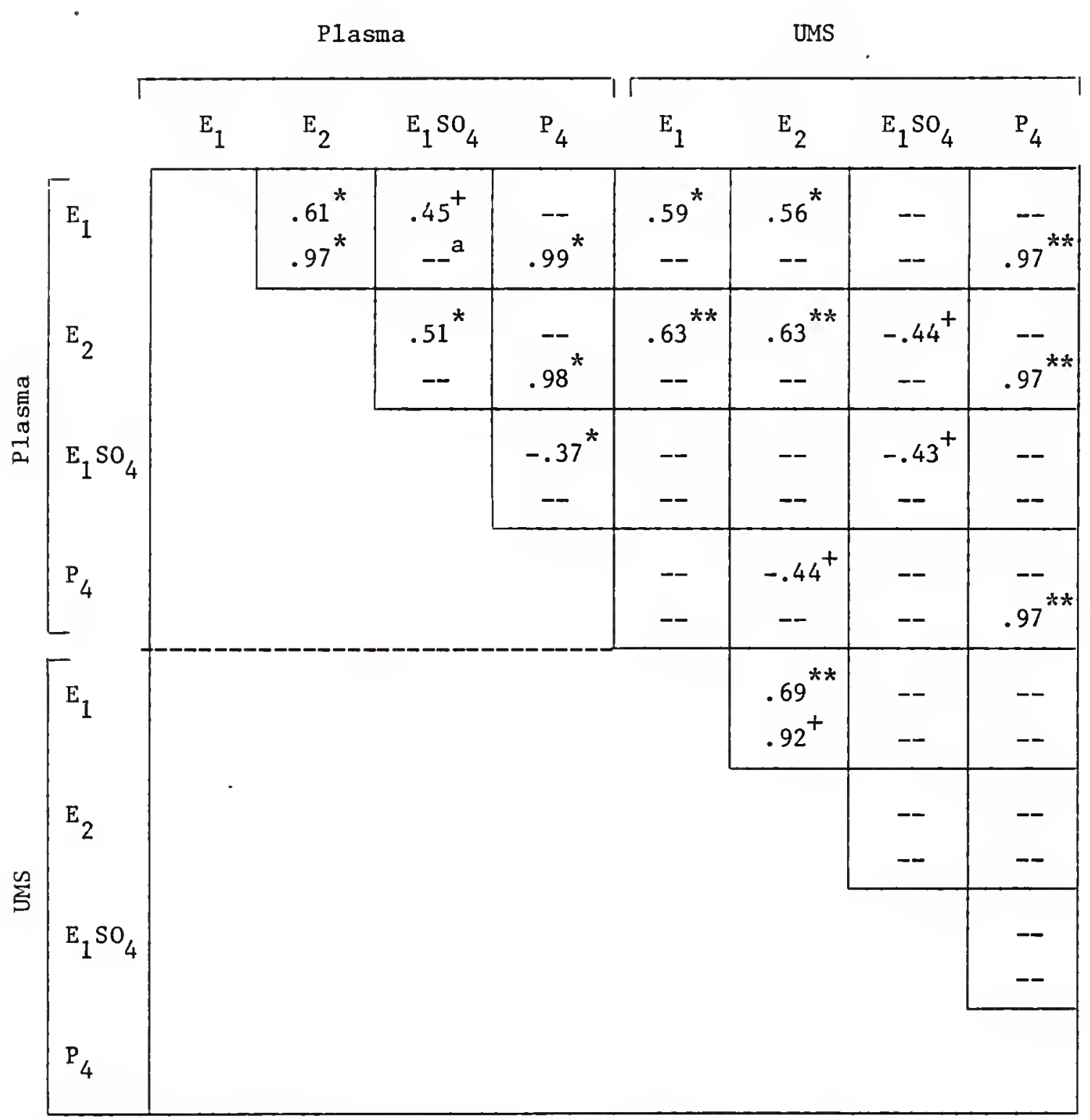

a -- indicates absence of significant correlation $(P>.10)$.

${ }^{+}$significant at $\mathrm{P}<.10 ;{ }^{*}$ significant at $\mathrm{P}<.05 ;{ }^{* *}$ significant at $\mathrm{P}<.01$. 
$\mathrm{P}<.05$; partial: $\mathrm{r}=.92, \mathrm{P}<.10)$. Positive correlations were detected between plasma and UMS unconjugated estrogens (Table 2.3). Negative correlations were found between plasma $E_{2}$ and $E_{1} \mathrm{SO}_{4}$ and UMS $\mathrm{E}_{1} \mathrm{SO}_{4}$, as well as between plasma $\mathrm{P}_{4}$ and UMS $\mathrm{E}_{2}$ (Table 2.3). Neither positive nor negative gross correlations remained significant when adjusted for the effects of cow. When data were adjusted for cow, however, significant partial within-animal correlations were detected between UMS $\mathrm{P}_{4}$ and plasma $\mathrm{E}_{1}(\mathrm{r}=.97, \mathrm{P}<.01), \mathrm{E}_{2}(\mathrm{r}=.97, \mathrm{P}<.05)$ and $\mathrm{P}_{4}(\mathrm{r}=.99, \mathrm{P}<.01)$. Reduction in the number of significant correlations found following adjustment of data for variability associated with cow reflected the high within-animal variation present in the data set.

Concentrations and total amounts $(\overline{\mathrm{X}} \pm \mathrm{SEM})$, as well as range values, of selected constituents of day 270 bovine UMS are presented in Table 2.4. Day 270 UMS contained large amounts of immunoreactive PGF (267.30 $\pm 86.62 \mu \mathrm{g} / 1$ igated horn) and total protein (11.84 $\pm 3.49 \mathrm{~g} / 1$ igated horn). Mean ( \pm SEM) protein concentration of UMS did not differ significantly among days $(63.36 \pm 8.37 \mathrm{mg} / \mathrm{ml}$ ). Mean ( \pm SEM) glucose content was $32.95 \pm 10.78 \mathrm{mg} /$ ligated horn, while fructose was undetectable in $1 \mathrm{ml}$ of UMS. Calcium concentration in undialyzed UMS was $28.35 \pm 8.52$ $\mathrm{mg} \%$ with a range of 5.83 to $66.19 \mathrm{mg}$. An average of $1.63 \pm 0.89 \%$ of total UMS Ca was nondialyzable indicating that 93.8 to $99.9 \%$ of total UMS Ca was present as free $\mathrm{Ca}$ in utero. Uterine milk predialysis Ca concentration was positively correlated with both UMS protein concentration $(r=.68, P<.09)$ and content of PGF $(r=.92, P<.08)$.

\section{Quantitative Analyses of Proteins}

Depicted in Figure 2.2 is a typical S-200 elution profile of UMS from day 270. Four primary fraction areas were identified with 
Table 2.4. Concentration and content ( $\bar{X} \pm$ SEM and range) of selected constituents of bovine uterine milk supernatant recovered on day 270 of gestation.

\begin{tabular}{|c|c|c|c|}
\hline ITEM & $\mathrm{N}$ & MEAN & RANGE \\
\hline PGF, ng/ml & 7 & $3049.5 \pm 831.51$ & $1279.9-5681.9$ \\
\hline Total PGF, $\mu \mathrm{g}$ & 7 & $267.30 \pm 86.62$ & $130.7-588.4$ \\
\hline Protein, mg/ml & 9 & $67.97 \pm 11.96$ & $20.6-133.4$ \\
\hline Total protein, $g$ & 9 & $11.84 \pm 3.49$ & $0.114-29.08$ \\
\hline Glucose, $\mathrm{mg} / \mathrm{ml}$ & 7 & $0.127 \pm 0.004$ & $0.105-0.140$ \\
\hline Total glucose, mg & 7 & $32.95 \pm 10.78$ & $2.99-85.70$ \\
\hline Fructose, mg/ml & 7 & N.D. ${ }^{a}$ & -- \\
\hline $\mathrm{Ca}^{++}, \mathrm{mg} / 100 \mathrm{ml}$ & 7 & $28.35 \pm 8.52$ & $5.83-66.19$ \\
\hline $\begin{array}{l}\text { Nondialyzable } \mathrm{Ca}^{++} \text {, } \\
\text { mg/100 ml }\end{array}$ & 7 & $0.21 \pm 0.07$ & $0.04-0.43$ \\
\hline$\% \mathrm{Ca}^{++}$nondialyzable & 7 & $1.63 \pm 0.89$ & $0.10-6.20$ \\
\hline
\end{tabular}

a fructose detectable in $1 \mathrm{ml}$ of sample. 


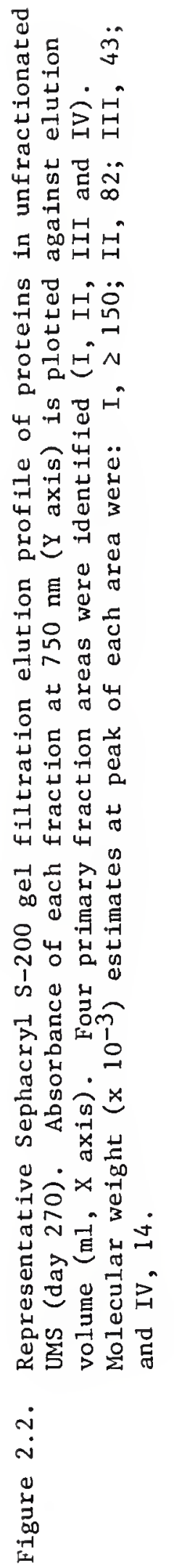




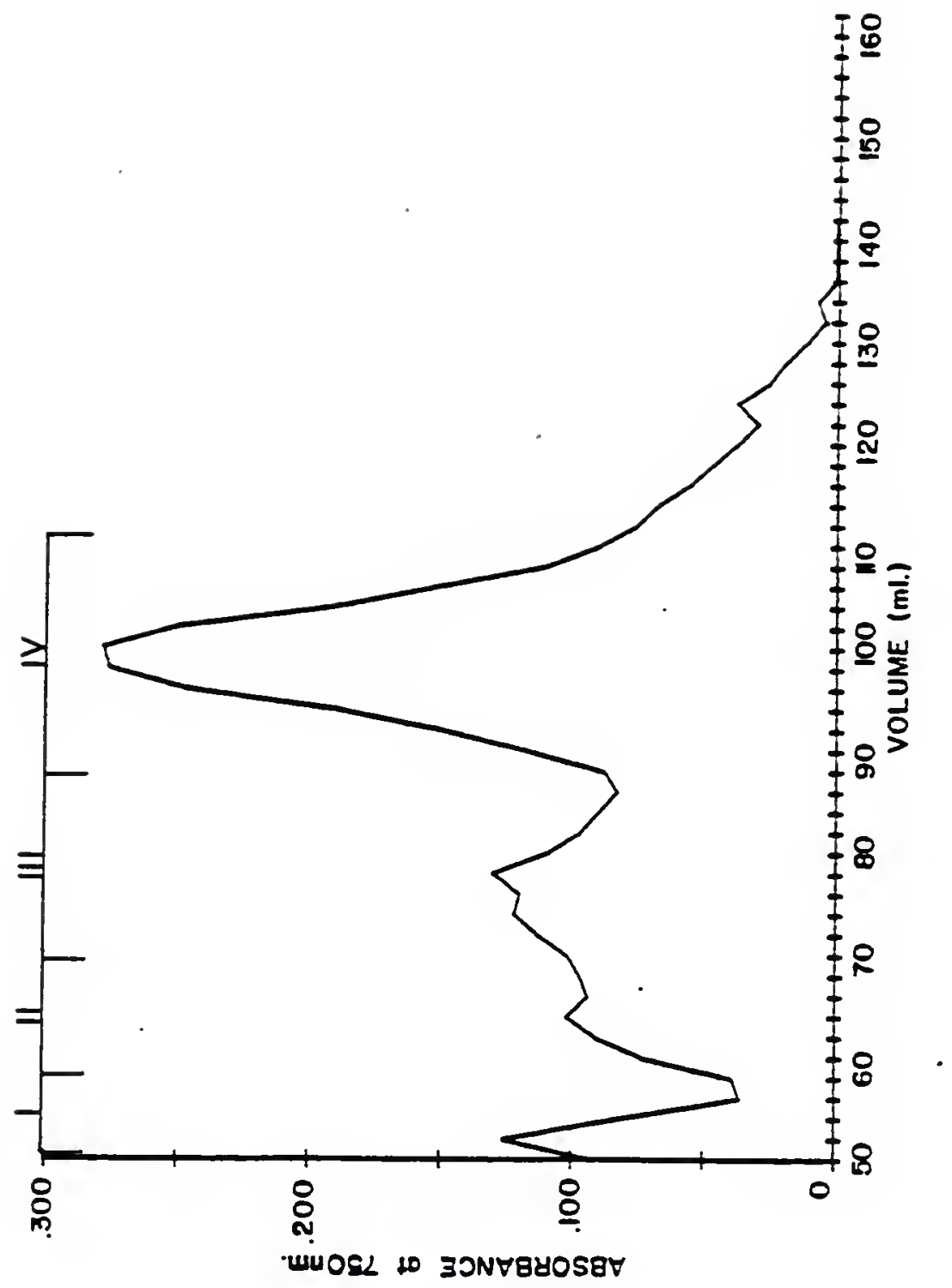


approximate molecular weight estimates $\left(\mathrm{M}_{\mathrm{r}} \times 10^{-3}\right)$ at their peak of $\mathrm{I}$, $\geq 150$; II, 82 ; III, 43; and IV, 14. The majority of UMS protein consistently eluted in fraction IV suggesting that major components of UMS were of lower molecular weight.

Representative Coomassie brilliant blue R-250-stained 2D-PAGE gels (12.5\% acrylamide) of UMS from two cows are shown in Figure 2.3. Acidic proteins are seen in panel $A($ IEF) and basic proteins in panel $B$ (NEPHGE). The 2D-PAGE technique revealed a complex polypeptide array in UMS. Proteins were present across the molecular weight range described by S-200 gel filtration (Figure 2.2). Those most likely representative of S-200 fraction area IV (Figure 2.2) were seen primarily on NEPHGE gels (Figure 2.3B). Polypeptides in this category had molecular weights of less than 35,000 and were present in the 6.8 to $8.6 \mathrm{pH}$ range.

Within-animal comparisons of 2D-PAGE (IEF) gels of UMS and peripheral plasma proteins revealed striking similarities in array of polypeptides present in these two fluid pools. Representative gels are shown in Figure 2.4. The dominant protein seen in gels of both UMS and plasma was bovine serum albumin (Figure 2.4). Numerous other polypeptides were common to both fluids as shown (Figure 2.4). Of note, however, were several polypeptides present in UMS which were consistently absent from 2D-PAGE (IEF) gels of peripheral plasma proteins. One group of UMS-specific polypeptides was found in the 25 to 30,000 molecular range with isoelectric points $\left(\mathrm{P}_{\mathrm{I}}\right)$ between 6.6 and 7.3 (Figure 2.4A). Two other polypeptides (Figure 2.4A, UM1 and UM2) had molecular weights of 20 to 21,000 and $P_{I}$ of approximately 6.3 and 6.1 , respectively. 
点

艺常

ने

苞品

u O

矛

๑

4

(1) ํํ

구

丞罗

นู้

ปั

ำ

กิ ชี

$\beth 4$

on on

क

(1)

농

只

U

บ

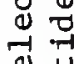

(1)

त)

न

용

药 ิ도

고송

包受

$\pi$

음

힘

주

러

0

車

पृ

总焉

i

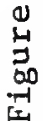




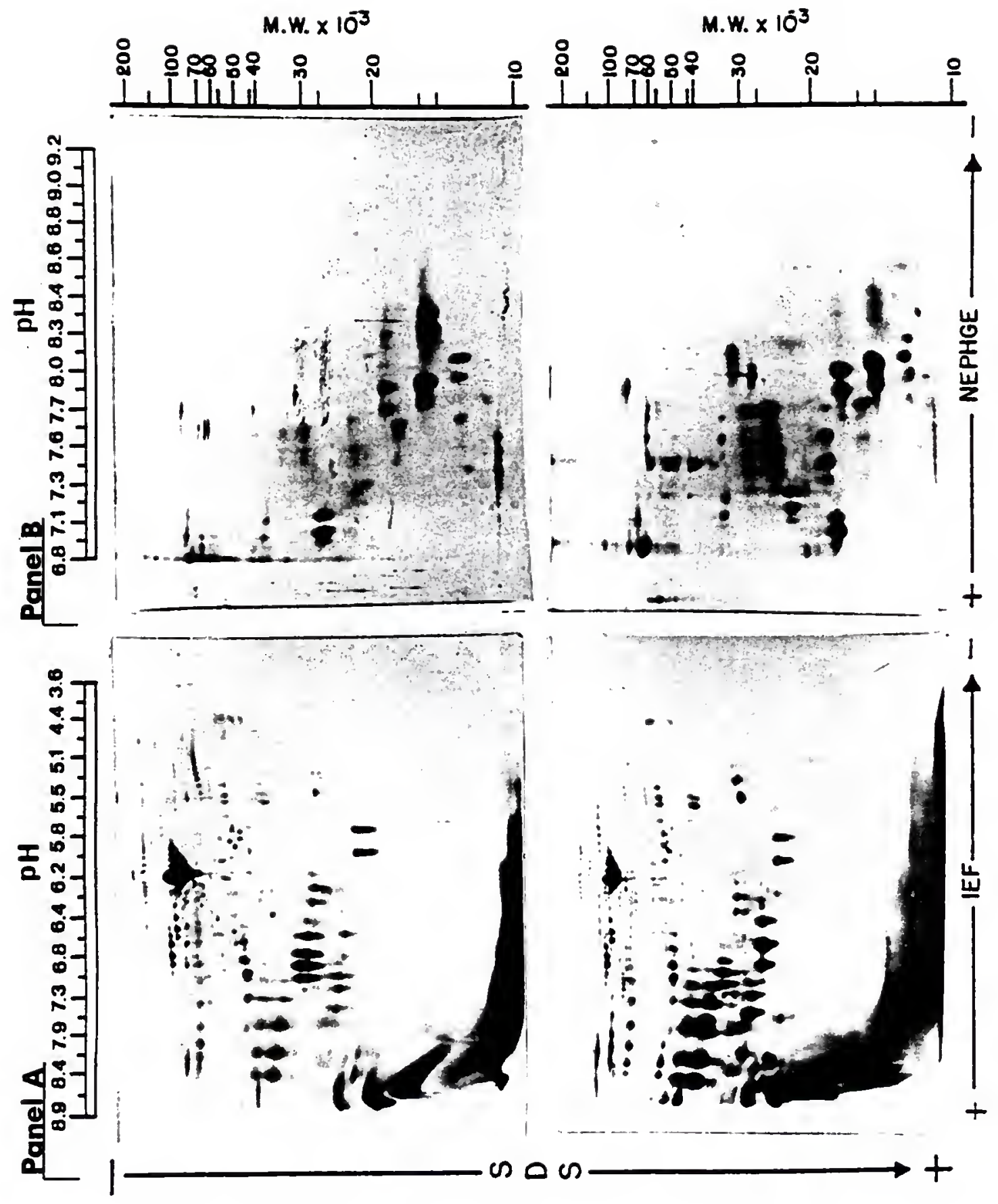


Figure 2.4. Two-dimensional polyacrylamide gel electrophoresis ( $10 \%$ acrylamide) of acidic (IEF) proteins characteristic of UMS (A) and peripheral plasma (B). BSA (shown in A) was dominant protein in both fluids. UMS-specific proteins (A) included one group in the molecular weight $\left(M_{\mathrm{r}} \times 10^{-3}\right) /$ $\mathrm{pH}$ range of 25-30/6.6-7.3 (indicated by large arrow); and two other polypeptides (UM1 and UM2) at approximately $20-21 / 6.3$ and 6.1 respectively. 


\section{pH}

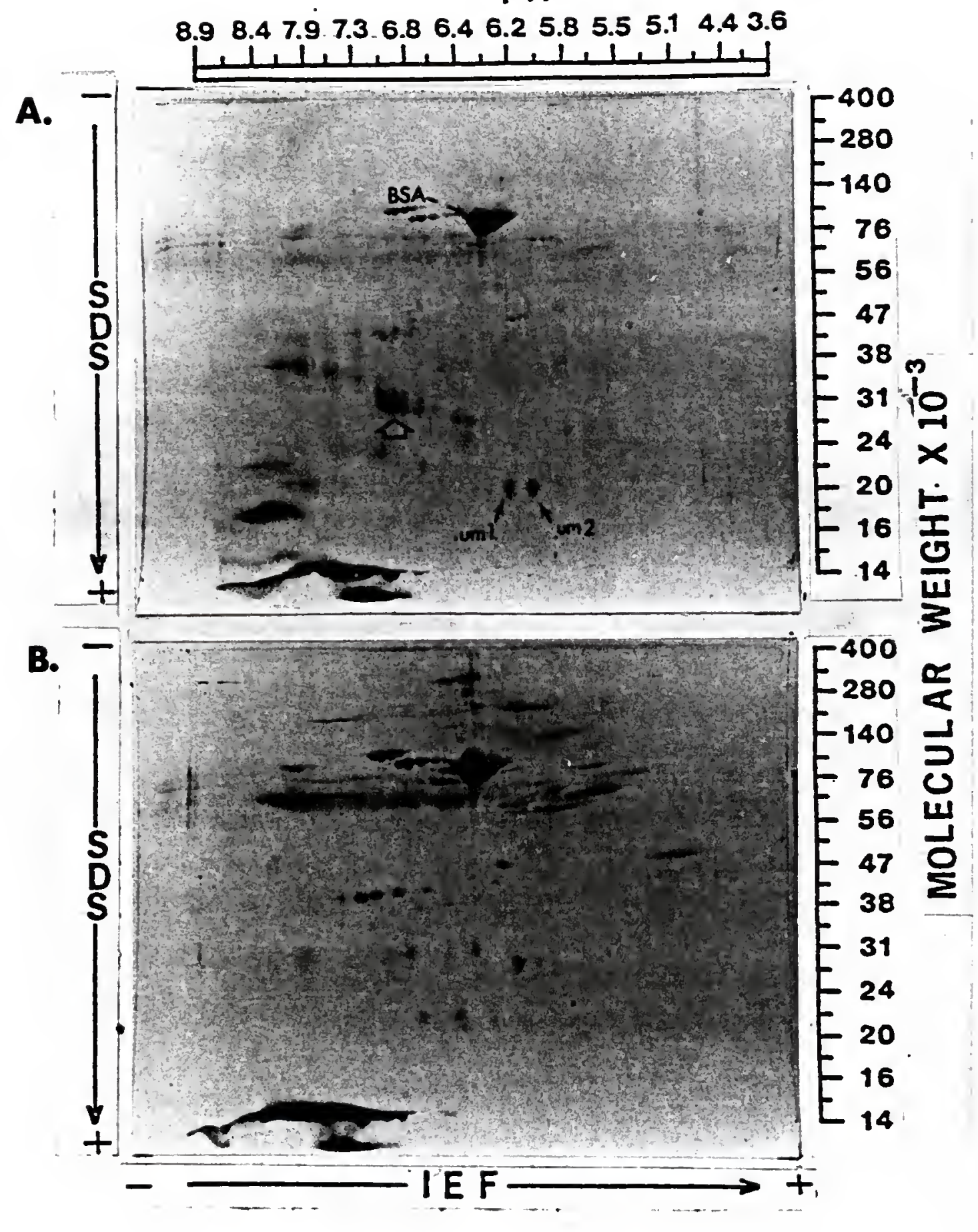


Crossed immunoelectrophoresis was used to examine immunochemical similarities between protein components of UMS and plasma. When equal amounts of UMS and plasma protein were run under identical conditions using goat anti-whole bovine serum (U.S. Biochemical Corp., Cleveland, OH), a large number of immunochemical identities were seen in both fluids (Figure 2.5). The largest most prominant peak seen in both UMS and plasma (Figure 2.5) was electrophoretically and immunochemically identical with a commercial preparation of BSA (Sigma fraction V; Sigma Chemical Co., St. Louis, MO). This protein was consistently present in UMS as the major serum protein. As shown in Figure 2.5, BSA was present in approximately equal proportions in UMS and plasma. Comparison of the array of proteins identified immunochemically in UMS and plasma by C-IEP indicated that not all proteins present in plasma were consistently present in UMS. Quantitatively, many UMS postalbumin proteins, migrating more slowly than BSA, were present in proportionately lower amounts compared to peripheral plasma as evidenced by smaller rockets in UMS gels (Figure 2.5). In these studies, where equal amounts of UMS or plasma proteins were loaded and electrophoresed under identical conditions, the proportionate reduction in amount of some postalbumin proteins suggested that a significant proportion of total UMS protein was not immunochemically identical with plasma.

Shown in Figure 2.6 are ion-exchange chromatograms of ammonium sulfate (41\%) precipitable proteins from UMS (panel A), bovine serum (panel B) and bovine colostral whey (panel C). Fraction areas designated I, II, III, IV and $V$ were eluted from DE-52 either with $10 . \mathrm{mM}$ sodium phosphate buffer $(\mathrm{pH} 7.4)$ or with $0.04 \mathrm{M}, 0.08 \mathrm{M}, 0.10 \mathrm{M}$ or $0.15 \mathrm{M}$ $\mathrm{NaCl}$, respectively. Williams and coworkers (1975) demonstrated that 
Figure 2.5. Crossed-immunoelectrophoresis indicating serum-identical proteins in UMS (top) and peripheral plasma (bottom) from a day 270 unilaterally pregnant cow. Presence of rockets in both gels indicates positive immunochemical response to goat anti-whole bovine serum (Lot No. 28475, U.S. Biochemical Corp., Cleveland, $\mathrm{OH}$; final dilution 1:75).

(*) Indicates largest rocket in both UMS and plasma which was electrophoretically and immunochemically identical with a commercial preparation of BSA (fraction V; Sigma Chemical Co., St. Louis, MO). Postalbumin proteins are to left of BSA. Equal amounts $(15 \mu \mathrm{g}$ ) of UMS and plasma protein were electrophoresed. Separations were performed toward the annode in $1 \%$ agarose $(\mathrm{w} / \mathrm{v})$ in barbital-trisglycine buffer ( $\mathrm{pH} 8.68$ ). 


\section{UMS}

*

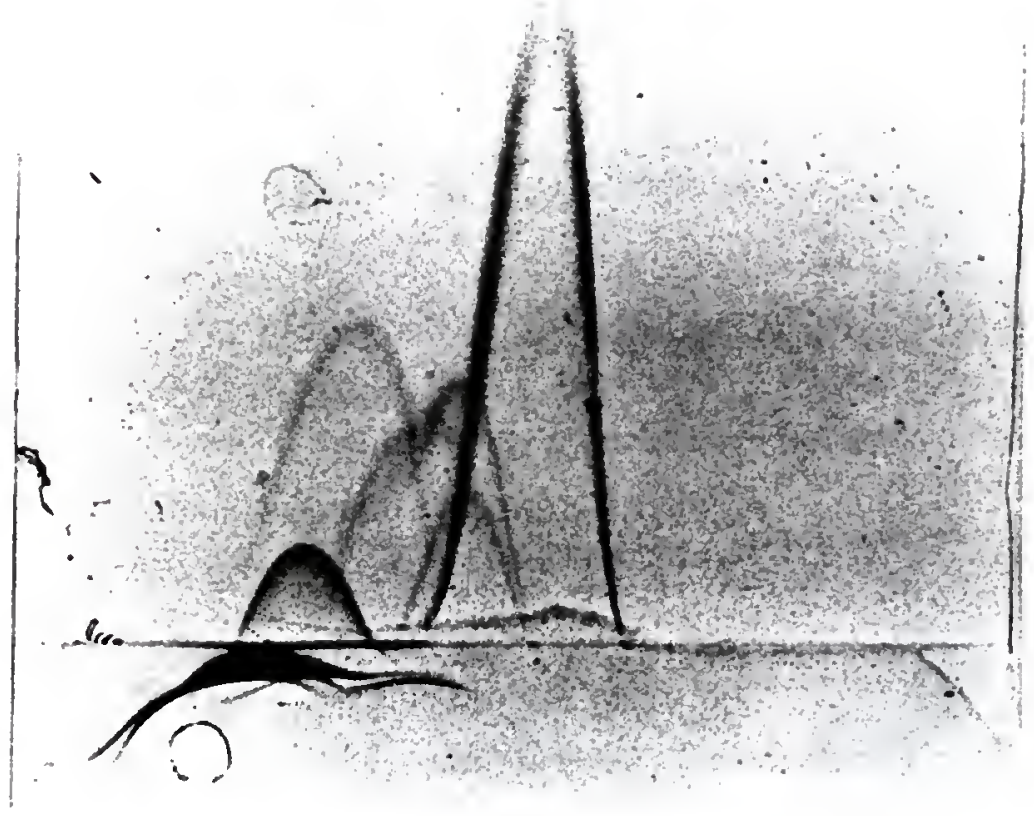

\section{Plasma}

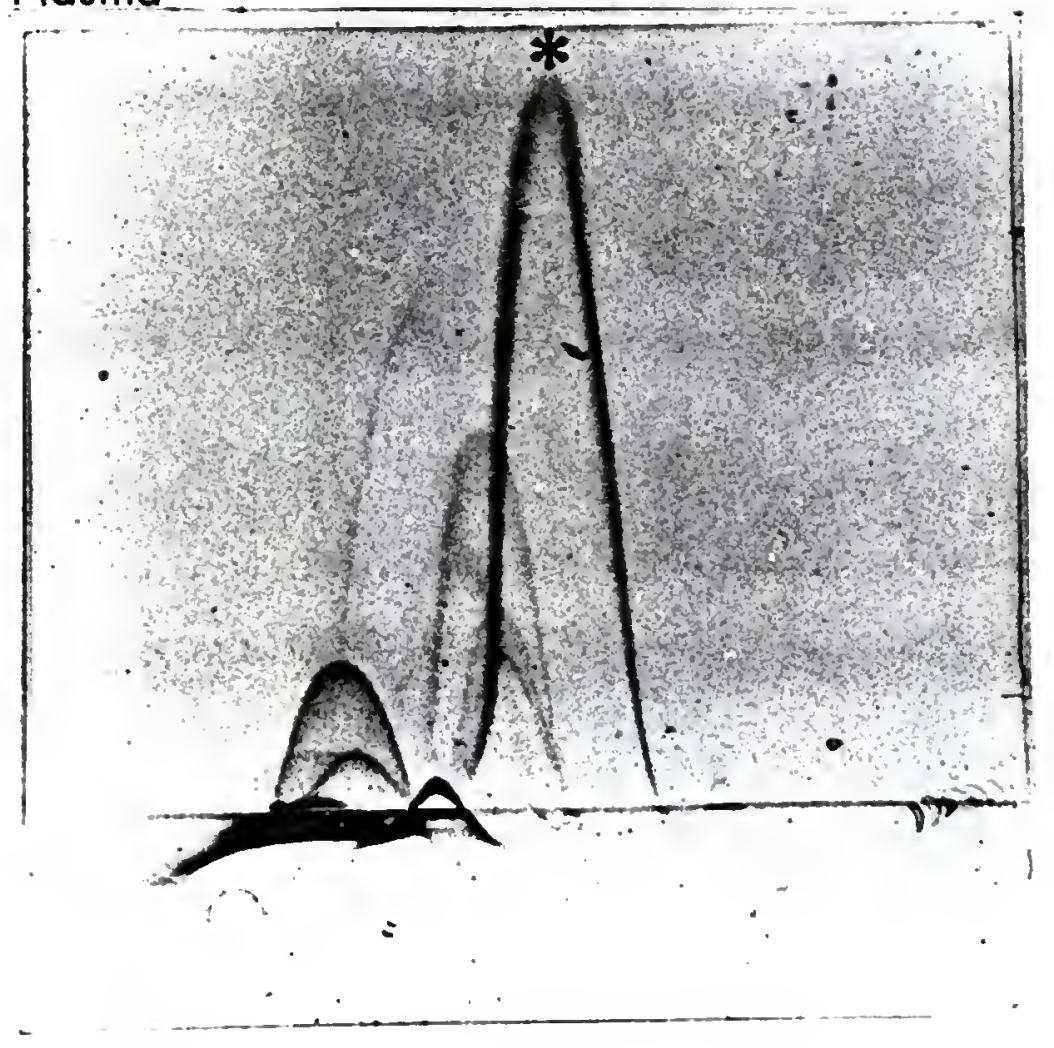


Figure 2.6. DEAE-ion-exchange chromatograms of ammonium-sulfate ( $41 \%$ ) precipitable proteins in UMS (A), bovine serum (B) and bovine colostral whey (C). DEAE (-) proteins (area I) were eluted with $10 \mathrm{mM}$ sodium-phosphate buffer ( $\mathrm{pH} 7.4$ ). Remaining DEAE $(+)$ proteins were eluted by stepwise increases in $\mathrm{NaCl}$ concentration through $0.04 \mathrm{M}$ (area II), $0.08 \mathrm{M}$ (area III), $0.10 \mathrm{M}$ (area IV) and $0.15 \mathrm{M}$ (area V). Absorbance at $280 \mathrm{~nm}$ for each fraction ( $Y$ axis) is expressed relative to peak absorbance, which was assigned an $\mathrm{A}-280_{\mathrm{r}}$ value of 1.0 . Fractionation was performed according to methods of Williams et al. (1975) which showed bovine serum fraction areas I, II, III and $V$ to be enriched in $\operatorname{IgG}_{2}, \operatorname{IgG}_{1}$, IgA and IgM respectively. 


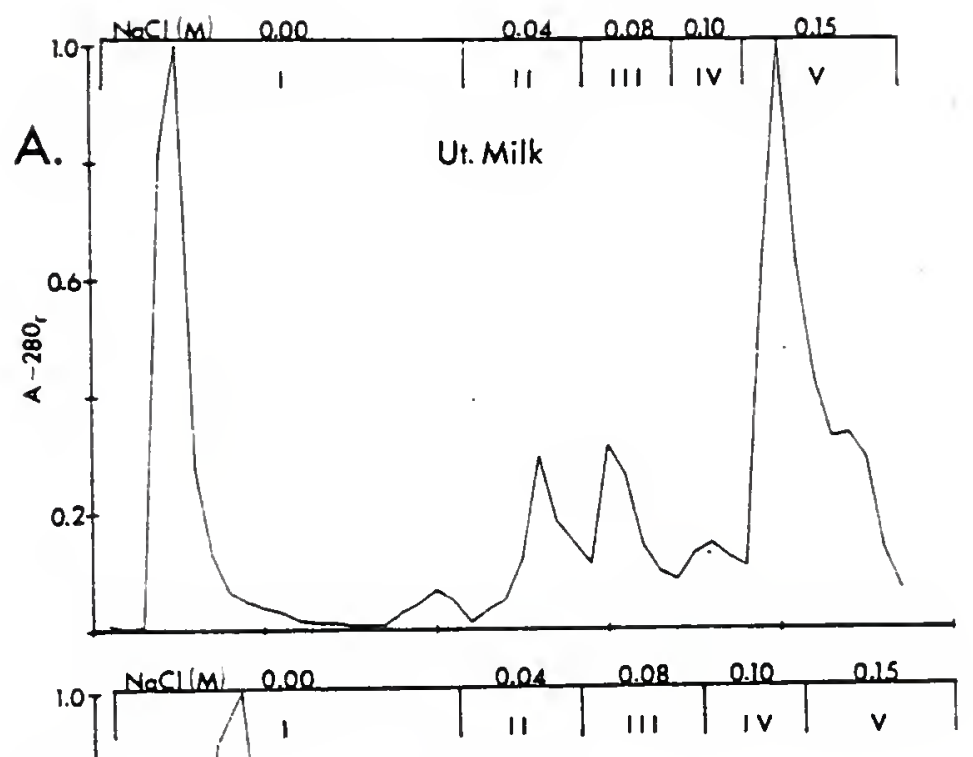

B.

Serum

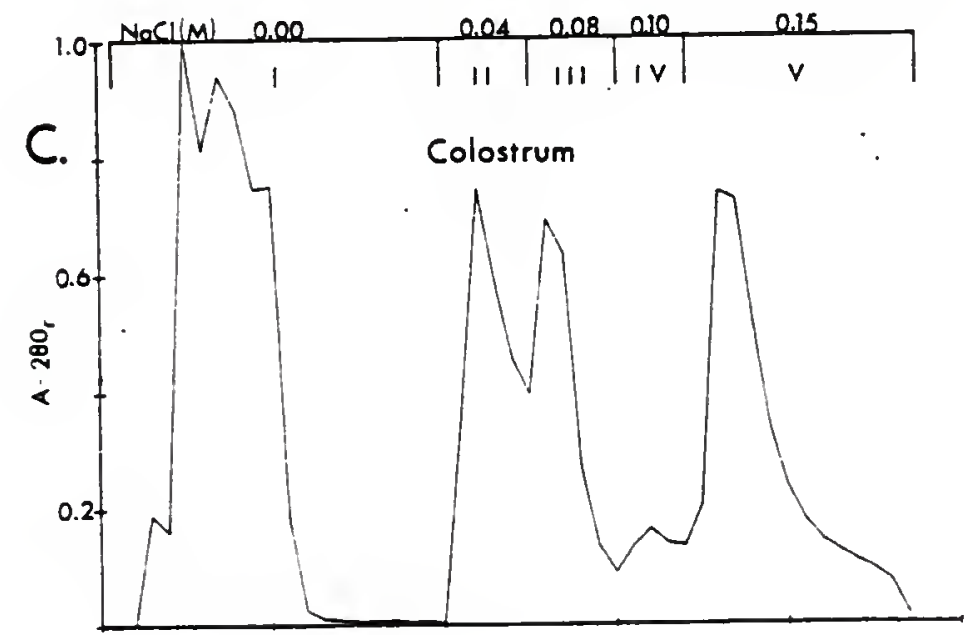


fractions I, II, III and V, obtained from bovine serum by identical methods, were enriched in immunoglobulins ( $I g) \operatorname{IgG}_{2}, \operatorname{Ig} G_{1}, \operatorname{IgA}$ and $\operatorname{Ig} M$, respectively. Present data (Figure 2.6) suggested that UMS contained significant proportions of Ig in all classes described by Williams et a1. (1975). Double immunodiffusion (Ouchterlony, 1958) revealed precipitin lines of identity when UMS fractions I, II and III (Figure 2.6A) were tested against rabbit antibovine IgG and when UMS fractions III and V (Figure $2.6 \mathrm{~A}$ ) were tested against rabbit anti-bovine IgA and IgM, respectively.

Immunoglobulins were immunochemically identified in whole UMS by C-IEP (Figure 2.7). Whole UMS (200 $\mathrm{hg}$ total protein) was subjected to C-IEP with goat anti-bovine whole serum to intensify the postalbumin area shown in panel A (Figure 2.7). Precipitin line rockets in panel B (Figure 2.7) illustrate positive immunochemical response between UMS proteins and rabbit anti-bovine IgG. Presence of three separate rockets indicates electrophoretically distinguishable antigens with immunochemical identities and, based on earlier double immunodiffusion results, reveal both IgG (1 and 2; Williams et al., 1975) and IgA. The single rocket in panel C (Figure 2.7) illustrates the electrophoretic mobility of a UMS antigen which reacted positively against rabbit anti-bovine IgA. Data suggest that IgG and IgA as well as IgM may be among the UMS antigens recognized by goat anti-bovine whole serum in the postalbumin area (Figure 2.7A).

\section{$\underline{\text { Discussion }}$}

In the present study it was demonstrated that unilateral ovariectomy and ligation of the ipsilateral uterine horn permitted establishment of unilateral pregnancy in 12 of 15 cattle. A similar 
Figure 2.7. Crossed-immunoelectrophoresis (C-IEP) revealing serum- and immunoglobulin-identical components of day 270 bovine UMS. (A) Whole UMS (200 $\mu \mathrm{g}$ total protein) subjected to C-IEP with goat anti-bovine whole serum (Lot No. 28475, U.S. Biochemical Corp., Cleveland, OH; final dilution 1:75). (B) positive immunochemical response between UMS proteins and rabbit anti-bovine IgG (Lot No. 31, Control No. R047; Miles Research Products, Elkhart, IN; final dilution 1:75). Presence of three separate rockets indicates electrophoretically distinguishable, immunochemically identical antigens which may include IgG ( 1 and 2 ; Williams et a1., 1975) and IgA. (C) Positive immunochemical response and characteristic position of a UMS antigen which reacted positively with rabbit anti-bovine IgA (Lot No. 23, Control No. R054; Miles Research Products, Elkhart, IN; final dilution 1:90). In each case (A, B, and $C$ ) whole, unfractionated UMS protein was electrophoresed. Separations were performed toward the annode in $1 \%$ agarose $(\mathrm{w} / \mathrm{v})$ in barbital-tris-glycine buffer ( $\mathrm{pH} 8.68)$. 
A

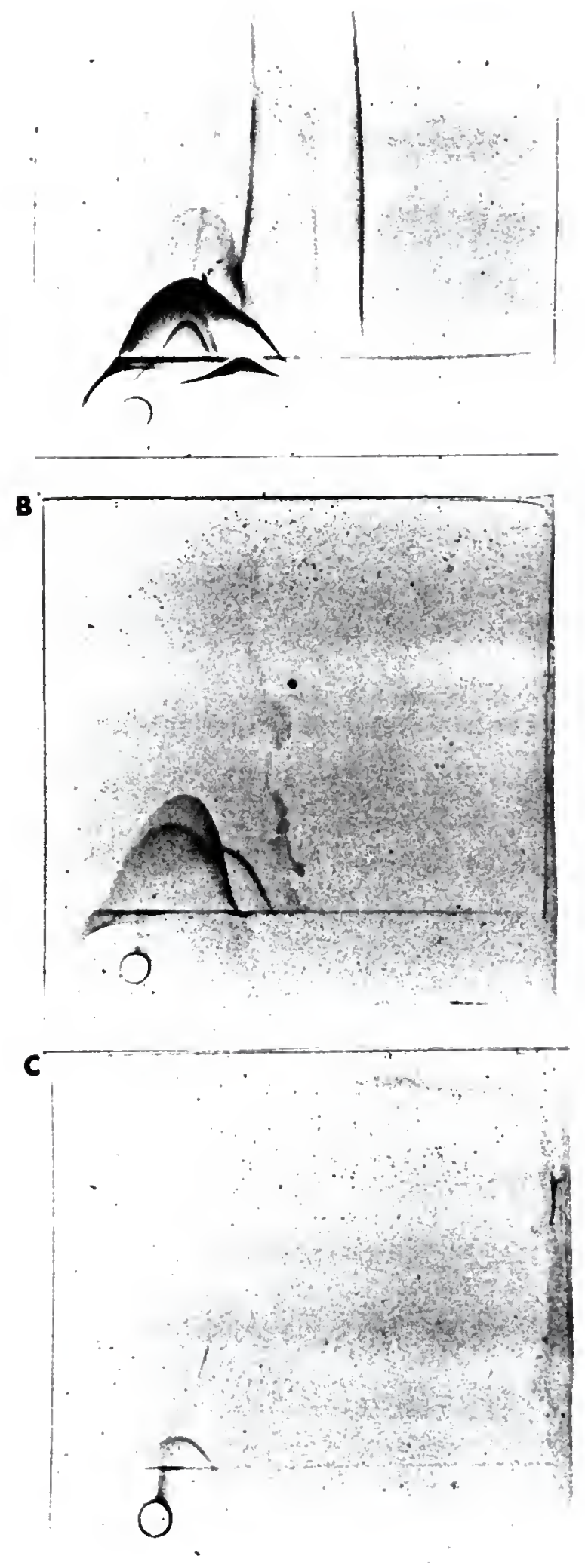


preparation was described for sheep by Bazer and coworkers (1979a). Fetal weights and placental weights and fluid volumes measured in nine cattle on day 270 (Table 2.1) were consistent with similar values reported for cattle by Eley et al. (1978), Ferrell et al. (1976) and Winters et a1. (1942).

In cattle, the point at which significant retardation of phenotypic expression of the conceptus (embryo and extraembryonic membranes) occurs as a consequence of limitations in the maternal component might be defined as uterine capacity. In the present study, confinement of the bovine conceptus largely to one uterine horn was not sufficient to compromise uterine capacity as reflected by physical or endocrinological responses measured. It was interesting, however, that three of 12 unilaterally pregnant cattle delivered calves, live at birth, prior to day 270. While every attempt was made to standardize placement of uterine ligatures, it is conceivable that fetal-placental confinement in three cows which delivered prematurely was sufficient to compromise uterine capacity. Unilateral pregnancy can be established in both cattle (present study) and sheep (Bazer et al., 1979a). These preparations present intriguing models for study of uterine capacity in animals which are generally monotocous and possess a cotyledonary placenta.

Development and general morphology of the bovine placenta was the subject of numerous investigations (Bjorkman, 1968a,b; Greenstein et al., 1958; Hafez and Rajakoski, 1964; King et al., 1980, 1981; Kingman, 1948). In the present study, morphology of placentae and placental attachments (placentomes) appeared normal. Alexander and Williams (1966) suggested that $\mathrm{P}_{4}$ was required for normal caruncular development in sheep. Bovine uterine arterial progesterone concentrations were shown to increase 
systematically during gestation (Ferrell and Ford, 1980). In the present study $\mathrm{P}_{4}$ was detected in UMS (Table 2.2). Despite the apparent potential endocrine support for maternal caruncular development, as evidenced by detection of both free estrogen and $\mathrm{P}_{4}$ in UMS, caruncles in the ligated uterine horn of unilaterally pregnant cattle were not developed significantly and were perhaps only slightly more prominent than those normally seen in the nonpregnant bovine uterus. These observations support the concept that a specific trophoblastic/chorionic stimulus and/or chorion-endometrial interaction is required for normal placentome development.

Observations in unilaterally pregnant sheep indicated that fluid accumulated in the ligated uterine horn (Bazer et al., 1979a) or uterine pouch (Harrison et a1., 1976) during gestation. Moffatt and coworkers (1980), following procedures of Bazer et al. (1979a), found ovine uterine fluid within the ligated uterine horn as early as day 30 of pregnancy. Copious amounts of fluid did not appear, however, until after day 100 (Bazer et al., 1979a).

In the present study, UM was palpably detectable by day 166 and, in one case, as much as $635 \mathrm{ml}$ accumulated in the ligated uterine horn by day 270 (Table 2.1). This period of rapid accumulation of bovine UM (> day 166) corresponds well developmentally with a similar period described above for sheep (Bazer et al., 1979a). In cattle, this period of gestation was preceeded by a rapid increase in uterine arterial and venous estrogen concentrations followed by increases in uterine blood flow (Ferrell and Ford, 1980) and increased net nitrogen accretion by the gravid uterus (Ferrell and Ford, 1980; Ferrell et a1., 1976). This period of gestation also corresponds to the time of maximal fetal 
growth rate (Eley et al., 1978; Winters et al., 1942) and may be associated with increasing circulating levels of bovine placental lactogen (Bolander and Fellows, 1976). While no causal relationships may be determined from the present study, observations agree with those of Bazer et al. (1979a) and support the concept that circulating agents of gonadal and/or placental origin may be important in the integration of uterine secretory activity.

Sustenance of the conceptus during gestation depends largely upon nutrients supplied by uterine endometrial epithelium, whereas sustenance of the neonate, postpartum, depends upon nutrients supplied by mammary gland epithelium. Transfer of function between these two tissues must be coordinated to insure maximal reproductive success. As reviewed above, bovine UM began to accumulate in significant quantities during a period of gestation associated with dynamic changes in uterine hemodynamics, fetal growth rate and maternal endocrine status. Onset of accumulation of bovine UM in the ligated uterine horn after day 166 could well reflect responses of a secretory epithelium to circulating agents present during late gestation. Additionally, however, this phenomenon may reflect a more general response of maternal secretory epithelia associated with integration of early events necessary not only to insure maximal nutrient support to a growing conceptus in utero, but also to insure smooth transition of nutritional support from uterus to mammary gland at birth.

Concentrations of peripheral plasma steroids presented in Table 2.2 are similar to those reported by Collier et al. (1982), Erb et al. (1968), Eley et al. (1981a,b) and Robertson and King (1979) for circulating levels of plasma steroids in late pregnant cattle. Overall mean 
concentrations of unconjugated estrogens $\left(E_{1}\right.$ and $\left.E_{2}\right)$ in UMS and plasma were not different significantly, while $\mathrm{E}_{1} \mathrm{SO}_{4}$ and $\mathrm{P}_{4}$ concentrations were nearly 30 and ten times higher respectively in plasma than UMS (Table 2.2).

Several lines of evidence suggest that the bovine placentome is the major site of estrogen synthesis in late pregnancy (Thatcher et al., 1982). Hoffman and coworkers (1976, 1979) suggested that fetal and maternal components of the placentome secreted estrogenic products into their respective fluid compartments. In this respect, steroids found in bovine UMS might be expected to reflect circulating plasma steroid profiles since no fetal membranes were present in the ligated uterine horn. Differences in steroid concentrations between UMS and plasma could reflect metabolism of steroids by uterine tissues.

Eley (1980) observed that $\mathrm{P}_{4}$ (pregn-4-ene-3, 20 dione) was not converted to estrogens in vitro by bovine endometrium but was shown to be converted to predominant1y $5 \alpha$-pregnane base steroids (Knickerbocker et al., 1980; Eley, 1980). Estrone sulfate was luteolytic when chronically administered to cyclic beef heifers suggesting the potential of sulfatase activity in bovine reproductive tissues (Eley et al., 1979b). Endometrial sulfatase activity was shown to increase during late gestation in both pigs and sheep (Dwyer and Robertson, 1979). From these studies it seems unlikely that UMS concentrations of free estrogens were affected by uterine metabolism of $\mathrm{P}_{4}$. If present, deconjugation of $\mathrm{E}_{1} \mathrm{SO}_{4}$ by a uterine sulfatase could account for $\mathrm{E}_{1} \mathrm{SO}_{4}$ concentration differences between UMS and plasma (Table 2.2) and might account, in part, for similar levels of free estrogens in the two fluid pools. Similarly, endometrial conversion of $\mathrm{P}_{4}$ to $5 \alpha$-pregnanes would reduce 
UMS $\mathrm{P}_{4}$ concentrations. In fact $\mathrm{P}_{4}$ in UMS was indeed less than in plasma. Alternatively, steroids might be in simple equilibrium between UM and plasma. Heap et al. (1971) observed that ratios of $\mathrm{P}_{4}$ :E affected their relative solubilities in aqueous solutions and liposomes. Lipid solubility of $E_{2}$ was enhanced by $\mathrm{P}_{4}$, whereas $\mathrm{P}_{4}$ solubility was retarded by $\mathrm{E}_{2}$.

Prostaglandin F concentrations and content in day 270 bovine UMS (Table 2.4) agreed with values reported for similar uterine fluids obtained from sheep (Bazer et al., 1979a; Harrison et al., 1972, 1976). However, these values were several hundred to several thousand-fold higher than those reported for uterine flushings collected either in vivo or post-mortem from cyclic or early pregnant cattle (Bartol et al., $1981 \mathrm{a}, \mathrm{b})$. Concentrations of PGF in day 270 UMS were several hundredfold higher than peak values reported by Knickerbocker et al. (1982) in uterine venous plasma from diestrus cattle $6 \mathrm{~h}$ following administration of $\mathrm{E}_{2}$ (3 mg, I.V.). The presence of a concentrated pool of PGF in UM supports the idea that specific endocrine conditions may permit intrauterine sequestering of prostaglandins (Bazer et al., 1979a; Bazer and Thatcher, 1977). Observations suggest the possibility of an active mechanism associated with bovine uterine accumulation of PGF. A mechanism for active transport of PGF in rabbit vaginal tissue was described by Bito and Spellane (1974).

Overall, total protein concentrations and content in UMS (Table 2.4) were equal to and generally greater than values reported for ovine uterine fluids obtained in a similar manner (Bazer et al., 1979a; Harrison et al., 1976) and bovine uterine fluid obtained following chronic $\mathrm{P}_{4}$ therapy (Dixon and Gibbons, 1979). Uterine milk protein content greatly 
exceeded those reported for bovine uterine flushings collected either in vivo (Bartol et al., 1981b; Schultz et al., 1971) or post-mortem (Bartol et al., 1981a,b; Roberts and Parker, 1974a, 1976; 01ds and Van Demark, 1957a,b) and establish bovine UM as a rich source of such material.

Glucose was shown to be an important metabolite in uterine as well as fetal and placental tissues in cattle, sheep, pigs and horses (Battaglia and Meschia, 1978; Silver and Comline, 1975, 1976). Mean uterine glucose uptake during late gestation in cattle was reported as $9.0 \pm 0.8 \mathrm{mg} / \mathrm{kg} / \mathrm{min}$. with total utero-placental tissue uptake of 14.7 $\mathrm{mg} / \mathrm{kg} / \mathrm{min}$. (Silver and, Comline, 1975). Glucose concentrations in bovine uterine arterial and venous plasma were relatively constant throughout gestation with no significant changes in uterine glucose $A-V$ difference between days 31 and 258 (Ferrell and Ford, 1980). The observed increase in uterine blood flow noted between gestational days 92 and 199, however, (Ferrell and Ford, 1980) suggested potential for increased utero-placental metabolism of glucose as gestation proceeded.

In the present study mean ( \pm SEM) day 270 UMS glucose concentration $(0.127 \pm 0.004 \mathrm{mg} / \mathrm{ml} ;$ Table 2.4$)$ was approximately five times lower than similar values reported for uterine arterial or peripheral plasma from cattle during late gestation (Ferre11 and Ford, 1980; Grigsby et al., 1974), supporting the possibility of uterine metabolism of glucose. Bovine UMS glucose concentrations were similar to those reported for ovine uterine fluid (Bazer et al., 1979a). Also as reported for sheep (Bazer et al., 1979a), fructose was not detected in bovine UMS (Table 2.4) although it appears as the principle carbohydrate of fetal blood in cattle, sheep, pigs and horses (Battaglia and Meschia, 1978). This further supports the nonplacental or conceptus source of UM. 
Mean ( \pm SEM) Ca concentration $(28.35 \pm 8.52 \mathrm{mg} \%)$ of day 270 bovine UMS (Table 2.4) was considerably higher than that reported for peripheral plasma $(9.0-10.3 \mathrm{mg} \%)$ or uterine flushings $(0.0-5.3 \mathrm{mg} \%)$ obtained from cyclic cattle (Heap, 1962; Schultz et a1., 1971). As much as $99 \%$ of total UMS Ca was dialyzable (Table 2.4) and likely available as free $\mathrm{Ca}$ in utero. Uterine milk $\mathrm{Ca}$ concentration correlated positively with both UMS protein concentration $(\mathrm{r}=.68, \mathrm{P}<.09)$ and content of PGF $(r=.92, \mathrm{P}<.08)$ suggesting an interrelationship among these UM components. A rise in intracellular Ca concentration is a key feature in the sequence of events referred to by Douglas (1968) as stimulus-secretion coupling. The source of $\mathrm{Ca}$ may be either intracellular or extracellular (Douglas, 1978). Extracellular Ca concentrations are generally higher than intracellular concentrations $\left(10^{-3} \mathrm{M}\right.$ vs. $10^{-7} \mathrm{M}$; Rasmussen and Goodman, 1977). Concentrations of $\mathrm{Ca}$ in UMS (Table 2.4) fell in or slightly above the normal extracellular range. Douglas (1978) observed that in exocrine cells, influx of extracellular Ca could provide an intense stimulus for secretion. It was further observed that such cells became increasingly dependent on extracellular Ca as stimulation was prolonged (Douglas, 1978). The essential role of Ca in activation of phospholipase $A_{2}$, essential for prostagland in synthesis, and accompanying alterations in plasma membrane phospholipid turnover were identified as critical to the chain of events leading to discharge of secretory product (exocytosis; Rubin, 1982). It was noted that agents which increase $C a$ availability would be expected to stimulate prostaglandin synthesis and were associated with increased exocytotic activity (Rubin, 1982). Energy dependent mechanisms associated with intracellular Ca efflux also were associated with regulation 
of permeability of intercellular gap junctions (Rasmussen and Goodman, 1977). Correlations noted above between UMS Ca, PGF and protein may, in this light, reflect the dynamic roles of these substances or their precursors in establishment of this rich fluid pool.

Bovine UMS was enriched in proteins of less than 40,000 $\mathrm{M}_{\mathrm{r}}$ (Figure 2.2). Gel filtration profiles were similar to those reported for equine (Zavy et al., 1979a,b) and bovine (Mil1s, 1975; Roberts and Parker, 1974a) uterine flushings, but did not reveal a major peak eluting in the 60 to $65,000 \mathrm{M}_{\mathrm{r}}$ range reported for ovine uterine fluid (Bazer et al., 1979a). Two dimensiona1-PAGE (Figure 2.3) of UMS proteins revealed the majority of polypeptides less than $40,000 \mathrm{M}_{\mathrm{r}}$ to be basic in nature, migrating on NEPHGE (Figure 2.2B) between $\mathrm{pH} 6.8$ and 8.6. Observations of several investigators indicated that uterinespecific proteins identified either in bovine uterine flushings (Roberts and Parker, 1974a, 1976) or $\mathrm{P}_{4}$ induced bovine uterine fluid (Dixon and Gibbons, 1979) were less than $50,000 \mathrm{M}_{\mathrm{r}}$ and migrated we11 electrophoretically at $\mathrm{pH} 4.5$ or below indicating products of a basic nature. Additionally, major uterine-specific or $\mathrm{P}_{4}$ induced uterine proteins. from the pig, sheep and horse were shown to be basic polypeptides on 2D-PAGE (NEPHGE; Bazer et a1., 1981b). The 2D-PAGE (NEPHGE) profiles of bovine UMS (Figure 2.3B), however, were distinct from those of other domestic species and did not reveal either a uteroferrin-1ike polypeptide, as described both for the pig and mare, or either of the two major polypeptides found in ovine uterine fluid $M_{r} \times 10^{-3}=57$ and 59 , IEP $\simeq 8.4-8.6$; Bazer et al., 1979a, 1981b). Comparison of 2D-PAGE (IEF) profiles of UMS and plasma (Figure 2.4) revealed several polypeptides apparently unique to UMS. One 
group appeared in the 25 to $30,000 \mathrm{M}_{\mathrm{r}}$ range with isoelectric points between 6.6 and 7.3 , consistent with observations cited above. Two other polypeptides (Figure 2.4A, UM1 and UM2) had nearly identical $M_{r}\left(X 10^{-3}\right)$ of 20 to 21 , and approximate isoelectric points of 6.3 and 6.2 , respectively. These polypeptides were nearly identical electrophoretically to those identified in porcine uterine secretions and endometrial explant medium (Basha et al., 1980a,b). Such electrophoretic properties were similar to those expected for retinol and retinoic acid binding proteins (Adams et al., 1981). These progesterone-induceable proteins were identified in uterine secretions of luteal phase gilts and are assumed to be involved in transport of Vitamin-A to the fetal-placental unit (Adams et al., 1981).

As shown in Figures 2.4 and 2.5, a-1arge number of proteins in bovine UMS were physically and immunochemically identical to proteins found in bovine serum. Roberts and Parker (1974a) noted that no more than $2 \%$ of total protein in bovine uterine flushings might be expected to be uterine-specific. The predominance of serum-1ike macromolecules in bovine uterine fluids should not be ignored. Such macromolecules may play important roles in maintenance of intrauterine osmotic or oncotic equilibrium with plasma and lymph and may be involved either specifically or nonspecifically in binding and/or transport of various hormones and nutrients. Bovine serum albumin, identified in this and other studies as a major component of bovine uterine fluid (Bartol et a1., 1981a; Roberts and Parker, 1974a) may, for example, be present in sufficient quantities in extracellular space to significantly alter equilibrium distribution of steroids in cells (Clark and Peck, 1981). The observations of fewer serum-1ike proteins in bovine UMS than plasma 
(Figure 2.5) were consistent with those of Roberts and Parker (1974a) and support the possibility that certain serum components of UMS may arrive through selective transport mechanisms.

Immunochemical identification of IgA, IgG and IgM in bovine UMS (Figures 2.6 and 2.7) was consistent with identification of these macromolecules in reproductive tract secretions of numerous domestic and Iaboratory species as well as in humans (Corbeil et al., 1981; Wira and Sandoe, 1980; Vaerman and Férin, 1974). These macromolecules are thought to participate in the secretory immune system (Vaerman and Férin, 1974) as a first line of defense against bacterial infection. The source of $\mathrm{Ig}$ in genital tract secretions was suggested to be primarily fixed plasma cells which populate the lamina propria of endometrial submucosa and produce specific Ig's (Vaerman and Férin, 1974). Transepithelial transport of dimeric IgA, IgG or pentameric IgM was shown to require J-chain, synthesized by monocytes of the lamina propria (Brandtzaeg and Baklien, 1977), and secretory component (SC), synthesized by epithelial cells (Brandtzaeg and Baklien, 1977; Vaerman and Férin, 1974). Halsey et al. (1980) noted that even transport of circulating Ig's into secretory fluids was mediated by SC availability at the epithelial cell border. Epithelial synthesis of SC was shown to require estrogens (Wira and Sandoe, 1980; Sullivan and Wira, 1981). Uterine fluid content of Ig's would be affected, therefore, by relative local steroid levels (Wira and Sandoe, 1980; Vaerman and Férin, 1974). Though no specific roles other than those associated with local immune response have been demonstrated for reproductive tract Ig's, . Ngah and coworkers (1982) recently reported bovine IgM to be a major factor contributing to serum-induced head-to-head agglutination in bovine spermatozoa. 
As previously observed, study of normal bovine uterine luminal fluids has been hampered by availability of only small amounts of material for analysis. In this respect, fluids suggested to contain larger amounts of uterine-specific components, including allantoic fluid (Roberts and Parker, 1976) and $\mathrm{P}_{4}$ induced uterine fluid (Dixon and Gibbons, 1979), may provide reasonable alternative sources for study. From the present study, however, it is apparent that copious amounts of protein-rich UM can be obtained from unilaterally pregnant cattle after days 166 to 180 of gestation. Components of this fluid are likely representative of substances which would appear in utero under normal physiological and endocrinological conditions of late pregnancy. Constituents of bovine UM appeared to include substances of serum origin as well as those either synthesized and secreted or possibly metabolized by uterine tissue, and were not directly contaminated by products of the fetal-placental unit. Evaluation of polypeptides produced by bovine endometrium using 2D-PAGE and fluorography (Horst and Roberts, 1979; Laskey and Mills, 1975) would reveal those macromolecular components contributed to UM specifically by endometrial synthesis and release. Developmentally, the pattern of bovine IM accumulation was similar to that described for sheep (Bazer et al., 1979a; Harrison et a1., 1976) suggesting common inductive mechanisms. Qualitatively, however, major polypeptide components of bovine UM were unique and did not reflect patterns seen in either porcine or ovine uterine fluids. In addition to providing a rich source of uterine fluid, unilaterally pregnant cattle present an intriguing model for study of bovine uterine capacity, placental development and epithelial response to physiological conditions of pregnancy. 
CHAPTER III

CHARACTERIZATION OF BOVINE ENDOMETRIAL PROTEINS

\section{$\underline{\text { Introduction }}$}

Recently, Mossman (1980) observed that, in placental mammals, the burden of sustenance of the conceptus from the early morula or blastocyst stage until parturition is borne largely by the uterine endometrium. This is especially true of domestic farm species such as the cow, sheep, horse and pig which possess chorioallantoic epitheliochorial placentae (Steven and Morriss, 1975; Wathes and Wooding, 1980) that do not invade or erode maternal endometrium, and in which ectopic (extrauterine) pregnancy does not occur. In these species, the uterus might be considered a preferred site for conceptus development. In this respect, components of the intrauterine environment of these species must serve, collectively, as a unique, permissive, non-hostile, complete medium in which the conceptus may develop.

What little is known of protein components of the bovine intrauterine environment has come primarily from analyses of uterine flushings (Bartol et al., 1981a; Roberts and Parker, 1974a,b, 1976), progesterone-induced uterine fluid (Dixon and Gibbons, 1979) and uterine milk obtained from unilaterally pregnant cattle (ChapterII). In addition, some studies dealt with biochemical and/or immunochemical analyses of bovine endometrial tissue homogenates (Laster, 1977) or explant medium following incubation of bovine uterine tissues with radiolabelled amino acids (Wathes, 1980). Consistent with observations in 
other domestic species (Bazer et a1., 1981b), these studies indicated that, while serum or serum-like proteins comprise a major proportion of the total intrauterine protein milieu, a small but important proportion of these proteins appear to be uterine-specific.

The array of polypeptides contributed to the bovine uterine environment specifically by endometrial tissue has not been characterized using high resolution techniques. Chromatographic and electrophoretic techniques including two dimensional polyacrylamide gel electrophoresis (2D-PAGE; Horst and Roberts, 1979; Horst et a1., 1980) and fluorography (Laskey and Mills, 1975) have permitted identification and characterization of both major and minor uterine-specific polypeptides produced in vitro by both porcine and ovine endometrial tissues (Bazer et a1., 1981b; Moffatt et a1., 1980; Roberts and Bazer, 1980).

It was the purpose of this study to characterize proteins (polypeptides) produced in vitro by bovine endometrial tissue obtained from pregnant and nonpregnant cattle.

\section{Materials and Methods}

\section{$\underline{\text { Materials }}$}

Tissue culture supplies were purchased from Grand Island Biological Co., Grand Island, NY; L-4,5- ${ }^{3} \mathrm{H}$-leucine ( ${ }^{3} \mathrm{H}-\mathrm{Leu} ; \mathrm{Sp}$. act. $\left.55 \mathrm{Ci} / \mathrm{mmol}\right)$ L-1- ${ }^{14} \mathrm{C}-1$ eucine $\left({ }^{14} \mathrm{C}\right.$-Leu; $\mathrm{Sp}$. act. $\left.50 \mathrm{mCi} / \mathrm{mmol}\right)$ and $\mathrm{D}-6-{ }^{3} \mathrm{H}-\mathrm{gluco}-$ samine hydrochloride ( ${ }^{3} \mathrm{H}-\mathrm{Glc}$; Sp. act. 10-25 Ci/mmol) were obtained from the Radiochemical Centre, Amersham, England; acrylamide, recrystalized according to procedures described by Loening (1967), N, N, $N^{\prime}, N^{\prime}$-tetramethylenediamine and X-Omat $R P$ film XRP-1 were products of 
Eastman Kodak, Rochester, NY; sodium dodecyl sulfate (SDS) and Nonidet P-40 were from BDH chemicals Ltd., Poole, England; N, N'-diallyltartardiamide and Coomassie brilliant blue R-250 were from Bio-Rad Laboratories, Richmond, CA; ampholines were from LKB, Uppsala, Sweden; urea was from Pierce Chemicals, Rockford, IL; insulin was from Eli Lilly; Lilly Research Laboratories, Indianapolis, IN; amino acids, dithiothreitol, protein standards, 2-mercaptoethanol, trishydroxymethylaminomethane (tris), glycine, glucose, sodium chloride ( $\mathrm{NaCl}$ ) and agarose were from Sigma Chemical Co., St. Louis, MO; diethylaminoethyl (DE-52; DEAE) cellulose and carboxymethyl cellulose (CM-52; CMS) were products of Whatman Inc., Clifton, NJ; Sephacryl S-200 and Sepharose CL-6B were purchased from Pharmacia Fine Chemicals, Piscataway, NJ. All inorganic chemicals were reagent grade or better.

\section{Preparation of Medium}

Eagle's minimum essential medium (MEM) was prepared according to procedures of Basha et a1. (1979). Content of L-leucine was limited to $5.2 \mu \mathrm{g} / \mathrm{ml}\left(1 / 10\right.$ normal) to enhance uptake of ${ }^{3}$ H-Leu added to endometrial explants. Medium was supplemented with penicillin (200 units/m1), streptomycin $(200 \mu \mathrm{g} / \mathrm{m} 1)$, fungizone $(0.5 \mu \mathrm{g} / \mathrm{m} 1)$, insulin $(0.2 \mathrm{units} / \mathrm{m} 1)$, nonessential amino acids $(1 \%, \mathrm{v} / \mathrm{v})$ and glucose $(5 \mathrm{mg} / \mathrm{ml})$. This medium was filter sterilized $(0.22 \mu)$ and stored at $4 \mathrm{C}$ until used.

\section{$\underline{\text { Anima1s }}$}

Twenty-three cross-bred beef heifers were observed twice daily for behavioral estrus and bred by natural service on the day of standing estrus (day 0). Cattle were then assigned to be slaughtered on day 16, 19, 22 or 24 post-mating. At slaughter each reproductive tract was 
excised within $15 \mathrm{~min}$. of exsanguination, trimmed of excess connective tissue, the ovary containing luteal tissue noted, the cervix clamped, and the tract transported to the laboratory on ice. Contents of each uterus were flushed out with 20 to $80 \mathrm{ml}$ of sterile isotonic saline under a sterile laminar flow hood according to procedures similar to those described by Bazer et al. (1978). Pregnancy was confirmed by identification of conceptus tissues in the saline flush which, if present, were transferred immediately to petri dishes containing $15 \mathrm{ml}$ sterile MEM and used in a separate study (Chapter IV). Reproductive tracts not containing conceptus tissues were designated nonpregnant. Distribution of early pregnant and nonpregnant cattle is shown in Table 3.1. Additionally, uterine tissues were obtained from one cyclic (nonbred) cow on day 4, one pregnant cow on day 69 of gestation, and from both pregnant and ligated (nonpregnant) uterine horns of three unilaterally pregnant cattle on day 270 of gestation (Chapter II).

\section{Preparation of Endometrial Explants}

Uteri, obtained as described above, were opened along their antimesometrial border to expose the uterine mucosa. Endometrial tissue was then dissected carefully away from underlying muscular and connective tissues using sterile forceps and number 10 scalpel blades. Tissue was recovered from both uterine horns and placed immediately into sterile MEM. Aliquots of endometrial tissue from each uterine horn were sliced into small pieces (approximately $2-4 \mathrm{~mm}^{3}$ ) using number 10 scalpel blades, blotted quickly on sterile gauze, weighed and approximately $500 \mathrm{mg}$ of wet tissue placed into individual petri dishes containing $15 \mathrm{ml}$ of sterile MEM. Between 5 and $50 \mu \mathrm{Ci}$ of ${ }^{3} \mathrm{H}$-Leu was then added to each explant dish. Explants of endometrium from 
Table 3.1. Distribution of cattle.

\begin{tabular}{|c|c|c|c|}
\hline \multirow{2}{*}{ Day Post-estrus ${ }^{a}$} & & \multicolumn{2}{|c|}{ No. Cattle } \\
\hline & & Pregnant & Nonpregnant \\
\hline 16 & & 4 & 4 \\
\hline 19 & & 6 & 2 \\
\hline 22 & & 3 & - \\
\hline 24 & & 4 & - \\
\hline & total: & 17 & 6 \\
\hline
\end{tabular}

$a_{\text {estrus }}=$ day 0 . 
unilaterally pregnant cattle received $100 \mu \mathrm{Ci}{ }^{14} \mathrm{C}$-Leu and $50 \mu \mathrm{Ci}{ }^{3} \mathrm{H}-\mathrm{G} 1 \mathrm{c}$. Procedures were carried out under a sterile laminar flow hood.

Explants, prepared as described, were placed into a controlled atmosphere chamber (Bellco Biological Glassware, Vineland, NJ), the chamber flooded for $2-3$ min. with a gas mixture consisting of $45 \% 0_{2}$ : $50 \% \mathrm{~N}_{2}: 5 \% \mathrm{CO}_{2}(\mathrm{v} / \mathrm{v})$ and tissues incubated on a rocking platform (Bellco Biological Glassware, Vineland, $\mathrm{NJ}$ ) at $6 \mathrm{cycles} / \mathrm{min}$. and $37 \mathrm{C}$ for $24 \mathrm{~h}$. This procedure is essentially the same as that described by Basha et al. (1979, 1980a) for explant culture of porcine endometrium. The protocol insures that tissue will be exposed alternately to MEM and the gaseous atmosphere. This technique was used successfully in several different tissue explant systems (Trump et al., 1980). Lewis and coworkers (1982) successfully employed an identical system to study in vitro metabolism of arachidonic acid by bovine endometrium. This system also was used to study synthesis and release of proteins in vitro by ovine endometrium (Moffatt et al., 1980) and bovine fetal cotyledonary tissue (Kensinger et al., 1982), as well as, ovine and porcine, peri-attachment conceptuses (Godkin et al., 1982a, b).

At the end of the incubation period tissue and medium were separated by centrifugation at $4 \mathrm{C}$ and $20,000 \mathrm{~g}$ for $20 \mathrm{~min}$. Medium (supernatant) was dialyzed extensively against several thousand volumes of $10 \mathrm{mM}$ tris-HCL buffer, $\mathrm{pH} 8.2$ in Spectrapor 1 dialysis tubing $\left(\mathrm{M}_{\mathrm{r}} \times 10^{-3}\right.$ cut-off $\simeq 6-8000$; Spectrum Medical Industries, Los Angeles, CA) . Comparison of content of radioactivity pre- and post-dialysis permitted calculation of percentage of total DPM radiolabelled amino acid added that was retained as nondialyzable material. Tissue and medium samples were stored in separate glass vials at $-20 \mathrm{C}$ until analyzed. 


\section{Synthesis and Release of Protein}

To determine viability of the explant system for study of in vitro production and release of polypeptides by bovine endometrium, 12 endometrial explant dishes were prepared from a single luteal phase bovine uterus as described above. Each explant contained approximately $500 \mathrm{mg}$ of endometrial tissue $(\overline{\mathrm{X}} \pm \mathrm{SEM}=498 \pm 5.30 \mathrm{mg}$ wet weight; $\mathrm{n}=12)$ and received $10 \mu \mathrm{Ci}{ }^{3} \mathrm{H}-\mathrm{Leu}$. Sample aliquots of medium $(225 \mu 1)$ were taken under aseptic conditions at $12 \mathrm{~h}$ intervals for $48 \mathrm{~h}(0,12,24,36$ and $48 \mathrm{~h}$ ) when the incubation was terminated. Sample aliquots of medium were mixed with distilled water $(1: 9.5, \mathrm{v} / \mathrm{v})$ and dialyzed extensively against $10 \mathrm{mM}$ tris-HCL buffer, $\mathrm{pH} 8.2$ as described above. Percent retention of ${ }^{3}$ H-Leu as nondialyzable product as well as total DPM ${ }^{3} \mathrm{H}$-Leu/ml of medium post-dialysis were determined for each explant at each time period.

\section{Gel Filtration Chromatography}

Aliquots of dialyzed endometrial explant medium were subjected to gel filtration chromatography on Sephacryl S-200 and selected S-200 void volume (Vo) fractions applied to Sepharose CL-6B. Gel filtration was conducted at $4 \mathrm{C}$ in $90 \times 1.5 \mathrm{~cm}$ glass columns and $10 \mathrm{mM}$ tris-HCL buffer, $\mathrm{pH} 8.2$ containing $0.33 \mathrm{M} \mathrm{NaCl}$. The $\mathrm{K}_{\text {av }}$ for each peak of nondialyzable radioactivity was calculated as described by Reiland (1971), and compared with $\mathrm{K}_{\mathrm{av}}$ values obtained for protein standards aldolase $\mathrm{M}_{\mathrm{r}} \simeq$ $158,000)$, bovine serum albumin $\left(B S A ; M_{r} \simeq 66,000\right)$, ovalbumin $\left(M_{r} \simeq\right.$ $45,000)$ and ribonuclease $A\left(M_{r} \simeq 13,700\right)$ for $\mathrm{S}-200$; and porcine IgM $\left(M_{r} \simeq 900,000\right)$, thyroglobulin $\left(M_{r} \simeq 669,000\right)$, ferritin $\left(M_{r} \simeq 440,000\right)$, catalase $\left(M_{r} \simeq 232,000\right)$ and $B S A\left(M_{r} \simeq 66,000\right)$ for $C L-6 B$. Void volumes of both columns were determined using Blue dextran $\left(M_{r} \simeq 2 \times 10^{6}\right.$; 
Pharmacia Fine Chemicals, Uppsala, Sweden). Elution profiles were generated by determining content of radioactivity in $100 \mu 1$ aliquots of each effluent fraction (Beckman LS-8000 Liquid scintillation spectrometer; Beckman, Palo Alto, CA). Absorbance at $280 \mathrm{nM}$ or, following a Lowry protein assay reaction (Lowry et al., 1951), at $750 \mathrm{nM}$ also was determined for an aliquot of each fraction (Model 35 Spectrophotometer; Beckman, Palo Alto, $\mathrm{CA}$ ).

\section{Ion Exchange Chromatography}

Materials retained in endometrial explant medium post-dialysis which were not subjected to gel filtration or electrophoresis (dialyzed, unfractionated products) were pooled by day post-estrus (pregnancy, days 16, 19, 22 and 24; nonpregnant, days 16 and 19) and adsorbed onto a $5 \times 1.5 \mathrm{~cm}$ carboxymethyl cellulose (CMC) column equilibrated at 4C in $10 \mathrm{mM}$ tris-HCL buffer, $\mathrm{pH}$ 8.2. Proteins which did not bind to CMC (CMC-) were eluted with a thorough wash of equilibration buffer. Bound proteins $(\mathrm{CMC}+)$ were eluted with a $150 \mathrm{ml}$ linear salt gradient $(0.0$ $0.5 \mathrm{M} \mathrm{NaC} 1)$. Fractions $(2.6 \mathrm{ml}$ ) were collected throughout the elution process. Content of radioactivity was determined for an aliquot $(100 \mu 1)$ of each effluent fraction in order to generate elution profiles. Proteins eluting in the CMC (-) peak were adsorbed onto a $10 \times 1.5 \mathrm{~cm}$ DEAE cellulose column equilibrated as described above for CMC. Elution of DEAE (+) proteins was accomplished with a $200 \mathrm{ml}$ linear salt gradient $(0.0-0.5 \mathrm{M} \mathrm{NaC1})$. Effluent fractions were collected and elution profiles generated as described for CMC.

Two Dimensional Polyacrylamide Gel Electrophoresis (2D-PAGE) and Fluorography

Aliquots of unfractionated, dialyzed explant medium were lyophilized and individual dried samples dissolved in a volume of $5 \mathrm{mM} \mathrm{K}_{2} \mathrm{CO}_{3}$, 
containing $9.4 \mathrm{M}$ urea, $2 \%(\mathrm{v} / \mathrm{v})$ Nonidet $\mathrm{P}-40$ and $0.5 \%(\mathrm{w} / \mathrm{v})$ dithiothreitol, sufficient to allow 100 to $500 \mu \mathrm{g}$ total protein, or 50,000 to $150,000 \mathrm{cpm}$ nondialyzable radioactivity to be loaded onto each gel in a total volume of not more than $150 \mu 1$. Endometrial tissue to be examined by 2D-PAGE was suspended in $0.5-1.0 \mathrm{ml}$ of $5 \mathrm{mM} \mathrm{K}_{2} \mathrm{CO}_{3}$ and $9.4 \mathrm{M}$ urea and sonicated on ice at 20 to $50 \%$ probe intensity (Bronwill Biosonic; Bronwill Scientific, Rochester, NY) for six $15 \mathrm{sec}$. periods at 1 min. intervals. Sonicated endometrial tissue was brought to $2 \%$ Nonidet P-40 ( $/ \mathrm{v})$ and $0.5 \%(\mathrm{~W} / \mathrm{v})$ dithiothreitol, centrifuged at $18 \mathrm{C}$ and $20,000 \mathrm{~g}$ for $30 \mathrm{~min}$. and an aliquot of the resultant supernatant subjected to 2D-PAGE. Sample preparation, tissue solubilization and electrophoretic separation of acidic and basic polypeptides by 2D-PAGE were accomplished according to methods described by Horst and Roberts (1979) and Horst et a1. (1980). In the first dimension, polypeptides of a more basic nature were separated by nonequilibrium $\mathrm{pH}$ gradient electrophoresis (NEPHGE), whereas polypeptides with isoelectric points (IEP) in a more acidic range between 4.0 and 9.0 were separated by isoelectric focusing. These procedures were described by Basha et al. (1980a).

Following electrophoresis, Coomassie blue R-250 stained polyacrylamide slab gels were photographed, impregnated with sodium salicylate (1M, 30 min.; Chamberlain, 1979), dried (Model 224 Gel Slab Dryer; BioRad Laboratories, Richmond, CA) and fluorographs prepared from Kodak XRP-1 x-ray film according to procedures of Laskey and Mills (1975). Fluorography of dried Coomassie blue R-250 stained 2D-PAGE gels permitted visualization and identification of radiolabelled polypeptides separated by 2D-PAGE. Fluorographs of endometrial tissue homogenates 
primarily revealed structural and functional polypeptides into which radiolabelled amino acids were incorporated during the incubation period (24h); whereas fluorographs of dialyzed explant medium primarily revealed polypeptides which were synthesized during the incubation period and released into the medium. The latter group would represent the array of polypeptides potentially synthesized and secreted by bovine endometrium.

\section{Protein Assay}

Total protein concentrations in explant medium were determined by the method of Lowry et al. (1951) using BSA (Fraction V; Sigma Chemical Co., St. Louis, MO) as a standard.

\section{Statistical Analyses}

Where appropriate, data were subjected to analysis of variance according to procedures available in the General Linear Models section of S.A.S. (Barr et a1., 1979). Analyses of endometrial explant time trial data considered variability due to individual explants with time (h) as a continuous independent variable. Analysis of data from thirty-four $50 \mu \mathrm{Ci}{ }^{3} \mathrm{H}$-Leu-supplemented endometrial explants obtained from seventeen pregnant cows on days 16, 19, 22 and 24 post-mating (Table 3.1) considered variability due to day and cow. Comparisons of similar explants from pregnant $(n=20)$ and nonpregnant cattle $(n=12$; days 16 and 19; Table 3.1) also considered variability due to pregnancy status and appropriate interactions. Explant tissue wet weight was included in analyses as a covariate. 


\section{$\underline{\text { Results }}$}

Synthesis and Release of Protein

The explant system described for this study has been used successfully by several investigators to examine the qualitative array of macromolecules, presumably proteins, produced and released by both endometrial and conceptus tissues (Basha et a1., 1979, 1980a; Moffatt et al., 1980; Kensinger et al., 1982; Godkin et a1., 1982a,b). In the present study, dialyzed samples of MEM, obtained aseptically at $12 \mathrm{~h}$ intervals between 0 and $48 \mathrm{~h}$ of culture from 12 bovine endometrial explants, contained increasing amounts of nondialyzable radiolabelled macromolecules (Figure 3.1). Nondialyzable radioactivity ( $\left.{ }^{3} \mathrm{H}-\mathrm{Leu}\right)$ in MEM increased steadily during the first $24 \mathrm{~h}$ and even more rapidly thereafter until $48 \mathrm{~h}$ when incubations were terminated. Data (Figure 3.1) were best described by a second order polynomial equation $\hat{(Y}=$ $2602.8-9.2190 \mathrm{X}+6.5551 \mathrm{X}^{2} ; \mathrm{R}^{2}=.98 ; \mathrm{P}<.0001 ; \hat{\mathrm{Y}}=\mathrm{DPM}$ of ${ }^{3} \mathrm{H}-\mathrm{Leu}$ $\mathrm{X}=$ hours of incubation). Percent retention of total ${ }^{3} \mathrm{H}-$ Leu added as nondialyzable product followed an identical curvilinear trend $\hat{(}=$ $0.6288=0.0008 \mathrm{X}+0.0016 \mathrm{X}^{2} ; \mathrm{R}^{2}=.97 ; \mathrm{P}<.0001 ; \hat{\mathrm{Y}}=$ Percentage of total ${ }^{3}$ H-Leu; $X=$ hours of incubation). Data indicate that bovine endometrial explants, prepared as described above, can be successfully maintained for periods in excess of $24 \mathrm{~h}$ for recovery of macromolecular (protein) products from explant medium. Tissue appeared viable throughout the $48 \mathrm{~h}$ incubation period.

Listed in Table 3.2 are responses (arithmetic means \pm SEM) of $24 \mathrm{~h}$ endometrial explants prepared from early pregnant ( $n=34$ explants) and nonpregnant ( $\mathrm{n}=12$ explants) cattle (Table 3.1 ) which received $50 \mu \mathrm{Ci}$ ${ }^{3}$ H-Leu. Mean ( \pm SEM) tissue wet weight (TW) for all explants $(n=46)$ 


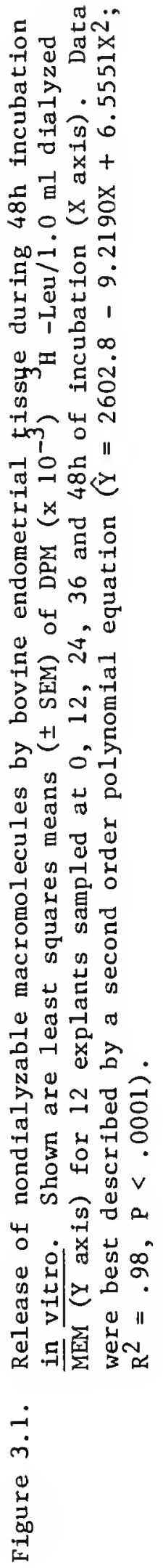




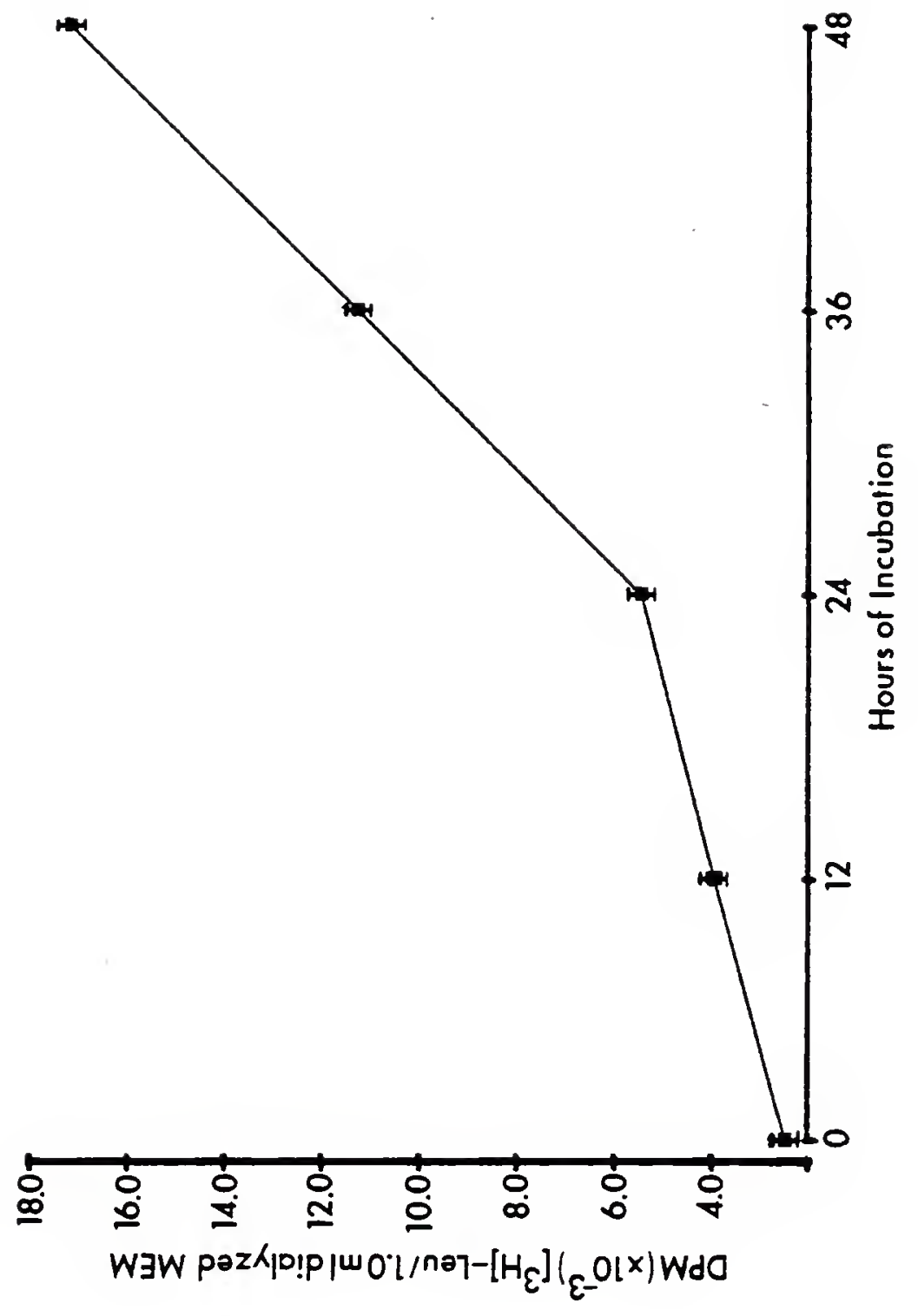




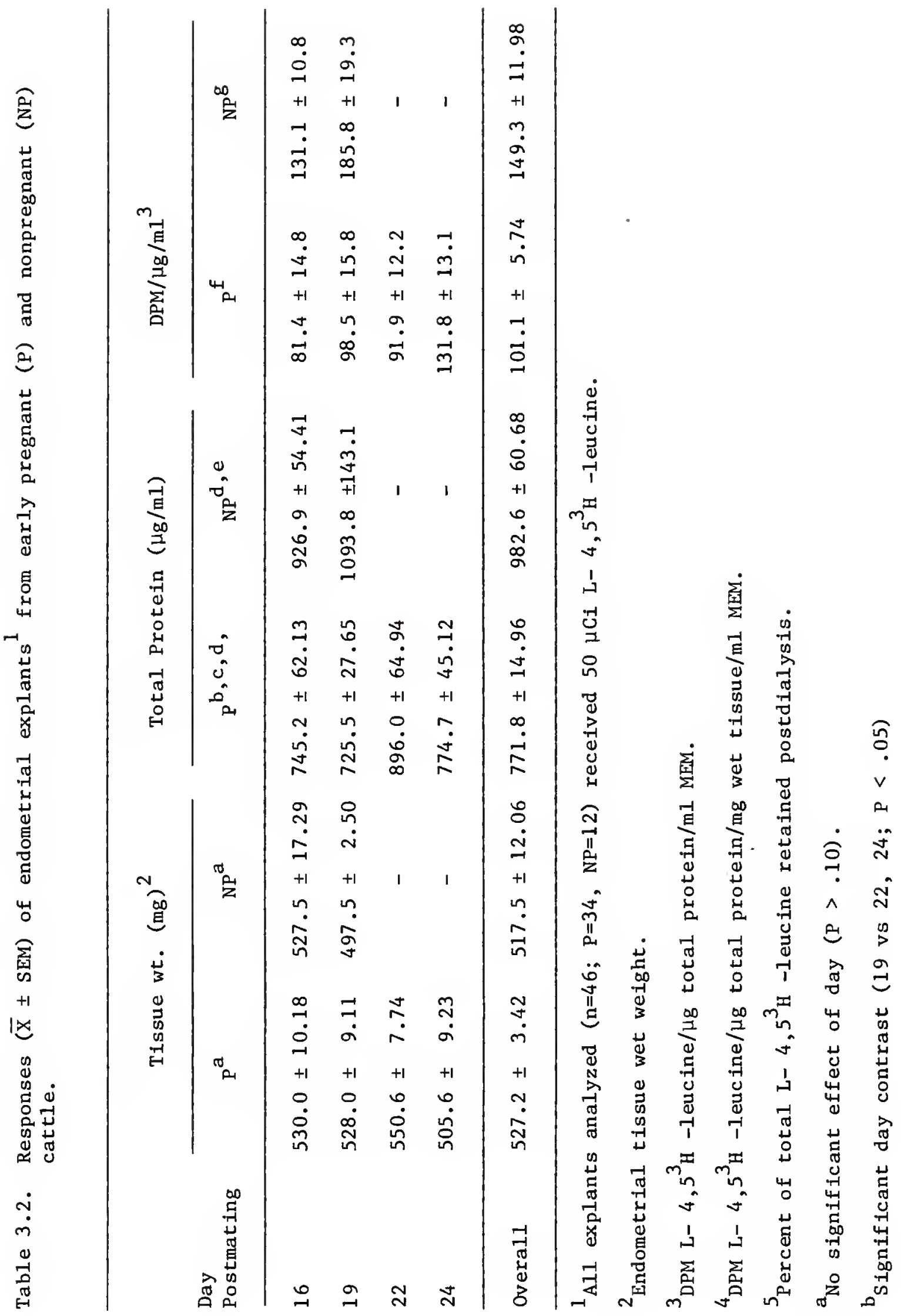




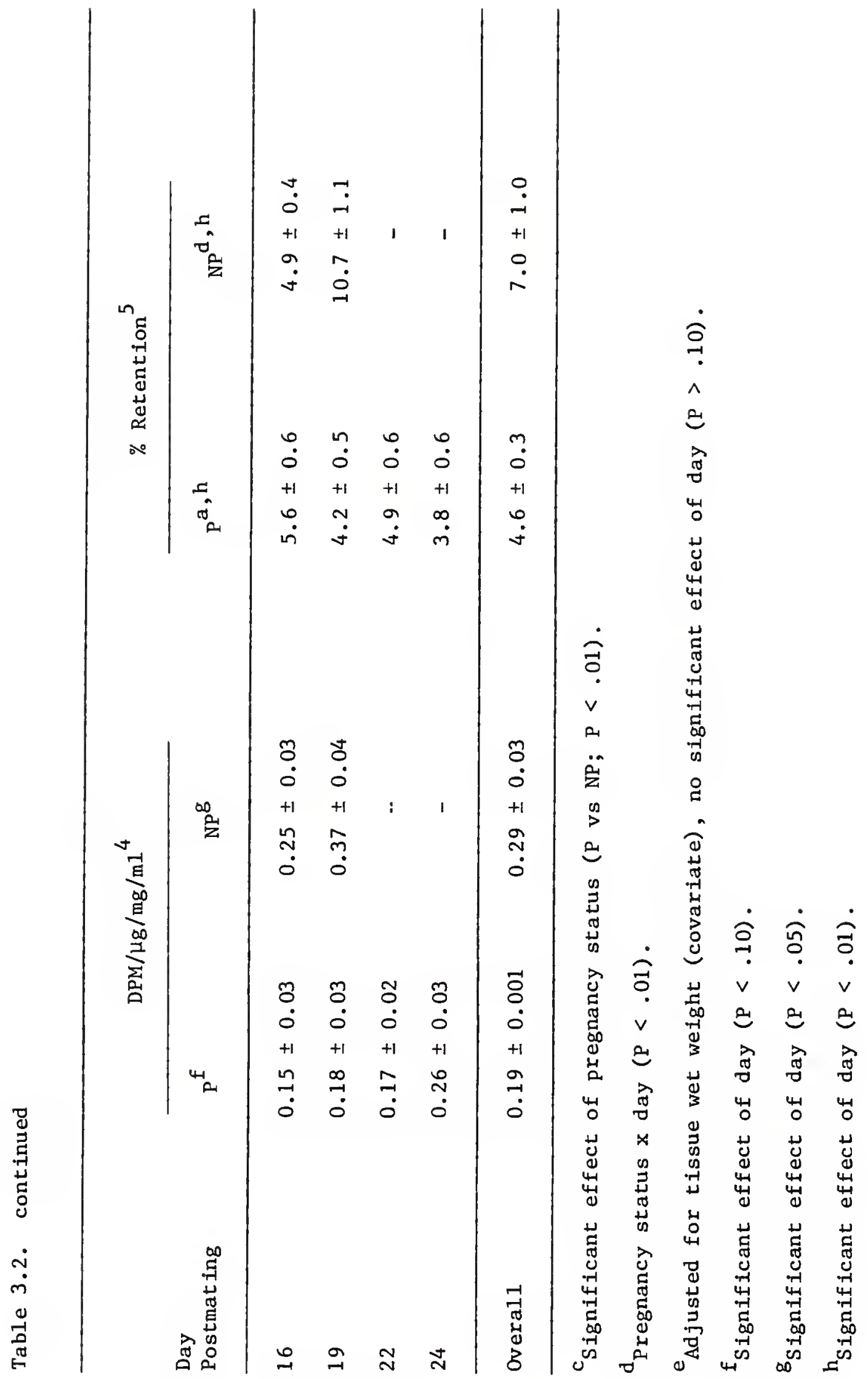


was $524 \pm 4.93 \mathrm{mg}$. When tissue weight was considered as a covariate and orthogonal contrasts made among days post-mating, overall total protein (TP) concentrations $(\mu \mathrm{g} / \mathrm{ml})$ in dialyzed MEM were lower for day 19 than for day 22 and 24 explants from pregnant cattle $(P<.05$; Table 3.2), and higher in explants from nonpregnant than pregnant cattle (days 16 and 19 only; $P<.01 ; 982.6 \pm 60.68$ vs. $771.8 \pm 14.96 \mu \mathrm{g} / \mathrm{m} 1$ ). Additionally, a pregnancy-status by day post-mating (status X day) interaction $(P<.01)$ was detected (Table 3.2). Specific activity of unfractionated, dialyzed proteins in MEM (DPM ${ }^{3}$ H-Leu/ $\mu$ g and DPM ${ }^{3}$ H-Leu/ $\mu \mathrm{g} / \mathrm{mg}$ ) was significantly affected by day post-mating in explants from both pregnant $(P<.10)$ and nonpregnant $(P<.05)$ cattle, tending to increase after day 16 (Table 3.2). Percent retention (\%r) of total ${ }^{3} \mathrm{H}$-Leu added $(50 \mu \mathrm{Ci})$ as nondialyzable radiolabelled molecules was not affected $(\mathrm{P}>.10)$ by day post-mating in explants of pregnant endometrium. In contrast, $\%$ was affected by day in explants of endometrium from nonpregnant cattle (days $16<19 ; \mathrm{P}<.01$; Table 3.2 ), and a status $\mathrm{X}$ day interaction was detected $(\mathrm{P}<.01)$. Percent retention was highest in explants of endometrium from day 19 nonpregnant cattle $(n=2 ; \bar{X} \pm$ SEM $\% \mathrm{r}=10.7 \pm 1.08 \%)$. Percent retention of ${ }^{3} \mathrm{H}$-Leu $(50 \mu \mathrm{C} i)$ in six endo-. metrial explants $(\bar{X} \pm S E M$ of $\mathrm{TW}=508.3 \pm 4.77 \mathrm{mg})$ from a single day 4 cyclic (non-bred) $\operatorname{cow}(\overline{\mathrm{X}} \pm \mathrm{SEM}$ ) was $14.69 \pm 0.402 \%$.

$$
\text { Mean ( } \pm \text { SEM) \% r of }{ }^{14} \text { C-Leu }\left(100 \mu \mathrm{C} i \text { total added) and }{ }^{3} \mathrm{H}-\mathrm{Glc}\right. \text { (50 }
$$

$\mu C i$ total added) in explants $(n=12 ; \simeq T W=500 \mathrm{mg})$ of endometrium from ligated ( $n=6$ explants) and pregnant ( $n=6$ explants) uterine horns of three unilaterally pregnant cows (day 270; Chapter 2) were: 1igated, $6.4 \pm 0.7 \%$ and $6.1 \pm 0.6 \%$; and pregnant, $6.4 \pm 0.7 \%$ and $6.2 \pm 0.7 \%$. Overall mean ( \pm SEM) \% r for ${ }^{14} \mathrm{C}$-Leu and ${ }^{3} \mathrm{H}-$ Glc in all endometrial 
explants (ligated and pregnant uterine horns) from day 270 unilaterally pregnant cows were $6.4 \pm 0.5 \%$ and $6.1 \pm 0.5 \%$. Data indicated that endometrium from both ligated and pregnant uterine horns were equally able to incorporate radiolabelled amino acids into nondialyzable products in vitro. Mean $(\overline{\mathrm{X}} \pm \mathrm{SEM}) \mathrm{TP}(\mu \mathrm{g} / \mathrm{m} 1)$ in MEM from 12 explants was $538.2 \pm 50.3$

\section{Gel Filtration}

Shown in Figure $3.2 \mathrm{~A}$ is a typical $\mathrm{S}-200$ gel filtration elution profile obtained following chromatography of dialyzed bovine endometrial explant medium. Absorbance of each fraction at $750 \mathrm{nM}$ is shown by the solid line and DPM ${ }^{3}$ H-Leu per fraction $(100 \mu 1)$ by connected symbols. Three major peak areas of nondialyzable radioactivity were consistently obtained including area I, $\mathrm{M}_{\mathrm{r}}>200 \times 10^{3}$; area II, $160 \times 10^{3}>\mathrm{M}_{\mathrm{r}}>$ $45 \times 10^{3}$; and area III, $\mathrm{M}_{\mathrm{r}}<35 \times 10^{3}$. Nearly identical s-200 elution profiles were obtained following chromatography of MEM from all stages of pregnancy. This is illustrated by comparison of Figure 3.2A with a similar elution profile obtained from day 270 endometrial explant medium shown in Figure 3.2B (absorbance of each fraction at $280 \mathrm{nM}$ shown in solid line). Additionally, MEM from explants of endometrium obtained from both ligated and pregnant uterine horns of unilaterally pregnant cattle (Chapter 2) produced similar S-200 gel filtration elution profiles.

A representative elution profile obtained following application of S-200 area I fractions to Sepharose CL-6B is presented in Figure 3.3. A peak of nondialyzable radioactivity eluted ahead of the porcine IgM standard ( $\left.\mathrm{PIgM} ; \mathrm{M}_{\mathrm{r}} \simeq 900,000\right)$, for a molecular weight estimate in excess of 1.0 to $1.5 \times 10^{6}$. A second area of high molecular weight endometrial 
Figure 3.2. Comparison of representative Sephacryl S-200 gel filtration elution profiles of dialyzed MEM from day 19 pregnant (A) and day 270 unilaterally pregnant (1igated uterine horn) endometrial explants (B). Absorbance of each fraction (left axis) at $750 \mathrm{nM}$ (A) or $280 \mathrm{nM}$ (B) is depicted by solid line. DPM $\left(x^{-2}\right)^{3}$ H-Leu (A) or ${ }_{\mathrm{H}-\mathrm{GlC}}$ (triangles) and ${ }^{14} \mathrm{C}$-Leu (squares) (B) per $100 \mu 1$ of each fraction are shown by connected symbols. Nondialyzable radioactivity consistently eluted in three areas (I, II and III). $M_{r}\left(x 10^{-3}\right)$ estimates were: I, $M_{r} \geq 200 ;$ II, $160>M_{r}>45 ;$ III, $M_{r}<35$. 
$-167-$

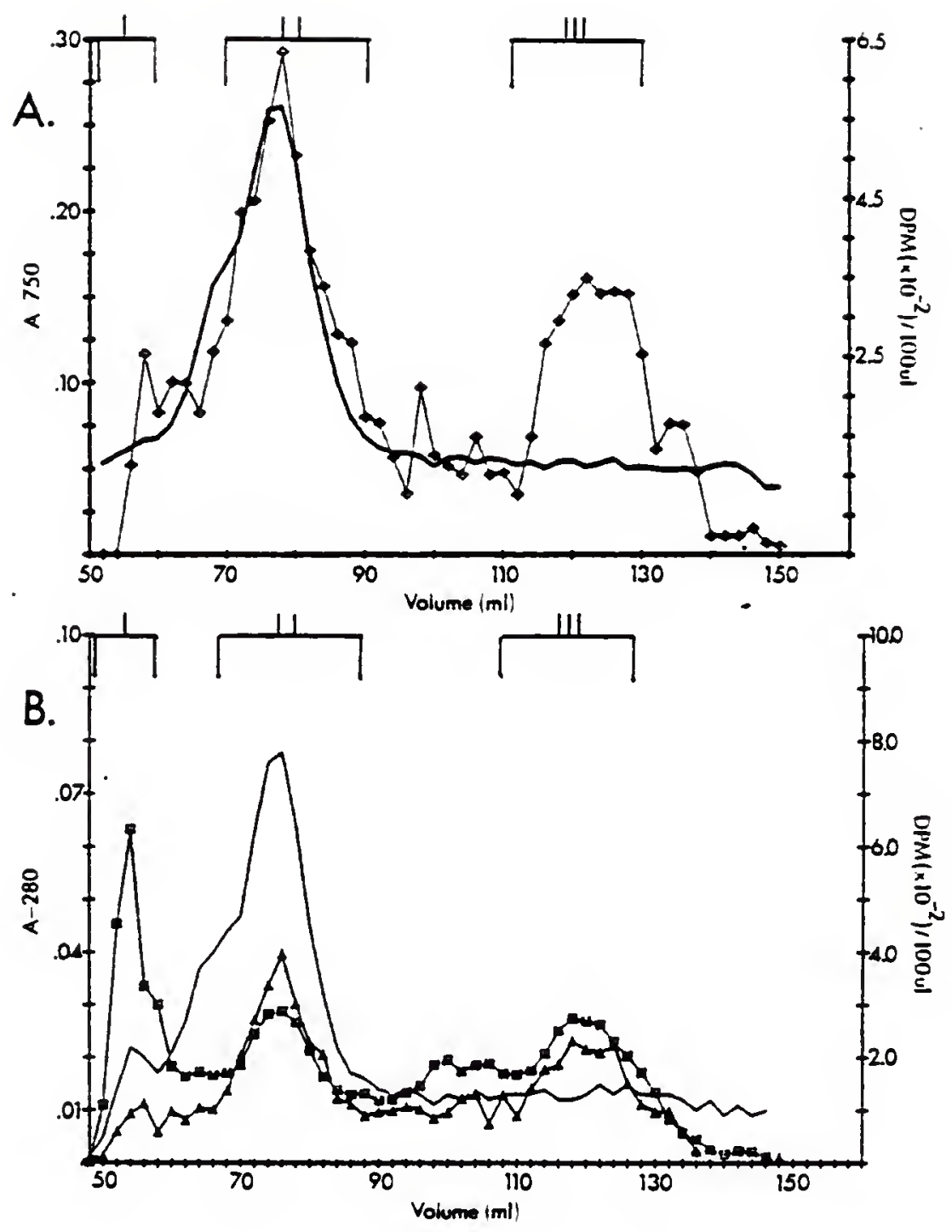




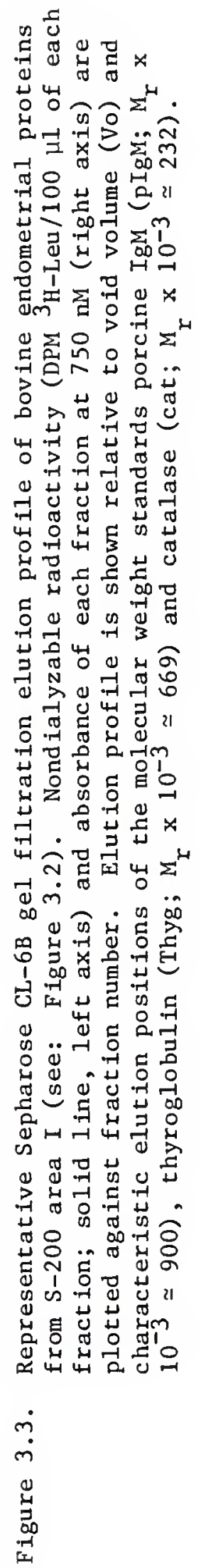




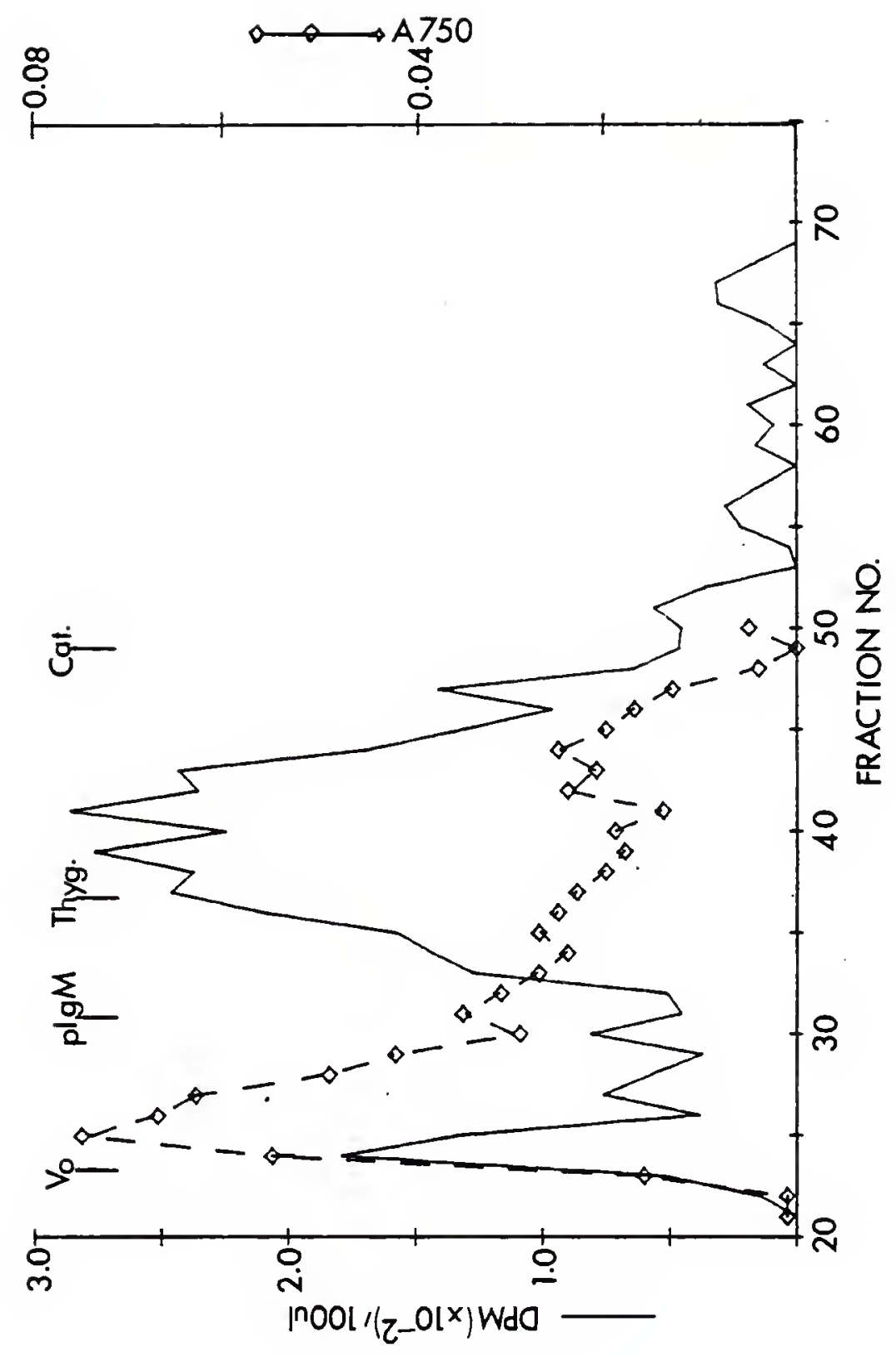


protein eluted after the thyroglobulin standard $\left(M_{r} \simeq 669,000\right)$ but ahead of catalase $\left(M_{r} \simeq 232,000\right)$, in the range $\left(M_{r} \times 10^{-3}\right)$ of 340 to 669 .

Together, gel filtration data indicated that, as assessed by gross partitioning by $\mathrm{M}_{\mathrm{r}}$ categories, bovine endometrium from all stages of gestation (days 16,19,22, 24 and 270) produced similar arrays of macromolecules in vitro. A fraction of these endometrial products (S-200 area I) was of extremely high molecular weight (>340 X 10 $0^{3}$ ) and would likely not enter standard polyacrylamide gels for electrophoresis.

\section{Ion Exchange Chromatography}

Ion exchange chromatography (CMC and DEAE) of dialyzed endometrial explant medium from cattle during early pregnancy (days 16, 19, 22 and 24), as well as from nonpregnant cattle (days 16 and 19) produced nearly identical elution profiles. As shown in Figure 3.4A, the majority of nondialyzable ${ }^{3}$ H-Leu (solid 1 ine) as well as total protein (connected symbols; assessed by absorbance of an aliquot of each fraction at 750 nM following Lowry protein assay; Lowry et al., 1951) was CMC (-) at $\mathrm{pH} 8.2$, eluting during the tris-HCL buffer wash prior to beginning of the linear salt ( $\mathrm{NaCl}$ ) gradient. Only one minor CMC (+) peak was consistently eluted during the gradient as shown on the expanded DPM scale in Figure $3.4 \mathrm{~A}$.

When CMC (-) proteins were adsorbed to DEAE and eluted as described above, elution profiles of nondialyzable ${ }^{3}$ H-Leu similar to that shown in Figure 3.4B were consistently obtained. The majority of CMC (-) proteins bound to DEAE at $\mathrm{pH} 8.2$ and were eluted during the linear salt gradient. Data suggested that bovine endometrial explants from early pregnant and nonpregnant cattle produced primarily acidic (DEAE +; pH 8.2) macromolecules in vitro. Data were consistent with results of gel 
Figure 3.4. Representative ion exchange chromatograms of dialyzed bovine endometrial explant medium. (A) CMC-cationexchange profile of unfractionated explant medium. CMC (-) proteins were eluted via an extensive wash with $10 \mathrm{mM}$ tris-HCL buffer ( $\mathrm{pH} 8.2$; indicated by horizontal line extending from origin to fraction 15). CMC (t) proteins were then eluted with a $150 \mathrm{ml}$ linear salt gradient $(0.0 \mathrm{M}-0.5 \mathrm{M} \mathrm{NaCl}$; indicated by the diagonal line). Absorbance at $750 \mathrm{nM}$ (connected symbols) and DPM $\left(x 10^{-2}\right)$ $3_{\mathrm{H}-L e u} / 100 \mu \mathrm{l}$ of each fraction (solid line) are shown. Note expanded DPM scale (inset) necessary to demonistrate minor CMC $(+)$ endometrial products. (B) DEAE-anion exchange profile of CMC (-), nondialyzable, bovine endometrial proteins. 

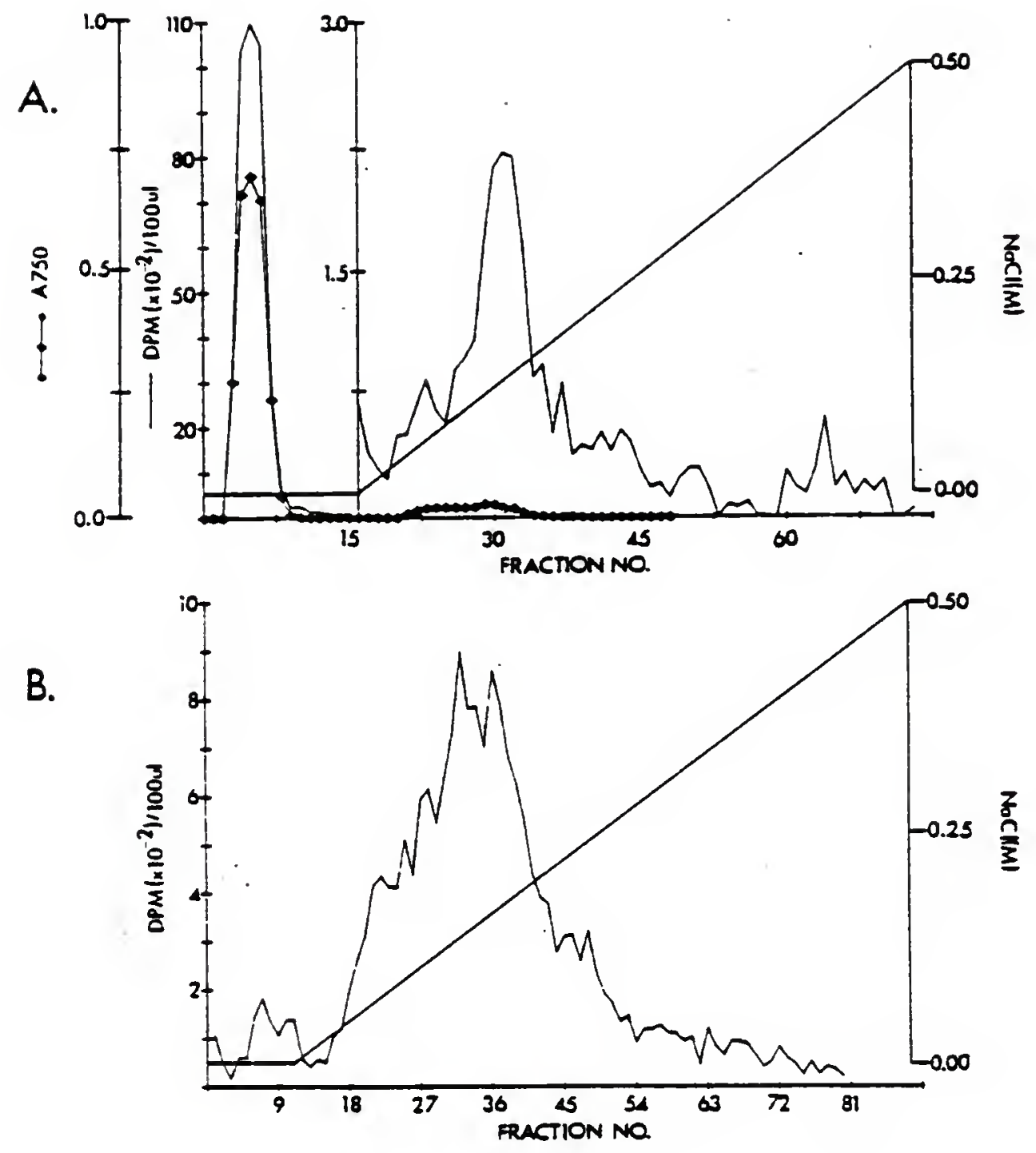
filtration studies in that no major qualitative differences were detected in ion exchange profiles of explant medium associated with pregnancy status or stage of gestation.

\section{$\underline{\text { 2D-PAGE }}$}

Analysis of polypeptides present in bovine endometrial explant medium and tissue homogenates was accomplished by 2D-PAGE (Horst and Roberts, 1979; Horst et a1., 1980) to assess both basic (NEPHGE) and acidic (IEF) components (Basha et al., 1980a). Fluorographs prepared from dried, Coomassie brilliant blue R-250-stained 10\% 2D-PAGE polyacrylamide slab gels revealed polypeptides into which radiolabelled amino acids were incorporated during the $24 \mathrm{~h}$ incubation period. Hence, fluorographs prepared from 2D-PAGE gels of unfractionated, dialyzed explant medium revealed those polypeptides which were synthesized and released during incubation. In contrast, fluorographs prepared from 2D-PAGE gels of endometrial tissue homogenates revealed those structural and functional proteins or polypeptides into which labelled amino acids were incorporated. Comparison of fluorographs prepared from MEM and tissue homogenates, respectively, permitted assessment of major and minor polypeptides which were not retained within tissue, but released into MEM (secreted) during incubation. This array of polypeptides should include major bovine endometrial secretory products.

Shown in Figure $3.5 \mathrm{~A}$ and $\mathrm{B}$ are representative Coomassie brilliant hlue R-250-stained 2D-PAGE gels depicting the array of basic (NEPHGE; Figure 3.5A) and acidic (IEF; Figure 3.5B) polypeptides seen in dialyzed bovine endometrial explant medium. Patterns were similar to those described for bovine uterine milk and peripheral plasma (Chapter 2) and included BSA as a major component on IEF gels (Figure 3.5B). Such 
永密 站

出

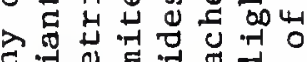

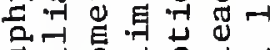

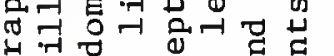

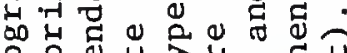

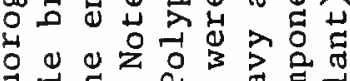

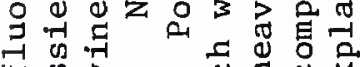

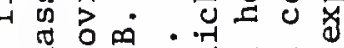

ซ

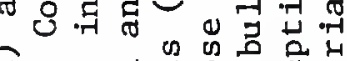

(ิ)

-

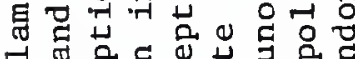

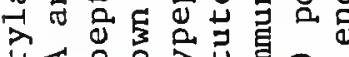

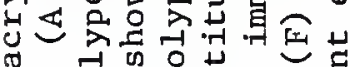

ㅇํㅇ.

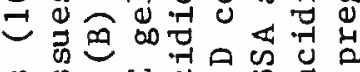

की की प्रु

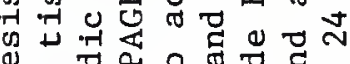

๙

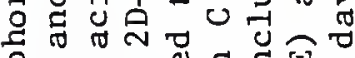

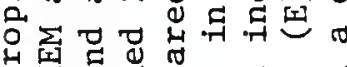

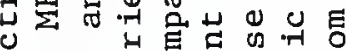

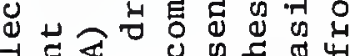

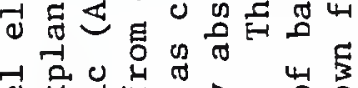

व

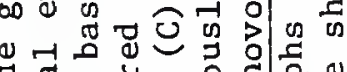

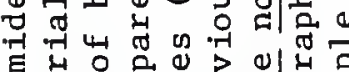

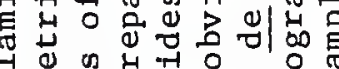

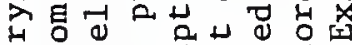

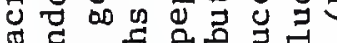

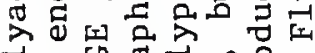

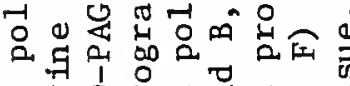

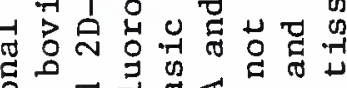

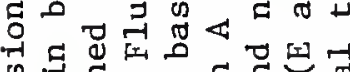

क न

的紫合

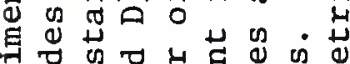

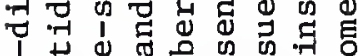

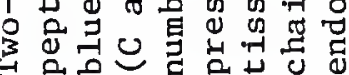

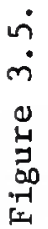




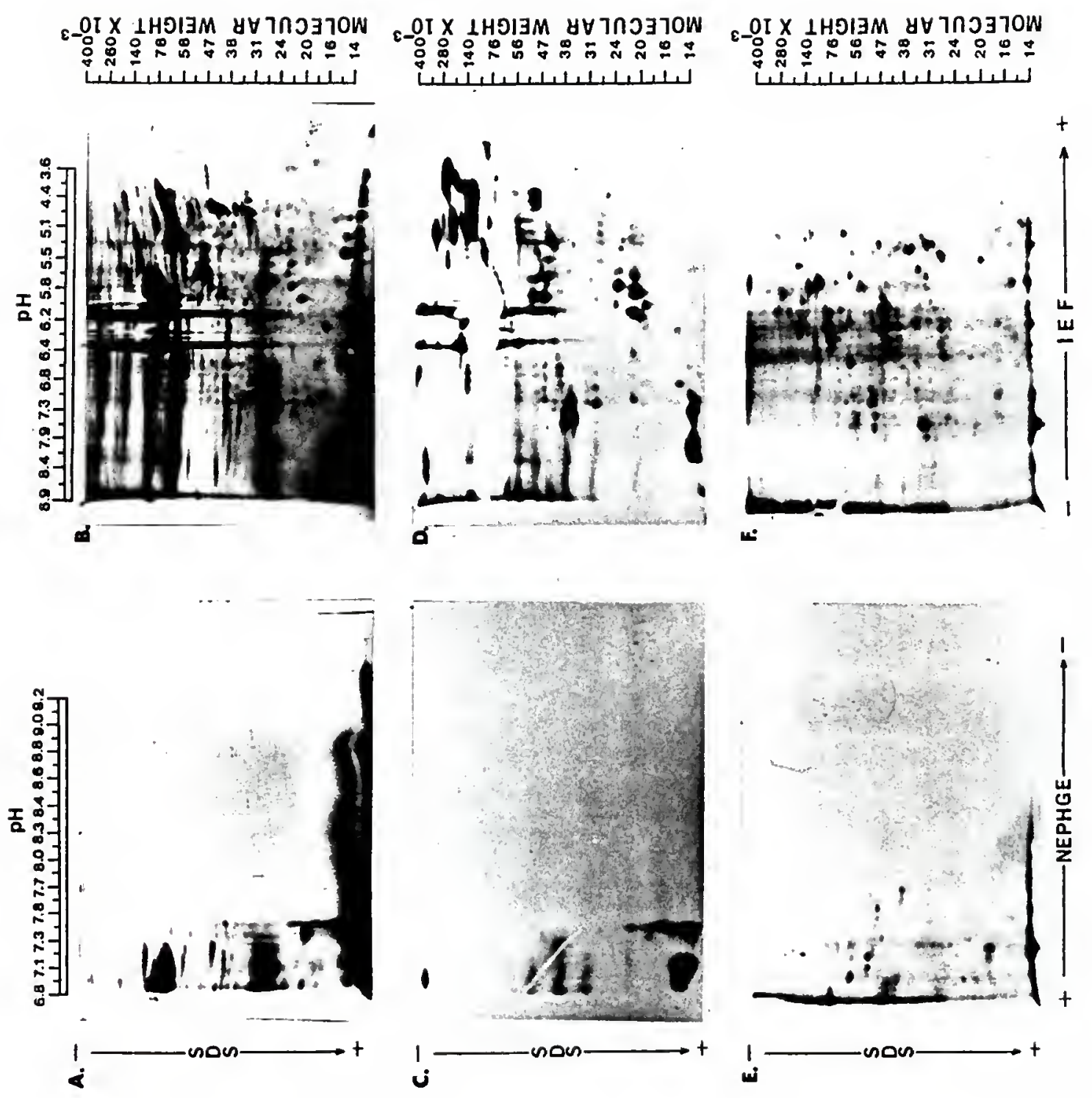


serum components were likely leached from tissues during incubation. Fluorographs prepared from gels shown in Figure 3.5A and B are presented in Figure $3.5 \mathrm{C}$ and $\mathrm{D}$, and may be compared with fluorographs of basic (NEPHGE) and acidic (IEF) polypeptide components of the same endometrial tissue homogenate shown in Figure $3.5 \mathrm{E}$ and $\mathrm{F}$ respectively.

As shown (Figure $3.5 \mathrm{C}$ and $\mathrm{D}$ ), bovine endometrium was capable of producing a complex array of polypeptides in vitro. The array of radiolabelled polypeptides identified on fluorographs of unfractionated, dialyzed explant medium (Figure $3.5 C$ and D) was consistent with results of gel filtration and ion exchange chromatography studies. Products in MEM were present across the entire molecular weight range resolvable by $10 \%$ polyacrylamide gels (approximately 14,000 to 400,000 ), and the majority of labelled polypeptides were seen on fluorographs of IEF 2D-PAGE gels (Figure 3.5D) indicating production of primarily acidic type proteins. Additionally, some very high molecular weight polypeptides $\left(M_{r} \times 10^{-3} \geq 400\right)$ were identified on fluorographs of unfractionated MEM (IEF and NEPHGE; Top, Figure 3.5C and D). These macromolecules were seen at the interface of $4 \%$ stacking and $10 \%$ running gels, or a streaks in the stacking gel. Hence, radiolabelled endometrial products were present in MEM which were not resolvable by 2D-PAGE.

Obvious absence of BSA from fluorographs of 2D-PAGE (IEF) gels of polypeptides in MEM (Figure 3.5B vs. 3.5D) supports the contention that, while significant amounts of serum proteins may have leached from tissues during incubation, products identified on fluorographs represent polypeptides which were synthesized during culture and released (secreted) into MEM. Polypeptides with 2D-electrophoretic characteristics typical of immunoglobulin ( $\mathrm{Ig}$ ) heavy and light chains (Anderson 
and Anderson, 1977; Latner et al., 1980) were also prominent on Coomassie-stained 2D-PAGE (IEF) gels of MEM proteins (Figure 3.5B), but absent on fluorographs (Figure 3.5D). If produced locally, Ig are thought to be synthesized by fixed plasma cells in the lamina propria of endometrial submucosa (Vaerman and Férin, 1974). Such cells may have constituted an insignificant proportion of the total tissue mass in culture. Alternatively, recent evidence (Sullivan and Wira, 1983) indicated that, in mice, rapid increases in uterine tissue content of IgA, IgG and IgM occurred primarily as a consequence of serum transudation. Hence, like BSA, Ig's may have simply leached from tissues during culture.

Careful comparison of fluorographs of unfractionated MEM (Figure $3.5 \mathrm{C}$ and $\mathrm{D}$ ) with those prepared from tissue homogenates (Figure 3.5E and F) indicated that polypeptides in at least four molecular weight $\left(M_{r}\right) / \mathrm{pH}$ (IEP) classes were absent or present in only trace amounts in tissue, but enriched in explant medium. Products of a more basic nature in this category (class I) included two polypeptides, identified at the dye front on both NEPHGE and IEF 2D-PAGE fluorographs $\left(M_{r} \simeq 14,000\right)$ in a $\mathrm{pH}$ range greater than 7.2 (Figure $3.5 \mathrm{C}$ and D). Molecular weight $\left(M_{\mathrm{r}} \times 10^{-3}\right) / \mathrm{pH}$ (IEP) ranges of other endometrial polypeptide classes included: class II, 19-24/5.4-6.3; class III, 28-31/6.9-7.3; and class IV, $\geq 150 / \leq 5.1$. These areas (classes I, II, III and IV) are identified on the fluorograph of polypeptides in MEM shown in Figure 3.6.

Polypeptides in class I (Figure 3.6) were of a similar size, a1though somewhat less basic, than several progesterone induced porcine endometrial-specific serine protease inhibitors (Mullins et al., 1980a; Fazleabas et al., 1982a,b). Bovine endometrial-specific polypeptides in 


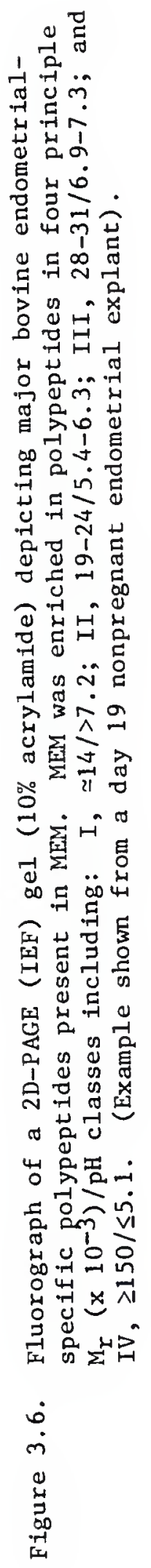




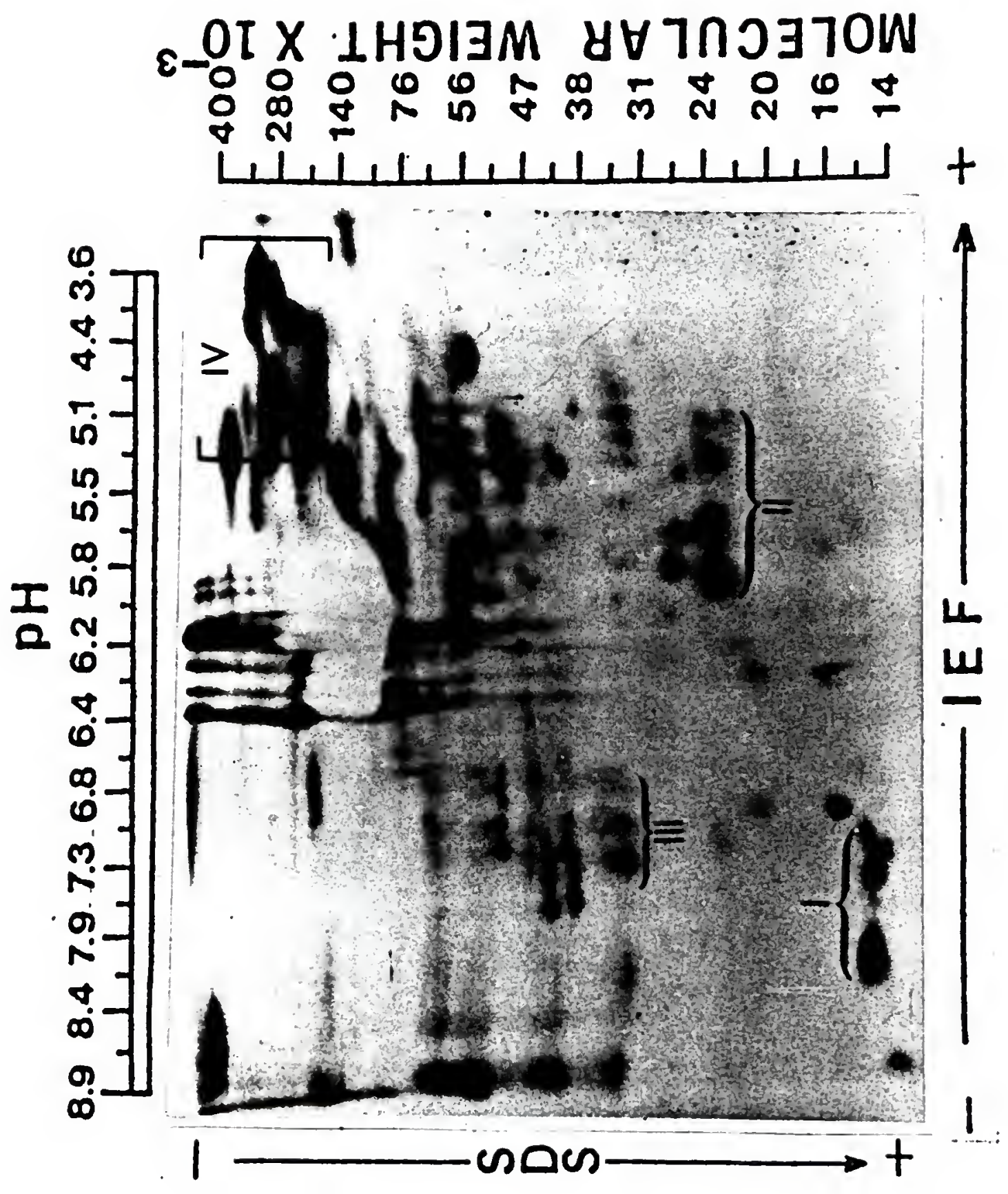


classes II and III (Figure 3.6) displayed electrophoretic mobility similar to several uterine-specific polypeptides identified in UM from unilaterally pregnant cattle (Chapter II). Products in class IV resembled polypeptides thought to be associated with the porcine endometrial epithelial cell brush border.

Fluorographs prepared from 2D-PAGE IEF gels of endometrial explant medium from a day 16 nonpregnant cow (Figure 3.7A) and day 24 and 69 pregnant cattle (Figure $3.7 \mathrm{~B}$ and $\mathrm{C}$ ) are presented for comparison in Figure 3.7. Comparison of individual fluorographs prepared from 2D-PAGE gels (IEF and NEPHGE) of endometrial explant medium from early pregnant and nonpregnant cattle (Table 3.1), one day 4 cyclic and one day 69 pregnant cow, and from pregnant and ligated uterine horns of three day 270 unilaterally pregnant cattle (Chapter II) failed to reveal any obvious qualitative differences in array of polypeptides synthesized by bovine endometrium associated with pregnancy status or stage of gestation. Polypeptides in all classes described above were produced and released in vitro during the $24 \mathrm{~h}$ incubation period by endometrial tissues from cyclic cattle on days 4,16 and 19, and pregnant cattle on days $16,19,22,24$ and 69 , as well as by tissue from both 1 igated and pregnant uterine horns of day 270 unilaterally pregnant cattle. Methods employed in the present study did not permit quantitative assessment of polypeptides produced in vitro by bovine endometrium. Data suggested, however, that quantitative rather than major qualitative alterations might be associated with changing reproductive status.

\section{Discussion}

In the present study it was demonstrated that bovine endometrial tissue explants could be maintained in vitro for periods of at least 
Figure 3.7. Fluorographs prepared from 2D-PAGE (IEF) gels of polypeptides in bovine endometrial explant MEM. Shown are polypeptides synthesized de novo from ${ }^{3} \mathrm{H}$-Leu substrate, and released into MEM by endometrial tissues from: (A) a day 16 nonpregnant cow; (B) a day 24 pregnant cow; and (C) a day 69 pregnant cow. 
$\mathrm{pH}$

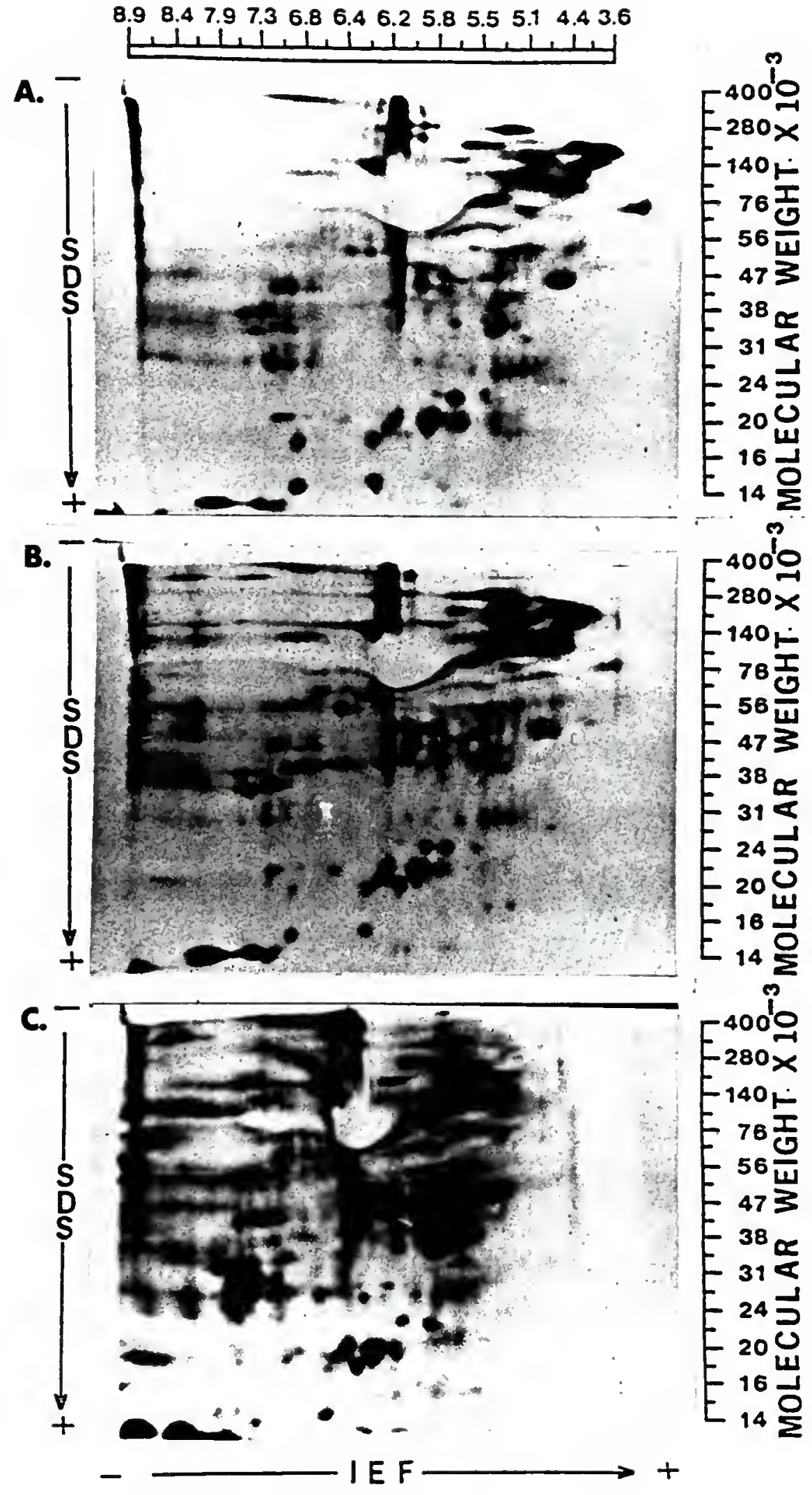


24 to $48 \mathrm{~h}$ as assessed by incorporation of radiolabelled amino acids into nondialyzable product (Figure 3.1). The procedures employed were essentially the same as those described by Basha et al. (1979, 1980a) for explant culture of porcine endometrium and were used previously to study bovine endometrial metabolism of arachidonic acid (Lewis et al., 1982). This system was also successfully employed to examine synthesis and release of proteins in vitro by ovine endometrium (Moffatt et al., 1980), bovine fetal cotyledonary tissue (Kensinger et al., 1982), and ovine and porcine peri-attachment conceptuses (Godkin et al., 1982a,b). These studies consistently demonstrated that explant medium was enriched in radiolabelled macromolecules which were absent, or present in only trace amounts in tissue homogenates. This suggests that methods employed in the present study provide excellent means for obtaining and identifying major bovine endometrial secretory products in vitro.

Medium from endometrial explants prepared from early pregnant cattle tended to contain TP of higher specific activity (DPM ${ }^{3} \mathrm{H}$-Leu/ $\mu \mathrm{g}$ TP and DPM ${ }^{3} \mathrm{H}$-Leu/ $\mu \mathrm{g}$ TP/mg TW) if tissues were recovered on day 24 (Table 3.2). This observation is consistent with earlier biochemical and histochemical data, generated from bovine uterine flushings and tissues from cattle of similar reproductive status, which indicated general stimulation and persistency of accumulation and/or production of uterine-specific luminal proteins during periods of chronic progesterone $\left(\mathrm{P}_{4}\right)$ exposure such as occur during diestrus and early pregnancy (Schultz et al., 1971; Roberts and Parker, 1974a,b, 1976; Leiser and Wille, 1975; Linford and Iosson, 1975; Wathes, 1980; Bartol et al., 1981a; Libby et a1., 1982). Absence of significant effects of day post-mating on \% for explants of endometrium from early pregnant cattle 
(Table 3.2) may reflect metabolic stability of these tissues. Such stability would be important during early pregnancy to insure consistent production of histotrophe and other substances required for support and maintenance of a conceptus.

In contrast to relatively stable responses of endometrial explants from early pregnant cattle, explants from nonpregnant cattle (days 16 and 19; Table 3.2) differed in response depending upon day of tissue recovery. Both specific activity of dialyzed MEM proteins and \% were higher in day 19 than day 16 explants (Table 3.2), and significant $(\mathrm{P}<.01)$ pregnancy status $\mathrm{X}$ day post-mating interactions were detected for both TP and \%r. Interactions reflected elevated responses of explants from day 19 nonpregnant cattle whereas explants of tissue from pregnant cattle maintained a stable but lower response (Table 3.2).

Endometrial tissues in short term explant culture appear to reflect metabolic state of tissues as they existed in vivo prior to excision. Attempts to modify activity of cultured endometrium by addition of steroids in vitro have not been successful. Basha et al. (1979) observed that treatment of porcine endometrial explants with $\mathrm{P}_{4}$ and/or estradiol-17B $\left(E_{2}\right)$ failed to alter qualitative patterns of proteins produced in vitro. Wathes (1980) reported that neither steroid treatment $\left(\mathrm{P}_{4}, \mathrm{E}_{2}\right.$ or both) nor coincubation of bovine uterine tissues with fetal-placental tissues altered the qualitative array of uterine proteins produced in culture. Similarly, Lewis et al. (1982) reported no significant alteration in production or metabolism of prostaglandins (PG) by explants of bovine endometrium following addition of $\mathrm{E}_{2}$ to cultures.

Since uteri of cattle designated nonpregnant did not contain conceptus tissues at the time of slaughter, these animals could be 
considered cyclic. Hence, by day 19 post-estrus, nonpregnant cattle would be in either late diestrus or early proestrus (Hansel et al., 1973; Ford et al., 1979). Ford et al. (1979) reported that in cyclic cattle, peripheral plasma concentrations of $\mathrm{P}_{4}$ declined after day 17 (estrus = day 0 ) as $E_{2}$ concentrations increased; while in pregnant cattle, $\mathrm{P}_{4}$ concentrations were consistently higher than $\mathrm{E}_{2}$ concentrations after day 16 until day 30 , the latest day considered. The increase in production of labelled proteins and \% of ${ }^{3} \mathrm{H}$-Leu by explants of endometrial tissues from day 19 as compared with day 16 nonpregnant or day 16 and 19 early pregnant cattle (Table 3.2) may, therefore, reflect in vitro responses of tissues which were exposed to a higher $\mathrm{E}_{2} / \mathrm{P}_{4}$ ratio in vivo.

Increased $\mathrm{E}_{2} / \mathrm{P}_{4}$ ratio is associated with increased uterine metabolic activity. Bovine and ovine endometrial epithelial cells from late diestrus or proestrus were observed to contain larger amounts of smooth endoplasmic reticulum and larger mitochondria when compared with cells from earlier in the estrous cycle (Kojima and Selander, 1970; Wathes and Wooding, 1980; Hoyes, 1972). Administration of exogenous $E_{2}$ during diestrus stimulated uterine metabolic activity as reflected by both increased uterine blood flow and PG synthesis in cattle (RomanPonce et al., 1978; Bartol et al., 1981a; Knickerbocker et al., 1982), sheep (Huckabee et al., 1970; Warren et al., 1973) and pigs (Dickson et al., 1969; Frank et al., 1978).

In cattle, several studies suggested that endocrine conditions which enhanced uterine PG production, a calcium (Ca) dependent process involving arachidonic acid ( $\mathrm{AA}$ ) as principle substrate (Ramwell et al., 1977), were related if not coupled to production and/or accretion of 
uterine proteins (Bartol et al., 1981a,b; Knickerbocker et al., 1982). Increases in endometrial concentrations of AA and PGF (Hansel et al., 1975; Shemesh and Hansel, 1975b), followed by increased uterine luminal content of PGF were associated with increases in amount and frequency of appearance of uterine luminal proteins in cyclic cattle (Bartol et al., 1981a).

Rubin (1982) suggested that products generated as a consequence of Ca-dependent turnover of AA within the cellular phosphatidylinositol pool might be involved with cellular processes governing discharge of secretory products. Volpi et al. (1980) indicated that metabolites of AA might participate in mechanisms regulating cellular Ca gating by acting as endogenous $\mathrm{Ca}$ ionophores. Agents which increase Ca availability were associated with increased exocytotic activity (Rubin, 1982). Metz et al. (1982) recently proposed that metabolism of AA could yield a feed-forward intermediate(s) involved in the sequence of events leading to release or secretion of cellular products.

In light of these observations it does not seem unreasonable to suggest that endometrial tissues obtained from nonpregnant cattle in late diestrus, a period associated with increasing $\mathrm{E}_{2}$ and decreasing $\mathrm{P}_{4}$, might well possess an increased capacity for synthesis and/or release of macromolecular products in vitro. By comparison, the systemic effect of chronic peripheral plasma $\mathrm{P}_{4}$ combined with the local effect of the conceptus itself appears to have a stabilizing effect on uterine tissues which may be necessary to insure continued secretion of endometrial products required for support of the conceptus.

Percent retention of radiolabelled amino acids was nearly identical in explants of endometrium from ligated and pregnant uterine horns of 
day 270 unilaterally pregnant cattle. This observation supports the contention that the ligation procedure and subsequent accumulation of UM did not adversely effect metabolic capacity of endometrial tissues as assessed in vitro by the present study. Results were generally consistent with those of Moffatt et al. (1980) from unilaterally pregnant sheep. Bovine endometrial explants from all reproductive statuses examined possessed the capacity to incorporate radiolabelled amino acids into nondialyzable products.

To date, attempts to identify bovine uterine-specific proteins have involved primarily comparisons of chromatographic and electrophoretic profiles of proteins in uterine flushings or fluids with those in peripheral plasma or serum (Roberts and Parker, 1974a,b, 1976; Laster, 1977; Dixon and Gibbons, 1979; Libby et al., 1982; ChapterII). Such studies consistently demonstrated that the majority of bovine uterine luminal proteins were of serum origin or serum-1ike. Uterinespecific proteins were defined as those consistently absent from serum, but present in uterine fluids. Therefore, uterine-specific products with similar chromatographic properties to serum proteins might have been overlooked. Additionally, since bovine uterine-specific proteins were suggested to comprise less than $3 \%$ of total recoverable uterine luminal proteins (Roberts and Parker, 1974b, 1976; Laster, 1977), amounts of uterine-specific proteins recovered in uterine flushings may have been insufficient to permit identification of the complete array of uterine products.

In the present study, short term (24h) explant culture of endometrial tissue from cyclic, pregnant, nonpregnant and unilaterally pregnant cattle in presence of radiolabelled amino acids permitted 
recovery and characterization of radiolabelled macromolecules produced by tissues and released into MEM. This approach allowed a relatively concentrated pool of proteins to accumulate in explant medium during the culture period. Serum proteins, which may have leached from tissues but were not produced by them, were radioinert, as demonstrated by the absence of BSA on fluorographs of explant medium (Figure 3.5). Radiolabelled proteins and polypeptides identified in dialyzed MEM therefore, clearly represented bovine uterine endometrial products produced de novo in culture.

Chromatographic techniques including gel filtration (Figure 3.2) and ion exchange (Figure 3.3), as well as the high resolution technique of 2D-PAGE and fluorography (Figures 3.5, 3.6 and 3.7 ) revealed consistently repeatable patterns of radiolabelled proteins and polypeptides in MEM. Data indicated that bovine endometrial tissue is capable of producing a much more complex array of macromolecules than was previously believed. Additionally, no obvious differences were noted in the qualitative array of proteins or polypeptides associated with pregnancy status (pregnant vs. nonpregnant) or stage of gestation (days $16,19,22,24,69$ and 270). Observations suggest that alterations in endometrial-specific components of the bovine uterine environment may reflect quantitative rather than qualitative changes in uterine proteins. Data are generally consistent with observations from other domestic species including pigs, sheep and mares which indicated that a relatively constant array of proteins is produced by or present in the uterine lumen throughout gestation or during prolonged periods of $\mathrm{P}_{4}$ treatment (Bazer, 1975; Bazer et al., 1981b).

Gel filtration chromatography (S-200 and CL-6B; Figures 3.2 and 3.3) of proteins in endometrial explant medium revealed several very 
high molecular weight proteins which were not resolvable by 2D-PAGE. These products eluted in the void volume on $\mathrm{S}-200$ (area $\mathrm{I}, \mathrm{M}_{\mathrm{r}}>200 \mathrm{X}$ $10^{3}$ ) and, when applied to $\mathrm{CL}-6 \mathrm{~B}$, eluted as two broad areas with weight estimates of greater than 1.0 to $1.5 \times 10^{6}$ and between 340 and $669 \times 10^{3}$ respectively. Gel filtration $(G-200)$ of uterine flushings from early pregnant and cyclic cows revealed trace amounts of a very high molecular weight, slightly hexose-rich component (Roberts and Parker, 1974b). Proteins eluting in or near the void volume of $G-200\left(\mathrm{M}_{\mathrm{r}} \times 10^{-3} \geq 200\right)$ were also reported for porcine (Murray et al., 1972) and equine uterine flushings (Zavy et al.,1979a,b), as well as for bovine UM (ChapterII). Hence, very high molecular weight proteins and/or glycoproteins may comprise a significant proportion of uterine-specific products in several domestic species:

The majority of radiolabelled proteins in dialyzed explant medium were CMC (-) at $\mathrm{pH} 8.2$, but bound to DEAE at this $\mathrm{pH}$ (Figure 3.4) indicating production of primarily acidic macromolecules. Consistent with these findings, fluorography of 2D-PAGE gels (IEF and NEPHGE) of proteins in explant medium (Figures 3.5 and 3.7 ) revealed the majority of uterine-specific polypeptides to be separated over a wider more acidic pH range on IEF gels. Polypeptides identified on fluorographs of NEPHGE gels were present only on the least basic side $(\mathrm{pH}<7.6)$ and were, in fact, resolvable by IEF 2D-PAGE (Figure 3.5). Noticeably absent from alI NEPHGE fluorographs, including those prepared from 2D-PAGE gels of day 270 MEM from both ligated and pregnant uterine tissues, were the very basic $(\mathrm{pH}>7.3)$ low $\mathrm{M}_{\mathrm{r}}$ polypeptides identified as major components of bovine UM (Chapter 2; Figure 2.3). These data suggest that low $M_{r}$ basic polypeptides in UM were either enzymatic 
degradation products, or were delivered to UM from serum. Bovine serum albumin and Ig heavy and light chain polypeptides, as well as other serum-1ike proteins (Anderson and Anderson, 1977), were prominent components of dialyzed MEM as assessed by Coomassie-blue-stained 2D-PAGE (IEF) gels (Figure 3.5B). Patterns were similar to those described for bovine UM (Chapter II; Figure 2.3) in which IgA, IgG and IgM were identified immunochemically (Chapter II; Figures 2.6 and 2.7). However, neither BSA nor the Ig polypeptide chains (prominent serum components in MEM) appeared as prominent radiolabelled components of MEM as assessed by fluorography of 2D-PAGE (IEF) gels of polypeptides from day 270 endometrial explants (ligated and pregnant uterine horn tissues) or explants from any earlier stage or pregnancy status (Figures 3.5, $3.6,3.7)$. Data suggest that such proteins appear in utero, and as components of bovine UM, primarily via transudation from serum and do not represent major uterine tissue products. Bovine endometrial explants did not produce polypeptides similar to either uteroferrin, a major progesterone-induced porcine endometrial specific glycoprotein (Roberts and Bazer, 1980), or the 50,000 to 55,000 ${ }_{\mathrm{r}}$ basic protein identified as the major ovine endometrial product (Moffatt et al., 1980; Bazer et a1., 1981b). In this respect the cow would appear to be functionally unique from the gilt, ewe and mare in that these species were all shown to produce or possess major basic proteins as uterine-specific products (Bazer et al., 1981b), while the bovine uterus appears to synthesize primarily more acidic polypeptides.

In the present study comparison of fluorographs of unfractionated MEM with those prepared from tissue homogenates (Figure 3.5) revealed

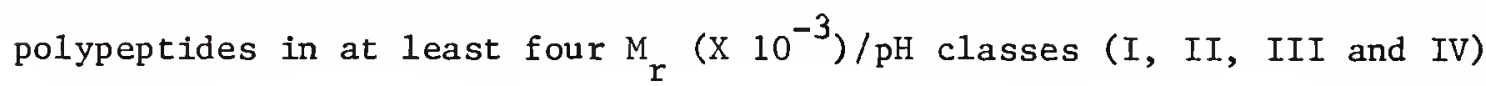


which were enriched in MEM (Figure 3.6). Two distinct polypeptides in class I $(\simeq 14 />7.2)$ were of similar size although somewhat less basic than a series of low $M_{r}$, basic, serine-protease inhibitors. These were identified as $\mathrm{P}_{4}$ induced products of porcine endometrium and thought to be involved in limiting invasiveness of the peri-attachment trophoblast (Mullins et al., 1980a; Fazleabas et al., 1982a,b). Polypeptides in this size class were also described as uterine-specific components of bovine uterine flushings (Roberts and Parker, 1976). Polypeptides in class II (19-24/5.4-6.3) included two products with similar electrophoretic properties to retinol and retinoic acid binding proteins (Adams et al., 1981; Bazer et a1., 1981b). These binding proteins were shown to be $\mathrm{P}_{4}$ induced products of porcine endometrium and were suggested to be involved in transport of Vitamin A to the porcine conceptus (Adams et al., 1981). Two polypeptides with nearly identical electrophoretic characteristics to the porcine Vitamin A binding proteins were also identified as major UM-specific polypeptides (ChapterII; Figure 2.4, UM1 and UM2). Several polypeptides with electrophoretic properties similar to those of class III uterine-specific polypeptides (28-31/6.9-7.3) were also found to be UM-specific (ChapterII, Figure 2.4). Identification of polypeptides in classes II and III on fluorographs of MEM gels from all reproductive statuses, including those from day 270 ligated and pregnant uterine tissue explants, indirectly supports the concept that endometrial tissues of unilaterally pregnant cattle were involved in active synthesis and secretion of uterine-specific products. Bovine UM may therefore provide a rich source of uterine-specific proteins for future investigations.

The array of polypeptides identified in class IV $(\geq 150 / \leq 5.1$; Figure 3.6) displayed similar characteristics to those described for a 
plasma membrane-enriched fraction from porcine endometrium (Mullins et al., 1980b). This membrane fraction was enriched in several brush border marker enzymes including alkaline phosphatase, leucine aminopeptidase and 5'-nucleotidase (Mullins et al., 1980b). These porcine endometrial brush border-associated polypeptides were lectin-binding glycoproteins and, like bovine class IV polypeptides, were present in cyclic and pregnant as well as pseudopregnant gilts. Moss et a1. (1954) detected alkaline phosphatase activity associated with the distal border of bovine uterine epithelial cell surfaces throughout the estrous cycle. Similar activity was detected in glandular epithelium and in glandular secretions (Moss et al., 1954). Histochemical studies indicated intense increases in endometrial surface alkaline phosphatase activity associated with the precontact stage of bovine conceptus attachment (Leiser and Wille, 1975).

Surface of brush border associated glycoproteins such as alkaline phosphatase were suggested to be involved in cellular processes important to establishment and maintenance of pregnancy. Considerable evidence exists to support involvement of such molecules in cell-cell adhesion and fusion (Frazier and Glaser, 1979). Cell fusion may be important during early pregnancy when functional fetal-maternal associations are first established. Fusion of trophoblast with endometrial cells was described for the cow (Wathes and Wooding, 1980), goat (Dent, 1973) and sheep (Wooding et al., 1980). Alkaline phosphatase was suggested to be involved with endometrial carbohydrate metabolism (Larson et al., 1970; Boshier, 1969) and stimulation of uterine secretory activity (Larson et a1., 1970; Murdoch, 1970, 1972) necessary to insure continued production of histotrophe (Leiser and Wille, 1975). 
The wide range of molecular weight and $\mathrm{pH}$ over which bovine uterine-specific polypeptides were identified on fluorographs of 2D-PAGE gels (Figures $3.5,3.6$ and 3.7 ) was not, in general, inconsistent with earlier reports of bovine uterine-specific proteins, identified by various single dimensional techniques, in uterine flushings, fluids, tissues or explant medium (Roberts and Parker, 1974a,b, 1976; Libby et al., 1982; Bartol et al., 1981a; Dixon and Gibbons, 1979; Laster, 1977; Wathes, 1980). While many uterine-specific polypeptides identified in the present study possessed physiochemical characteristics similar to proteins of known biological function, no specific functions have been definitively demonstrated for any isolated bovine uterine-specific protein. Potential functional roles for such molecules, however, are many and, as noted above, may include (1) control of trophoblast invasiveness, (2) binding and transport of nutrients and hormones, (3) stimulation of uterine secretory activity, (4) mediation of conceptus-maternal tissue interactions, and (5) regulation of maternal immune response to the conceptus, as well as serving as part of the general histotrophe (Bazer, 1975; Bazer et al., 1981b; Beer and Billingham, 1979; Segerson et al., 1982). Characterization of the diverse array of polypeptides produced by bovine endometrial tissue in vitro sets the stage for future investigations directed toward isolation and identification of function of the major bovine uterinespecific macromolecules.

Absence of obvious differences in qualitative array of polypeptides produced in vitro by endometrial tissues from pregnant, nonpregnant and cyclic cattle (Figure 3.7 ) suggests that reports of pregnancy-specific bovine uterine proteins (Laster, 1977; Bartol et al., 1981a) reflect 
contributions made to the uterus or uterine environment by the conceptus. Conceptus contributions to the uterine environment are, no doubt, critical for establishment and maintenance of pregnancy. As observed by Beier and Mootz (1979), it is the balance of interactions between the complete array of both maternal and conceptus products in utero that ultimately determines success or failure of a pregnancy. In order to begin to understand dynamics of the intrauterine environment that permit establishment and maintenance of pregnancy it will be important to identify and characterize contributions of conceptus as well as maternal units. 
CHAPTER IV

CHARACTERIZATION OF PROTEINS PRODUCED IN VITRO BY

PERI-ATTACHMENT BOVINE CONCEPTUSES

\section{Introduction}

Amoroso and Perry (1975) noted that, from an evolutionary

standpoint, adaptation of eutherian embryos to prolonged uterine gestation must have required development of self-sufficiency with respect to production and secretion of complex biologically active molecules by the conceptus (embryo and extraembryonic membranes). In large domestic species including cattle, sheep and pigs, in which ectopic pregnancy does not occur, presence of conceptus tissues in utero prior to (estrus = day 0) days 17 (Northey and French, 1980; Sreenan, 1978; Betteridge et al., 1978), 12 (Moore and Rowson, 1966a,b,c) and 13, respectively (Dhindsa and Dziuk, 1968; Bazer et al., 1982), results in prolongation of the estrous cycle as a consequence of maintenance of functional ovarian corpora lutea (luteostasis). A central phenomenon associated with maternal recognition of pregnancy, luteostasis is only one of several conceptus induced or mediated events. Others include establishment of immunological privilege and induction of histotrophe, which must occur if pregnancy is to be established and maintained (Cook and Hunter, 1978; Beer and Billingham, 1979). Clearly, therefore, conceptuses of these species must acquire the ability to produce and secrete biologically active molecules very early in development which effect a myriad of physiological processes essential to their sustenance throughout gestation. 
of the biologically active substances known to be produced by peri-attachment conceptuses of large domestic animals, steroids, especially estrogens, play a major role in establishment of pregnancy in the pig (Bazer et a1., 1982). Production of steroids by conceptus tissues was investigated in sheep (Heap et al., 1981; Gadsby et al., 1980) and to a greater extent in cattle (Shemesh et al., 1979; Eley et a1., 1979a; Eley et al., 1983; Gadsby et a1., 1980; Knickerbocker et al., 1980; Chenau1t, 1980; Thatcher et al., 1980), but no definitive roles for these conceptus products have been established. Production of prostaglandins (PG) of both F and E series was demonstrated in pre-attachment bovine conceptuses (Lewis et a1., 1982; Shemesh et al., 1979). The latter $\left(\mathrm{PGE}_{2}\right)$ was suggested to be involved with conceptus induced antiluteolytic effects in sheep (Pratt et al., 1977; Ellinwood et al., 1979b; Huie et a1., 1981; Reynolds et al., 1981). Conceptus produced proteins were suggested to play important roles in maternal recognition of pregnancy in both sheep (Martal et al., 1979) and cattle (Beal et al., 1981) and protein extracts from pig conceptuses were shown to bind to LH receptors in porcine luteal tissue (Saunders et a1., 1980). Recently, Godkin and coworkers (1982a,b) reported that peri-attachment stage porcine and ovine conceptuses were capable of producing complex arrays of polypeptides in vitro. Additionally, Masters et al. (1983) identified high molecular weight $\left(M_{r}\right)$ glycoproteins released by peri-attachment ovine, porcine and bovine blastocysts in vitro. The approach in these studies was to culture peri-attachment conceptuses in presence of radiolabelled amino acid substrate and, after approximately $24 \mathrm{~h}$, to examine medium for nondialyzable radiolabelled polypeptides. Such polypeptides were interpreted to represent 
macromolecular products of the type presumably released in utero by conceptuses. Production of polypeptides appeared related to stage of conceptus development (Godkin et al., 1982a,b).

While recent data reveal a rather complete picture of polypeptides produced by peri-attachment porcine and ovine conceptuses (Godkin et al., 1982a,b; Masters et al., 1983), data of a similar nature are not available for the cow. Considering the potential physiological importance of such macromolecules, the objective of the present study was to characterize polypeptides produced by bovine peri-attachment stage conceptuses.

\section{Materials and Methods}

\section{Materials}

Tissue culture supplies were purchased from Grand Island Biological Co., Grand Island, NY; L- 4, 5- ${ }^{3} \mathrm{H}$-leucine ( ${ }^{3} \mathrm{H}$-Leu; Sp. act. $\left.55 \mathrm{Ci} / \mathrm{mmol}\right)$ and D- $6-{ }^{14} \mathrm{C}$-glucosamine hydrochloride $\left({ }^{14} \mathrm{C}-\mathrm{Glc}\right.$; Sp. act. Ci/mmol) were from the Radiochemical Centre, Amersham, England; acrylamide, recrystalized according to procedures described by Loening (1967), N, N, $N^{\prime}, N^{\prime}$-tetramethylenediamine and X-Omat RP film XRP-1 x-ray film were products of Eastman Kodak, Rochester, NY; sodium dodecyl sulfate (SDS) and Nonidet P-40 were from BDH Chemicals Ltd., Poole, England; N, N'diallyltartardiamide and Coomassie brilliant blue R-250 were from Bio-Rad Laboratories, Richmond, CA; ampholines were from LKB, Uppsala, Sweden; urea was from Pierce Chemicals, Rockford, IL; insulin was from Eli Lilly, Lilly Research Laboratories, Indianapolis, IN; amino acids, dithiothreitol, protein standards, 2-mercaptoethanol, trishydroxymethylaminomethane (tris, glycine, glucose, sodium chloride, polyethylene glycol, and agarose were from Sigma Chemical Company, St. Louis, MO; 
diethylaminoethy1 (DE-52; DEAE) cellulose was purchased from Whatman Inc., Clifton, NJ; Sephacryl S-200, Sephadex G-75 (superfine) and Sepharose CL-6B were from Pharmacia Fine Chemicals, Piscataway, NJ. All inorganic chemicals were reagent grade or better.

\section{Preparation of Medium}

Eagle's minimum essential medium (MEM) was prepared according to procedures described by Basha et al. (1979) and was identical to that described by Godkin et al. (1982a,b). The same MEM preparation was used also for explant culture of bovine endometrium (Chapter III). As in these studies, content of L-leucine was limited to $5.2 \mu \mathrm{g} / \mathrm{ml}(0.1$ norma1) to enhance tissue uptake of ${ }^{3} \mathrm{H}$-Leu.

\section{Animals}

Normally cyclic cross-bred beef heifers were bred by natural service on the day of estrus (day 0 ). Individual conceptuses were recovered from pregnant cattle on days $16(n=4), 19(n=6), 22(n=3)$ and $24(n=4)$ as described previously (Chapter III). This range of developmental stages was chosen since it encompassed that period of early pregnancy in cattle associated with maternal recognition of pregnancy (Northey and French, 1980; Sreenan, 1978) as well as with early stages of trophoblast-endometrial contact and attachment prerequisite to establishment of a functional placenta (Wathes and Wooding, 1980). Additional day 19 conceptuses were recovered from two cows which were superovulated with FSH-p (Armour-Baldwin Laboratories, Omaha, NE; Bellows et a1., 1969). Based upon total number of corpora lutea on ovaries from FSH-p treated cattle, a maximum of 13 conceptuses (13 Cp) were recovered from one and $17(17 \mathrm{Cp}$ ) from the other cow. 
Conceptuses appeared normal if not somewhat less expanded than single day 19 tissues. Conceptus tissues also were recovered from a day 29 and a day 69 pregnant cow. In these instances uteri, recovered as previously described (Chapter III), were placed in a sterile laminar flow hood and carefully opened along their antimesometrial surfaces to expose conceptus tissues. The entire day 29 conceptus was removed aseptically and representative pieces of day 69 chorion dissected free of underlying allantois. Tissues were incubated as described below.

\section{In Vitro Culture of Conceptuses}

Individual bovine conceptuses or conceptus tissues, recovered as described, were placed immediately into sterile MEM. Since conceptuses increased in size with increasing gestational age, those from days 16 and 19 were incubated in $15 \mathrm{ml}$ MEM, while those from later stages (days 22, 24 and 29) were incubated in 40-50 $\mathrm{ml}$. Day 19 conceptuses recovered from superovulated cattle $(n=2)$ were incubated en mass in $50 \mathrm{ml}$ MEM since they tended to be tangled and difficult to separate. Two pieces of isolated day 69 bovine chorion ( $3.8 \mathrm{~g}$ and $3.6 \mathrm{~g}$ wet weight) were incubated in separate $50 \mathrm{ml}$ aliquots of MEM. Individual conceptus culture dishes were supplemented with 50 to $150 \mu \mathrm{Ci}^{3} \mathrm{H}$-Leu. Cultures of day 19 conceptuses from superovulated cattle were supplemented with ${ }^{3}$ H-Leu alone $(100 \mu \mathrm{Ci} ; \mathrm{n}=1 ; 17 \mathrm{Cp})$ or both ${ }^{3} \mathrm{H}$-Leu $(100 \mu \mathrm{Ci})$ and ${ }^{14} \mathrm{C}-\mathrm{Glc}$ $\left(20 \mu \mathrm{C}_{i} ; \mathrm{n}=1 ; 13 \mathrm{Cp}\right.$ ). Each day 69 chorion explant received $300 \mu \mathrm{C} i$

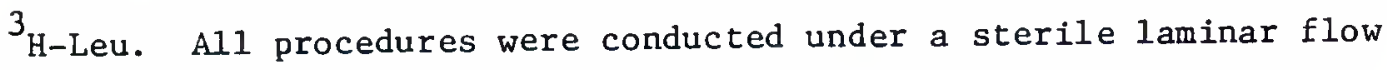
hood.

Conceptus explants were incubated under physical and atmospheric conditions identical to those previously described for short term explant culture of bovine endometrial tissue (Chapter III). Identical 
procedures were used previously by Godkin et al. (1982a,b) for in vitro culture of porcine and ovine conceptuses. Additionally, nondialyzable radioactivity in explant medium increased significantly over a $24 \mathrm{~h}$ period during in vitro culture of porcine, ovine and bovine conceptuses maintained under essentially identical conditions to those described above (Masters et a1., 1983).

At the end of the $24 \mathrm{~h}$ incubation period, tissue and MEM were separated by centrifugation at $4 \mathrm{C}$ and $20,000 \mathrm{~g}$ for 20 min. Medium (supernatant) was dialyzed extensively against several thousand volumes of $10 \mathrm{mM}$ tris-HCL buffer, $\mathrm{pH} 8.2$, in Spectrapor 1 dialysis tubing ${ }^{M_{r}}$ cut-off $\simeq 6-8000$; Spectrum Medical Industries, Los Angeles, CA). Comparison of content of radioactivity in MEM pre- and post-dialysis permitted calculation of percentage of total DPM radiolabelled amino acid added that was retained as nondialyzable product $(\% r)$. Tissue and MEM samples were stored in separate vials at $-20 \mathrm{C}$ until used.

\section{Ion Exchange Chromatography}

An aliquot (3-5 ml) of dialyzed, unfractionated MEM from each individual conceptus explant was saved for electrophoresis and materials in the remaining volume adsorbed to a $10 \times 1.5 \mathrm{~cm}$ DEAE cellulose column equilibrated in $10 \mathrm{mM}$ tris-HCL buffer, $\mathrm{pH} 8.2$, at 4C. After the entire volume of each MEM sample was loaded, columns were thoroughly washed with at least two bed volumes (approximately $40 \mathrm{ml}$ ) of equilibration buffer to elute DEAE (-) proteins. Bound proteins $(\mathrm{DEAE}+)$ were eluted with a $300 \mathrm{ml}$ linear salt gradient $(0.0-0.5 \mathrm{M} \mathrm{NaCl}$ in $10 \mathrm{mM}$ tris-HCL, $\mathrm{pH} 8.2)$. Fractions $(\simeq 2.6 \mathrm{ml})$ were collected throughout the loading and elution periods. Elution profiles for each explant were generated by plotting content of radioactivity in a $100 \mu 1$ aliquot of each fraction 
versus fraction number (elution volume). Peaks of radioactive proteins identified in this manner were pooled. Specific peaks of pooled DEAE (t) conceptus proteins were concentrated either by exchanging material back onto $0.5 \times 1.0 \mathrm{~cm}$ DEAE columns and eluting again with $3-5 \mathrm{ml}$ of $0.5 \mathrm{M} \mathrm{NaC1}$ (Godkin et al., 1982b) or by dehydration of pooled DEAE $(+$ ) fractions with polyethylene glycol $\left(M_{r} \geq 20,000\right)$ through Spectrapor 3 dialysis tubing $\left(M_{r}\right.$ cut-off $\simeq 3500$; Spectrum Medical Ind., Los Angeles, CA). Concentrated DEAE ( $t$ ) fractions could then be subjected to gel filtration.

\section{Gel Filtration Chromatography}

Pooled, concentrated DEAE $(t)$ bovine conceptus proteins were subjected to gel filtration chromatography on Sephacry1 S-200, Sephadex G-75 (superfine) or Sepharose CL-6B as appropriate. Gel filtration was conducted at $4 \mathrm{C}$ in $90 \mathrm{X} 1.5 \mathrm{~cm}$ glass columns and $10 \mathrm{mM}$ tris-HCL buffer, $\mathrm{pH} 8.2$, containing $0.33 \mathrm{M} \mathrm{NaCl}$. The $\mathrm{K}_{\mathrm{av}}$ for each peak of nondialyzable radioactivity was calculated as described by Reiland (1971) and compared with similar values of protein standards. Protein standards used to calibrate S-200 and CL-6B columns were described previously (Chapter III). The G-75 column was calibrated with conalbumin $\left(M_{r} \simeq 77,000\right)$, ovalbumin $\left(M_{r} \simeq 43,000\right)$ and lysozyme $\left(M_{r} \simeq 13,900\right)$. Void volumes of all columns were determined using blue dextran $\left(_{r} \simeq 2 \times 10^{6}\right.$; Pharmacia Fine Chemicals, Uppsala, Sweden) and elution profiles generated as described for ion exchange chromatography.

Two Dimensional Polyacrylamide Gel Electrophoresis (2D-PAGE) and Fluorography

Aliquots (3-5 ml) of unfractionated, dialyzed explant medium from each individual conceptus culture were lyophilized and individual dried 
samples dissolved in a volume of $5 \mathrm{mM} \mathrm{K}_{2} \mathrm{CO}_{3}$ containing $9.4 \mathrm{M}$ urea, $2 \%$ $(\mathrm{v} / \mathrm{v})$ Nonidet $\mathrm{P}-40$ and $0.5 \%(\mathrm{~W} / \mathrm{v})$ dithiothreitol, sufficient to allow 100,000 to $150,000 \mathrm{cpm}$ of nondialyzable radioactivity to be loaded onto each gel in a total volume of not more than $100 \mu l$. Conceptus tissues to be examined by 2D-PAGE were suspended in $0.5-1.0 \mathrm{ml}$ of $5 \mathrm{mM} \mathrm{K} \mathrm{CO}_{3}$ with $9.4 \mathrm{M}$ urea and sonicated on ice at 20 to $30 \%$ probe intensity (Bronwill Biosonic; Bronwill Scientific, Rochester, NY) for six $15 \mathrm{sec}$ periods of 1 min. intervals. Sonicated conceptus tissue was brought to $2 \%$ Nonidet $\mathrm{P}-40(\mathrm{v} / \mathrm{v})$ and $0.5 \%$ dithiothreitol, centrifuged at $18 \mathrm{C}$ and $20,000 \mathrm{~g}$ for $30 \mathrm{~min}$. and an aliquot of resultant supernatant subjected to 2D-PAGE. Methods of sample preparation, tissue solubilization and electrophoretic separation of polypeptides by 2D-PAGE were those described previously by Horst and Roberts (1979) and Horst et al. (1980), and were essentially identical to procedures described previously both for bovine endometrial polypeptides (Chapter III) and by Godkin et al. (1982a,b) for porcine and ovine conceptus polypeptides. Following electrophoresis, Coomassie blue R-250 stained 10\% polyacrylamide slab gels were photographed and fluorographs were prepared as described previously (Chapter III; Chamberlain, 1979; Laskey and Mills, 1975).

\section{Protein Assay}

Total protein concentrations in dialyzed MEM were determined by the method of Lowry et al. (1951) using bovine serum albumin as a standard (BSA; Fraction V; Sigma Chemical Co., St. Louis, MO).

\section{Statistical Analyses}

Where appropriate, data were subjected to analysis of variance according to procedures available in the General Linear Models section 
of SAS (Barr et aí., 1979). Analyses considered variability due to conceptus age (day) and comparison among days 16, 19, 22 and 24 were made by orthogonal contrasts.

\section{Results}

\section{Incorporation of Labelled Amino Acids}

Least square means $( \pm S E M)$ for percent retention of ${ }^{3} \mathrm{H}-\mathrm{Leu}(\% \mathrm{r})$ labelled nondialyzable product in $24 \mathrm{~h}$ cultures of bovine conceptuses from days 16, 19, 22 and 24 are presented graphically in Figure 4.1. Percent retention was lowest in day 16 cultures $(P<.01 ; 1.16 \pm 4.10 \%)$, increased in day $19(16.8 \pm 3.67 \%)$ and day 22 cultures $(20.9 \pm 5.80 \%)$, and decreased $(\mathrm{P}<.07)$ in day 24 cultures $(6.87 \pm 4.10 \%)$. Mean $(\bar{X} \pm S E M)$ content of total protein $(\mu \mathrm{g} / \mathrm{ml} \times \mathrm{ml}$ of MEM) in MEM from days $16,19,22$ and 24 conceptus cultures ( $N=17$ ) was not significantly effected by conceptus age (day; $7.40 \pm 1.23 \mathrm{mg} /$ culture). Since content of total protein was similar for conceptus cultures of all early stages, but \%r increased after day 16 (Figure 4.1), data suggested a general increase in production of labelled polypeptides by bovine conceptuses from later stages of early pregnancy.

Percent retention of radiolabelled amino acids by day 19 conceptuses from superovulated cattle was $7.21 \%$ for those which received only ${ }^{3} \mathrm{H}$-Leu $\left(17 \mathrm{C}_{\mathrm{P}}\right)$. Percent retention in the day 19 culture MEM to which both ${ }^{3}$ H-Leu and ${ }^{14} \mathrm{C}$-Glc were added (13 Cp) was $4.16 \%$ and $7.11 \%$ respectively. Content of total protein in these two cultures was $10.2 \mathrm{mg}$ and $10.8 \mathrm{mg}$ respectively. Hence, comparatively more total protein was recovered in MEM from cultures of day 19 conceptuses from superovulated cattle $(\bar{X} \pm S E M=10.5 \pm 0.3 \mathrm{mg})$, than from cultures of individual bovine conceptuses $(7.4 \pm 1.2 \mathrm{mg})$. However, \%r data suggested that 


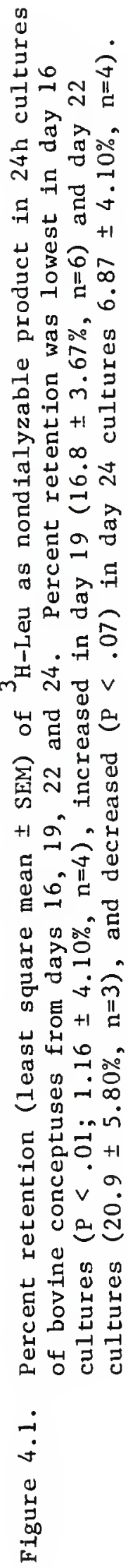




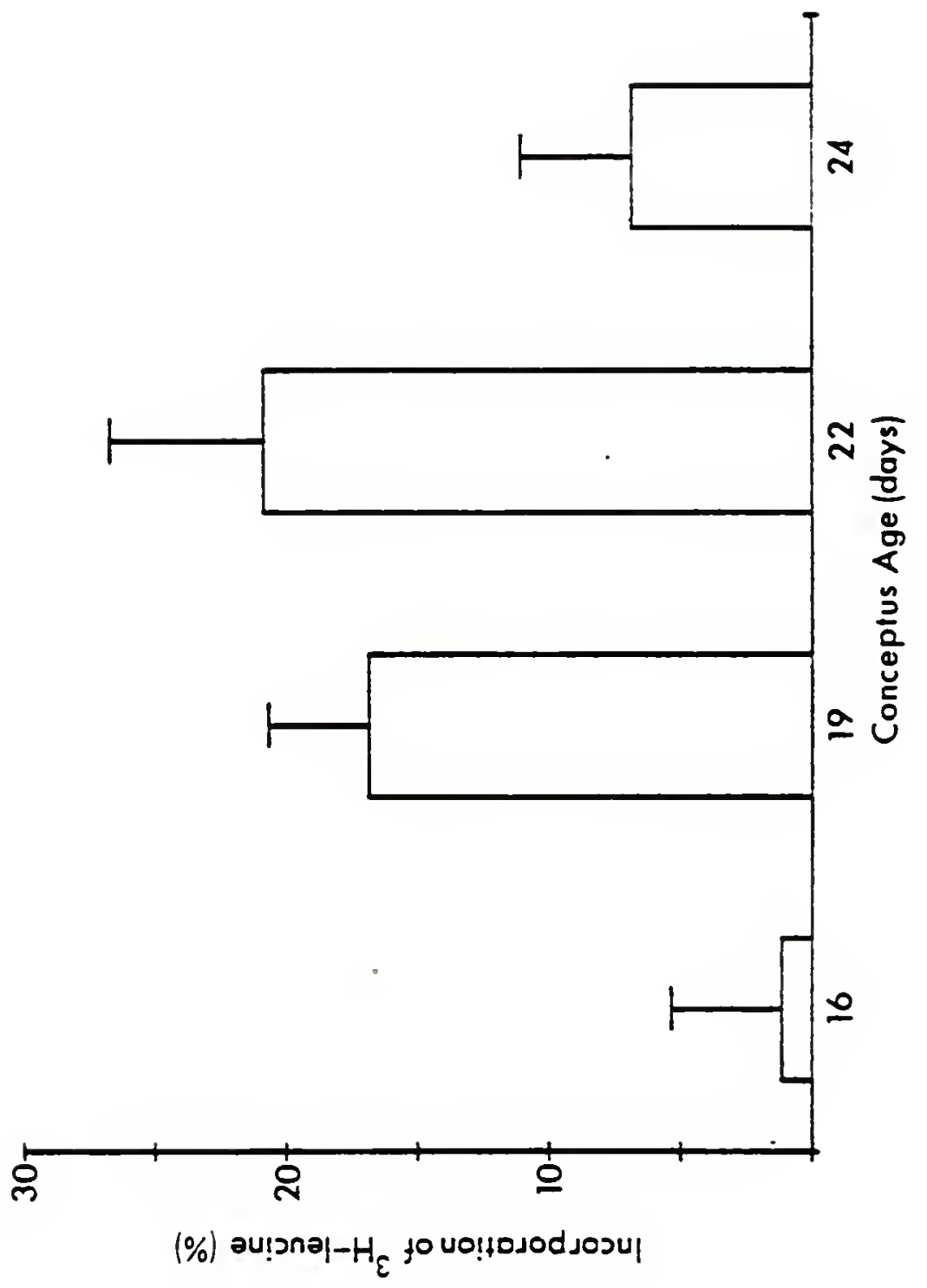


conceptuses from superovulated cattle, cultured en mass, were less active in incorporating radiolabelled amino acids into nondialyzable product in MEM. Further study is warranted to determine comparative efficacy of these two procedures for obtaining bovine conceptus-specific products in vitro. The single day 29 and two day 69 cultures retained $16.2 \%$ and $20.4 \pm 0.6 \%$ of total ${ }^{3} \mathrm{H}$-Leu added as nondialyzable product. DEAE Anion Exchange Chromatography

Representative DEAE anion exchange chromatograms of labelled proteins in MEM from day 16, 19, 22 and 24 conceptus cultures are shown in Figure 4.2. Although the proportionate amount of various labelled proteins produced by conceptuses in vitro may have changed with gestational age, qualitative patterns of DEAE chromatograms were reproducible and fairly constant. Anion exchange chromatography consistently revealed labelled conceptus proteins in three distinct areas (Figure 4.2; 1,2 and 3) including a small DEAE (-) area (1), an early eluting DEAE (+) area (2) and a later eluting DEAE (+) area (3). The majority of nondialyzable radiolabelled proteins bound to DEAE at $\mathrm{pH} 8.2$ indicating conceptus production of primarily acidic polypeptides.

\section{D-PAGE of Bovine Conceptus Proteins}

Fluorographs prepared from representative 2D-PAGE (IEF) gels of polypeptides in dialyzed bovine conceptus culture medium from days 16 , 19, 22 and 24 are shown in Figure 4.3. Primary polypeptides produced by day 16 conceptuses (Figure 4.3A) had $M_{r}\left(X 10^{-3}\right)$ of 22-26 based on electrophoretic mobility in presence of SDS, and migrated in an isoelectric point (IEP) range of 6.5 - 5.6 under denaturing conditions in 


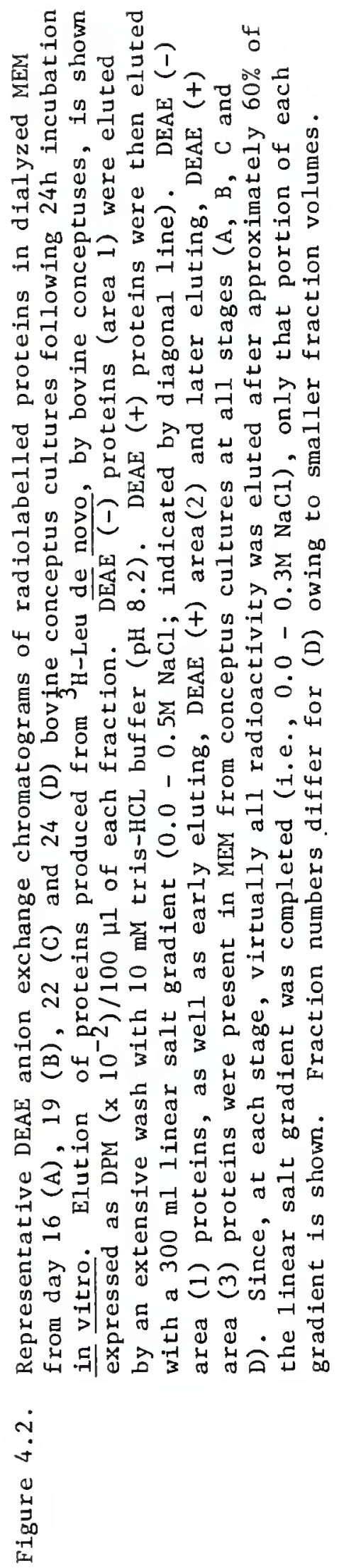



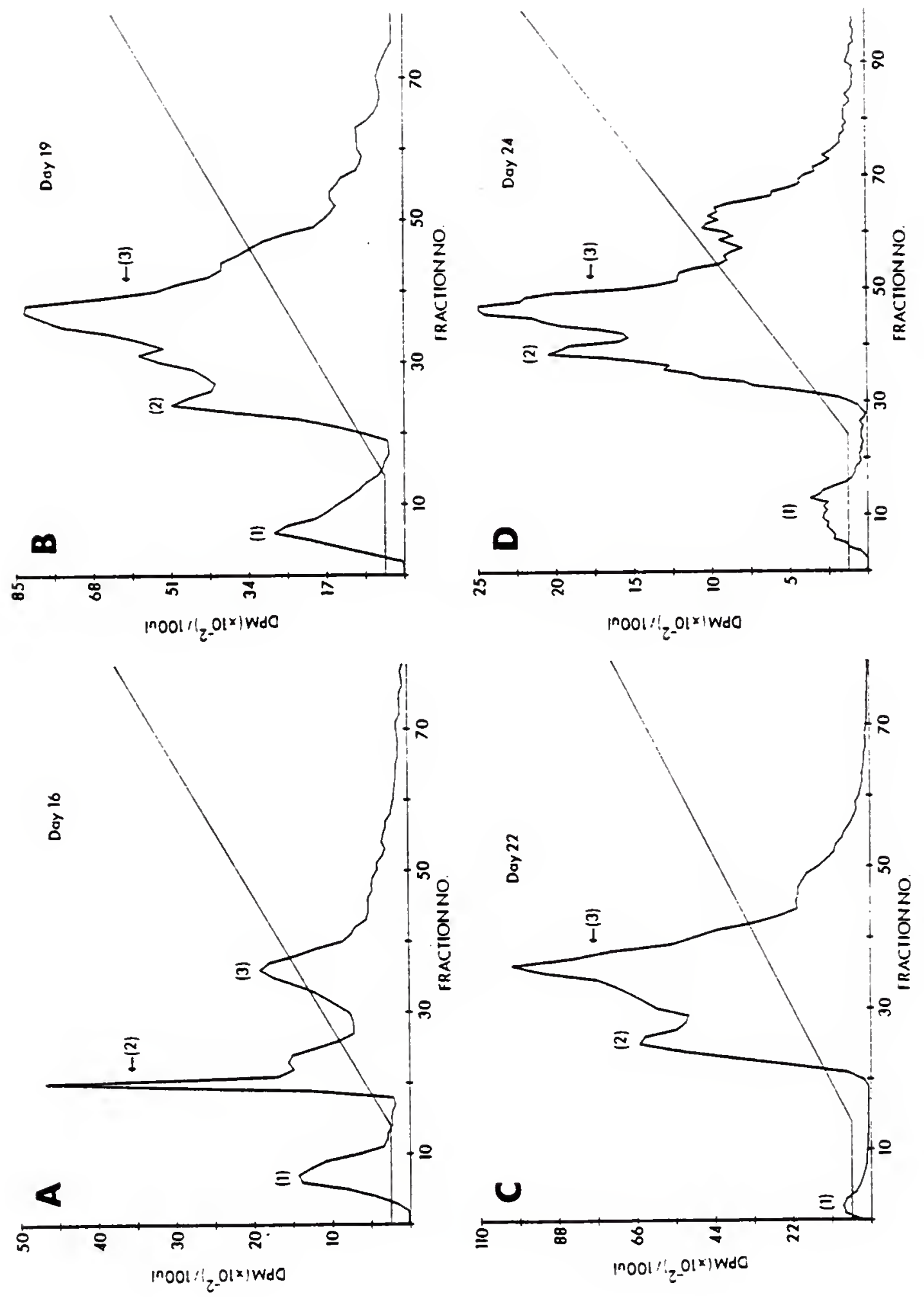


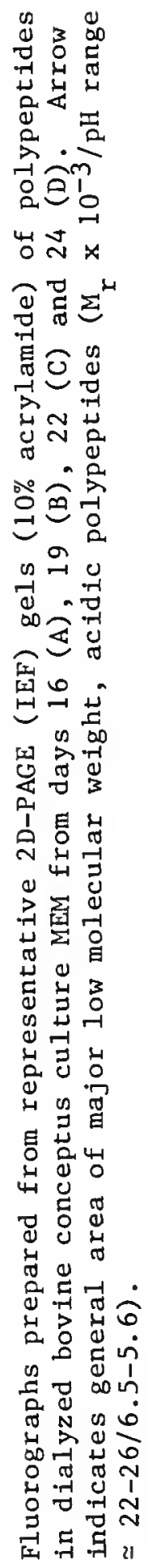

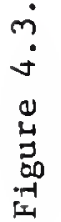



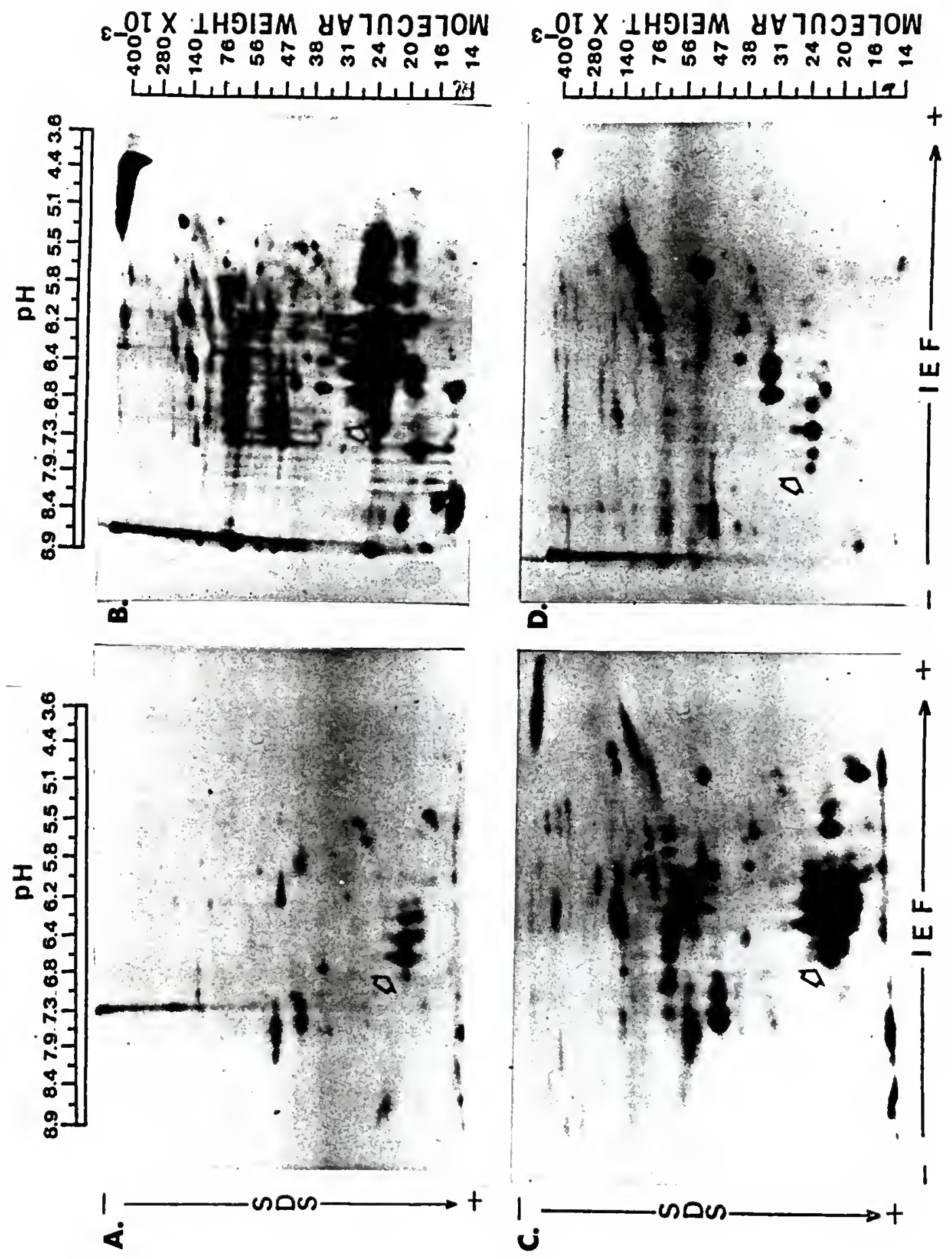
presence of urea. Other less prominent polypeptides identified at this stage included several in the $M_{r}\left(X 10^{-3}\right) /$ IEP range of $40-50 / 6.2-7.4$. The array of polypeptides shown in Figure 4.3A was typical of the two day 16 conceptuses which were at least $5-6 \mathrm{~cm}$ in length. These conceptuses incorporated $1.5 \%$ and $2.7 \%$ respectively of the total ${ }^{3} \mathrm{H}-\mathrm{Leu}$ added to MEM (50 $\mu \mathrm{C} i)$. The same array of polypeptides was less prominent or undetectable on fluorographs of MEM proteins from the two day 16 conceptuses which were less than $2.0 \mathrm{~cm}$ in length. These conceptuses incorporated $0.02 \%$ and $0.40 \%$ of total ${ }^{3}$ H-Leu added to culture medium $(50 \mu \mathrm{Ci})$. Data suggest that the ability of peri-attachment stage bovine conceptuses to incorporate amino acids and synthesize and release proteins is related to the process of elongation of the trophoblast or their developmental stage.

Pattern of polypeptides synthesized by day 19 and later stage conceptuses (Figure 4.3B, C and D) was somewhat more complex than that of day 16 conceptuses and suggested a general qualitative and quantitative increase in protein production. The lower $M_{r}$ acidic polypeptides $\left(M_{r} \times 10^{-3} 22-26 / 6.5-5.6\right)$ remained as prominent products in MEM through day 24 (Figure 4.3D). Two even more acidic lower $M_{r}$ polypeptides were particularly evident on fluorographs from days 19 and 22 although they were also present in day 24 culture medium. These products included one polypeptide in $M_{r}\left(X 10^{-3}\right) /$ IEP ranges of $20-26 / 5.5-5.4$ and a second of 16-20/5.0-4.5 (Figure 4.3B, C). Higher $M_{r}$ products included several polypeptides in the 40-70/7.4-5.5 range and a very large acidic product in the $\geq 400 /<5.0$ range.

Fluorographs of 2D-PAGE (IEF) gels revealing the array of conceptus tissue polypeptides into which ${ }^{3} \mathrm{H}$-Leu was incorporated are shown for 
representative day 16 and 22 conceptus homogenates in Figure 4.4. Primary polypeptides identified in day 16 conceptus tissue homogenates are seen on the central right side of Figure $4.4 \mathrm{~A}$ and migrated in a $M_{r}\left(X 10^{-3}\right) / I E P$ range of 46-60/6.3-4.5. Fluorographs of conceptus homogenates from later stages of gestation (days 19, 22 and 24; Figure 4.4B) were virtually identical but more complex than those from day 16 , and did not include the distinct array of polypeptides shown in Figure 4.4A. Data indicated a significant alteration in type and diversity of structural and functional bovine conceptus polypeptides into which

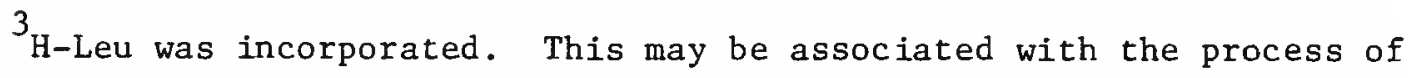
trophoblast elongation and increased secretory activity.

The array of bovine conceptus tissue polypeptides into which $3_{\mathrm{H}-\mathrm{Leu}}$ was incorporated (Figure 4.4) was distinct from that of polypeptides identified in dialyzed MEM at all stages (Figure 4.3). Therefore, the majority of polypeptides identified by fluorography in dialyzed MEM represent proteins produced and released (secreted) by bovine conceptuses in vitro, and are likely most representative of the array of macromolecules secreted by peri-attachment bovine conceptuses in utero.

To determine if the low $\mathrm{M}_{\mathrm{r}}$ acidic array of polypeptides continued to represent a major product of bovine conceptus tissues later in gestation when fetal-maternal attachments were more intimate and placentomes were formed, fluorographs prepared from early stage (day 16, 19, 22 and 24) conceptus MEM (Figure 4.5A) were compared with those from day 29 (Figure 4.5B) conceptus and day 69 chorionic MEM (Figure 4.5C). While the total array of polypeptides produced by bovine conceptus tissues tended to increase in complexity with gestational age, low $M_{r}$ acidic 
Figure 4.4. Fluorographs of 2D-PAGE (IEF) gels ( $10 \%$ acrylamide) showing conceptus tissue polypeptides into which ${ }^{3} \mathrm{H}$-Leu was incorporated in vitro. (A) Day 16 bovine conceptus tissue homogenate. (B) Day 22 bovine conceptus tissue homogenate. 


\section{pH}
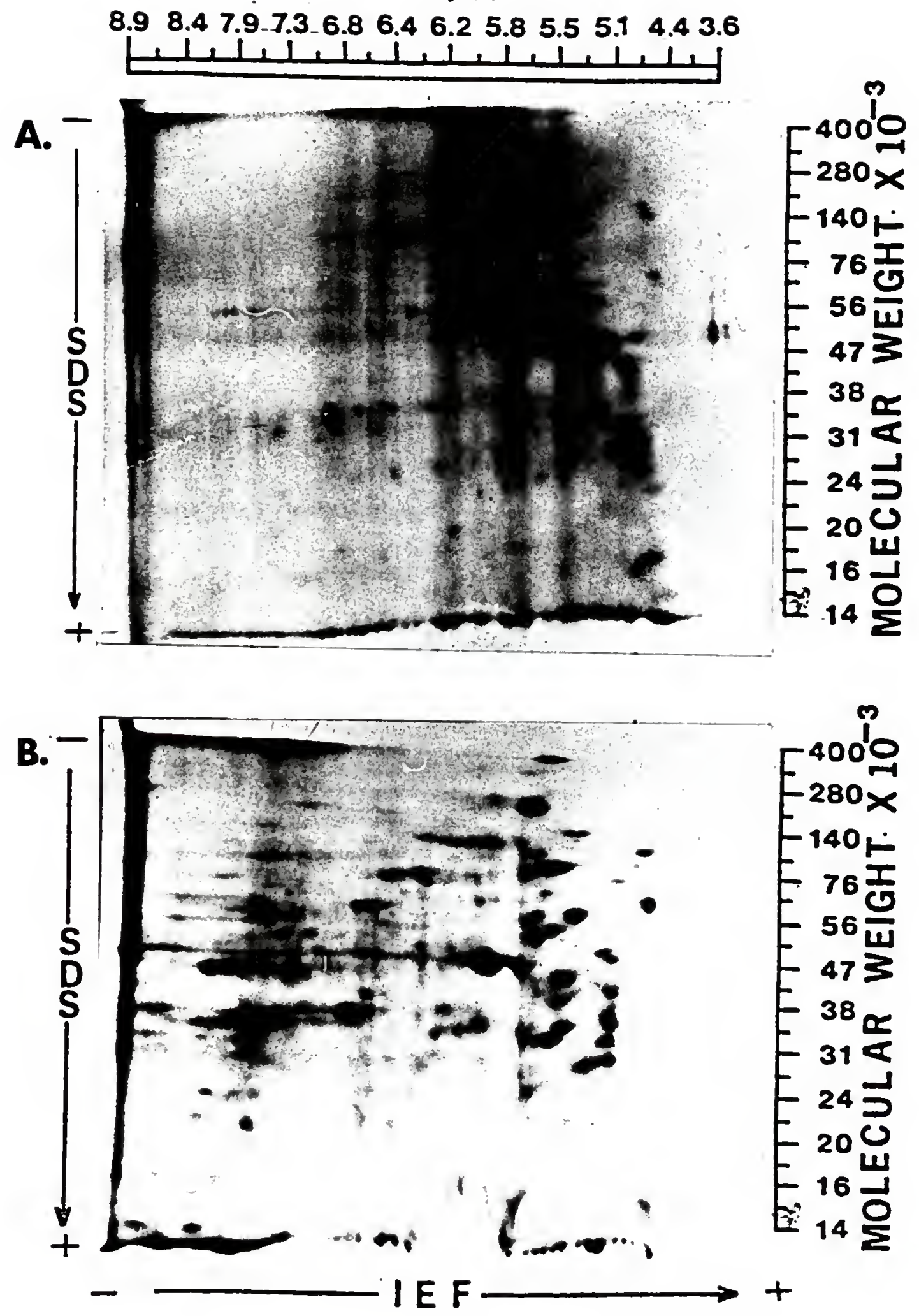
Figure 4.5. Fluorographs prepared from 2D-PAGE (IEF) gels (10\% acrylamide) of polypeptides in dialyzed bovine conceptus culture MEM from days 19 (A) and 29 (B), and isolated chorionic culture MEM from day 69 (C). Arrow indicates general area of major low molecular weight, acidic polypeptides. 
pH
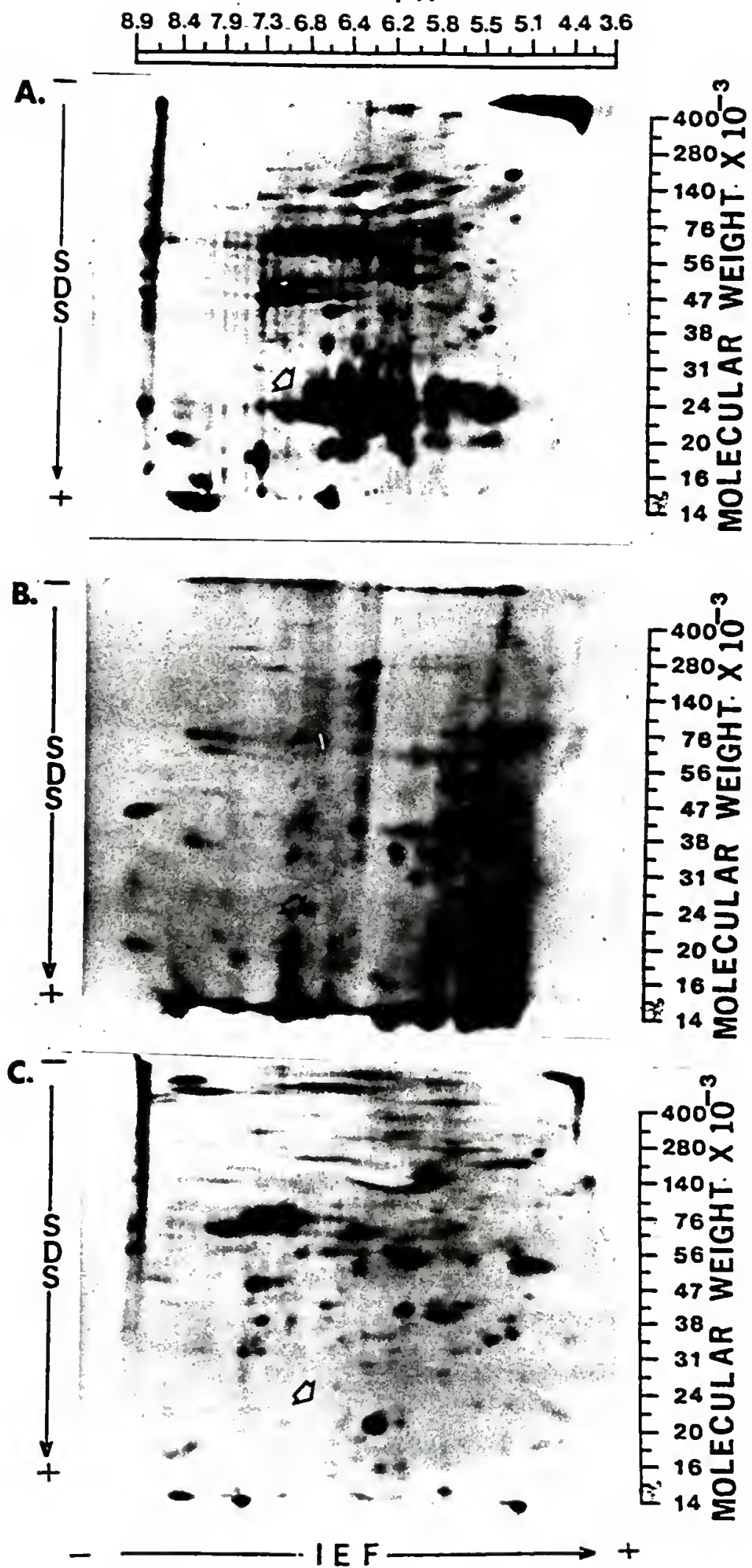
products (22-26/6.5-5.6) in MEM, prominent on fluorographs from early stage bovine conceptuses (days 16, 19, 22 and 24; Figure 4.3), were absent or present in only trace amounts on fluorographs from day 29 and 69 conceptus tissue cultures (Figure 4.5A, B, C). Polypeptides with extremely similar electrophoretic character to the major 10 $M_{r}$ acidic products (22-26/6.5-5.6) of early stage conceptuses were detected on fluorographs from day $69 \mathrm{MEM}$ (Figure 4.5C). It is possible that the larger mass of chorionic tissue incubated in these cultures $(>3.0 \mathrm{~g} /$ $50 \mathrm{ml}$ ) produced sufficient low $M_{r}$ acidic product for detection on fluorographs. Clearly, however, these polypeptides were no longer major products of the bovine conceptus by day 29 of gestation.

\section{Characterization of Major Bovine Conceptus Proteins}

As noted above (Figure 4.2), anion exchange chromatography of proteins in dialyzed MEM from conceptus cultures revealed two major DEAE (+) fraction areas (2 and 3 ). When fractions from the later eluting DEAE (t) area 3 were pooled, as shown in Figure 4.6A, concentrated, and proteins subjected to S-200 gel filtration chromatography, the majority of nondialyzable radioactivity consistently eluted as a major peak with a $K_{a v}$ slightly less than that of chymotrypsinogen-A $\left(\mathrm{K}_{\mathrm{av}} \simeq 0.44 ; \mathrm{M}_{\mathrm{r}} \simeq 27,500\right)$, for $\mathrm{a} \mathrm{M}_{\mathrm{r}}$ estimate of $26,750 \pm 1030\left(\mathrm{~K}_{\mathrm{av}}\right.$ .40 ; Figure 4.6B). The two step fractionation procedure described above and illustrated in Figure 4.6 involved identical conditions to those used to purify a major low $_{\mathrm{r}}(17,000)$ acidic protein produced by ovine trophoblast between days 13 and 21 of gestation (Godkin et al., 1982b).

When low ${ }_{r}$ acidic bovine conceptus product, prepared as shown in Figure 4.6, was subjected to 2D-PAGE (IEF), fluorographs similar to 
Figure 4.6. Fractionation procedure for partial purification of major low molecular weight, acidic polypeptides produced in vitro by bovine conceptuses. (A) Unfractionated, dialyzed MEM is subjected to DEAE anion exchange chromatography and late eluting DEAE (+) area (3) fractions pooled as indicated by stippled area. (B) Representative Sephacryl S-200 gel filtration elution profile obtained following chromatography of DEAE ( + ) area (3) bovine conceptus proteins. Majority of nondialyzable radioactivity appears as a major broad based peak eluting just ahead of chymotrypsinogen-A (Chym-A; $\left.M_{r} \simeq 27,500\right)$. 

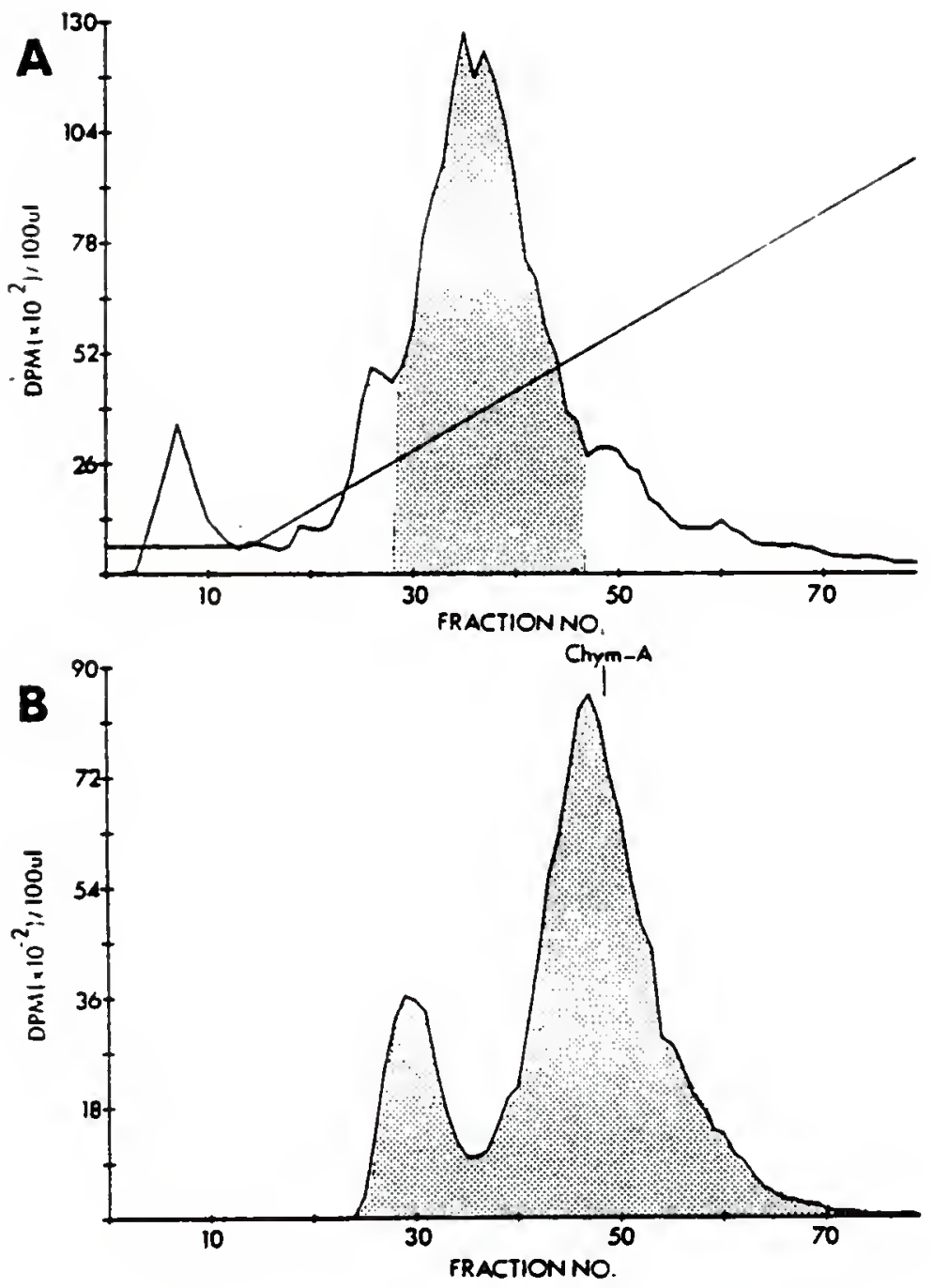
that shown in Figure $4.7 \mathrm{~A}$ were obtained consistently. Primary labelled polypeptides were those in the 22-26/6.5-5.6 range identified as major low $M_{\mathrm{r}}$ products of peri-attachment bovine conceptuses (Figure 4.3). However, traces of labelled product were also seen just above the major group in the same IEP range with $M_{r}\left(X 10^{-3}\right)$ of 50-55 and 75-80. When aliquots of DEAE (3) proteins, purified through S-200, were applied to Sephadex G-75 three symmetric peaks of nondialyzable radioactivity were

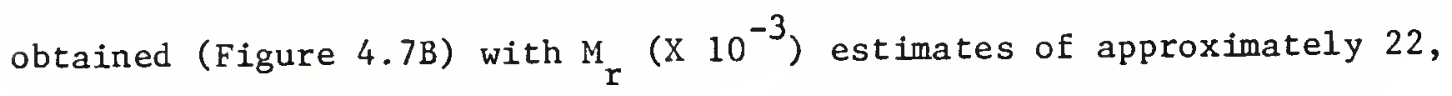
49 and 77. It appeared, therefore, that labelled DEAE (+) area 3 bovine conceptus proteins, fractionated through S-200, approached radiochemical purity as assessed by fluorography of 2D-PAGE (IEF) gels. However, identification of trace amounts of higher $\mathrm{M}_{r}$ polypeptides of the same IEP as the major low $M_{r}$ polypeptides on fluorographs of fractionated material (Figure 4.7A), together with the fact that S-200 purified product produced three distinct peaks on G-75, (two with $\mathrm{M}_{r}$ weight estimates at roughly twice and three times that determined for the primary product $22-26 \times 10^{-3}$ by gel filtration and 2D-PAGE; Figure 4.7B) suggested that this bovine conceptus protein had strong tendencies to aggregate under condition used in the present study. Additionally, these fractionation procedures were apparently inadequate for separation of the major grouping of low $_{\mathrm{r}}$ polypeptides from the even smaller more acidic product seen in the bottom right of Figure 4.7A (see Figure $4.3 \mathrm{~B}$ and $\mathrm{C}$ ).

In addition to the prominent group of low $\mathrm{M}_{\mathrm{r}}$ acidic polypeptides produced by peri-attachment bovine conceptuses (days 16, 19, 22 and 24) a second major product was identified in the early eluting DEAE $(+)$ area (2) fractions of dialyzed conceptus MEM from all stages examined 
Figure 4.7. Characteristics of partially purified low molecular weight, acidic bovine conceptus proteins. (A) Fluorograph prepared from a 2D-PAGE (IEF) gel ( $10 \%$ acrylamide) of DEAE $(+)$ area (3) bovine conceptus proteins following fractionation on Sephacry1 S-200 (see: Figure 4.6). (B) Sephadex G-75 elution profile of DEAE $(+$ ) area (3) bovine conceptus

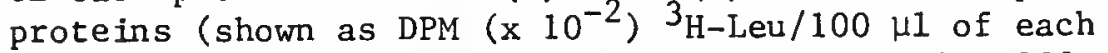
fraction) following fractionation on Sephacryl S-200. Three peaks of nondialyzable radioactivity are shown relative to elution positions of molecular weight standards conalbumin (Con; $M_{r} \simeq 77,000$ ), ovalbumin (Oval; $M_{r} \simeq$ 43,000 ) and Iysozyme (Lys; $M_{r} \simeq 13,900$ ). 


\section{$\mathrm{pH}$}

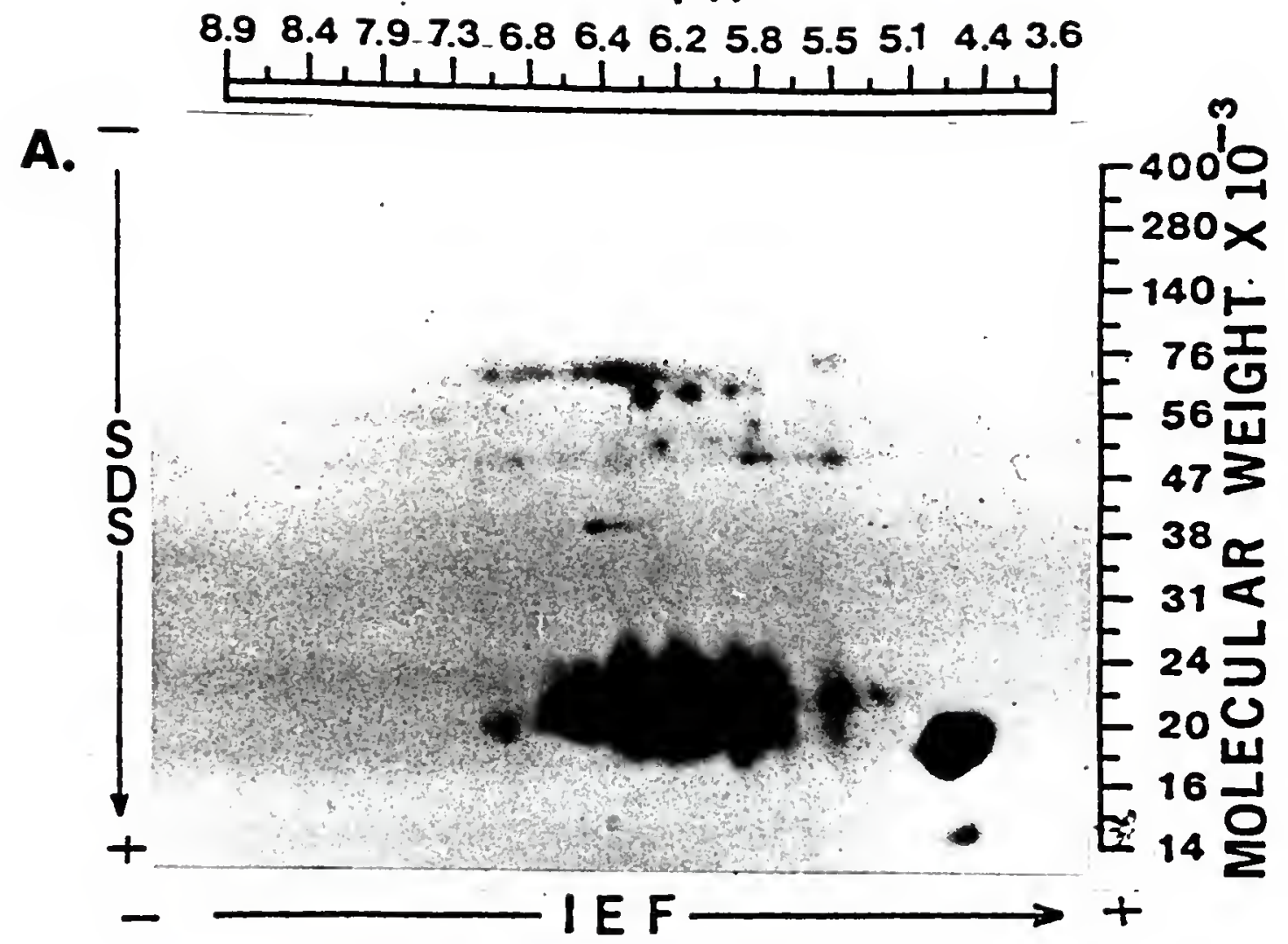

B.

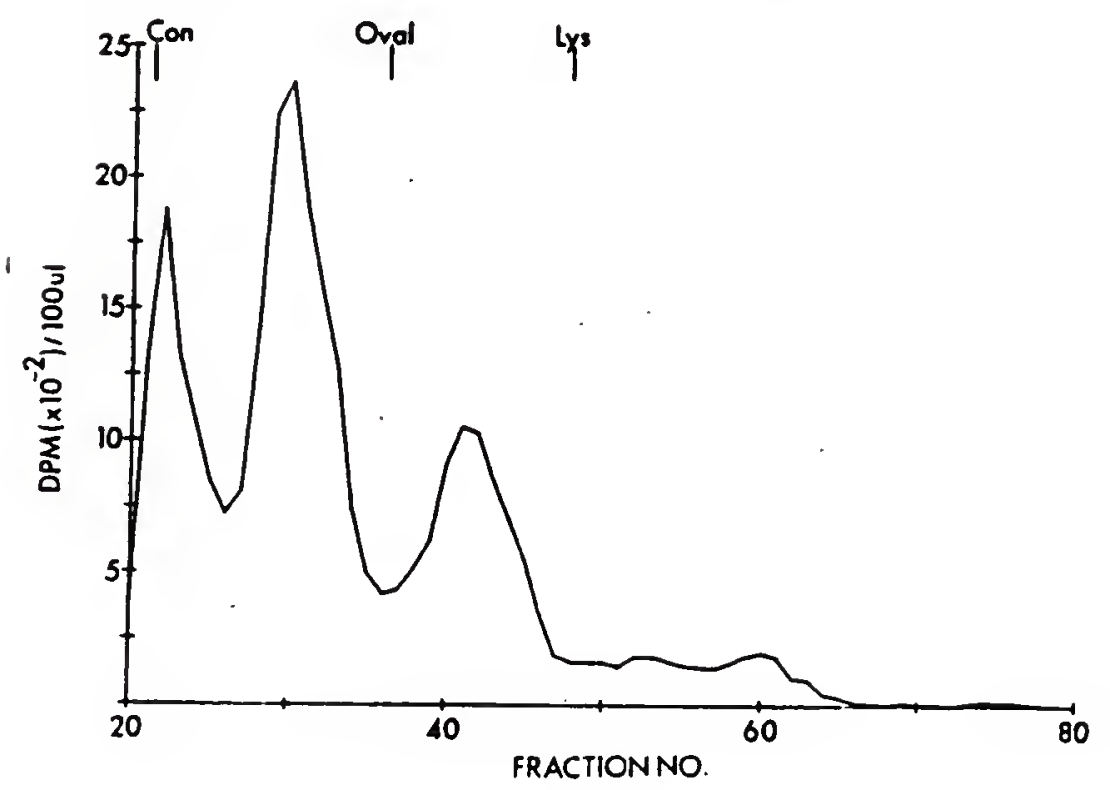


(days 16, 19, 22, 24 and 69). When day 19 conceptuses from a superovulated cow were incubated in presence of both ${ }^{3} \mathrm{H}$-Leu and ${ }^{14} \mathrm{C}-\mathrm{Glc}$, proteins in DEAE (+) area (2) were heavily labelled with ${ }^{14} \mathrm{C}-\mathrm{Glc}$ (Figure 4.8A). When early eluting (area 2) DEAE (+) fractions from conceptus MEM from each stage (days 16, 19, 22, 24 and 69) were concentrated and subjected individually to CL-6B gel filtration, a symmetric peak of nondialyzable radioactivity was consistently obtained as shown in Figure 4.8B. This high $\mathrm{M}_{\mathrm{r}}$ bovine conceptus glycoprotein

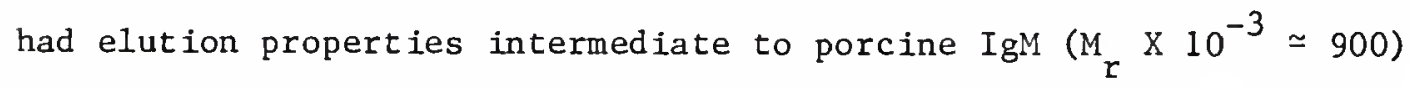
and thyroglobulin $\left(M_{r} \times 10^{-3} \simeq 669\right)$ for an estimated $M_{r}\left(\times 10^{-3}\right.$; $\bar{X} \pm \mathrm{SEM}, \mathrm{n}=10)$ of $735 \pm 22$. This high $\mathrm{M}_{\mathrm{r}}$ glycoprotein was previously described by Masters et al. (1983) as a major product of day 19 bovine conceptuses. In the present study fractionation of day 16, 19, 22, 24 and 69 DEAE (+) area (2) proteins through CL-6B (Figure 4.8) indicated that this high $\mathrm{M}_{\mathrm{r}}$ bovine conceptus glycoprotein was produced throughout the peri-attachment period as well as by explants of chorion from day 69 of gestation.

\section{Discussion}

In the present study, polypeptides produced in vitro by periattachment stage bovine conceptuses were characterized. Using an identical explant system, Lewis et al. (1979) first described uptake of radiolabelled amino acids and de novo synthesis of labelled proteins by day 19 bovine conceptuses. Later, Masters et al. (1983) used this system to obtain high $\mathrm{M}_{\mathrm{r}}$ glycoproteins from cultured bovine, porcine and ovine conceptuses. Methods employed in all studies were essentially identical to those described by Godkin et al. (1982a,b) for characterization of polypeptides produced by peri-attachment stage porcine and ovine conceptuses. 
Figure 4.8. Isolation of the high molecular weight bovine conceptus glycoprotein. (A) DEAE anion exchange chromatogram of radiolabelled proteins in MEM from a day 19 bovine conceptus culture. Conceptuses (from a single superovulated cow; $13 \mathrm{cp}$ ) were incubated with both ${ }^{3} \mathrm{H}$-Leu (solid 1 ine; DPM $\left(x 10^{-2}\right){ }^{3} \mathrm{H}-$ Leu/ $/ 100 \mu 1$ of each fraction) and ${ }^{14} \mathrm{C}-\mathrm{Glc}$ (connected symbols; DPM $\left(x 10^{-2}\right){ }^{14} \mathrm{C}-\mathrm{Glc} / 100 \mu 1$ of each fraction). Stippled area (A) indicates heavily glucosamine-labelled early eluting DEAE (+) area (2) fractions which were pooled and applied to Sepharose CL-6B. (B) Sepharose CL-6B gel filtration elution profile of DEAE ( + ) area (2) bovine conceptus proteins. Major peak of nondialyzable radioactivity is shown relative to elution positions of molecular weight standards porcine IgM (pIgM; $M_{r} \simeq 900,000$ ) and thyroglobulin (Thyg; $M_{r} \simeq 669,000$ ). 

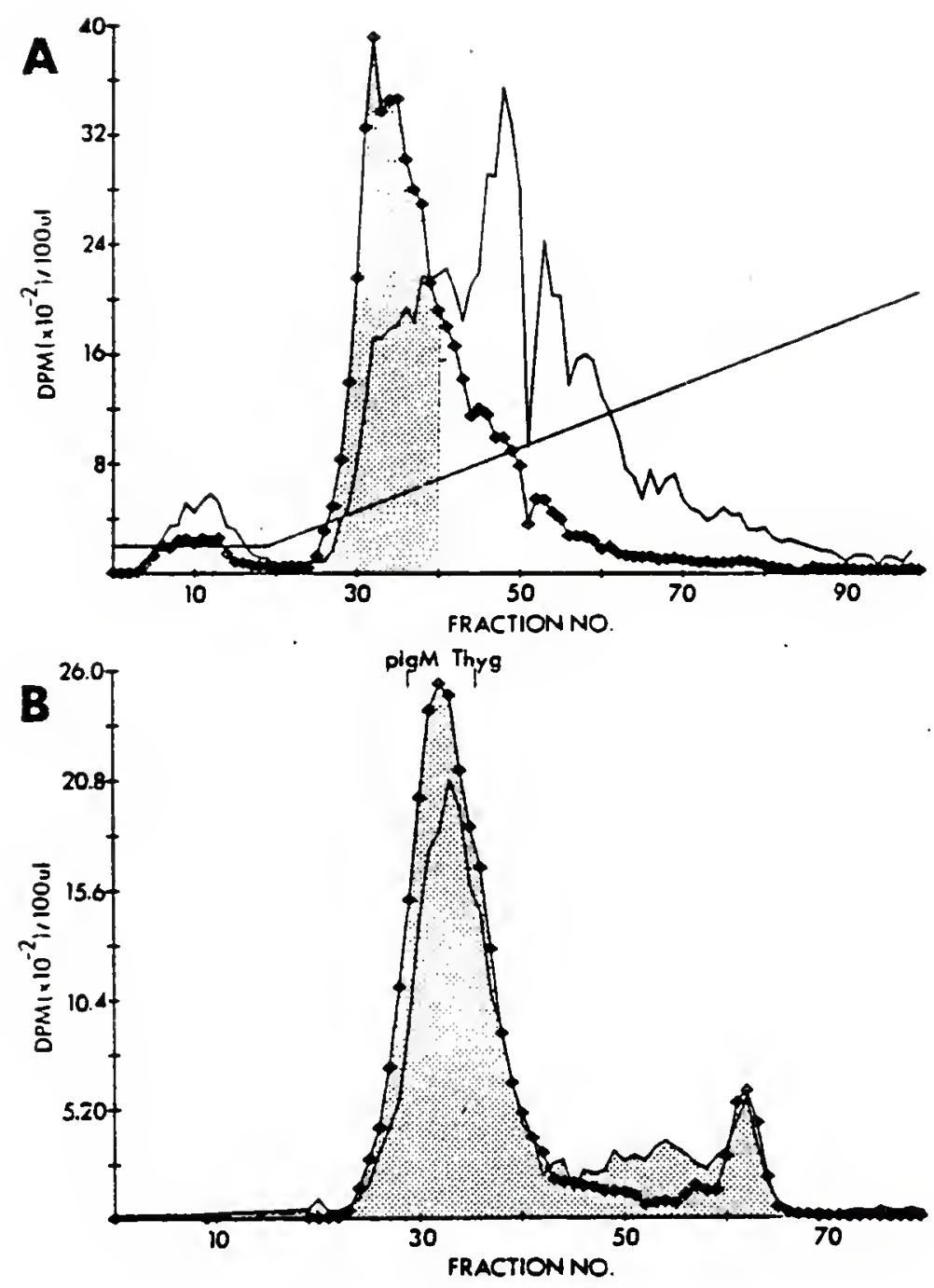
To date, few studies have dealt with proteins associated with or produced by bovine conceptus tissues during the peri-attachment stage of early pregnancy. Several studies of bovine conceptus related proteins involved examination of extracts of placental tissues. Butler et a1. (1982) described two very acidic proteins in.extracts of bovine placental membranes from days 25 through 270 of gestation. One had an estimated $M_{r}\left(X_{10^{-3}}\right)$ of $65-70$ and an IEP of 4.6-4.8. This placental component was suggested to be $\alpha_{1}$-fetoprotein. The second was somewhat smaller $\left(M_{r} \times 10^{-3} \simeq 47-53\right)$ and more acidic $(I E P \simeq 4.0-4.4)$. Avivi et al. (1982) isolated and characterized a 94,000 dalton protein with thyrotropic activity from bovine placentae obtained from days 40 to 120 of gestation. Products described in those studies were associated with conceptus tissues from later stages of pregnancy than were of interest in the present study. Regardless, these products did not appear as singularly unique, prominent labelled components of either MEM or conceptus tissues as assessed by fluorography of 2D-PAGE (IEF) gels in the current study. Clearly, a variety of products were seen in both tissue and MEM.

Flint et al. (1979) detected bovine placental lactogen (bPL) in homogenates of bovine conceptuses from days 17, 24 and 25, but other conceptus products were not investigated. Wathes (1980) examined effects of steroids and co-culture of conceptus and uterine tissues on ability of bovine chorion from days 24-44 of gestation to incorporate radiolabelled leucine in vitro. However, products detected in medium were not subjected to high resolution chromatographic and electrophoretic techniques. In this 1 ight, present results represent a first attempt to identify and characterize proteins produced by bovine 
conceptuses obtained during a period associated with maternal recognition of pregnancy and establishment of a functional placenta.

The percentage of total ${ }^{3} \mathrm{H}$-Leu added to individual bovine conceptus cultures which was incorporated into nondialyzable product (Figure 4.1) was lowest in day 16 cultures ( $P<.01 ; 1.16 \pm 4.10 \%$ ) and increased markedly in day $19(16.8 \pm 3.67 \%)$ and day 22 cultures $(20.9 \pm 5.80 \%)$. These observations agreed with earlier reports which indicated that the extent to which bovine conceptuses converted substrates for both steroid and prostaglandin synthesis increased with gestational age (Chenault, 1980; Eley et al., 1983; Lewis et al., 1982). The decrease $(P<.07)$ in $\% \mathrm{r}$ noted in day 27 cultures $(6.87 \pm 4.10 \%)$ may reflect reduction in tissue viability as a consequence of procedural damage. By day 24, conceptus tissues extended through both uterine horns and superficial attachment between conceptus and maternal tissues had begun (Wathes and Wooding, 1980). Increased physical manipulations were necessary to extract day 24 conceptuses from the uterine lumen and may have been sufficient to damage delicate trophoblastic tissues. Alternatively, this stage of conceptus development (day 24) was associated with expansion of the allantois and almost complete regression of the yolk sac (Greenstein et al., 1958; Wimsatt, 1951; Chang, 1952). Although the allantois is not fully vascularized until after day 26 (Greenstein et al., 1958), the fetal heart has begun to beat by days 20-22 (Greenstein and Foley, 1958a). Consequently, by day 24 the yolk sac has regressed and a rudimentary functional chorioallantoic exchange system is present. Decreased incorporation of ${ }^{3}$ H-Leu substrate into macromolecular product at this stage may therefore reflect a transition in function of extraembryonic membranes towards a more absorptive and somewhat less secretory role with respect to macromolecules. 
Anion exchange (DEAE) profiles of dialyzed proteins in bovine conceptus MEM (Figure 4.2) were similar to those reported for both porcine and ovine conceptus proteins (Godkin et al., 1982a,b). Bovine conceptuses, however, did not produce a major DEAE (-) basic protein such as that produced by porcine conceptuses (Godkin et al., 1982a), and in this respect DEAE profiles more nearly resembled those presented for peri-attachment ovine conceptuses (Godkin et al., 1982b). The majority of nondialyzable radiolabelled proteins in bovine conceptus MEM from all stages examined bound to DEAE at $\mathrm{pH} 8.2$ indicating that, like ovine conceptuses (Godkin et al., 1982b), peri-attachment bovine conceptuses produced primarily acidic proteins. No major qualitative changes in DEAE profiles of bovine conceptus proteins were. associated with stage of gestation (Figure 4.2). These profiles suggested that major alterations in conceptus protein production after day 16 were primarily quantitative.

Uptake of ${ }^{3} \mathrm{H}$-Leu and production of polypeptides by day 16 bovine conceptuses appeared related to stage or extent of development of the trophoblast. Those day 16 conceptuses which had expanded to some degree were apparently more active in incorporation of labelled amino acid substrate and synthesis and release of labelled polypeptides. Consistent with present observations, several studies indicated day 16 bovine conceptus lengths to be highly variable, extending over a range of less than $2 \mathrm{~mm}$ to over $200 \mathrm{~mm}$ (Hawk et al., 1955; Staples et al., 1961; Betteridge et al., 1980). Elongation of bovine trophoblast begins after establishment of endoderm, progenitor of both yolk sac and allantoic membranes (Eckstein and Kelly, 1977; Greenstein and Foley, 1958a), and is accompanied by appearance of extraembryonic somatopleuric 
mesoderm, source of trophoblastic/chorionic tissues (Greenstein and Foley, 1958a). Therefore, ability of elongated day 16 bovine conceptuses to metabolize amino acid substrate and produce detectable amounts of labelled polypeptides suggests that these processes are initiated following establishment of embryonic endoderm, and are associated with appearance of somatopleuric mesoderm which ultimately gives rise to the chorionic layer of the chorioallantois.

Further indirect evidence of a relationship between stage of conceptus development and metabolic capacity was revealed by fluorography of 2D-PAGE (IEF) gels of polypeptides in MEM and conceptus tissue homogenates. As illustrated in Figure 4.3, the number and/or amount of polypeptides produced in vitro and released into MEM by bovine conceptuses increased after day 16 . These changes were related to or accompanied by alterations in the array of structural and functional conceptus tissue polypeptides into which ${ }^{3}$ H-Leu was incorporated. This pattern became qualitatively different and more complex in later stage conceptuses (day 16 vs. 19, 22 and 24; Figure 4.4).

The time between days 16 and 19 of bovine gestation constitutes a dynamic period of rapid elongation of the trophoblast, initial expansion of allantois, establishment of a functional but temporary yolk sac and vitteline circulation, and appearance of large binucleate cells on the external trophoblastic surface (Greenstein and Foley, 1958a; Greenstein et a1., 1958; Chang, 1952; Wathes and Wooding, 1980; King et a1., 1980). Consequently, the array of tissues and cell types which may contribute to the compliment of proteins produced in vitro by conceptuses is established during this period. With the exception of regression of the yolk sac and continued expansion of the allantois, this array of 
tissues is relatively constant throughout the peri-attachment period after day 16 until placentome formation begins. The dramatic change observed after day 16 (Figure 4.4) in array of conceptus tissueassociated polypeptides into which ${ }^{3} \mathrm{H}$-Leu was incorporated undoubtedly reflected these dynamic developmental events. Similarly, products identified by fluorography in dialyzed MEM from later stage conceptus cultures may represent contributions of the yolk sac as well as the chorion and chorioallantois. Labelled polypeptides released by isolated peri-attachment stage ovine yolk sac and porcine embryo-amnion units were shown to be distinct from corresponding trophoblastic (chorionic) products (Godkin et al., 1982a, b).

As evidenced by comparison of Figure 4.4 with Figure 4.3 , the array of bovine conceptus tissue polypeptides into which ${ }^{3} \mathrm{H}-$ Leu was incorporated was distinct from that identified in MEM. Therefore, polypeptides identified as being enriched in MEM, but absent or present in only trace amounts in tissue, appeared to be selectively released by conceptuses during culture. Consequently, these polypeptides are most likely representative of macromolecular products contributed to the uterine environment by peri-attachment stage bovine conceptuses. Additionally, observations suggest that it would be difficult to extract significant amounts of these conceptus products from tissues themselves.

Present data indicated that bovine conceptuses were capable of producing a variety of polypeptides in vitro when recovered from as early as day 16 of gestation (Figure 4.3 and 4.4 ). Of the many polypeptides produced by conceptus tissues and resolved by fluorography of 2D-PAGE (IEF) gels, a family of 1 ow $M_{r}$ acidic polypeptides was especially enriched in MEM from day 16 conceptus cultures, and remained a 
prominent component of day 19,22 and 24 cultures. Synthesis and release of these polypeptides by early expanded day 16 conceptuses suggested a trophoblastic source for this product as discussed above. The major group of 1 low $M_{r}$ acidic polypeptides in MEM was found in a $M_{r}\left(X 10^{-3}\right) /$ IEP range of $22-26 / 6.5-5.6$. Associated with this primary group were two more acidic polypeptides at 22-26/5.6-5.5 and 16-20/ 5.0-4.5 (Figure 4.3). Comparison of 2D-PAGE (IEF) fluorographic patterns of polypeptides in MEM from peri-attachment stage (day 16, 19, 22 and 24 ) bovine conceptuses with that of a day 29 conceptus (Figure 4.5) Indicated that, by day 29 , the low $M_{r}$ acidic family of polypeptides were no longer major conceptus products. In MEM of day 69 explants, trace amounts of polypeptides were detected with identical electrophoretic character to several of the low $M_{r}$ acidic products on fluorographs of polypeptides in MEM from peri-attachment preparations. This suggested that production of some of these proteins may not be terminated later in gestation, even after placentome formation.

Identification of a major group of low $\mathrm{M}_{r}$ acidic polypeptides (22-26/6.5-5.6) produced in vitro by peri-attachment stage bovine conceptuses was consistent with reports of similar but not identical polypeptide groupings produced in vitro by porcine and ovine trophoblasts (Godkin et al., 1982a,b). These polypeptides were also prominent but transient products, produced by ovine conceptuses from days 13-21 and by porcine conceptuses from days 10.5-16. The temporal pattern of appearance and transient nature of production of such low $\mathrm{M}_{\mathrm{r}}$ acidic polypeptides by conceptuses of three major domestic species allows one to speculate that such products might serve important functional roles during the peri-attachment period associated with establishment of pregnancy 
Evidence for the role of a conceptus produced protein in maternal recognition of pregnancy is perhaps strongest, although still circumstantial, in sheep. In cyclic ewes intrauterine infusion of homogenates of day 14-16 ovine conceptuses was luteostatic. This effect was ablated in heat treated conceptus homogenates and not reproducible when homogenates of day 21-23 conceptuses were infused (Rowson and Moor, 1967; Martal et al., 1979). Martal et al. (1979) presented evidence for a heat labile, protease intolerant component of day 14-16 ovine conceptus homogenates (trophoblastin) which was antiluteolytic when infused into uteri of cyclic ewes. The period of time during which the ovine conceptus possessed antiluteolytic properties in these studies coincided well with the period of production of ovine trophoblastic protein-X (Godkin et al., 1982b). This 1 low $\mathrm{M}_{\mathrm{r}}$ acidic protein is produced in vitro by sheep conceptuses from days 13-21. However, a definitive role for this protein has yet to be established.

Evidence that the bovine conceptus can alter corpus luteum (CL) function early in gestation was presented by Northey and French (1980). In this study interestrous interval was extended in cattle from which conceptuses were removed on day 17 (25 \pm 1.2 days) as compared with either non-mated controls (21 days) or cattle from which conceptuses were removed on day 15 (20.2 \pm 0.8 days). Additionally, intrauterine infusions of conceptus homogenates on days 15 through 17 extended interestrous interval and delayed decline in peripheral plasma progesterone associated with luteal regression. Results indicated that a conceptus related component must be present in utero from at least days 15 to 17 in order to exert an antiluteolytic effect, and that this component is either not present, or present in insufficient quantity to elicit an 
effect on or before day 15. Beal et al. (1981) demonstrated that homogenates and extracts of day 18 bovine blastocysts stimulated progesterone synthesis by dispersed Iuteal cells in vitro. Luteotrophic activity appeared to be due to a heat labile substance of less than $12,000 \mathrm{M}_{\mathrm{r}}$, but authors did not exclude the possibility that nonprotein molecules such as steroids or prostaglandins might be involved. Poffenbarger et al. (1982) indicated that luteinizing hormone activity was not present in day 16-20 bovine conceptus homogenates or explant medium as assessed by mouse Leydig cell bioassay.

Available evidence suggests that both antiluteolytic and luteotrophic mechanisms may be involved in maternal recognition of pregnancy in the cow as defined by luteostasis. Data also suggest that conceptus products involved in initiating these processes may act both at the level of the uterus and directly at the level of the CL. Present data indicate that, in addition to a variety of steroids and prostaglandins of both $E$ and $F$ series produced by bovine conceptuses from as early as day 13 (Shemesh et al., 1979; Chenault, 1980; Lewis et al., 1982; Eley et al., 1983), a group of low $\mathrm{M}_{r}$ acidic polypeptides appear as major products of the bovine conceptus from day 16 to at least day 24 . Like steroid and prostaglandin products, these polypeptides are present during a critical period associated with maternal recognition of pregnancy. At present it is only the transient nature of production of detectable amounts of these polypeptides that suggests a functional relationship. No definitive roles related to luteostatis have yet been established for any bovine peri-attachment conceptus products.

Another potential but as yet unconfirmed role for transiently produced low $M_{r}$ acidic conceptus polypeptides may be related to stimulation of histotrophe production. The period of time during which bovine 
as well as ovine and porcine low $\mathrm{M}_{\mathrm{r}}$ acidic products are produced coincides developmentally with rapid expansion of the trophoblast, regression of the yolk sac and establishment of a functional chorioallantois (Heuser, 1927; Green and Winters, 1945; Winters et a1., 1942; Greenstein et al., 1958). All three species produce miolecithal eggs (Mossman, 1980), and transient production of 1 low $\mathrm{M}_{\mathrm{r}}$ acidic polypeptides by each speciesoccurs during a critical period of transition from embryonic dependence on yolk nutrients from the temporary vitteline circulation, to dependence on histotrophic nutrients provided from the uterine environment by the chorioallantoic circulation. Godkin et al. (1981) presented immunocytochemical evidence for uptake of ovine trophoblast protein-X (Godkin et al., 1982b) by uterine endometrium in intact pregnant sheep. Recent evidence indicated that this association may effect selective stimulation of specific uterine proteins in vitro (J.D. Godkin, personal communication). Production of polypeptides during the peri-attachment period which might selectively stimulate uterine histotrophe production would be particularly beneficial to the conceptus during this period of transition in nutrient source dependence.

Fractionation of DEAE (+) area (3) bovine conceptus proteins through S-200 (Figure 4.6) produced a relatively broad based peak of nondialyzable radioactivity with an average $M_{r}$ estimate $(\bar{X} \pm S E M)$ of $26,750 \pm 1030$. When proteins from such pooled S-200 peaks were subjected to 2D-PAGE (IEF) and fluorography, this protein fraction was found to consist primarily of the major low $M_{r}$ acidic polypeptides (22-26/ 6.5-5.6), but also included the two minor acidic polypeptides (22-26/ 5.5-5.4; 16-20/5.0-4.5; Figure 4.7A). Evidence of aggregation was seen on fluorographs above the major products in the same IEP range. Further 
fractionation of this S-200 purified material indicated that the major low $M_{r}$ acidic polypeptides had a tendency to aggregate in tris-HCL buffer ( $\mathrm{pH} 8.2$ with $0.33 \mathrm{M} \mathrm{NaCl}$ ), both in presence and absence of IM sucrose. Consequently these polypeptides were not definitively purified. Data indicated that purification of the major low $_{r}$ acidic polypeptide products of peri-attachment bovine conceptuses may require more elaborate fractionation procedures and altered buffer conditions from those described above and by Godkin et al. (1982b) for purification of ovine trophoblastic protein-X.

The $M_{r}\left(X 10^{-3}\right) /$ IEP estimate determined for the major group of low $M_{\mathrm{r}}$ acidic polypeptides (22-26/6.5-5.6; Figure 4.3) was similar to that reported for bPL $(22.15 / 5.9)$ by Bolander and Fellows (1976). More recent estimates indicated purified bPL to have a $M_{r}\left(X_{10}^{-3}\right)$ in the 32-35 range (Kensinger et al., 1982; Murthey et a1., 1982). Although this placental protein was detected by radioreceptor assay in homogenates of bovine conceptuses from days 17, 24 and 25 (Flint et al., 1979) it appears to be produced throughout gestation and not transiently during the peri-attachment period (Bolander and Fellows, 1976; Buttle and Forsyth, 1976; Murthey et al., 1982). Therefore, it seems unlikely that the low $\mathrm{M}_{\mathrm{r}}$ acidic polypeptides are bPL.

The high $M_{r}$ glycoprotein identified as the major component of early eluting DEAE (t) area (2) (Figure 4.8) was first described by Masters et al. (1983) as the major glucosamine-labelled product released in vitro by day 19 bovine blastocysts as well as by day 14-16 ovine and day 16 porcine blastocysts. Present data extend the observations of Masters et al. (1983) and indicate that this early eluting DEAE (+) glycoprotein is a major product of peri-attachment stage bovine 
conceptuses from days 16, 19, 22 and 24 , as well as bovine chorion from day 69 of gestation. Gel filtration of DEAE (+) area (2) glycoprotein from each of these stages on CL-6B (Figure 4.8) indicated a $M_{r}$ estimate $\left(\mathrm{X} 10^{-3}\right)$ for this major bovine conceptus product $(\bar{X} \pm \mathrm{SEM})$ of $735 \pm 22$. Masters and coworkers (1983) reported that, in each species examined, the high $M_{r}$ glycoprotein consisted of at least $50 \%$ carbohydrate. These products did not possess biochemical characteristics typical of mucins. The ovine glycoprotein was shown to be composed of $\mathrm{N}$ - rather than 0-linked oligosaccharide chains containing D-galactose, N-acetylglucosamine, D-mannose and L-fucose. No sialic acid was detected. None of these species produced any sulfated proteoglycans or hyaluronic acid. In contrast to the major low $\mathrm{M}_{r}$ acidic polypeptides, production of the high $M_{r}$ glycoprotein by peri-attachment conceptuses or chorionic tissue suggested a less transient role for this macromolecule. The high $M_{r}$ glycoprotein may normally be more intimately associated with the trophoblast. It was suggested that such products might not normally be released in soluble form but, instead, deposited between trophoblast cells or on the trophoblastic surface (Masters et al., 1983). In this way such macromolecules might provide a protease resistant or immunologically tolerant coating for the blastocyst or chorion, or be necessary for control of cell movement or cell-cell interaction during the elongation process (Masters et al., 1983). Cellular rearrangement was reported to be a major mechanism associated with porcine trophoblast elongation (Geisert et al., 1982a). Production of high $\mathrm{M}_{\mathrm{r}}$ glycoprotein by peri-attachment stage ovine conceptuses was not apparent until elongation had begun (Godkin et al., 1982b).

Results of the present study indicated that peri-attachment stage bovine conceptuses produced a complex array of proteins and polypeptides 
in vitro. Production of these macromolecules appeared related to developmental stage of the conceptus. Two major bovine conceptus products were identified. These included a group of late eluting $\operatorname{DEAE}(+)$ low $\mathrm{M}_{\mathrm{r}}\left(\mathrm{X} 10^{-3}\right)$ acidic polypeptides $(22-26 / 6.5-5.6)$, and an earlier eluting DEAE $(+)$ high $\mathrm{M}_{\mathrm{r}}(735 \pm 22)$ glycoprotein. The former were detected as major products of bovine conceptuses from as late as day 24 , but were no longer prominent products of day 29 conceptus tissues. These polypeptides were produced during a period of early pregnancy associated with maternal recognition of pregnancy and establishment of a functional chorioallantois. The latter were prominent products of conceptuses and conceptus tissues from all stages examined. Results agreed generally with those reported for both ovine and porcine conceptuses (Godkin et a1., 1982a,b) and suggest a commonality in nature and pattern of production of polypeptides by peri-attachment conceptuses by three major domestic species. Similarity among species in physicochemical properties and pattern of production of these products does not necessarily imply similarity in function. However, identification of these properties and subsequent isolation and purification of the proteins themselves are necessary first steps in elucidation of specific roles for this intriguing class of conceptus products. 


\section{CHAPTER $V$ \\ GENERAL DISCUSSION}

Establishment and maintenance of pregnancy in eutherian mammals involves complex interactions between two interdependent systems, the maternal uterus and the conceptus (Mossman, 1937). As observed by Mossman (1980; p.3) the purpose of the uterus is to "contain and sustain the developing conceptus from the morula or early blastocyst period until parturition". Consequently, maternal uterine support of the conceptus is both physical and environmental. Such support is particularly important in species (including cattle) which possess an epitheliochorial placenta (Steven, 1975b; Wathes and Wooding, 1980). Pregnancy in these species is not established ectopically, and conceptuses undergo a characteristically prolonged free-living period in utero (Cook and Hunter, 1978). During this period (which, in cattle, may extend from days 3-4 until days 21-22; Greenstein et al., 1958; Leiser, 1975; Wathes and Wooding, 1980) the conceptus depends upon the intralumenal uterine environment for both physico-chemical and, presumably, nutritional support (Amoroso, 1952; Bazer et al., 1981b). An embryotrophic uterine environment is established early in pregnancy as a consequence of uterine response to maternal endocrine and other physiological signals (see Chapter I). Components of this environment may originate from maternal serum (hemotrophic elements) or as products of the uterine endometrium (histotrophic elements). Maintenance of this environment, pursuant to the embryotrophic rather 
than the luteolytic path, is thought to require participation of the conceptus with respect to production of biologically active agents (Amoroso and Perry, 1974).

In cattle the period of early pregnancy, from initiation of trophoblast elongation (days 14-16) until definitive microvillar attachment of the outer trophoblastic membrane (chorion) to maternal endometrium ( $\simeq$ days 22-24), is especially critical (Chang, 1952; Greenstein et al., 1958; Leiser, 1975; Wathes and Wooding, 1980). During this period uterine integration of appropriately timed maternal and conceptus signals may result in "recognition" and establishment of pregnancy (Short, 1969; Bazer et al., 1981c). However, the consequence of failure of either maternal or conceptus components is failure of pregnancy. The delicate nature of the relationship between maternal and conceptus units during the peri-attachment period is illustrated by the high incidence of embryonic mortality and fertility failure characteristic of this stage of bovine gestation (Ayalon, 1978; Hawk, 1979; Hawk et al., 1955). Knowledge of factors which may contribute to successful intercommunication between maternal and conceptus units is necessary if solutions to bovine fertility problems are to be obtained. Additionally, information of this nature contributes to basic understanding of phenomena associated with establishment and maintenance of pregnancy.

Analysis of uterine secretions from cyclic and early pregnant cattle and sheep has been hampered by small amounts of material recoverable in uterine flushings (Bazer et al., 1978). In sheep it was demonstrated that copious amounts of protein-rich uterine fluid could be obtained late in gestation (> day 100). This was achieved by 
creating a pouch in one uterine horn via two different experimental approaches (1) surgical anastomosis of apposing endometrial surfaces (Harrison et al., 1976), or (2) unilateral ovariectomy and ligation of the ipsilateral uterine horn (Bazer et al., 1979a), so that the fetalplacental unit was confined to the remaining intrauterine space.

Present research (ChapterII) demonstrated that unilateral ovariectomy and 1igation of the ipsilateral uterine horn permitted establishment of unilateral pregnancy in cattle (Figure 2.1). The technique employed was similar to that described for sheep by Bazer et a1. (1979a). Fetal weights, placental weights and fetal fluid volumes, measured in nine unilaterally pregnant cows on day 270 of gestation (Table 2.1), were consistent with similar values reported for normally pregnant cattle by Eley et al. (1978), Ferrel et al. (1976) and Winters et al. (1942). Thus, confinement of the bovine conceptus to one uterine horn was not, in general, sufficient to compromise growth and development of the fetal-placental unit. The observation that three of twelve unilaterally pregnant cattle delivered live calves prior to day 270 suggested that uterine capacity in these cows may have been compromised by the ligation procedure. It also was observed that, while placental morphology was normal, caruncles in the ligated uterine horn of unilaterally pregnant cattle were not developed significantly. This observation demonstrated a clear requirement for a trophoblastic/chorionic stimulus and/or chorion-endometrial interaction for normal placentome development. Hence, in addition to providing a rich source of uterine fluid, unilateral pregnancy presents an intriguing model for study of bovine uterine capacity and chorion-endometrial interaction.

Bovine UM was palpated per rectum by day 166 of gestation and accumulated rapidly thereafter. Developmentally, the pattern of bovine 
UM accumulation was similar to that described for unilaterally pregnant sheep (Bazer et al., 1979a; Harrison et al., 1976). This period of bovine gestation is associated with the time of maximal fetal growth rate (Eley et al., 1978; Winters et al., 1942) and is preceded by dramatic increases in uterine arterial and venous $E$ concentrations, UBF and net uterine nitrogen accretion (Ferrell and Ford, 1980; Ferrell et al., 1976). Additionally, this period may be associated with elevated circulating levels of bPL (Bolander and Fellows, 1976). Thus, while no causal relationships may be determined from the present study, data support the notion that circulating agents of gonadal, placental and/or fetal origin may be involved in stimulation of UM accumulation (Bazer et al., 1979a). Such uterine response may be necessary to meet increased demands of the rapidly growing fetus (conceptus). Increases in amount, number, frequency and persistency of appearance of proteins in uterine flushings also occur during the peri-attachment period in cattle (Roberts and Parker, 1976; Bartol et al., 1981a), as we11 as sheep (Roberts et al., 1976a) and pigs (Geisert et al., 1982b). Such responses are associated with rapid expansion of the trophoblast and accompanying transient increases in uterine blood flow (Ford et al., 1979; Greiss and Anderson, 1970; Ford and Christenson, 1979). Increases in uterine content of embryotrophe may, therefore, occur regularly in response to both local and systemic stimuli produced or induced by rapidly growing conceptus tissues.

In unilaterally pregnant sheep, UM was recovered as early as day 30 of gestation, but did not appear in copious quantities until after day 100 (Moffatt et al., 1980; Bazer et a1., 1979a). Proteins characteristic of ovine UM were present in uterine flushings of ovariectomized 
ewes treated 120 days with $\mathrm{P}_{4}$ alone, or $\mathrm{P}_{4}$ plus $\mathrm{E}_{1}$. Maximal stimulation occurred in the latter group (Moffatt et a1., 1980, 1981). These proteins were not detected in uterine flushings from cyclic ewes between days 0 and 16 postestrus (Moffatt et al., 1981). If mechanisms responsible for induction of UM are similar in sheep and cattle, data suggest that some protein components of this fluid may be characteristic of those which require protracted $\mathrm{P}_{4} / \mathrm{E}_{1}$ stimulation for synthesis and secretion.

Differences in steroid concentrations between UMS and peripheral plasma (Table 2.2) supported the notion that these two fluid pools are not in simple equilibrium. Data suggested that differences noted between UMS and plasma steroid concentrations might be explained, in part, by uterine steroid metabolism (Eley et al., 1983; Knickerbocker et al., 1980) and/or relative solubility of steroids in uterine cell membranes (Heap et al., 1971). Uterine endometrial metabolism of steroids was suggested to be important in (1) providing the conceptus with more readily metabolizable steroid substrate, (2) decreasing the amount of biologically active steroid present in utero, and (3) enhancing uterine responsiveness to conceptus-produced steroids or other signals (Bazer et al., 1982; Eley et a1., 1983; Heap and Perry, 1974). During early pregnancy in both pigs (Geisert et al., 1982b) and mares (Sharp, 1980) dramatic increases in uterine luminal steroid content is thought to reflect conceptus steroid production and metabolism of available substrate. Since fetal membranes were absent from the ligated uterine horn in unilaterally pregnant cattle, UM steroid profiles do not reflect conceptus contributions, but may be representative of the normal substrate pool available to the conceptus. 
Detection of glucose but not fructose in bovine UMS (Table 2.4) is consistent with earlier reports which described glucose as the major free sugar in bovine (Suga and Masaki, 1973), ovine, porcine and equine uterine flushings (Haynes and Lamming, 1967; Zavy et a1., 1982a). Renard et a1. (1980) demonstrated that, while there was no morphological difference between day 10-11 bovine blastocysts which either did or did not take up glucose in vitro, development in vivo following embryo transfer was better for those which had taken up glucose (\% pregnant at day $50 ; 69.2 \%$ vs $14.2 \%$ ). Thus, glucose may be an important substrate during early bovine embryonic development. Observations of Zavy et a1. (1982a), suggesting a conceptus source for uterine lumenal fructose, are consistent with present findings in that levels of fructose were undetectable in bovine UM, since feta1 membranes were absent from the ligated uterine horn.

Day 270 bovine UM was enriched in PGF, protein and $\mathrm{Ca}$ (Table 2.4) and consistent with observations in sheep (Bazer et a1., 1979a; Harrison et al., 1976). Presence of a concentrated pool of PGF in UM supports the idea that specific endocrine conditions may permit sequestering of prostaglandins within the uterine lumen (Bazer et al., 1979a; Bazer and Thatcher, 1977). Indeed, evidence that PG may be subject to active, carrier-mediated transport in reproductive tissues of various species was presented by Bito and coworkers (Bito, 1972; Bito and Spellane, 1974). Specific evidence to this effect is lacking in cattle. However, data from the University of Florida (D. Wolfenson, personal communication) indicated that increases in ovarian arterial concentrations of $\mathrm{PGF}_{2 \alpha}$, observed during the period of luteolys is in cyclic cattle (days 19-20), were absent in pregnant cattle at the same stage. Additionally, recent observations of Curl (J. Curl, 
personal communication) suggest an effect of pregnancy on bovine endometrial uptake of $P G$. Such uterine responses are thought to be effected locally by presence of the conceptus. However, elevated PGF levels in bovine (and ovine; Bazer et al., 1979a) UM suggest potential for a systemic effect of the conceptus as well.

Both concentration and content of protein in bovine UMS (Table 2.4) were equal to or greater than similar values reported for ovine UM (Bazer et al., 1979a; Harrison et al., 1976) and bovine uterine fluid obtained following chronic $\mathrm{P}_{4}$ therapy (Dixon and Gibbons, 1979). Uterine milk protein content greatly exceeded similar reports for bovine uterine flushings collected either in vivo (Bartol et al., 1981b; Schultz et al., 1971) or postmortem (Bartol et a1., 1981a,b; Roberts and Parker, 1974a, 1976; 01ds and Van Demark, 1957a,b) and establish bovine UM as a rich source of this proteinaceous material. Although mechanisms responsible for induction of bovine UM are unclear, positive correlations were detected between Ca concentration of UMS and both protein concentration $(r=-68, P<.09)$ and PGF content $(r=.92$, $\mathrm{P}<.08$ ) of UMS suggesting a functional interrelationship among these UM components. Positive correlations were reported between uterine lumenal content of PGF and total protein in both cyclic and early pregnant cattle (Bartol et al., 1981a), and similar relationships were noted in sheep (E1linwood et al., 1979b). Additionally, Geisert et al. $(1982 b, c)$ reported that increases in uterine lumenal content of both $P G F$ and $\mathrm{PGE}_{2}$, accompanied by rapid transient increases in $\mathrm{Ca}$ content, preceded persistent increases in both amount and complexity of proteins in porcine uterine flushings. These relationships occurred whether induced locally by presence of a conceptus or systemically by 
administration of EV. Data reviewed by Rasmussen (1981) and Rubin (1982) indicated that the process of secretion involves obligatory Ca-dependent turnover of membrane-associated arachidonic acid and synthesis of PG. Substances produced (PG) or released (Ca) as a consequence of this process may further potentiate secretory events and/or alter epithelial cell membrane electrophysiology (Rasmussen, 1981; Rubin, 1982). Consequently, intercellular transudative processes may also be affected (Rasmussen, 1981). Thus, relationships noted between UM Ca, protein and PGF may reflect active mechanisms associated with luminally directed secretions and transudation of proteins and other substances. Such mechanisms may be characteristic of processes required to establish an embryotrophic uterine environment. Qualitative analyses of proteins in bovine UM revealed a complex array of polypeptides (Figures 2.2 and 2.3). Bovine UM was enriched in proteins of less than $40,000 \mathrm{M}_{\mathrm{r}}$ (Figure 2.2), the majority of which were basic in nature, migrating on NEPHGE between approximately $\mathrm{pH}$ 6.8 and 8.6 (Figure 2.3B). However, NEPHGE profiles of bovine UMS polypeptides were distinct from similar profiles of uterine fluid proteins from other species and revealed neither a Utf-like polypeptide, as described for both the pig and mare, nor either of the two major polypeptides found in ovine UM (Bazer et al., 1979a,1981b).

Two-dimensional PAGE (IEF) and C-IEP (Figures 2.4 and 2.5) indicated that the majority of proteins in bovine UMS were physically and immunochemically identical to bovine serum proteins. This observation is consistent with earlier reports indicating that no more than 2 to $3 \%$ of total protein in bovine uterine flushings might be expected to be uterine-specific (Roberts and Parker, 1974a, 1976). 
Beier (1980) noted that transudation of serum proteins into the uterine lumen occurs irrespective of protein molecular size. Present data indicated a general qualitative and slight quantitative disparity between serum-identical proteins seen in UM and plasma (Figure 2.5). Collectively, data support selective uptake of serum proteins into UM. In this respect, selective uterine uptake of serum proteins is 1ikely as important as synthesis and secretion of uterine-specific products in establishment of an embryotrophic environment. Immunoglobulins, such as IgA, IgG and IgM, identified immunochemically in bovine UM (Figures 2.6 and 2.7), may be important for maintenance of uterine luminal sterility and bacteriocidal activity (Sullivan and Wira, 1983). Serum proteins, in addition to serving as a source of hemotrophic nutrition to the conceptus, may be involved functionally with maintenance of dynamic equilibrium between the uterine lumen and peripheral plasma (see Clark and Peck, 1981; Clark et a1., 1977). Despite the preponderance of serum-identical proteins in bovine UM, several polypeptides apparently unique to UMS were identified (Figure 2.4). One group appeared in the 25 to $30,000 \mathrm{M}_{\mathrm{r}}$ range with isoelectric points between 6.4 and 7.0. Two other polypeptides (Figure 2.4A; UMl and UM2) had nearly identical $M_{r}$ of 20 to 21,000 and approximate isoelectric points of 6.3 and 6.1 , respectively. These polypeptides were similar, electrophoretically, to porcine uterine retinol and retinoic acid binding proteins (Adams et al., 1981; Bazer et a1., 1981b). Thus, as has been demonstrated for bovine uterine flushings obtained from cyclic and early pregnant cattle (Roberts and Parker, 1974a,b, 1976), bovine UM contained both uterine luminal-specific, serum-identical proteins and uterine-specific proteins as determined by absence of these components from plasma. 
Chromatographic and electrophoretic analyses of radiolabelled proteins and polypeptides in dialyzed MEM from endometrial explants (Chapter III) indicated that bovine endometrial tissue may produce a much more complex array of macromolecules than has been demonstrated previously (Roberts and Parker, 1976; Laster, 1977; Dixon and Gibbons, 1979; Wathes, 1980). However, in contrast to other major domestic species including the pig, sheep and mare (Bazer et al., 1981b), bovine endometrium synthesized primarily acidic polypeptides in vitro as assessed by ion exchange chromatography (Figure 3.4) and fluorography of 2D-PAGE (IEF and NEPHGE) gels (Figures $3.5,3.6$ and 3.7 ). Consistent with observations of bovine UM, bovine endometrial explants did not produce polypeptides similar to either Utf (Roberts et al., 1980) or the 50 to $55,000 \mathrm{M}_{\mathrm{r}}$, basic proteins identified as the major ovine endometrial products (Moffatt et al., 1980; Bazer et al., 1981b). Also absent from all NEPHGE fluorographs, including those prepared from 2D-PAGE gels of day 270 MEM proteins from both ligated and pregnant uterine tissue explants, were the very basic $(\mathrm{pH}>7.3)$ low $M_{r}$ polypeptides identified as major components of bovine UM (Figure 2.3). Data suggest that, if these low $M_{r}$ polypeptides appear as normal components of the uterine environment, they are either derived from serum, or appear as enzymatic degradation products. Such proteolysis may be necessary to make hemotrophic and histotrophic elements more accessible to the conceptus.

Endometrial tissues from nonpregnant/cyclic (days 4, 16 and 19), pregnant (days 16, 19, 22, 24 and 69) and unilaterally pregnant cattle (day 270; ligated and pregnant uterinehorns) produced virtually identical arrays of polypeptides from radiolabelled amino acid substrate 
in vitro (Figures 3.2 and 3.7 ). As compared to tissue, MEM was en-

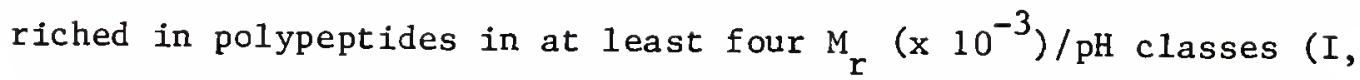
$\simeq 14 />7.2$; II, 19-24/5.4-6.3; III, 28-31/6.9-7.3 and IV, $\geq 150 / \leq 5.1$; Figures 3.5 and 3.6 ) suggesting that these polypeptides are major endometrial secretory or cell surface products. Several polypeptides in both classes II and III had electrophoretic characteristics similar to nonserum-identical UM-specific proteins (Figure 2.4 ). Included (class II) were polypeptides resemb1ing UM1 and UM2, suggested to be similar electrophoretically to porcine retinol and retinoic acid binding proteins (Adams et al., 1981; Bazer et al., 1981b). Thus, UM may serve as a valuable reservoir of uterine-specific proteins. Uterine-specific polypeptides in class I were observed to be similar, although somewhat less basic, than a series of low $_{\mathrm{r}}, \mathrm{P}_{4}$-induced, serine-protease inhibitors shown to be products of porcine endometrium (Fazleabas et al., 1982a,b). Anti-trypsin activity was described in uterine flushings from early pregnant cattle, although its origin (uterine vs serum) was not determined (Roberts and Parker, 1974b). Such uterine proteins were suggested to be involved in limiting invasiveness of the trophoblast (Fazleabas et al., 1982a). Polypeptides in class IV were suggested to be similar to endometrial surface or brush border glycoproteins thought to be important in a number of processes critical to establishment and maintenance of pregnancy including (1) regulation of endometrial carbohydrate metabolism (Larson et al., 1970; Boshier, 1969), (2) stimulation of uterine secretory activity (Larson et a1., 1970; Murdoch et al., 1970), and (3) adhesion and fusion of cells (Frazier and Glaser, 1979; Wathes and Wooding, 1980; Wooding et a1., 1980; Dent, 1973). Absence of obvious differences 
in the qualitative array of proteins produced by bovine endometrial tissues associated with reproductive status (nonpregnant, pregnant or unilaterally pregnant) or stage, suggests that alterations in endometrial-specific components of the uterine environment reflect quantitative rather than major qualitative changes.

Absence of obvious qualitative differences in array of polypeptides produced de novo by bovine endometrial explants is consistent with observations in other domestic species, including pigs, sheep and mares, which indicated that a relatively constant array of proteins is produced by, or present in the uterus throughout gestation or during prolonged periods of $\mathrm{P}_{4}$ treatment (Bazer, 1975; Roberts et al., 1980; Bazer et al., 1981b; Zavy et al., 1982b). Maintenance of histotrophe production is considered critical for pregnancy maintenance in these species (Cook and Hunter, 1978). In this respect, relatively stable responses of endometrial explants from early pregnant cattle (Table 3.2) reflected metabolic stability of tissues. Such stability may be important to insure continued production of histotrophe. Comparison of responses of endometrial explants from pregnant and nonpregnant cattle (days 16 and 19 only; Table 3.2) suggested that stability in protein synthetic capacity of tissues from early pregnant cattle was related to presence of a conceptus. Pregnancy status $\mathrm{x}$ day postmating interactions, detected for both $\mathrm{TP}$ and $\% \mathrm{r}(\mathrm{P}<.01)$, reflected elevated responses of day 19 as compared to day 16 tissues from nonpregnant cattle versus stable, lower responses of tissues from pregnant cattle at the same stage (Table 3.2). Data suggested that the systemic effect of chronic peripheral plasma $\mathrm{P}_{4}$ (Ford et al., 1979; Lukazewska and Hanse1, 1980), combined with the local effect of the conceptus itself, had a stabilizing effect on uterine tissues. 
Differences in metabolic capacity of endometrium between early pregnant and cyclic cattle, particularly after days 16 to 17 , may reflect differences in physiological commitment; the former committed to an embryotrophic and the latter to a luteolytic goal. Lewis et al. (1982) showed that endometrial slices from day 16 and 19 pregnant cattle produced equal quantities of PG from ${ }^{3}$ H-arachidonic acid in vitro. Curl (J. Curl, personal communication) observed that, while neither concentration nor content of $\mathrm{PGF}_{2 \alpha}$ or PGFM in endometria1 tissues differed between cyclic and pregnant cattle on day 17 postestrus, PG synthetic capacity was greater in tissues from cyclic cattle. Present data are generally consistent with these observations and suggest that enhanced endometrial metabolic activity during late diestrus in cyclic/nonpregnant cattle reflects events pursuant to uterine mediated luteolysis. Such events are enhanced by increased $\mathrm{E}_{2} / \mathrm{P}_{4}$ ratio characteristic of late diestrus (Ford et al., 1979; Bartol et al., 1981b). Studies in sheep suggest that such E-induced effects may involve responses of different areas (caruncular vs intercaruncular) and/or cell types within the endometrium (Findlay et a1., 1981; Huslig et al., 1979).

If an embryotrophic uterine environment is to be established and maintained, then the conceptus must contribute to the array of stimuli integrated by uterine tissues. Although specific sites of action have not been identified for any bovine conceptus products, in vitro production of known biologically active agents, including both prostaglandins and steroids, was documented for bovine conceptuses from as early as day 13. Production increased in a manner related to elongation of the trophoblast and increasing conceptus mass (Chenault, 
1980; Eley et al., 1983; Shemesh et al., 1979; Lewis et al., 1982). As shown for both ovine and porcine peri-attachment conceptuses (Godkin et al., 1982a,b), present data (Chapter IV) indicate that bovine peri-attachment conceptuses can also produce a variety of complex polypeptide macromolecules de novo from radiolabelled amino acid substrate.

Ability of bovine conceptuses to incorporate radiolabelled amino acid substrate into nondialyzable product was clearly related to stage of conceptus development. Among day 16 conceptuses, those which had expanded to some degree were more active in incorporation of ${ }^{3} \mathrm{H}$-Leu into labelled polypeptides. Overa11, \% of ${ }^{3}$ H-Leu, as nondialyzable product in MEM was lowest in day 16 cultures $(\bar{X} \pm \mathrm{SEM}=1.16 \pm 4.11 \%$, $P<.01)$, increased in day $19(16.8 \pm 3.67 \%)$ and 22 cultures $(20.9 \pm$ $5.80 \%)$ and decreased $(P<.07)$ in day 24 cultures $(6.87 \pm 4.10 \%)$. Marked increases in \% after day 16 were reflected by increases in complexity of the array of polypeptides identified in both tissue and MEM (Figures 4.3 and 4.4). Such striking changes are undoubtedly related to development and differentiation of tissues and cell types required to produce the complete array of conceptus proteins. In vitro production of proteins was related to stage of development in both sheep and pig conceptuses (Godkin et al., 1982a,b).

Polypeptides produced by bovine conceptuses were primarily DEAE $(+)$ acidic macromolecules (Figure 4.2). Anion exchange profiles of radiolabelled macromolecules in dialyzed MEM were especially similar to those reported for sheep (Godkin et al., 1982b). For each conceptus stage examined (days 16, 19, 22 and 24), numerous polypeptides identified in MEM were absent, or present in only trace amounts in tissues 
(Figures 4.3 and 4.4). Consequently, these polypeptides were considered most likely representative of proteins contributed to the uterine environment by peri-attachment stage bovine conceptuses. Observations are consistent with those of Lewis et al. (1979) for day 19 bovine conceptuses and with similar studies in both sheep and pigs (Godkin et al., 1982a,b). Data indicate that explant medium following short term (24-48h) culture of conceptus tissue, rather than tissue extracts, may provide the richest source of these products for future study. Medium from bovine conceptus explants was enriched in two major types of protein products, including (1) a group of late eluting $\operatorname{DEAE}(+)$, Low $M_{r}$ acidic polypeptides $\left(M_{r} \times 10^{-3} /\right.$ IEP $\left.\simeq 22-26 / 6.5-5.6\right)$, and, (2) an earlier eluting $\operatorname{DEAE}(+)$, high $\mathrm{M}_{\mathrm{r}}\left(\mathrm{x} 10^{-3} ; 735 \pm 22\right)$ glycoproteins. The low $\mathrm{M}_{\mathrm{r}}$ polypeptides were principle products of day 16 conceptuses and remained major products of conceptuses from days 19 , 22 and 24 (Figure 4.3). These polypeptides were no longer prominent components of MEM from a day 29 conceptus explant, suggesting transient production of these conceptus proteins. However, MEM from day 69 bovine chorionic explants contained trace amounts of polypeptides with similar electrophoretic character to some of the low $M_{r}$ proteins identified in earlier stage conceptus MEM (Figure 4.5). Hence, production of certain of the $10 \mathrm{w} \mathrm{M}_{\mathrm{r}}$ acidic polypeptides may not be terminated, but only depressed in chorionic tissues from later in gestation. Transient production of low $M_{r}$, acidic polypeptides was also reported for peri-attachment stage porcine and ovine conceptuses (Godkin et al., $1982 a, b)$.

Temporal pattern of appearance of the 1 ow ${ }_{r}$ acidic polypeptides suggests that these conceptus products may play important functional 
roles in establishment and maintenance of pregnancy. Appearance of these polypeptides as major products of bovine conceptuses from day 16 , the point after which removal of the conceptus results in prolongation of the estrous cycle (Northey and French, 1980), presents the possibility that these proteins may be involved, either directly or indirectly, with the process of luteostasis. Ginther (1981) presented evidence suggesting the presence of a "luteotrophic factor" in uterine venous effluent of the gravid uterine horn during the bovine periattachment period. However, current evidence for a bovine conceptusproduced, proteinaceous luteotrophin is equivocal (Beal et al., 1981; Poffenberger et al., 1982; Snith et a1., 1982). As observed above, it is difficult, if not impossible, to separate those conceptus-induced maternal responses associated with luteostasis from those required for maintenance of an embryotrophic uterine environment. Indeed, mechanisms associated with one may well insure the other. Data reviewed above suggested that low $M_{r}$ acidic proteins, produced transiently by periattachment stage conceptuses, may be required to stimulate endometrial production and secretion of histotrophe during a critical period of conceptus development. Such conceptus-induced changes in endometrial protein synthesis and secretion may involve alterations in endometrial arachidonic acid metabolism and prostaglandin production characteristic of stimulus-secretion coupled events (Rubin, 1982; Rasmussen, 1981). Consequently, endometrial responses to these conceptus products, necessary to insure maintenance of an embryotrophic uterine environment, may have indirect effects on luteostasis as a result of altered PG metabolism.

Identification of the early eluting DEAE $(+)$, high $\mathrm{M}_{\mathrm{r}}$ glycoprotein $\left(\overline{\mathrm{X}} \mathrm{M}_{\mathrm{r}} \times 10^{-3} \pm \mathrm{SEM} \simeq 735 \pm 22\right)$ as a major component of MEM from day 
16, 19, 22 and 24 bovine conceptus cultures, as well as from day 69 bovine chorion cultures, confirmed and extended earlier observations of Masters et a1. (1983). It was suggested that such molecules, shown to be produced by bovine, ovine and porcine peri-attachment conceptuses, might normally provide an immunologically tolerant or protease resistant coating to the chorion (Masters et al., 1983). Guillomot et al. (1982) reported that cytochemical alterations in the glycoprotein surface coat of ovine conceptuses between days 13 and 15 were related to initiation of conceptus attachment. It was suggested that such alterations might involve de novo synthesis of glycoprotein and that these products might be important in adhesion between conceptus (chorionic) and endometrial surfaces (Guillomot et al., 1982).

Pattern of production of bovine conceptus proteins may reflect functional necessity for these products. Proteins such as the low $\mathrm{M}_{\mathrm{r}}$, acidic polypeptides, produced transiently prior to day 29 , may be required specifically during the peri-attachment period to induce conditions necessary for support of the conceptus prior to completed vascularization of the chorioallantois and establishment of definitive placental attachments (Greenstein et a1., 1958; King et al., 1980). Present data do not exclude the possibility that synthesis and secretion of certain "transiently produced" polypeptides continue beyond attachment at reduced rates. Other polypeptides may be involved in processes less specific to the peri-attachment period including (1) maintenance of immunological privelege for the conceptus, (2) compensation for hormonal effects of pregnancy on maternal physiology, (3) stimulation of local uterine responses required for continued fetal-placental development, and (4) interaction with other components 
of the extraplacental (uterine) environment so as to make them more readily available to the conceptus (i.e., binding/carrier proteins or proteases; see Krieger, 1982; Beer and Billingham, 1976). Clearly, any or all of these processes may require the integrated action of several conceptus products including polypeptides, steroids, prostaglandins and other as yet unidentified compounds.

Collectively, present data indicate that, in cattle, proteins characteristic of an embryotrophic uterine environment may appear in utero as a consequence of both selective uptake from serum and de novo endometrial synthesis and secretion. Additionally, de novo production of proteins by peri-attachment stage bovine conceptuses may provide a third source of uterine lumenal proteins which, together with other conceptus products, may be essential for maintenance of pregnancy. Bovine uterine-specific proteins were primarily acidic and, in this respect, unique from more basic porcine, ovine and equine uterine-specific proteins (Bazer et al., 1981b; Zavy et al., 1982b). In contrast, both nature and pattern of production of $10 \mathrm{w} \mathrm{M}_{r}$ acidic and high $\mathrm{M}_{\mathrm{r}}$ glycoproteins by bovine conceptuses were similar to those reported for ovine and porcine conceptuses from comparable developmental stages (Godkin et al., 1982a,b), suggesting a common requirement for such products. Historically, study of form has preceded that of function. In this light, present data provide a basis from which elucidation of functional interrelationships of these maternal and conceptus products may proceed. 


\section{LITERATURE CITED}

Abraham, G.E., R. Swerdloff, D. Tulchinsky, and W.D. Ode11. 1971. Radioimmunoassay of plasma progestin. J. CIin. Endocrinol. $32: 619$.

Adams, K.L., F.W. Bazer, and R.M. Roberts. 1981. Progesterone-induced secretion of a retinol-binding protein in the pig uterus. J. Reprod. Fertil. 62:39.

Ainsworth, L., and K.J. Ryan. 1967. Steroid hormone transformations by endocrine organs from pregnant mammals. II. Formation and metabolism of progesterone by bovine and sheep placental preparations in vitro. Endocrinol. 81:1349.

Aitken, R.J. 1977. Embryonic diapause. P. 307. In M.H. Johnson (Ed.) Development in Mammals. Vol. 1. North-Holland, Amsterdam.

Aitken, R.J. 1979. Tubal and uterine secretions: The possibilities for contraceptive attack. J. Reprod. Fertil. 55(Supp1. 13):247.

Alen, W.R., and L.E.A. Rowson. 1973. Control of the mare's oestrous cycle by prostaglandins. J. Reprod. Fertil. 33:539.

Alexander, G., and D. Williams. 1966. Progesterone and placental development in the sheep. J. Endocrinol. 34:241.

Alexander, R.L. 1971. Evaluation of an automatic calcium titrator. Clin. Chem. 17:1171.

Allen, W.R. 1979. Maternal recognition of pregnancy and imanological implications of trophoblast-endometrium interactions in equids. P. 323. Maternal Recognition of Pregnancy Ciba Foundation Symposium 64. Excerpta Medica, Amsterdam, Netherlands.

Amoroso, E.C. 1952. Placentation. P. 207. In A.S. Parks (Ed.) Marshall's Physiology of Reproduction. Vol. 2 Longmans, Green and Co. Ltd., London.

Amoroso, E.C., and J.S. Perry. 1975. The existence during gestation of an immunological buffer zone at the interface between maternal and foetal tissues. Philos. Trans. R. Soc. Lond. B. Biol. Sci. $271: 343$.

Anderson, L., and N.G. Anderson. 1977. High resolution two-dimensional electrophoresis of human plasma proteins. Proc. Natl. Acad. Sci. $74: 5421$.

Anderson, L.L., K.P. Bland, and R.M. Melampy. 1969. Comparative aspects of uterine-luteal relationships. Rec. Prog. Horm. Res. 25:57. 
Anggard, D. 1971. Studies on the analysis and metabolism of the prostaglandins. Ann. N.Y. Acad. Sci. 180:200.

Arave, G.W., and J.L. Albright. 1981. Cattle behavior. J. Dairy Sci. $64: 1318$.

Armstrong, D.T., and W. Hansel. 1959. Alteration of the bovine estrous cycle with oxytocin. J. Anim. Sci. 42:533.

Atkins, D.T., D.C. Kraemer, P.G. Harms, and J.L. Fleeger. 1980. Progesterone-receptor complex in the nuclear fraction of the bovine endometrium. Biol. Reprod. 23:317.

Atkinson, B.A., G.J. King, and E.C. Amoroso. 1982. Development of the endometrium in the pre and post natal heifer. ASAS and CSAS 539:335 (Abstr.).

Avivi, A., A.B. Schreiber, and M. Shemesh. 1982. Isolation and characterization of a 94,000-dalton protein with thyrotropic activity from early bovine placenta. J. Biol. Chem. 257:11384.

Ayalon, N. 1978. A review of embryonic mortality in cattle. J. Reprod. Fertil. 54:483.

Babcock, J.C. 1966. Luteotrophic and luteolytic mechanisms in bovine corpora lutea. J. Reprod. Fertil. (Supp1. 1):47.

Ball, G.D., and B.N. Day. 1982a. Bilateral luteal maintenance in unilaterally pregnant pigs with infusions of embryonic extract. J. Anim. Sci. 54:142.

Bal1, G.D., and B.N. Day. 1982b. Local effects of PGF $2 \alpha$ and embryonic extracts on luteal function in swine. J. Anim. Sci. 54:150.

Bal1, P., H.P. Gelbke, and R. Knuppen. 1975. The excretion of 2-hydroxyestrone during the menstrual cycle. J. C1in. Endocr. Metab. 40:406.

Barcroft, J. 1934. Features in the Architecture of Physiological Function. Cambridge Univ. Press, England.

Barcroft, J. 1946. Researches on Prenatal Life. C.C. Thomas Publisher, Springfield, England.

Barr, A.J., J.H. Goodnight, J.P. Sall, W.H. Blair, and D.M. Chilko. 1979. SAS User's Guide. SAS Institute Inc., Raleigh, N.C.

Bartol, F.F., W.W. Thatcher, F.W. Bazer, F.A. Kimball, J.R. Chenault, C.J. Wilcox, and R.M. Roberts. 1981a. Effects of the estrous cycle and early pregnancy on bovine uterine, luteal, and follicular responses. Biol. Reprod. 25:759.

Barto1, F.F., W.W. Thatcher, G.S. Lewis, E.L. Bliss, M. Drost, and F.W. Bazer. 1981b. Effect of estradiol-17B on PGF and total protein content in bovine uterine flushings and peripheral plasma concentration of 13,14-dihydro-15-keto-PGF $\alpha$. Theriogenology 15:345. 
Basha, S.M.M., F.W. Bazer, R.D. Geisert, and R.M. Roberts. 1980a. Progesterone-induced uterine secretions in pigs. Recovery from pseudopregnant and unilaterally pregnant gilts. J. Anim. Sci. $50: 113$.

Basha, S.M.M., F.W. Bazer, and R.M. Roberts. 1979. The secretion of a uterine specific, purple phosphatase by cultured explants of porcine endometrium dependency upon the state of pregnancy of the donor animal. Biol. Reprod. 20:431.

Basha, S.M.M., F.W. Bazer, and R.M. Roberts. 1980b. Effect of the conceptus on quantitative and qualitative aspects of uterine secretions in pigs. J. Reprod. Fertil. 60:41.

Batson, D.B., D.D. Richardson, and R.L. Murphree. 1972. Progesterone and estrogen levels in the plasma of nonbred, nonpregnant and pregnant cows. J. Dairy Sci. 56:309 (Abstr.).

Batta, S.K. 1975. Effect of the prostaglandins on steroid biosynthesis. J. Steroid Biochem. 6:1975.

Battaglia, F.C., and G. Meschia. 1978. Principle substrates of fetal metabolism. Physiol. Rev. 58:499.

Bazer, F.W. 1975. Uterine protein secretions: Relationship to development of conceptus. J. Anim. Sci. 41:1376.

Bazer, F.W., T.T. Chen, J.W. Knight, D.C. Schlosnagle, N.J. Baldwin, and R.M. Roberts. 1975. Presence of a progesterone-induced uterine specific, acid phosphatase in allantoic fluid of gilts. J. Anim. Sci. 41:1112.

Bazer, F.W., R.E. Geisert, W.W. Thatcher, and R.M. Roberts. 1982. The establishment and maintenance of pregnancy. P. 227. In D.J.A. Cole and G.R. Foxcroft (Eds.) Control of Pig Reproduction. Butterworth Scientific, London.

Bazer, F.W., M.H. Goldstein, and D.H. Barron. 1981a. Water and electrolyte transport by pig chorioallantois. P. 299. In L. Mastroianni, Jr., and J.D. Biggers (Eds.) Fertilization and Embryonic Development In Vitro. Plenum Publishing Corp., New York.

Bazer, F.W., R.M. Roberts, S.M.M. Basha, M.T. Zavy, D. Caton, and D.H. Barron. 1979a. Method for obtaining ovine uterine secretion from unilaterally pregnant ewes. J. Anim. Sci. 49:1522.

Bazer, F.W., R.M. Roberts, and D.C. Sharp. 1978. Collection and analysis of female genital tract secretions. P. 503. In J.C. Daniel (Ed.) Methods in Mammalian Reproduction. Academic Press, New York.

Bazer, F.W., R.M. Roberts, D.C. Sharp, III, and W.W. Thatcher. 1981b. Uterine proteins synthetized during the progestative period and pregnancy. P. 17. In Utérus et Fecondité. Colloque de la Société Nationale pour l'Étude de la Stérilité et de la Fécondité. 
Bazer, F.W., R.M. Roberts, and W.W. Thatcher. 1979b. Actions of hormones on the uterus and effect on conceptus development. J. Anim. Sci. (Suppl. 49):35.

Bazer, F.W., D.C. Sharp, III, W.W. Thatcher, and R.M. Roberts. 1981c. Comparative approach to mechanisms in the maintenance of early pregnancy. P. 581. In K.W. McKerns (Ed.) Reproductive Processes and Contraception. Plenum Press, New York.

Bazer, F.W., and W.W. Thatcher. 1977. Theory of maternal recognition of pregnancy in swine based on estrogen controlled endocrine versus exocrine secretion of prostaglandin $\mathrm{F}_{2} \alpha$ by the uterine endometrium. Prostagland ins 14:397.

Beal, W.E., J.H. Lukaszewska, and W. Hansel. 1981. Luteotropic effects of bovine blastocysts. J. Anim. Sci. 52:567.

Beer, A.E., and R.E. Billingham. 1976. The Immunobiology of Mammalian Reproduction. Prentice-Hall, Inc., Englewood Cliffs, New Jersey.

Beer, A.E., and R.E. Billingham. 1979. Maternal immunological recognition mechanisms during pregnancy. P. 293. In R. B. Heap

(Chairman) Maternal Recognition of Pregnancy. Vo1. 64. Ciba Foundation Symposium.

Beer, A.E., and J.0. Bio. 1982. Placenta as an immunological barrier. Biol. Reprod. 26:15.

Beier, H.M. 1980. The role of uterine proteins in the establishment of receptivity of the uterus. Prog. Reprod. Biol. 7:158.

Beier, H.M., and U. Mootz. 1979. Significance of maternal uterine proteins in the establishment of pregnancy. P. 111. In R.B. Heap (Chairman) Maternal Recognition of Pregnancy. Vo1. 64. Ciba Foundation Symposium.

Bellows, R.A., D.C. Anderson, and R.E. Short. 1969. Dose-response relationships in synchronized beef heifers treated with follicle stimulating hormone. J. Anim. Sci. 28:638.

Bernard, C. 1865. An introduction to the Study of Experimental Medicine. Translated by Henery Copley Greene. 1957. Dover Publications, Inc., New York.

Betteridge, K.J., M.D. Eaglesome, G.C.B. Randall, and D. Mitchell. 1980. Collection, description and transfer of embryos from cattle 10-16 days after oestrus. J. Reprod. Fertil. 59:205.

Betteridge, K.J., N.D. Eaglesome, G.C.B. Randall, D. Mitchell, and E.A. Sugden. 1978. Maternal progesterone levels as evidence of luteotrophic or antiluteolytic effects of embryos transferred to heifers 12-17 days after estrous. Theriogenology 9:86 (Abstr.). 
Betteridge, K.J., D. Mitchell, N.D. Eaglesome, and G.C.B. Randall. 1976. Embryo transfer in cattle 10-17 days after estrus. Proc. 8th Int. Congr. Anim. Reprod. and A.I., Krakow 3:237.

Biggers, J.D., and R.M. Borland. 1976. Physiological aspects of growth and development of the preimplantation mammalian embryo. Ann. Rev. Physiol. 38:95.

Biggers, J.D., B.V. Leonov, J.F. Baskar, and J. Fried. 1978. Inhibition of hatching of mouse blastocysts in vitro by prostaglandin antagonists. Biol. Reprod. 19:519.

Bindon, B.M. 1971. Systematic study of preimplantation stages of pregnancy in the sheep. Aust. J. Biol. Sci. 24:131.

Bito, L.Z. 1972. Comparative study of concentrative prostaglandin accumulation by various tissues of mammals and marine vertebrates and invertebrates. Comp. Biochem. Physio1. 43A:65.

Bito, L.Z., and P.J. Spellane. 1974. Saturable, "carrier-mediated," adsorption of prostaglandin $F_{2}$ from the in vivo rabbit vagina and its inhibition by prostaglandin $F_{2}$. Prostaglandins 8:345.

Bito, L.Z., M. Wallenstein, and R. Baroody. 1976. The role of transport processes in the distribution and disposition of prostaglandins. Adv. Prostaglandin Thromboxane Res. 1:297.

Bjorkman, N.H. 1968a. Fine structure of crystal and trophoblastic giant cells in the bovine placentome. J. Ultrastruc. Res. $24: 249$.

Bjorkman, N.H. 1968b. Light and electron microscopic studies on cellular alteration in the normal bovine placentome. Anat. Rec. $163: 17$.

Bjorkman, N. 1973. Fine structure of the fetal-maternal area of exchange in the epitheliochorial and endotheliochorial types of placentation. Acta Anat. 86(Supp1. 1):1.

Bjorkman, N.H., and G. Bloom. 1957. On the fine structure of the foetal-maternal junction in the bovine placentome. Z. Zellforsch. Mikrosk. Anat. 45:649.

Bland, K.P. 1970. Congenital abnormalities of the uterus and their bearing on ovarian function. Vet. Rec. $86: 44$.

Boime, I., M. Boothby, M. Hoshina, S. Daniels-McQueen, and R. Darnell. 1982. Expression and structure of human placental hormone genes as a function of placental development. Bio1. Reprod. 26:73.

Bolander, F.F., Jr., and R.E. Fellows. 1976. Purification and characterization of bovine placental lactogen. J. Biol. Chem. $251: 2703$. 
Bolander, F.F., Jr., L.C. Ulberg, and R.E. Fellows. 1976. Circulating placental lactogen levels in dairy and beef cattle. Endocrinol. $99: 1273$.

Bond, C.J. 1898. Preliminary note on certain undescribed features in the secretory function of the uterus and fallopian tubes in the human subject and in some mammalia. J. Physiol. (London) 22:296.

Boshier, D.P. 1969. A histological and histochemical examination of implantation and early placentome formation in sheep. J. Reprod. Fertil. 19:51.

Boshier, D.P. 1970. A Pontamine Blue reaction in pregnant sheep uteri. J. Reprod. Fertil. 22:595.

Boyd, H., P. Bacsich, A. Young, and J.A. McCracken. 1969. Fertilization and embryonic survival in dairy cattle. Brit. Vet. J. 125:87.

Brackett, B.G. 1981. In vitro culture of the zygote and embryo. P. 61. In L. Mastroianni and J.D. Biggers (Eds.) Fertilization and Embryonic Development In Vitro. Plenum Press, New York.

Brackett, B.G., Y.K. Oh, J.F. Evans, and W.J. Donawick. 1980. Fertilization and early development of cow ova. Biol. Reprod. $23: 189$.

Brandtzaeg, P., and K. Baklien. 1977. Intestinal secretion of IgA and IgM a hypothetical mode1. P. 77. Vo1. 46. In Ciba Foundation Symposium.

Britt, J.H., N.M. Cox, and J.S. Stevenson. 1981. Advances in reproduction in dairy cattle. J. Dairy Sci. 64:1378.

Brunner, M.A., L.E. Donaldson, and W. Hansel. 1969. Exogenous hormones and luteal function in hysterectomized and intact heifers. J. Dairy Sci. 52:1849.

Buhi, W.C., C.A. Ducsay, F.W. Bazer, and R.M. Roberts. 1982. Iron transfer between the purple phosphatase uteroferrin and transferrin and its possible role in iron metabolism of the fetal pig. J. Biol. Chem. 257:1712.

Butler, J.E., W.C. Hamilton, R.G. Sasser, C.A. Ruder, G.M. Hass, and R.J. Williams. 1982. Detection and partial characterization of two bovine pregnancy-specific proteins. Biol. Reprod. 26:925.

Buttle, H.L., and I.A. Forsyth. 1976. Placental lactogen in the cow. J. Endocrino1. 68:141.

Carnegie, J.A., J.S.D. Chan, M.E. McCully, H.A. Robertson, and H.G. Frissen. 1982. The cellular localization of chorionic somatomammotrophin in ovine chorion. J. Reprod. Fertil. 66:9. 
Carter, A.M., J. Gothlin, and T. 01in. 1971. An angiographic study of the structure and function of the uterine and maternal placental vasculature in the rabbit. J. Reprod. Fertil. 25:201.

Chamberlain, J.P. 1979. Fluorographic detection of radioactivity in polyacrylamide gels with the water soluble fluor, sodium salicylate. Ana1. Biochem. $98: 132$.

Chan, J.S.D., H.A. Robertson, and H.G. Friesen. 1976. Purification and characterization of ovine placental lactogen. Endocrinol. $98: 65$.

Chang, M.C. 1952. Development of the bovine blastocyst with a note on implantation. Anat. Rec. 113:143.

Channing, C.P. 1970. Influences of the in vivo and in vitro hormonal environment upon luteinization of granulosa cells in tissue culture. Rec. Prog. Horm. Res. 26:589.

Chen, T.T., F.W. Bazer, J.J. Cetorelli, W.E. Pollard, and R.M. Roberts. 1973. Purification and properties of a progesterone-induced basic glycoprotein in the uterine fluids of pigs. J. Biol. Chem. 248:8560.

Chen, T.T., F.W. Bazer, B.M. Gebhardt, and R.M. Roberts. 1975. Uterine secretion in mammals: Synthesis and placental transport of a purple acid phosphatase in pigs. Biol. Reprod. 13:304.

Chenault, J.R. 1980. Steroid metabolism by the early bovine conceptus. I. $5_{\beta}$-reduction of neutral C-19 steroids. J. Steroid Biochem. 13:499.

Chenault, J.R., W.W. Thatcher, P.S. Kalra, R.M. Abrams, and C.J. Wilcox. 1975. Transitory changes in plasma progestins, estradiol, and luteinizing hormone approaching ovulation in the bovine. J. Dairy Sci. 58:709.

Chenault, J.R., W.W. Thatcher, P.S. Kalra, R.M. Abrams, and C.J. Wilcox. 1976. Plasma progestins, estradiol and luteinizing hormone following prostaglandin $\mathrm{F}_{2} \alpha$ injection. J. Dairy Sci. $59: 1342$.

Choudary, J.B., H.T. Gier, and G.B. Marion. 1968. Cyclic changes in bovine vesicular follicles. J. Anim. Sci. 27:468.

Clark, J.H., and E.J. Peck. 1981. Steroid hormone receptors: Basic principles and measurement. P. 1. In W.T. Schrader and V.W. O'Malley (Eds.) Laboratory Methods Manual for Hormone Action and Molecular Endocrinology. Houston Biological Association.

Clark, J.H., E.J. Peck, Jr., and S.R. Glasser. 1977. Mechanism of action of steroid hormones in the female. P. 143. In H.H. Cole and P.T. Cupps (Eds.) Reproduction in Domestic Animals. Academic Press, New York. 
Clarke, K.W., and L.W. Ha11. 1969. Xylezine--A new sedative for horses and cattle. Vet. Rec. 85:512.

Collier, R.J., S.G. Doelger, H.H. Head, W.W. Thatcher, and C.J. Wilcox. 1982. Effects of heat stress during pregnancy on maternal hormone concentrations, calf birth weight, and postpartum milk yield of Holstein cows. J. Anim. Sci. 54:309.

Cook, B., and R.H.F. Hunter. 1978. Systemic and local hormonal requirements for implantation in domestic animals. J. Reprod. Fertil. 52:471.

Corah, L.R., A.P. Quealy, T.J. Dunn, and C.C. Kaltenbach. 1974. Prepartum and postpartum levels of progesterone and estradiol in beef heifers for two levels of energy. J. Anim. Sci. 38:380.

Corbeil, L.B., G.G. Schurzig, J.R. Duncan, B.N. Wilkie, and A.J. Winter. 1981. Immunity in the female bovine reproductive tract based on the response to "campylobacter fetus." Adv. Exp. Biol. 137:729.

Cornette, J.C., K.T. Kirton, K.L. Barr, and A.D. Forbes. 1972. Radioimmunoassay of prostaglandins. J. Reprod. Med. 9:355.

Cumming, I.A., R. Baxter, and R.A.S. Lawson. 1974. Steroid hormone requirements for the maintenance of early pregnancy in sheep. A study using ovariectomized adrenalectomized ewes. J. Reprod. Fertil. 40:443.

Davies, I.J., F. Naftolin, K.J. Ryan, J. Fishman, and J. Siu. 1975. The affinity of catechol estrogens for estrogen receptors in the pituitary and anterior hypothalamus of the rat. Endocrinol. $97: 554$.

Deaver, D.R., and H.D. Guthrie. 1980. Cytoplasmic estrogen receptor, estradiol and progesterone concentrations in endometrium of nonpregnant and pregnant pigs. Biol. Reprod. 23:72.

DeWitt, F. 1959. An historical study on theories of the placenta through 1900. J. Hist. Med. $14: 360$.

Dhindsa, D.S., and P.J. Dziuk. 1968. Effect on pregnancy in the pig after killing embryos or fetuses in one uterine horn in early gestation. J. Anim. Sci. 27:122.

Dickmann, Z. 1979. Blastocyst oestrogen: An essential factor for the control of implantation. J. Steroid Biochem. 11:771.

Dickmann, Z., S.K. Dey, and J. Sen Gupta. 1976. A new concept: Control of early pregnancy by steroid hormones originating in the preimplantation embryo. Vitams. Horm. 34:215. 
Dickson, W.M., M.J. Bose, and A. Locatelli. 1969. Effect of estrogen and progesterone on uterine blood flow in castrate sows. Am. J. Physiol. 217:14.31.

Dieh1, J.R., and B.N. Day. 1974. Effect of prostaglandin $F_{2} \alpha$ on luteal function in swine. J. Anim. Sci. 39:392.

Dixon, S.N., and R.A. Gibbons. 1979. Proteins in the uterine secretion of the cow. J. Reprod. Fertil. 56:119.

Douglas, W.W. 1968. Stimulus secretion coupling: The concept and clues from chromaffin and other cells. Br. J. Pharmacol. 34:541.

Douglas, W.W. 1978. Stimulus secretion coupling: Variation of the theme of calcium-activated exocytosis involving cellular and extracellular sources of calcium. Ciba Foundation Symposium. 54:61.

Douglas, R.H., and O.J. Ginther. 1972. Effect of prostaglandin $\mathrm{F}_{2} \alpha$ on length of diestrus in mares. Prostaglandins $2: 265$.

Dueben, B.D., T.H. Wise, F.W. Bazer, and M.J. Fields. 1977. Metabolism

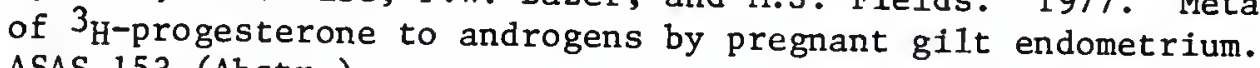
ASAS 153 (Abstr.).

Dueban, B.D., T.H. Wise, F.W. Bazer, M.J. Fields and P.S. Kalra. 1979.

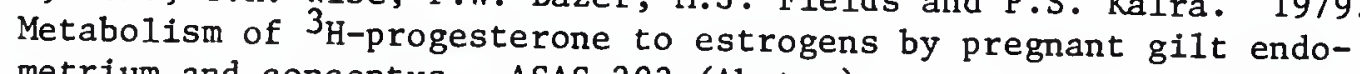
metrium and conceptus. ASAS 293 (Abstr.).

Dufour, J., H.L. Whitmore, O.J. Ginther, and L.E. Casida. 1972. Identification of the ovulating follicle by its size on different days of the estrous cycle in heifers. J. Anim. Sci. 34:85.

Du Mesnil Du Buisson, F. 1966. Regression unilaterale des corps jaunes apres hysterectomie partielle chez la truie. Ann. Biol. Anim. Biochim. Biophys. $1: 105$.

Dwyer, R.J., and H.A. Robertson. 1979. Patterns of sulphotransferase and sulphatase activities in the endometrium of the sheep and pig during pregnancy. Biol. Reprod. 20(Supp 1. I):16A (Abstr.).

Eckersa11, P.D., and J.A. Beeley. 1980. A comparison of crossed immunoelectrophoresis and crossed immunoelectrofocusing for the investigation of human salivary proteins. Electrophoresis $1: 62$.

Eckstein, P., and W.A. Kelley. 1977. Implantation and development of the conceptus. P. 315. In H.H. Cole and P.T. Cupps (Eds.) Reproduction in Domestic Animals. 3rd edition. Academic Press Inc., New York.

Eley, D.S., W.W. Thatcher, H.H. Head, R.J. Collier, and C.J. Wilcox. 1981a. Periparturient endocrine changes of conceptus and maternal units in Jersey cows bred for milk yield. J. Dairy Sci. 64:296. 
Eley, D.S., W.W. Thatcher, H.H. Head, R.J. Collier, and C.J. Wilcox. 1981b. Periparturient and postpartum endocrine changes of conceptus and maternal units of Jersey cows bred for milk yield. J. Dairy Sci. 64:312.

Eley, R.M. 1980. Steroid metabolism and blood flow associated with the bovine uterus and conceptus. Ph.D. Dissertation, Univ. of Fla., Gainesville.

Eley, R.M., F.W. Bazer, W.W. Thatcher, and M.J. Fields. 1979a. Metabolism of progesterone and androsteindione in vitro by bovine endometrium and conceptus. ASAS 294 (Abstr.).

Eley, R.M., W.W. Thatcher, and F.W. Bazer. 1979b. Hormonal and physical changes associated with bovine conceptus development. J. Reprod. Fertil. $55: 181$.

Eley, R.M., W.W. Thatcher, and F.W. Bazer. 1979c. Luteolytic effect of oestrone sulphate on cyclic beef heifers. J. Reprod. Fertil. $55: 191$.

Eley, R.M., W.W. Thatcher, F.W. Bazer, and M.J. Fields. 1983. Steroid metabolism by the bovine uterine endometrium and conceptus.

Biol. Reprod. (In press).

Eley, R.M., W.W. Thatcher, F.W. Bazer, C.J. Wilcox, R.B. Becker, H.H. Head, and R.W. Adkinson. 1978. Development of the conceptus in the bovine. J. Dairy Sci. 61:467.

Ellinwood, W.E., T.M. Nett, and G.D. Niswender. 1979a. Maintenance of the corpus luteum of early pregnancy in the ewe. I. Luteotropic properties of embryonic homogenates. Biol. Reprod. $21: 281$.

Ellinwood, W.E., T.M. Nett, and G.D. Niswender. 1979b. Maintenance of the corpus luteum of early pregnancy in the ewe. II. Prostaglandin secretion by the endometrium in vitro and in vivo. Biol. Reprod. $21: 845$.

Erb, R.E., V.L. Estergreen, Jr., W.R. Gomes, E.D. Plotka, and O.L. Frost. 1968. Progestin levels in corpora lutea and progesterone in ovarian venous and jugular vein blood plasma of the pregnant bovine. J. Dairy Sci. 51:401.

Ezra, B.D. 1979. Neovasculogenesis. Triggering factors and possible mechanisms. Surv. Opthalm. 24:167.

Fahning, M.L., R.H. Schultz, and E.F. Graham. 1967. The free amino acid content of the uterine fluids and blood serum in the cow. J. Reprod. Fertil. 13:229.

Fazleabas, A.T., F.W. Bazer, and R.M. Roberts. 1982a. Purification and properties of a progesterone-induced plasmin/trypsin inhibitor from uterine secretions of pigs and its immunocytochemical localization in the pregnant uterus. J. Biol. Chem. 257:6886. 
Fazleabas, A.T., R.D. Geisert, F.W. Bazer, and R.M. Roberts. 1982b. Plasmin inhibitor secretion by the pig uterus during the estrous cycle and early gestation. ASAS 576:351 (Abstr.).

Fellows, R.E., F.F. Bolander, T.W. Hurley, and S. Handwerger. 1976. Isolation and characterization of bovine and ovine placental lactogen. P. 315. In A. Pecile and E.E. Muller (Eds.) Growth Hormone and Related Peptides. Excerpta Medica, Amsterdam.

Ferrel1, C.L., and S.P. Ford. 1980. Blood flow steroid secretion and nutrient uptake of the gravid bovine uterus. J. Anim. Sci. 50: 1113.

Ferre11, C.L., W.N. Garrett, and N. Hinman. 1976. Growth, development and composition of the udder and gravid uterus of beef heifers during pregnancy. J. Anim. Sci. 42:1477.

Findlay, J.K. 1981. Blastocyst-endometrial interactions in early pregnancy in the sheep. J. Reprod. Fertil. (Supp1. 30):171.

Findlay, J.K., N. Ackland, R.D. Burton, A.J. Davis, F.M. Waulker, D.E. Walters, and R.B. Heap. 1981. Protein, prostaglandin and steroid synthesis in caruncular and intercaruncular endometrium of sheep before implantation. J. Reprod. Fertil. 62:361.

Findlay, J.K., I.J. Clarke, J. Swaney, N. Colvin, and B. Doughton. 1982. Oestrogen receptors and protein synthesis in caruncular and intercaruncular endometrium of sheep before implantation. J. Reprod. Fertil. 64:329.

Fisher, H.E., F.W. Bazer, M.J. Fields, W.W. Thatcher, J.L. Fleeger, and R.M. Roberts. 1981. Conversion of progesterone to estrogens by pregnant and pseudopregnant porcine endometrium and conceptus tissues. ASAS 469:315 (Abstr.).

Fishnan, J. 1977. The catechol estrogens. Neuroendocrinol. 22:363.

Fléchon, J.E., and J.P. Renard. 1978. A scanning electron microscope study of the hatching of bovine blastocysts in vitro. J. Reprod. Fertil. 53:9.

Flint, A.P.F., A. Henville, and W.B. Christie. 1979. Presence of a placental lactogen in bovine conceptuses before attachment. J. Reprod. Fertil. 56:305.

Flood, P.F., K.J. Betteridge, and D.S. Irvinæ. 1979. Evidence of steroid production by the equine conceptus during the second and third week of gestation. J. Reprod. Fertil. (Supp1. 27):413.

Flood, P.F., and A.W. Marrable. 1975. A histochemical study of steroid metabolism in the equine fetus and placenta. J. Reprod. Fertil. (Supp1. 23):569. 
Foley, R.C., and R.P. Reece. 1953. Histological studies of the bovine uterus, placenta and corpus luteum. Mass. Agr. Exp. Sta. Bull. 468.

Folman, Y., M. Rosenberg, Z. Herz, and M. Davidson. 1973. The relationship between plasma progesterone concentration and conception in post partum dairy cows maintained on two levels of nutrition. J. Reprod. Fertil. 34:267.

Foote, W.D., L.D. Gooch, A.L. Pope, and L.E. Casida. 1957. Maintenance of early pregnancy in the ovariectomized ewe by injection of ovarian hormones. J. Anim. Sci. 16:986.

Ford, S.P., and J.R. Chenault. 1981. Blood flow to the corpus luteumbearing ovary and ipsilateral uterine horn of cows during oestrous cycle and early pregnancy. J. Reprod. Fertil. 62:555.

Ford, S.P., J.R. Chenault, and S.E. Echternkamp. 1979. Uterine blood flow of cows during the oestrous cycle and early pregnancy: Effect of the conceptus on the uterine blood supply. J. Reprod. Fertil. $56: 53$.

Ford, S.P., and R.K. Christenson. 1979. Blood flow to uteri of sows during the estrous cycle and early pregnancy: Local effect of the conceptus on the uterine blood supply. Biol. Reprod. 21:617.

Forsyth, I.A. 1974. The comparative study of placental lactogenic hormones. P. 47. In J.B. Josimovich, M. Reynolds, and E. Cobo (Eds.) Lactogenic Hormones, Fetal Nutrition and Lactation. John Wiley and Son Inc., New York.

Frank, M., F.W. Bazer, W.W. Thatcher, and C.J. Wilcox. 1978. A study of prostaglandin $\mathrm{F}_{2} \alpha$ as the luteolysin in swine. IV. An explanation for the luteotrophic effect of estradiol. Prostaglandins $15: 151$.

Frazier, W., and L. Glaser. 1979. Surface components and cell recognition. Ann. Rev. Biochem. 48:491.

Freemark, M., and S. Handwerger. 1983. Ovine placental lactogen, but not growth hormone, stimulates amino acid transport in fetal rat diaphragm. Endocrino1. 112:402.

Gadsby, J.E., R.B. Heap, and R.D. Burton. 1980. Oestrogen production by blastocysts and early embryonic tissue of various species. J. Reprod. Fertil. 60:409.

Gardner, R.M., J.L. Kirkland, J.S. Ireland, and G.M. Stancel. 1978. Regulation of the uterine response to estrogen by thyroid hormone. Endocrinol. 103:1166.

Geisert, R.D., J.W. Brookbank, R.M. Roberts, and F.W. Bazer. 1982a. Establishment of pregnancy in the pig. II. Cellular remodeling of the porcine blastocyst during elongation on day 12 of pregnancy. Biol. Reprod. 27:941. 
Geisert, R.D., R.H. Renegar, W.W. Thatcher, R.M. Roberts, and F.W. Bazer. 1982b. Establishment of pregnancy in the pig. I. Interrelationships between preimplantation development of the pig blastocyst and uterine endometrial secretions. Biol. Reprod. $27: 925$.

Geisert, R.D., W.W. Thatcher, R.M. Roberts, and F.W. Bazer. 1982c. Establishment of pregnancy in the pig. III. Endometrial secretory response to estradiol valerate administered on day 11 of the estrous cycle. Biol. Reprod. 27:957.

Gentry, B.E., L.L. Anderson, and R.N. Melampy. 1973. Exogenous progesterone and estradiol benzoate on early embryonic survival in the pig. J. Anim. Sci. 37:722.

Getty, R. 1975. Sisson and Grossman's The Anatomy of Domestic Animals. 5th edition. W.B. Saunders, Philadelphia.

Ginther, 0.J. 1967. Local utero-ovarian relationships. J. Anim. Sci. $26: 578$.

Ginther, O.J. 1976. Comparative anatomy of utero ovarian vasculature. Scope XX(1) Upjohn, Kalamazoo, Michigan.

Ginther, O.J. 1979. Reproductive Biology of the Mare: Basic and Applied Aspects. McNaughton and Gunn, Inc., Ann Arbor, Michigan.

Ginther, 0.J. 1981. Local versus systemic utero ovarian relationships in farm animals. Acta Vet. Scand. (Suppl. 77):103.

Ginther, O.J., and C.H. Del Campo. 1974. Vascular anatomy of the uterus and ovaries and the unilateral luteolytic effect of the uterus: Cattle. Amer. J. Vet. Res. 35:193.

Ginther, O.J., and N.L. First. 1971. Maintenance of the corpus Iuteum in hysterectomized mares. Amer. J. Vet. Res. 32:1687.

Gitlin, D., and M. Boesman. 1967. Fetus-specific serum proteins in several mammals and their relation to human $\alpha$-feto protein. Comp. Biochem. Physiol. 21:327.

Glencross, R.G., I.B. Munio, B.E. Senior, and G.S. Pope. 1973. Concentrations of $E_{2}-17 \beta$, oestrone and progesterone of jugular venous plasma of cows during the oestrous cycle and in early pregnancy. Acta Endocrino1. 73:374.

Goding, J.R. 1974. The demonstration that $\mathrm{PGF}_{2} \alpha$ is the uterine luteolysin in the ewe. J. Reprod. Fertil. 38:261.

Godkin, J.D., F.W. Bazer, G.S. Lewis, R.D. Geisert, and R.M. Roberts. 1982a. Synthesis and release of polypeptides by pig conceptuses during the period of blastocyst elongation and attachment. Biol. Reprod. $27: 977$. 
Godkin, J.D., F.W. Bazer, R.A. Masters, and R.M. Roberts. 1981. Comparative studies on the polypeptides secreted by the sheep and pig preimplantation conceptuses. ASAS 483:321 (Abstr.).

Godkin, J.D., F.W. Bazer, J. Moffat, F. Sessions, and R.M. Roberts. 1982b. Purification and properties of a major, low molecular weight protein released by the trophoblast of sheep blastocysts at day 13-21. J. Reprod. Fertil. 65:141.

Godkin, J.D., C. Coty, and R.T. Duby. 1978. Embryonic stimulation of ovine and bovine corpora lutea. J. Reprod. Fertil. 54:375.

Granstrom, E. 1981. Prostaglandin chemistry. Acta Vet. Scand. (Supp1. 77):1.

Grass, J.A., P.J. Hansen, J.J. Rutledge, and E.R. Hauser. 1982. Genotype $x$ environmental interactions on reproductive traits of bovine females. I. Age at puberty as influenced by breed, breed of sire, dietary regimen and season. J. Anim. Sci. 55:1441.

Green, W.W., and L.M. Winters. 1945. Prenatal development of the sheep. Univ. of Minnesota Agr. Exp. Sta., Tech. Bull. No. 169.

Greenstein, J.S., and R.C. Foley. 1955. Preliminary observations on the development of the normal bovine embryo from the late blastocyst stage to differentiation of organ primordia. J. Anim. Sci. $14: 1183$.

Greenstein, J.S., and R.C. Foley. 1958a. Early embryology of the cow. I. Gastrula and primitive streak stages. J. Dairy Sci. 41:409.

Greenstein, J.S., and R.C. Foley. 1958b. The early embryology of the cow with notes on comparable human development. Int. J. Fertil. $3: 67$.

Greenstein, J.S., R.W. Murray, and R.C. Foley. 1958. Observations on the morphogenesis and histochemistry of the bovine pre-implantation placenta between 16 and 33 days of gestation. Anat. Rec. $132: 321$.

Greiss, F.C., Jr., and S.G. Anderson. 1969. Uterine vascular changes during the ovarian cycle. Am. J. Obstet. Gynecol. 103:629.

Greiss, F.C., Jr., and S.G. Anderson. 1970. Uterine blood flow during early ovine pregnancy. Am. J. Obstet. Gynecol. 111:299.

Grigsby, J.S., W.J. Oxender, H.D. Hafs, D.G. Britt, and R.A. Merkel. 1974. Serum insulin, glucose, and free fatty acids in cow and fetus during gestation. Proc. Soc. Exp. Biol. Med. 147:830.

Guillomot, M., J. Flechon, and S. Wintenberger-Torres. 1982. Cytochemical studies of uterine and trophoblastic surface coats during blastocyst attachment in the ewe. J. Reprod. Fertil. 65:1. 
Guthrie, H.D., and C.E. Rexroad, Jr. 1981. Endometrial prostaglandin F release in vitro and plasma 13,14-dihydro-15-keto-prostaglandin $\mathrm{F}_{2} \alpha$ in pigs with luteolysis blocked by pregnancy, estradiol benzoate or human chorionic gonadotrophin. J. Anim. Sci. 52:330.

Guthrie, H.D., C.E. Rexroad, and D.J. Bolt. 1978. In vitro synthesis of progesterone and prostaglandin $F$ by luteal tissue and prostaglandin $F$ by endometrial tissue from the pig. Prostaglandins $16: 433$.

Haecke1, E. 1897. The Evolution of Man: A Popular Exposition of the Principle Points of Human Ontogeny and Phylogeny. Vol. 1. D. Appleton and Company, New York.

Hafez, E.S.E., and M.R. Jainudeen. 1974. Gestation, prenatal physiology and parturition. P.166. In E.S.E. Hafez (Ed.) Reproduction in Farm Animals. Lea and Febiger, New York.

Hafez, E.S.E., and E. Rajakoski. 1964. Placental and fetal development during multiple bovine pregnancy anatomical and physiological studies. Anat. Rec. 150:303.

Hafs, H.D., T.N. Louis, E.A. Noden, and W.D. Oxender. 1974. Control of the estrous cycle with prostaglandin $\mathrm{F}_{2} \alpha$ in cattle and horses. J. Anim. Sci. 38(Supp1. 1):10.

Halsey, J.F., B.H. Johnson, and J.J. Cebra. 1980. Transport of immunoglobulins from serum into colostrum. J. Exp. Med. 151:767.

Hamilton, W.J., and J.A. Laing. 1946. Development of the egg of the cow up to the stage of blastocyst formation. J. Anat. 80:194.

Hammond, J. 1927. Physiology of Reproduction in the Cow. Cambridge University Press, London.

Hanse1, W., and S.A. Asde11. 1951. The effects of estrogens and progesterone on the arterial system of the uterus of the cow. J. Dairy Sci. $34: 37$.

Hanse1, W., P.W. Concannon, and J.H. Lukaszewska. 1973. Corpora Iutea of large domestic animals. Biol. Reprod. 8:222.

Hanse1, W., M. Shemesh, J. Hixon, and J. Lukaszewska. 1975. Extraction, isolation and identification of a luteolytic substance from bovine endometrium. Biol. Reprod. 13:30.

Hansel, W., and W.C. Wagner. 1960. Luteal inhibition in the bovine as a result of oxytocin injections, uterine dilatation and intra uterine infusions of seminal and preputial fluids. J. Dairy Sci. 43:796. 
Harrison, F.A., R.B. Heap, E.W. Horton, and H.L. Poyser. 1972. Identification of prostaglandin $\mathrm{F}_{2} \alpha$ in uterine fluid from the nonpregnant sheep with an autotransplanted ovary. J. Endocrinol. 53:215.

Harrison, F.A., R.B. Heap, and N.L. Poyser. 1976. Production, chemical composition and prostaglandin $F_{2} \alpha$ content of uterine fluids in pregnant sheep. J. Reprod. Fertil. 48:61.

Harrison, L.M., T.R. Hansen, and R.D. Randel. 1982. Evidence for seasonal and nutritional modification of ovarian and pituitary function in crossbred heifers and brahman cows. J. Anim. Sci. $55: 649$.

Hartman, C. 1924. The interruption of pregnancy by ovariectomy in the aplacental opossum: A study in the physiology of implantation. Amer. J. Physiol. 74:436.

Hasler, J.F., R.A. Bowen, L.D. Nelson, and G.E. Seide1, Jr. 1980. Serum progesterone concentrations in cows receiving embryo transfers. J. Reprod. Fertil. 58:71.

Hawk, H.W. 1968. Effect of intra uterine devices on corpus luteum function. J. Anim. Sci. 1 (Supp1. 27):119.

Hawk, H.W. 1979. Infertility in dairy cattle. P. 19. In H.W. Hawk (Chairman) Beltsville Symposia in Agricultural Research. [3] Animal Reproduction. Allenheld, Osmun and Company Publishers, Incorporated, Montclair, New Jersey.

Hawk, H.W., T.H. Brinsfield, G.D. Turner, G.E. Whitmore, and N.A. Norcross. 1963. Embryo survival in first-service and repeatbreeder cattle after ovariectomy and hormone therapy. J. Dairy Sci. $46: 1397$.

Hawk, H.W., J.N. Wiltbank, H.E. Kidder, and L.E. Casida. 1955. Embryonic mortality between 16 and 34 days post-breeding in cows of low fertility. J. Dairy Sci. 38:673.

Haynes, N.B., and G.E. Lamming. 1967. The carbohydrate content of sow uterine flushings. J. Reprod. Fertil. 14:335.

Heap, R.B. 1962. Some chemical constituents of uterine washings: A method of analysis with results from various species. J. Endocrino1. 24:367.

Heap, R.B., A.P.F. Flint, and J.E. Gadsby. 198la. Embryonic signals and maternal recognition. P. 3Il. In S. Glasser and D.W. Bullock (Eds.) Cellular and Molecular Aspects of Implantation. Plenum Press, New York.

Heap, R.B., A.P.F. Flint, J.E. Gadsby, and C. Rice. 1979. Hormones, the early embryo and the uterine environment. J. Reprod. Fertil. 55(Supp1. 13): 167 . 
Heap, R.B., A.P.F. Flint, P.E. Hartmann, J.E. Gadsby, L.D. Staples, N. Ackland, and M. Hamon. 1981b. Oestrogen production in early pregnancy. J. Endocrinol. 89:77P.

Heap, R.B., and G.E. Lamming. 1960. Studies of the uterine environment of different species. I. Influence of ovarian hormones on the chemical composition of uterine secretions. J. Endocrinol. $20: 23$.

Heap, R.B., and G.E. Lamming. 1962. The influence of ovarian hormones on some chemical constituents of the uterine washings of rat and rabbit. J. Endocrinol. 25:57.

Heap, R.B., and J.S. Perry. 1974. The maternal recognition of pregnancy. Brit. J. Hosp. Med. 12:8.

Heap, R.B., A.F. Symons, and J.C. Watkins. 1971. On interaction between estradiol and progesterone in aqueous solutions and in a model membrane system. Biochim. Biophys. Acta 233:307.

Henderson, K.M., R.J. Scaramuzzi, and D.T. Baird. 1977. Simultaneous influsion of prostaglandins $\mathrm{E}_{2}$ antagonizes the luteolytic action of prostaglandin $\mathrm{F}_{2} \alpha$ in vivo. J. Endocrinol. $72: 379$.

Henricks, D.M., J.F. Dickey, and G.D. Niswender. 1970. Serum LH and plasma progesterone levels during the estrous cycle in early pregnancy in cows. Biol. Reprod. 2:346.

Henricks, D.M., and R.B. Harris. 1978. Cytoplasmic estrogen receptors and estrogen concentrations in bovine endometrium. Endocrinol. $103: 176$.

Henricks, D.M., and D.J. Tinda11. 1971. Metabolism of progesterone4-C 14 in porcine uterine endometrium. Endocrinol. 89:920.

Heuser, C.H. 1927. A study of the implantation of the ovum of the pig. from the stage of the bilaminar blastocyst to the completion of the fetal membranes. Contrib. Embryol. 19:229.

Hixon, J.E., and W. Hansel. 1974. Evidence for preferential transfer of $\mathrm{PGF}_{2} \alpha$ to the ovarian artery following intra uterine administration in cattle. Biol. Reprod. 11:543.

Hoffman, B., W.C. Wagner, and T. Giménez. 1976. Free and conjugated steroid in maternal and fetal plasma in the cow near term. Biol. of Reprod. 15:126.

Hoffman, B., W.C. Wagner, J.E. Hickson, and J. Bohr. 1979. Observations concerning the functional status of the corpus luteum and the placenta around parturition in the cow. Anim. Reprod. Sci. $2: 253$. 
Holness, D.H., J.H. Ellison, and L.M. Wilkins. 1977. Conception of beef cows in relation to the concentration of progesterone in peripheral blood. Rhod. J. Agric. Res. 15:3.

Holzbauer, M. 1976. Physiological aspects of steroids with anaesthetic properties. Med. Biol. 54:227.

Horst, M.N., S.M.M. Basha, G. Baumbach, E.H. Mansfield, and R.M. Roberts. 1980. Alkaline urea solubilization, 2 dimensional electrophoresis and lectin staining of mammalian plasma membrane and plant seed proteins. Analytical Biochim. 102:399.

Hors:, M.N., and R.M. Roberts. 1979. Analysis of polypeptide turnover rates in Chinese hamster ovary cells, plasma membranes using two dimensional electrophoresis. J. Biol. Chem. 254:5000.

Hoyes, A.D. 1972. The endometrial glands of pregnant sheep: An ultrastructural study. J. Anat. 111:55.

Hubbert, W.T., O.H.B. Stalheim, and G.D. Booth. 1972. Changes in organ weights and fluid volumes during growth of the bovine fetus. Growth $36: 217$.

Huckabee, W.E., C. Crenshaw, L.B. Curat, L. Mann, and D.H. Barron. 1970. The effect of exogenous oestrogen on the blood flow and oxygen consumption of the uterus of the nonpregnant ewe. Q. J. Exp. Physiol. 55:16.

Hughes, J.P., G.H. Stabenfeldt, and J.W. Evans. 1977. The oestrous cycle of the mare and its uterine control. Aust. Vet. J. 53:253.

Huie, J.M., R.R. Magness, R.P. Reynolds, G. Hoyer, T. Huecksteadt, M. Colcord, B. Stalcup, G. Whysong, and C.W. Weems. 1981. The effect of chronic ipsilateral or contralateral intrauterine infusion of prostaglandin $E_{1}\left(P_{G E}\right)$ on luteal function of unilaterally ovariectomized ewes. Prostaglandins 21:945.

Hurley, T.W., C.N. Kuhn, S.M. Schanberg, and S. Handwerger. 1980. Differential effects of placental lactogen, growth hormone and prolactin on rat liver ornithine decarboxylase activity in perinatal period. Life Sci. 27:2269.

Huslig, R.L., R.L. Fogwell, and W.L. Smith. 1979. The prostaglandin forming cyclo-oxygenase of ovine uterus: Relationship to luteal function. Biol. Reprod. 21:589.

Hyland, J.H., J.G. Manns, and W.D. Humphrey. 1982. Prostaglandin production by ovine embryos and endometrium in vitro. J. Reprod. Fertil. 65:299.

Innskeep, E.K., L. Wilson, W.R. Butler, D.J. Dierschke, G.R. Fritz, and E. Knobil. 1980. Endometrial secretion of prostaglandins during the ovarian cycle and early pregnancy. P. 287. In F.A. Kimbal1 (Ed.) The Endometrium. Spectrum Publications Inc., New York. 
Ireland, J.J., P.B. Coulson, and R.L. Murphree. 1979. Follicular development during four stages of the estrous cycle of beef cattle. J. Anim. Sci. 49:1261.

Iritani, A., W.R. Gnomes, and N.L. Van Demark. 1969. Secretion rates and chemical composition of oviduct and uterine fluids in ewes. Biol. Reprod. 2:245.

Janne, 0., V. Isomaa, H. Isotalo, E. Kokko, and P. Vierikko. 1978. Uterine estrogen and progestin receptors and their regulation. Uppsala J. Med. Sci. (Supp1. 22):62.

Janson, P.O., I. Albrecht, and K. Ahren. 1975. Effects of prostaglandin $F_{2} \alpha$ on ovarian blood flow and vascular resistance in the pseudopregnant rabbit. Acta Endocrinol. 79:337.

Janzen, R.G., E.R. Mably, T. Tamaoki, R.B. Church, and F.L. Lorscheider. 1982. Synthesis of alpha-feto protein by the pre-implantation and post-implantation bovine embryo. J. Reprod. Fertil. 65:105.

Katzenellenbogen, B.S., H.S. Bhakoo, J.R. Hayes, and W.N. Schnidt. 1980. Uterine estrogen-induced protein: An index of uterine sensitivity to hormones. P. 267. In M. Beato (Ed.) Steroid Induced Uterine Protein. Elsvier/North-Holland Biomedical Press, Amsterdam, Netherlands.

Keilin, D., and E.F. Hartee. 1952. Specificity of glucose oxidase (Notatin). Biochem. J. 50:331.

Kelly, R.W., and M.H. Abel. 1980. Comparison of the action of various catechol estrogens on prostaglandin production in vitro. Endocrine Society 13 (Abstr.).

Kennedy, T.G. 1980. Estrogen and uterine sensitization for the decidual cell reaction: Role of prostaglandins. Biol. Reprod. $23: 955$.

Kenney, R.M., K. Usui, and K. McEntee. 1965. Some histochemical and biochemical enzymatic parameters of the estrous cycle of the bovine endometrium. J. Am. Vet. Med. Assoc. 147:1660 (Abstr.).

Kensinger, R.S., R.J. Collier, C.R. Wallace, and R.M. Roberts. 1982. Production and isolation of bovine placental lactogen by cotyledonary explant culture. ASAS and CSAS 603:363 (Abstr.).

Killam, A.P., C.R. Rosenfeld, F.C. Battaglia, E.L. Makowski, and G. Meschia. 1973. Effect of estrogens on blood flow of oophorectomized ewes. Am. J. Obstet. Gynecol. 115:1045.

Kimbal1, F.A., and J.W. Lauderdale. 1975. Prostaglandin $E_{1}$ and $F_{2} \alpha$ specific binding in bovine corpora lutea: Comparison with luteolytic effects. Prostaglandins 10:313. 
Kindahl, H., L.E. Edqvist, A. Bane, and E. Granstrom. 1976. Blood levels of progesterone and 15-keto-13,14 dihydro-prostaglandin $\mathrm{F}_{2} \alpha$ during the normal estrous cycle and early pregnancy in heifers. Acta Endocrinol.. 82:134.

Kindahl, H., J.0. Linde11, and L.E. Edqvist. 1981. Release of prostaglandin $F_{2} \alpha$ during the oestrous cycle. Acta Vet. Scand. (Supp1. 77): 143.

King, G.J., B.A. Atkinson, and H.A. Robertson. 1979. Development of the bovine placentome during the second month of gestation. J. Reprod. Fertil. 55:173.

King, G.J., B.A. Atkinson, and H.A. Robertson. 1980. Development of the bovine placentome from days 20 to 29 of gestation. J. Reprod. Fertil. $59: 95$.

King, G.J., B.A. Atkinson, and H.A. Robertson. 1981. Development of the intercaruncular areas during early gestation and establishment of the bovine placenta. J. Reprod. Fertil. 61:469.

Kingman, H.E. 1948. The placentome of the cow. Amer. J. Vet. Res. $9: 125$.

Kirkland, J.L., R.M. Gardner, V.R. Mukku, M. Akhtar, and G.M. Stancel. 1981. Hormonal control of uterine growth: The effect of hypothyroidism on estrogen-stimulated cell division. Endocrinol. $108: 2346$.

Knickerbocker, J.J., J.L. Fleeger, R.F. Roberts, R.M. Eley, W.W. Thatcher, F.W. Bazer, and M.J. Fields. 1980. Differential metabolism of progesterone in vitro by the bovine endometrium and early conceptus. ASAS 454:293 (Abstr.).

Knickerbocker, J.J., W.W. Thatcher, D.B. Foster, D. Wolfenson, F.F. Bartol, and D. Caton. 1982. Uterine production of $\mathrm{PGF}_{2} \alpha$ in response to estradiol-17B in cyclic cattle. ASAS and CSAS 606: 364 (Abstr.).

Knight, J.W., F.W. Bazer, W.W. Thatcher, D.E. Franke, and H.D. Wallace. 1977. Conceptus development in intact and unilaterally hysterectomized-ovariectomized gilts: Interrelations among hormonal status, placental development, fetal fluids and fetal growth. J. Anim. Sci. 44:620.

Knight, J.W., F.W. Bazer, and H.D. Wallace. 1974a. Effect of progesterone-induced increase in uterine secretory activity on development of the porcine conceptus. J. Anim. Sci. 39:743.

Knight, J.W., F.W. Bazer, H.D. Wallace, and C.J. Wilcox. 1974b. Dose-response relationships between exogenous progesterone and estradiol and porcine uterine protein secretions. J. Anim. Sci. $39: 747$. 
Kojima, Y., and U. Selander. 1970. Cyclical changes in the fine structure of bovine endometrial gland cells. Zeitschrift fur Zellforschung und Mikroskopische Anatomie 104:69.

Koligian, K.B., and F. Stormshak. 1977a. Nuclear and cytoplasmic estrogen receptors in ovine endometrium during the estrous cycle. Endocrinol. 101:524.

Koligian, K.B., and F. Stormshak. 1977b. Progesterone inhibition of estrogen receptor replinishment in ovine endometrium. Biol. Reprod. $17: 412$.

Krieger, D.T. 1982. Placenta as a source of "brain" and "pituitary" hormones. Biol. Reprod. 26:55.

Kubli-Garfias, C., A. Lopez-Fiesco, M.T. Pacheco-Cano, H. Ponce-Monter, and A. Bondani. 1980. In vitro effects of androgens on the spontaneous rat uterine contractility. Steroids 35:633.

Kubli-Garfias, C., L. Medrano-Conde, C. Beyer, and A. Bondani. 1979.

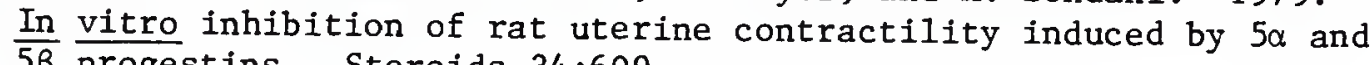
$\overline{5 \beta}$ progestins. Steroids 34:609.

Lacroix, E., W. Eechaute, and I. Leusen. 1974. The biosynthesis of estrogens by cow follicles. Steroids 23:337.

Lai, P.C.W., G.J. Mears, G.R. Van Petten, D.M. Hay, and F.L. Lorscheider. 1978a. Fetal-maternal distribution of ovine alpha-feto protein. Am. J. Physiol. 235:27E.

Lai, P.C.W., E.H. Peters, and F.L. Lorscheider. 1978b. Bovine fetusspecific serum proteins: Purification and characterization of $\alpha_{1}$-fetoprotein and immunological identification of $\alpha_{2}$ - and $\beta-$ fetoproteins. Biochim. Biophys. Acta 535:138.

Lamonthe, P., D. Bousquet, and P. Guay. 1977. Cyclic variation of $F$ prostaglandins in the uterine fluids of the cow. J. Reprod. Fertil. $50: 381$.

Lamonthe, P., and P. Guay. 1970. Electrolytes of bovine intra-uterine secretions during infertility sine materia. Can. J. Comp. Med. $34: 167$.

Larson, L.L., G.B. Marion, and H.T. Gier. 1970. Glycogen metabolism in bovine endometrium. Am. J. Vet. Res. 31:1929.

Laskey, R.A., and A.D. Mills. 1975. Quantitative film detection of $3 \mathrm{H}$ and $14 \mathrm{C}$ in polyacrilamide gels by fluorography. Eur. J. Biochem. $252: 6510$.

Laster, D.B. 1977. A pregnancy-specific protein in the bovine uterus. Biol. Reprod. 16:682. 
Latner, A.L., T. Marsha11, and M. Gambie. 1980. Simplified technique of high resolution two-dimensional electrophoresis: Serum immunoglobulins. Clin. Chimica Acta 103:51.

Lauderdale, J.W. 1974. Distribution and biological effects of prostaglandins. J. Anim. Sci. 38(Supp1. 1):22.

Leiser, R. 1975. Kontaktaufnahme zwischen trophoblast und unterusepithel während der fruhen implantation beim rind. Anat. Histol. Embryo1. 4:63.

Leiser, R., and K.H. Wille. 1975. Alkaline phosphatase in the bovine endometrium and trophoblast during the early phase of implantation. Anat. Embryol. 148:145.

Lewis, G.S., S.M.M. Basha, F.W. Bazer, R.M. Roberts, and W.W. Thatcher. 1979. Proteins originating from bovine and porcine blastocysts. ASAS 424:313 (Abstr.).

Lewis, G.S., P.E. Jenkins, R.L. Fogwe11, and E.K. Inskeep. 1978. Concentrations of prostaglandins $E_{2}$ and $F_{2} \alpha$ and their relationship to luteal function in early pregnant ewes. J. Anim. Sci. $47: 1314$.

Lewis, G.S., W.W. Thatcher, F.W. Bazer, and J.S. Cur1. 1982. Metabolism of arachidonic acid in vitro by bovine blastocysts and endometrium. Biol. Reprod. $27: 431$.

Libby, D.W., E.C. Segerson, W.R. Getz, T.R. Hansen, and R.D. Randel. 1982. Uterine protein secretions in angus and brahman cows. ASAS and CSAS 613:367 (Abstr.).

Linford, E., and J.M. Iosson. 1975. A quantitative study of some lysosomal enzymes in the bovine endometrium during early pregnancy. J.'Reprod. Fertil. 44:249.

Lobe1, B.L., and E. Levy. 1968. Enzymic correlates of development, secretory function and regression of follicles and corpora lutea in the bovine ovary. Acta Endocrino1. 59(Supp1. 132):1.

Loeb, L. 1923. The effect of exterpation of the uterus and the life and function of the corpus luteum in the guinea pig. Proc. Soc. Exp. Biol. Med. 441 .

Loening, U.E. 1967. The fractionation of high molecular weight ribonucleic acid by polyacrylamide-gel electrophoresis. Biochem. J. $102: 251$.

Lowry, O.H., N.C. Rosebrough, A.L. Farr, and R.J. Randa11. 1951. Protein measurement with the Folin phenol reagent. J. Biol. Chem. 193:265. 
Luebke, M.B., N.A. Hirota, and F. Stormshak. 1980. Estradiol-induced changes in ovine endometrial RNA polymerase activities during the mid-1uteal phase of the estrous cycle. ASAS 470:300 (Abstr.).

Lukaszewska, J., and W. Hanse1. 1980. Corpus Iuteum maintenance during early pregnancy in the cow. J. Reprod. Fertil. 59:485.

McCracken, J.A., and B.B. Caldwe11. 1969. Corpus luteum maintenance in a ewe with one congenitally absent uterine horn. J. Reprod. Fertil. 20:139.

McCracken, J.A., W. Schramm, B. Barcikowski, and L. Wilson, Jr. 1981. The identification of prostaglandin $\mathrm{F}_{2} \alpha$ as a uterine luteolytic hormone and the hormonal control of its synthesis. Acta Vet. Scand. (Supp1. 77):71.

MacManus, J.P., and J.F. Whitfield. 1974. Cyclic AMP, prostaglandins and the control of cell proliferation. Prostaglandins 6:475.

Malven, P.V., and W. Hansel. 1964. Ovarian function in dairy heifers following hysterectomy. J. Dairy Sci. 47:1388.

Marinov, U., and J.E. Lovell. 1968. Cytology of the bovine uterine epithelium during the estrous cycle. Amer. J. Vet. Res. 19:13.

Marion, G.B., and H.T. Gier. 1958. The process of placentation in the bovine. J. Anim. Sci. 17:1216.

Marion, G.B., H.T. Gier, and J.B. Choudary. 1968. Micromorphology of the bovine ovarian follicular system. J. Anim. Sci. 27:451.

Marshal1, P.J., J.F. Dixon, and L.E. Hokin. 1980. Evidence for a role in stimulus-secretion coupling of prostaglandins derived from release of arachidonoyl residues as a result of phosphatidylinosito1 breakdown. Proc. Nat1. Acad. Sci. 77:3292.

Martal, J., and J. Djiane. 1977. Production of chorionic somatomammotrophin in sheep. J. Reprod. Fertil. 49:285.

Martal, J., J. Djiane, and M. Dubois. 1977. Immunofluorescent localization of ovine placental lactogen. Cell. Tiss. Res. $184: 427$.

Marta1, J., M.C. Lacroix, C. Loudes, M. Saunier, and S. WintenbergerTorres. 1979. Trophoblastin, an antiluteolytic protein present in early pregnancy in sheep. J. Reprod. Fertil. 56:63.

Masters, R.A., R.M. Roberts, G.S. Lewis, W.W. Thatcher, F.W. Bazer, and J.D. Godkin. 1983. High molecular weight glycoproteins released by expanding preattachment sheep, pig and cow blastocysts in culture. J. Reprod. Fertil. 66:571. 
Maule-Walker, F.M., C.E. Patek, C.F. Leaf, and J. Watson. 1977. The metabolism of prostaglandins $F_{2} \alpha$ and $E_{2}$ by non-pregnant porcine endometrial and luteal tissue and early pregnant porcine endometrial tissue, luteal tissue and conceptuses in vitro. Prostaglandins $14: 557$.

Me1ton, A.A., R.0. Berry, and O.D. Butler. 1951. The interval between the time of ovulation and attachment of the bovine embryo. J. Anim. Sci. 10:993.

Menezo, Y., J.P. Renard, B. Delobel, and J.F. Pageaux. 1982. Kinetic study of fatty acid composition of day 7 to day 14 cow embryos. Biol. Reprod. 26:787.

Merz, E.A., E.R. Hauser, and B.G. England. 1981. Ovarian function in the cycling cow: Relationship between gonadotropin binding to theca and granulosa and steroidogenesis in individual follicles. J. Anim. Sci. 52:1457.

Metz, S.A., W.Y. Fujimoto, and R.P. Robertson. 1982. Lypoxygenation of arachidonic acid: A pivotal step in stimulus-secretion coupling in the pancreatic beta cell. Endocrinol. 111:2141.

Milgrom, E., L. Thi, M. Atger, and E.E. Baulieu. 1973. Mechanisms regulating the concentration and the conformation of progesterone receptor(s) in the uterus. J. Biol. Chem. 248:6366.

Miller, B.G., L. Murphy, and G.M. Stone. 1977. Hormone receptor levels and hormone, RNA and protein metabolism in the genital tract during the oestrous cycle of the ewe. J. Endocrino1. 73:91.

Mills, A.C. 1975. Cyclic nature of bovine uterine luminal proteins and their relationship to peripheral plasma progesterone and estrogen levels. Ph.D. Dissertation, Univ. of Fla., Gainesville.

Milutinovic, S., B.E. Argent, I. Schulz, and G. Sachs. 1977. Studies on isolated subcellular components of cat pancreas. II. $\mathrm{A} \mathrm{Ca}^{++}$ dependent interaction between membranes and zymogen granules of cat pancreas. J. Memb. Bio1. 36:281.

Milvae, R.A., and $W$. Hansel. 1980. The effects of prostacyclin ( $\mathrm{PGI}_{2}$ ) and 6 -keto-PGF ${ }_{1} \alpha$ on bovine plasma progesterone and LH concentrations. Prostaglandins 20:641.

Moeljono, M.P.E., F.W. Bazer, and W.W. Thatcher. 1976a. A study of $\mathrm{PGF}_{2} \alpha$ as the luteolysin in swine. I. Effect of $\mathrm{PGF}_{2} \alpha$ in hysterectomized gilts. Prostaglandins 11:737.

Moeljono, M.P.E., M. Frank, L.J. Owens, C.J. Wilcox, F.W. Bazer, and W.W. Thatcher. 1976b. PGF in utero ovarian vein of pregnant and nonpregnant gilts. J. Anim. Sci. 43:298. 
Moffatt, R.J., F.W. Bazer, D. Caton, and R.M. Roberts. 1980. Secretory activity of endometrium from pregnant and nonpregnant uterine horns of ewes. ASAS 307:487 (Abstr.).

Moffatt, R.J., F.W. Bazer, D. Caton, and R.M. Roberts. 1981. Steroid regulation of fluid and proteins of ovine uterine secretions. ASAS 552:350 (Abstr.).

Moor, R.M., and L.E.A. Rowson. 1966a. The corpus luteum of the sheep: Effect of the removal of embryos on luteal function. J. Endocrinol. $34: 497$.

Moor, R.M., and L.E.A. Rowson. 1966b. The corpus luteum of the sheep: Functional relationship between the embryo and the corpus luteum. J. Endocrinol. $34: 233$.

Moor, R.M., and L.E.A. Rowson. 1966c. Local uterine mechanisms affecting luteal function in sheep. J. Reprod. Fertil. 11:307.

Moore, N.W., and A.V. Nalbandov. 1953. Neurogenic effects of uterine distension on the estrous cycle of the ewe. Endocrinol. 53:1.

Moss, S., T.R. Wrenn, and F.F. Sykes. 1954. Alkaline phosphatase, glycogen and periodic acid-Schiff positive substances in the bovine uterus during the estrous cycle. Endocrinol. 55:261.

Mossman, H.W. 1937. Comparative morphogenesis of the fetal membranes and accessory uterine structures. Contrib. Embryol. 158:133.

Mossman, H.W. 1980. Comparative morphology of the endometrium. P. 3. In F.A. Kimbal1 (Ed.) The Endometrium. Spectrum Publications Inc., Wexford Terrace, Jamaica, New York.

Mullins, D.E., F.W. Bazer, and R.M. Roberts. 1980a. Secretion of a progesterone-induced inhibitor of plasminogen activator by the porcine uterus. Ce11 20:865.

Mullins, D.E., M.N. Horst, F.W. Bazer, and R.M. Roberts. 1980b. Isolation and characterization of a plasma membrane fraction derived from the luminal surface of a pig uterus during the estrous cycle and early pregnancy. Biol. Reprod. 22:1181.

Murdoch, R.N. 1970. Uterine endometrial phosphomonoesterases in relation to implantation in the ewe and rabbit doe. Aust. J. Biol. Sci. 23:1089.

Murdoch, R.N. 1972. Phosphomonoesterases and histamine in the uterus of the ewe during early pregnancy. Aust. J. Anim. Sci. 25:1289.

Murray, F.A., F.W. Bazer, J.W. Runde11, C.K. Vincent, H.D. Wallace, and A.C. Warnick. 1971. Development failure in swine embryos restricted to the oviductal environment. J. Reprod. Fertil. $24: 445$. 
Murray, F.A., F.W. Bazer, H.D. Wallace, and A.C. Warnick. 1972. Quantitative and qualitative variation in the secretion of protein by the porcine uterus during the estrous cycle. Biol. Reprod. $7: 314$.

Murray, F.A., and J.R. Chenault. 1982. Effects of steroids on bovine T-lymphocyte blastogenesis in vitro. J. Anim. Sci. 5:1132.

Murthy, G.S., C. Schellenberg, and H.G. Friesen. 1982. Purification and characterization of bovine placental lactogen. Endocrinol. $111: 2117$.

Needham, J. 1950. Biochemistry and Morphogenesis. Cambridge University Press, London.

Needham, J. 1959. A History of Embryology. Cambridge University Press, London.

Nelson, N.A., R.C. Kelly, and R.A. Johnson. 1982. Prostaglandins and the arachidonic acid cascade. Chem. En. News Aug.:30.

Ngah, M.B., K.W. Kelley, and P.L. Singer. 1982. Bovine immunoglobulin $M$ as a major factor contributing to serum-induced head-to-head agglutination in bovine spermatozoa. Biol. of Reprod. 27:62.

Noden, P.A., W.D. Oxender, and H.D. Hafs. 1974. Estrus, ovulation, progesterone and luteinizing hormone after prostaglandin $F_{2} \alpha$ in mares. Proc. Soc. Exp. Biol. Med. 145:145.

Northey, D.L., and L.R. French. 1980. The effect of embryo removal and intrauterine infusion of embryonic homogenates on the lifespan of the bovine corpus luteum. J. Anim. Sci. 50:298.

Olds, D., and N.L. Van Demark. 1957a. Physiological aspects of fluids in female genitalia with special reference to cattle: A review. Amer. J. Vet. Res. 18:587.

Olds, D., and N.L. Van Demark. 1957b. Luminal fluids of bovine female genitalia. J. Amer. Vet. Med. Assoc. 131:555.

O'Malley, B.W., and W.T. Schrader. 1976. The receptors of steroid hormones. Sci. Amer. 234:32.

O'Malley, B.W., and A.R. Means. 1974. Female steroid hormones and target cell nuclei. Science 183:610.

Oppenheimer, S.P. 1978. Cell curface carbohydrates in adhesion and migration. Am. Zoo1. 18:13.

Ouchterlony, 0. 1958. Diffusion-in-gel methods for immunological analysis. Progr. Allergy 5:1. 
Patek, C.E., and J. Watson. 1976. Prostaglandin F and progesterone secretion by porcine endometrium and CL in vitro. Prostaglandins $12: 97$.

Perry, J.S. 1981. The mammalian fetal membranes. J. Reprod. Fertil. $62: 321$.

Peters, K.R., L.T. Chapin, R.S. Emery, and H.A. Tucker. 1980. Growth and hormonal response of heifers to various photoperiods. J. Anim. Sci. $51: 1148$.

Peterson, A.J., H.R. Tervit, R.J. Fairclough, P.G. Havik, and J.F. Smith. 1976. Jugular levels of 13,14-dihydro-15-keto-prostaglandin $F$ and progesterone around luteolysis and early pregnancy in the ewe. Prostaglandins 12:551.

Pharriss, B.B., and L.J. Wyngarden. 1969. The effect of prostaglandin $\mathrm{F}_{2} \alpha$ on the progesterone content of ovaries from pseudopregnant rats. Proc. Soc. Exp. Bio1. Med. 130:92.

Pietras, R.J., and C.M. Szego. 1977. Specific binding sites for oestrogen at the outer surfaces of isolated endometrial cells. Nature 223:29.

Pippi, N.L., and W.V. Lumb. 1979. Objective tests of analgesic drugs in ponies. Amer. J. Vet. Res. 40:1082.

Poffenbarger, J.I., D.M. Henricks, and T. Gimenez. 1982. Biologically active LH in bovine embryos and umbilical plasma. ASAS 636:377 (Abstr.).

Pope, C.E., and B.N. Day. 1972. Development of pig embryos following restriction to the ampullar portion of the oviduct. J. Reprod. Fertil. 31:135.

Porter, D.G. 1980. Review article: Feto-maternal relationships: The actions and the control of certain placental hormones. Placenta $1: 259$.

Pratt, B.R., R.L. Butcher, and E.K. Inskeep. 1977. Antiluteolytic effect of the conceptus and of $\mathrm{PGE}_{2}$ in ewes. J. Anim. Sci. 45:784.

Priedkalns, J. 1976. Female reproductive system. Ch. 13. In H.D. Dellman and E.N. Brown (Eds.) Textbook of Veterinary Histology. Lea and Febiger, Philadelphia.

Priedkalns, J., and A.F. Weber. 1969. Ultrastructural studies of the bovine graffian follicle and corpus luteum. Z. Zellforsch Mikrosk. Anat. $91: 554$.

Psychoyos, A., and V. Casimiri. 1980. Factors involved in uterine receptivity and refractoriness. Prog. Reprod. Bio1. 7:143. 
Rajakoski, E. 1960. The ovarian follicular system in sexually mature heifers with special reference to seasonal, cyclical and leftright variations. Acta Endocrinol. (Supp1. 52):34.

Ramwel1, P.W., E.M.K. Leovey, and A.L. Sintestos. 1977. Regulation of the arachadonic acid cascade. Biol. Reprod. 16:70.

Rasmussen, H. 1981. Calcium and CAMP as Synarchic Messengers. John Wiley and Sons Inc., New York.

Rasmussen, H., and D.B.P. Goodman. 1977. Relationships between calcium and cyclic nucleotides in cell activation. Physiol. Rev, 57:421.

Reddy, S., and W.B. Watkins. 1978. Immunofluorescence localization of ovine placental lactogen. J. Reprod. Fertil. 52:173.

Reiland, J. 1971. Gel filtration. P. 287. In W.B. Jakoby (Ed.) Methods in Enzymology. Academic Press, New York.

Reitzer, L.J., B.M. Wice, and D. Kenne11. 1979. Evidence that glutamine, not sugar, is the major energy source for cultured HeLa cells. J. Biol. Chem. 254:2669.

Renard, J.-P., A. Philippon, and Y. Menezo. 1980. In-vitro uptake of glucose by bovine blastocysts. J. Reprod. Fertil. 58:161.

Renegar, R.H., F.W. Bazer, and R.M. Roberts. 1982. Placental transport and distribution of uteroferrin in the feral pig. Biol. Reprod. $27: 12 \dot{4} 7$.

Reynolds, L.P., J. Stigler, G.L. Hoyer, R.R. Magness, J.M. Huie, T.P. Huecksteadt, G.L. Whysong, H.R. Behrman, and C.W. Weems. 1981. The effect of $\mathrm{PGE}_{1}$ or $\mathrm{PGE}_{2}$ on $\mathrm{PGF}_{2} \alpha$-induced luteolysis in nonbred ewes. Prostaglandins 21:957.

Reyrolds, S.R.M. 1949. The Physiology of the Uterus. Hoeber, New York.

Rice, C., N. Ackland, and R.B. Heap. 1981. Blastocyst-endometrial interactions and protein synthesis during pre-implantation development in the pig. Placenta 2:129.

Rico, L.E., W.W. Thatcher, M. Drost, D. Wolfenson, and M. Terqui. 1981. Plasma PGFM responses to estradiol injection in pregnant and cycling cows. ASAS $582: 363$ (Abstr.).

Roberts. G.P.. and J.M. Parker. 1974a. Macromolecular components of the luminal fluid from the bovine uterus. J. Reprod. Fertil. $40: 291$.

Roberts. G.P.. and J.M. Parker. 1974b. An investigation of enzymes and hormone binding proteins in the luminal fluid of the bovine uterus. J. Reprod. Fertil. 40:308. 
Roberts, G.P., and J.M. Parker. 1976. Fractionation and comparison of proteins from bovine uterine fluid and bovine allantoic fluid. Biochem et Biophysica Acta 446:69.

Roberts, G.P., J.M. Parker, and H.W. Symonds. 1976a. Macromolecular components of the genital tract fluids from sheep. J. Reprod. Fertil. 48:99.

Roberts, R.M., and F.W. Bazer. 1980. The properties, function and hormonal control of synthesis of uteroferrin, the purple protein of the pig uterus. P. 133. In M. Beato (Ed.) Steroid Induced Uterine Proteins. Elsevier, North-Holland Biomedical Press.

Roberts, R.M., F.W. Bazer, N.J. Baldwin, and W.E. Pollard. 1976b. Induction of lysozyme and leucine amino peptidase in the uterine flushings of pigs by progesterone. Archs. Biochem. Biophys. 177: 499.

Robertson, H.A., and G.J. King. 1979. Conjugated and unconjugated oestrogens in foetal and maternal fluids of the cow throughout pregnancy. J. Reprod. Fertil. 55:463.

Robinson, T.J. 1977. Reproduction in cattle. P. 433. In H.H. Cole and P.T. Cupps (Eds.) Reproduction in Domestic Animals. Academic Press, New York.

Roe, J.H. 1934. Colorimetric method for the determination of fructose in blood and urine. J. Biol. Chem. 107:15.

Roman-Ponce, H., W.W. Thatcher, D. Caton, D.H. Barron, and C.J. Wilcox. 1978. Thermal stress effects on uterine blood flow in dairy cows. J. Anim. Sci. 46:175.

Rowson, L.E.A., and R.M. Moor. 1967. The influence of embryonic tissue homogenate infused into the uterus, on the lifespan of the corpus luteum in the sheep. J. Reprod. Fertil. 13:511.

Rubin, R.P. 1982. Calcium-phospholipid interactions in secretory cells: A new perspective on stimulus-secretion coupling. Fed. Amer. Soc. Biol. Proc. 41:2181.

Ryan, K.J., and O.W. Smith. 1965. Biogenesis of steroid hormones in the human ovary. Rec. Prog. Horm. Res. 21:367.

Rzepkowski, R.A., J.J. Ireland, R.L. Fogwe11, L.T. Chapin, and H.A. Tucker. 1982. Serum luteinizing hormone, follicle stimulating hormone and prolactin response to photoperiod during the estrous cycle of holstein heifers. J. Anim. Sci. 55:1125.

Salisbury, G.W., N.L. Van Denmark, and J.R. Lodge. 1978. Physiology of Reproduction and Artificial Insemination of Cattle. W.H. Freeman and Company, San Francisco. 
Sauer, M.J. 1979. Review: Hormone involvement in the establishment of pregnancy. J. Reprod. Fertil. 56:725.

Saunders, J.B. de C.M., and C.D. O'Malley. 1982. The Anatomical Drawings of Andreas Vesalius. Crown Publishers Inc., New York.

Saunders, P.T.K., A.J. Ziecik, and A.P.F. Flint. 1980. Gonadotropin like substance in pig placenta and embryonic membranes. J. Endocrinol. 85:25P.

Schams, D., E. Schallenberger, B. Hoffman, and H. Karg. 1977. The oestrous cycle of the cow: Hormonal parameters and time relationships concerning oestrus, ovulation, and electrical resistance of the vaginal mucous. Acta Endocrinol. 86:180.

Schellenberg, W.C., and H.G. Friesen. 1982. The bioassay of bovine placental lactogen. Endocrinol. 111:2125.

Schlosnagle, D.C., F.W. Bazer, J.C.M. Tsibris, and R.M. Roberts. 1974 . An iron-containing phosphatase induced by progesterone in the uterine flushings of pigs. J. Biol. Chem. 249:7574.

Schrader, W.T., and B.W. O'Malley. 1978. Molecular structure and analysis of progesterone receptors. P. 189. In B.W. O'Malley and L. Birnbaumer (Eds.) Receptors and Hormone Action. Vol. 2. Academic Press, New York.

Schultz, R.H., M.L. Fahning, and E.F. Graham. 1971. A chemical study of uterine fluid and blood serum of normal cows during the oestrous cycle. J. Reprod. Fertil. 27:355.

Seamans, K.W., M.J. Fields, F.W. Bazer, M.W. Vernon, and D.C. Sharp. 1979. In vitro aromatase activity of pregnant and nonpregnant equine endometrium and conceptus membranes. ASAS 477:335 (Abstr.).

Segerson, E.C. 1981. Specificity and immunosuppressive activity of ovine uterine secretory protein from day 16 and 18 pregnant ewes upon lymphocytes in vitro. ASAS 588:365 (Abstr.).

Segerson, E.C., D.W. Libby, W.R. Getz, and R.D. Rande1. 1982. Immunosuppressive activity of uterine luminal protein secretions collected from angus and brahman cows. ASAS and CSAS 666:390 (Abstr.).

Seidel, G.E., Jr. 1981. Superovulation and embryo transfer in cattle. Science 211:351.

Senior, B.E. 1975. Cytoplasmic oestradiol-binding sites and their relationship to oestradiol content in the endometrium of cattle. J. Reprod. Fertil. 44:501.

Sharp, D.C. 1980. Factors associated with maternal recognition of pregnancy in mares. North Amer. Vet. Clinics $2: 277$. 
Shemesh, M., and W. Hansel. 1975a. Stimulation of prostaglandin synthesis in bovine ovarian tissues by arachidonic acid and luteinizing hormone. Biol. Reprod. 13:448.

Shemesh, M., and W. Hansel. 1975b. Levels of prostaglandin F (PGF) in the bovine endometrium, uterine venous, ovarian artery and jugular plasma during the estrous cycle. Proc. Soc. Exp. Biol. Med. 148:123.

Shemesh, M., F. Milaguir, N. Ayalon, and W. Hansel. 1979. Steroidogenesis and prostagland in synthesis by cultured bovine blastocysts. J. Reprod. Fertil. 56:181.

Short, R.V. 1969. Implantation and the maternal recognition of pregnancy. P. 2. In G.E.W. Wolstenholme and M. O'Connor (Eds.) Foetal Autonomy. Ciba Foundation Symposium. J. and A. Churchill Ltd., London.

Short, R.V. 1976. The evolution of human reproduction. Proc. Roy. Soc. Lond. 195:10.

Silver, M., and R.S. Comline. 1975. Transfer of gases and metabolites in the equine placenta: A comparison with other species. J. Reprod. Fertil. (Suppl. 23):589.

Silver, M., and R.S. Comline. 1976. Fetal and placental $\mathrm{O}_{2}$ consumption and the uptake of different metabolites in the ruminant and horse during late gestation. P. 731-736. In D.D. Reneau and J. Grote (Eds.) Oxygen Transport to Tissue. Symposium II. Vol. 75. Plenum Press, New York.

Skjerven, 0. 1956a. Endometrial biopsy studies in reproductively normal cattle. Acta Endocrinol. Copenh. 26(Supp1. ):134.

Skjerven, 0. 1956b. Phosphatase, fat and carbohydrate content of normal bovine endometrium. Fertil. Steril. 7:31.

Smith, K.M., P.C.W. Lai, H.A. Robertson, R.V. Church, and F.L. Lorscheider. 1979. Distribution of alpha 1 -feto protein in fetal plasma, allantoic fluid, amniotic fluid and maternal plasma of cows. J. Reprod. Fertil. 57:235.

Smith, M.F., M.S. Amoss, and J.N. Wiltbank. 1982. Relationship between extraembryonic membrane length and secretion of progesterone in vitro in beef heifers. ASAS and CSAS 669:392 (Abstr.).

Smith, V.G., L.A. Edgerton, H.D. Hafs, and E.M. Convey. 1973. Bovine serum estrogens, progestins and glucocorticoids during late pregnancy, parturition and early lactation. J. Anim. Sci. 36:391.

Spies, H.G., D.R. Zimmerman, H.L. Self, and L.E. Casida. 1958. Influence of hysterectomy and exogenous progesterone on size and progesterone content of the corpora lutea in gilts. J. Anim. Sci. 17:1234 (Abstr.). 
Squire, G.D., F.W. Bazer, and F.A. Murray. 1972. Electrophoretic patterns of porcine uterine protein secretions during the estrous cycle. Biol. Reprod. 7:321.

Sreenan, J.M. 1978. Non-surgical embryo transfer in cattle. Theriogenology $9: 69$.

Staples, L.D., I.R. Fleet, and R.B. Heap. 1982. Anatomy of the uteroovarian lymphatic network and the composition of afferent lymph in relation to the establishment of pregnancy in the sheep and goat. J. Reprod. Fertil. 64:409.

Staples, R.E., K. McEntee, and W. Hansel. 1961. Luteal function as related to pituitary and ovarian cytology and embryo development in the bovine. J. Dairy Sci. 44:2049.

Steven, D.H.1975a. Placenta depicta: Illustrations and ideas. P. 1. In D.H. Steven (Ed.) Comparative Placentation: Essays in Structure and Function. Academic Press, New York.

Steven, D.H. 1975b. Anatomy of the placental barrier. P. 25. In D.H. Steven (Ed.) Comparative Placentation: Essays in Structure and Function. Academic Press, New York.

Steven, D.H., F. Bass, C.J.M. Jansen, E.J. Krane, K. Ma1lon, C.A. Samuel, A.L. Thomas, and P.W. Nathanielz. 1978. Ultrast-ictural changes in the placenta of the ewe after fetal pituitary stalk section. Quart. J. Exp. Physiol. 63:221.

Steven, D.H., and G. Morriss. 1975. Development of the foetal membranes. P. 58. In D.H. Steven (Ed.) Comparative Placentation: Essays in Structure and Function. Academic Press, New York.

Stormshak, F. 1979. Uterine estrogen and progesterone receptors. P. 399. In H. Hawk (Ed.) Beltsville Symposia in Agricultural Research. 3. Animal Reproduction. Allanheld, Osmun and Company Publishers Inc., Montclair, New Jersey.

Stormshak, F., H.E. Kelly, and H.W. Hawk. 1969. Suppression of ovine luteal function by 17ß-estradiol. J. Anim. Sci. 29:476.

Suga, T., and J. Masaki. 1973. Studies on the uterine secretion of the cow. 6. Sugar and polyol constituents in the luminal fluid of bovine uterus. Jap. J. Anim. Reprod. 18:143.

Sullivan, D.A., and C.R. Wira. 1981. Estradiol regulation of secretory component in the female reproductive tract. J. Steroid Biochem. $15: 439$.

Sullivan, D.A., and C.R. Wira. 1983. Hormonal regulation of immunoglobulins in the rat uterus: Uterine response to a single estradiol treatment. Endocrinol. 112:260. 
Suzuki, K., and T.B. Tomasi. 1980. Mechanism of immune suppression by murine neonatal fluids. J. Immuno1. 125:1806.

Swett, W.W., C.A. Matthews, and M.H. Fohrman. 1948. Development of the fetus in the dairy cow. Tech. Bull. U.S. Dept. Agr. 964.

Thatcher, W.W., and J.R. Chenault. 1976. Reproductive physiological responses of cattle to exogenous prostaglandin $F_{2} \alpha$. J. Dairy Sci. $59: 1366$.

Thatcher, W.W., L.A. Guilbault, R.J. Collier, G.S. Lewis, M. Drost, J. Knickerbocker, D.B. Foster, and C.J. Wilcox. 1982. The impact of anti-partum physiology on postpartum performance in cows. $P .3$. In H. Karg and E. Schallenberger (Eds.) Factors Influencing Fertility in the Postpartum Cow. Martinus Nijhoff Publishers.

Thatcher, W.W., G.S. Lewis, R.M. Eley, F.W. Bazer, M.J. Fields, W.F. Williams, and C.J. Wilcox. 1980. Contribution of the bovine conceptus to the endocrinological phenomenon existing at implantation, during gestation, and around parturition. 9th International Conference of Animal Reproduction and AI. Plenary Session 1:9.

Thatcher, W.W., M. Terqui, J. Thimonier, J.P. Ravau1t, and P. Mauleon. 1979. 15-keto PGF and hormonal responses to injection of estradiol in heifers. Proc. S. Div. Amer. Soc. Anim. Sci. 43 (Abstr.).

Thibault, C. 1977. Are follicular maturation and oocyte maturation independent processes? Hammond Memorial Lecture. J. Reprod. Fertil. $51: 1$.

Tomasi, T.B., Jr. 1978. Suppressive factors in amiotic fluid and newborn serum: Is alpha-feto protein involved? Cell. Immunol. $37: 459$.

Trump, B.F., J. Resau, and L.A. Barrett. 1980. Methods of organ culture of human bronchis. P. 1. In D.M. Prescott (Ed.) Methods in Cell Biology. Vol. 21A. Academic Press, New York.

Tucker, H.A., and R.K. Ringer. 1982. Controlled photoperiodic environments for food animals. Science 216:1381.

Vaerman, J.P., and J. Férin. 1974. Local immunological response in the vagina, cervix, and endometrium. Acta Endocrino1. (Supp1.) 78:281.

Vernon, M.W., M.T. Zavy, R.L. Asquith, and D.C. Sharp. 1981. Prostaglandin $\mathrm{F}_{2} \alpha$ in the equine endometrium: Steroid modulation and production capacities during the estrous cycle and early pregnancy. Bio1. Reprod. $25: 581$.

Villa-Godoy, A., J.J. Ireland, J.A. Wortman, N.K. Ames, and R.L. Fogwe11. 1981. Luteal function in heifers following destruction of ovarian follicles at three stages of diestrus. ASAS 603:372 (Abstr.). 
Volpi, M., P.H. Naccache, and R.I. Sacha'afi. 1980. Arachidonate metabolite(s) increase the permeability of the plasma membrane of the neutrophils to calcium. Biochem. Biophys. Res. Comm. 92:1231.

Walters, M.R., and J.H. Clark. 1980. Estrogen and progesterone modulation of progesterone receptor content in the rat uterus. P. 183. In M. Beato (Ed.) Steroid Induced Uterine Proteins. Elsevier/ North-Holland Biomedical Press, Amsterdam, Netherlands.

Warren, J.E., H.W. Hawk, and D.J. Bolt. 1973. Evidence for progestational priming of estradiol induced luteal regression in the ewe. Biol. Reprod. 8:435.

Wathes, D.C. 1980. Protein synthesis by bovine chorion and uterine endometrium during the period of implantation. J. Reprod. Fertil. $60: 323$.

Wathes, D.C., and F.B.P. Wooding. 1980. An electron microscopic study of implantation in the cow. Amer. J. Anat. 159:285-306.

Watkins, W.B., and S. Reddy. 1980. Ovine placental lactogen in the cotyledonary and intercotyledonary placenta of the ewe. J. Reprod. Fertil. 58:411.

Watson, J., and C.E. Patek. 1979. Steroid and prostaglandin secretion by the corpus luteum, endometrium and embryos of cyclic and pregnant pigs. J. Endocrinol. 82:425.

Weeke, B. 1973. Rocket immunoelectrophoresis. Scandinavian J. Immuno1. 2(Supp1. 1):47.

Wetteman, R.P., and H.D. Hafs. 1973. LH, prolactin, estradiol and progesterone in bovine blood serum during early pregnancy. J. Anim. Sci. 36:51.

Wetteman, R.P., H.D. Hafs, L.A. Edgerton, and L.V. Swanson. 1972. Estradiol and progesterone in blood serum during the bovine estrous cycle. J. Anim. Sci. 34:1020.

Wietsma, H.T., F.A. Murray, and R.L. Allen. 1981. Species specificity of the immunosuppressive proteins secreted by the porcine uterus. ASAS $611: 375$ (Abstr.).

Williams, M.R., D.A.G. Maxwe11, and R.L. Spooner. 1975. Quantitative

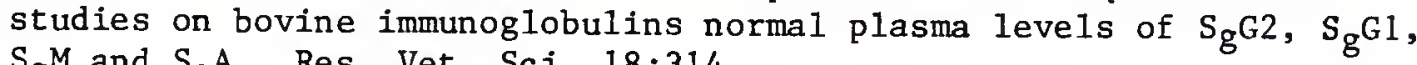
$\mathrm{S}_{\mathrm{g}} \mathrm{M}$ and $\mathrm{S}_{\mathrm{gA}}$. Res. Vet. Sci. 18:314.

Willis, M.C., M.J. Fields, T.H. Wise, B.D. Bueban, and F.W. Bazer.

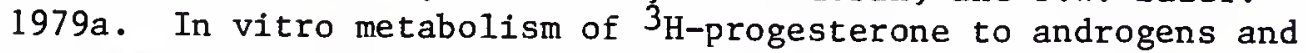
estrogens by pregnant sheep endometrium. ASAS 512:350 (Abstr.).

Willis, M.C., M.J. Fields, T.H. Wise, B.D. Bueban, and F.W. Bazer. 1979b. In vitro metabolism of $3 \mathrm{H}$-progesterone to androgens and estrogens by pregnant sheep endometrium and conceptus membranes. ASAS 513:350 (Abstr.). 
Willis, M.C., T.H. Wise, M.J. Fields, R.F. Roberts, J.L. Fleeger, and F.W. Bazer. 1981. In vitro steroid metabolism of $3 \mathrm{H}$-labelled substrate by the early ovine blastocyst and endometrium. ASAS 614:377 (Abstr.).

Wilson, J.D. 1972. Recent studies on the mechanisms of action of testosterone. New Eng1. J. Med. 287:1284.

Wiltbank, J.N., and L.E. Casida. 1956. Alteration of ovarian activity by hysterectomy. J. Anim. Sci. 15:134.

Wiltbank, J.N., J.E. Ingalls, and W.W. Rowden. 1961. Effect of various forms and levels of estrogen alone or in combinations with gonadotrophins on the estrous cycle of beef heifers. J. Anim. Sci. $20: 341$.

Wimsatt, W.A. 1951. New histological observations on the placenta of the sheep. Am. J. Anat. 87:391.

Wintenberger-Torrés, S. 1956. Les rapports entre I'oef en segmentation et le tractus maternel chez la brebis. Third Int. Congr. Animal Reprod., Cambridge 1:62.

Winters, L.M., W.W. Green, and R.E. Comstock. 1942. Prenatal development of the bovine. Minn. Agr. Exp. Sta. Tech. Bull. 151:21.

Wira, C.R., and C.P. Sandoe. 1980. Hormonal regulation of immunoglobulins: Influence of estradiol on immunoglobulins $A$ and $G_{1}$ in the rat. Endocrinol. 106:1020.

Wise, T.H., D. Caton, W.W. Thatcher, D.H. Barron, and M.J. Fields. 1982. Ovarian function during the estrous cycle of the cow: Ovarian blood flow and progesterone release rate. J. Anim. Sci. $55: 627$.

Wlodawer, P., H. Kindah1, and M. Hamberg. 1976. Biosynthesis of prostaglandin $\mathrm{F}_{2} \alpha$ from arachidonic acid and prostaglandin endoperoxides in the uterus. Biochim. Biophys. Acta 431:603.

Wooding, F.B.P., S.G. Chambers, J.S. Perry, M. George, and R.B. Heap. 1980. Migration of binucleate cells in the sheep placenta during normal pregnancy. Anat. Embryol. 158:361.

Wooding, F.B.P., and D.C. Wathes. 1980. Binucleate cell migration in the bovine placentome. J. Reprod. Fertil. 59:425.

Wordinger, R.J., and K.R. Amslev. 1980. Histochemical identification of the glycocalyx layer in the bovine oviduct and endometrium. Anim. Reprod. Sci. 3:189.

Wright, R.W., Jr., and K.R. Bondioli. 1981. Aspects of in vitro

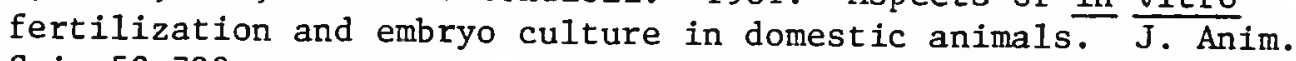
Sci. 53:702. 
Yamauchi, S., and S. Fumihiko. 1968. Studies on the vascular supply of the uterus of a cow. II. Morphological investigation of arteries on the uterine wall with special reference to those in the caruncular region. Jap. J. Vet. Sci. 30:207.

Yamauchi, S., and F. Sasaki. 1969a. Studies on the vascular supply to the uterus of a cow. III. Morphological studies of veins in the broad ligament. Jap. J. Vet. Sci. $31: 9$.

Yamauchi, S., and F. Sasaki. 1969b. Studies on the vascular supply to the uterus of a cow. IV. Morphology of veins in the uterine wall especially in the caruncular region. Jap. J. Vet. Sci. $31: 253$.

Zavy, M.T., F.W. Bazer, and D.C. Sharp. 1978a. Uterine luminal proteins in the cycling mare. J. Anim. Sci. 47:672.

Zavy, M.T., F.W. Bazer, D.C. Sharp, M. Frank, and W.W. Thatcher. 1978b. Uterine luminal prostaglandin $\mathrm{F}$ in cycling mares. Prostaglandins $16: 643$.

Zavy, M.T., F.W. Bazer, D.C. Sharp, and C.J. Wilcox. 1979a. Uterine luminal proteins in the cycling mare. Biol. Reprod. 20:689.

Zavy, M.T., F.W. Bazer, W.W. Thatcher, and C.J. Wilcox. 1980. The study of prostaglandin $\mathrm{F}_{2} \alpha$ as the luteolysin in swine. V. Comparison of prostaglandin F, progestins, estrone and estradiol in uterine flushings from pregnant and nonpregnant gilts. Prostaglandins $20: 837$.

Zavy, M.T., W.R. Clark, D.C. Sharp, R.M. Roberts, and F.W. Bazer. 1982a. Comparison of glucose, fructose, ascorbic acid and glucosephosphate isomerase enzymatic activity in uterine flushings from non pregnant and pregnant gilts and pony mares. Biol. Reprod. $27: 1147$.

Zavy, M.T., R. Mayer, M.W. Vernon, F.W. Bazer, and D.C. Sharp. 1979b. An investigation of the uterine luminal environment of nonpregnant and pregnant pony mares. J. Reprod. Fertil. (Supp1. 27): 403.

Zavy, M.T., D.C. Sharp, F.W. Bazer, A. Fazleabas, F. Sessions, and R.M. Roberts. 1982b. Identification of stage-specific hormonally induced polypeptides in the uterine protein secretions of the mare during the oestrous cycle and pregnancy. J. Reprod. Fertil. $64: 199$.

Zelinski, M.B., P. Noe1, D.W. Weber, and F. Stormshak. 1982. Characterization of cytoplasmic progesterone receptors in the bovine endometrium during proestrus and diestrus. J. Anim. Sci. 55:376. 
BIOGRAPHICAL SKETCH

Frank Fitzhugh Barto1, son of Dorothy Foster and the late Henry Fitzhugh Bartol, was born in Arlington, Virginia, on April 15, 1953. Attending Arlington County public schools throughout his primary and secondary education, he graduated from Yorktown High School, Arlington County, Virginia, in June, 1971. He received his Bachelor of Science degree in dairy science from Virginia Polytechnic Institute and State University, Blacksburg, Virginia, in June, 1975. Having a special interest in reproductive physiology, he began graduate work in the Department of Dairy Science at the University of Florida, Gainesville, Florida, in fall of 1975. Under guidance of Dr. William W. Thatcher of that department, he received the Master of Science degree in dairy science in March, 1980. Remaining in the Department of Dairy Science at the University of Florida, he continued study pursuant to the Doctor of Philosophy degree in animal science, with emphasis in reproductive biology. In June of 1981 he was elected as an associate member of Sigma Xi. On August 22, 1981, he was married to Anne Ambrose Wiley. Upon completion of the Doctor of Philosophy degree he will serve in the position of assistant professor in the Department of Animal and Dairy Science, Auburn University, Auburn, Alabama. 
I certify that I have read this study and that in my opinion it conforms to acceptable standards of scholar1y presentation and is fully adequate in scope and quality, as a dissertation for the degree of Doctor of Philosophy.

William W. Thatcher, Chairman Professor of Animal Science and Dairy Science

I certify that I have read this study and that in my opinion it conforms to acceptable standards of scholarly presentation and is fully adequate in scope and quality, as a dissertation for the degree of Doctor of Philosophy.

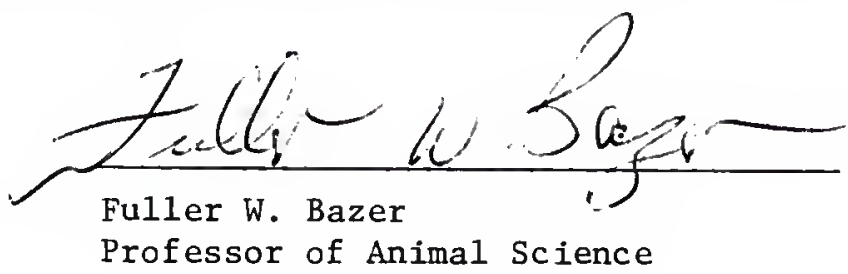

I certify that I have read this study and that in my opinion it conforms to acceptable standards of scholarly presentation and is fully adequate in scope and quality, as a dissertation for the degree of Doctor of Philosophy.

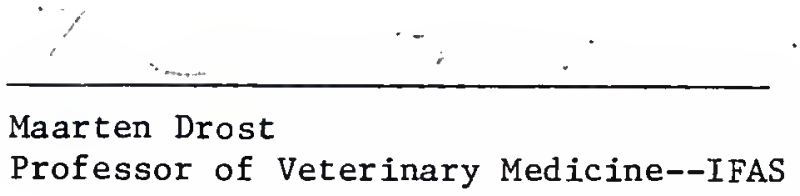


I certify that I have read this study and that in my opinion it conforms to acceptable standards of scholarly presentation and is fully adequate in scope and quality, as a dissertation for the degree of Doctor of Philosophy.

R. Michae1 Roberts

Professor of Biochemistry and Molecular Biology

I certify that I have read this study and that in my opinion it conforms to acceptable standards of scholarly presentation and is fully adequate in scope and quality, as a dissertation for the degree of Doctor of Philosophy.

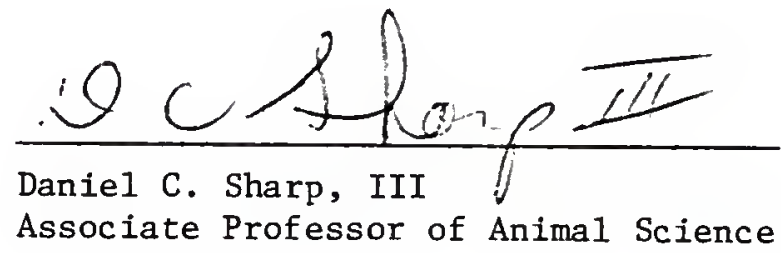

This dissertation was submitted to the Graduate Faculty of the College of Agriculture and to the Graduate School, and was accepted as partial fulfillment of the requirements for the degree of Doctor of Philosophy.

Apri1 1983

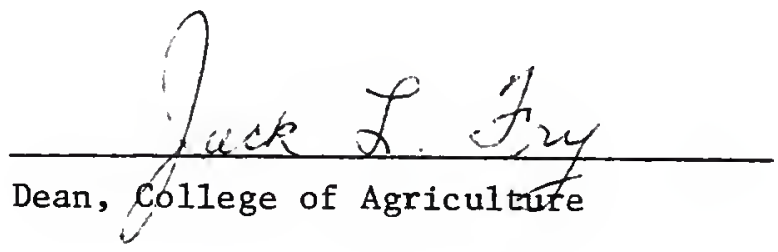

Dean for Graduate Studies and Research 
UNIVERSITY OF FLORIDA

31262085540101 
UNIVERSITY OF FLORIDA

31262085540101 